\title{
A macro-financial theory of corporate financing and forecast modelling of market movements
}

By

David Sutton

\begin{abstract}
A thesis
submitted to the Victoria University of Wellington in fulfilment of the requirements for the degree of Doctor of Philosophy
\end{abstract}

Victoria University of Wellington 


\section{Acknowledgements}

I would like to acknowledge the contributions made to this thesis by my supervisors, Dr. Carolyn Cordery and Professor Morris Altman. In the case of both I have been frequently challenged by their suggestions but this is as it should be. Both have provided me sage guidance through to this point. In the case of Carolyn I have benefitted from her vast decency and strength of character. I would also like to acknowledge the contribution made to my progress through this thesis of Dr John Singleton. John was my original supervisor, along with Carolyn, before his departure to England. John provided me with brutally forthright guidance and, again, this is as it should be. Finally, I would like to acknowledge the invaluable contribution of Dr. Dalice Sim for her contribution to the development of my statistical analysis. It is difficult to imagine how much more challenging this aspect of the thesis would have been without her input. 


\begin{abstract}
This thesis identifies a gap in existing theories of corporate finance. This gap is an implication of a Keynesian-Minskian analysis of markets and market-based economies. From a founding theoretical perspective rooted in the view that markets are not reliably efficient the case is developed that past price trend extrapolation is an important factor in corporate financing decisions. At a macro-financial level, companies repurchase equity over periods of strong market rises, while increasing debt at the same time. During periods of sustained, substantial market decline debt is retired and large new equity issues occur. This change in corporate financing is implicitly expensive as relatively low prices are realised for the new stock issued at these times. These factors suggest that conventional theories of corporate financing decisions that rely on corporate rationality and optimisation do not provide a compelling fit with observations in the period 1980-2012. Moreover, inference to Minsky's (1986) argument that companies are compelled through market declines to shore up their balance sheets provides a better fit with the evidence. These arguments form the basis for the development of the 'extrapolative expectations' theory of corporate finance.
\end{abstract}

The second major development in this thesis draws on the theoretical development outlined above to create market movement description and prediction models. These models operate on data drawn from the US Standard \& Poors 500 index over the period 1980-2012. Two primary models are developed using binomial logistic regressions. The dichotomous dependent variables are drawn as quarters of market rise (1) or no rise (0), and market falls (1) or no fall (0), respectively for the 'buy' model and the 'sell' model. Variables tested and those found to add to an explanation of the dependent variables include: corporate debt flows, corporate equity flows, corporate dividend flows, interest rates, market volumes, and historical market levels. Each variable is tested for up to ten lags (two-and-a-half years). Collectively, the variables add to our understanding of those factors influencing (or at the least, signalling) market levels, enabling quarter ahead market forecasts to be made with greater accuracy than arises from an assumption of a random walk. This conclusion crystallises the view that 
company macro-financial flows and prices are an important cause or signal of future market direction. 


\section{A macro-financial theory of corporate financing and forecast modelling of market movements}

\section{Table of Contents}

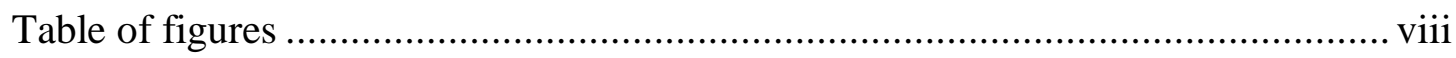

Table of tables ........................................................................................... ix

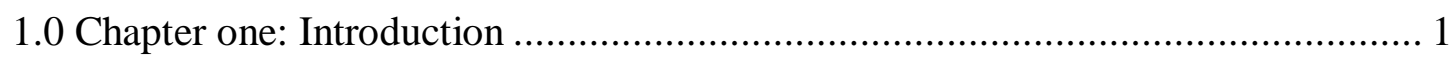

1.1 Market efficiency and its limitations .......................................................... 3

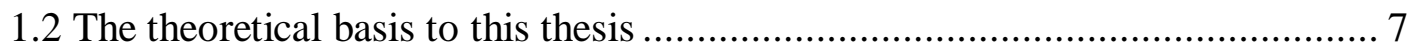

1.3 Corporate financial structures, preferences, theories about these, and the limits of those theories, and an alternative theory …................................................ 10

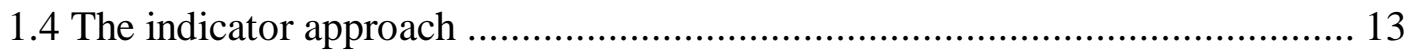

1.5 Methodology: variables, time span, and empirical foundations of this research 14

1.6 Problems, limitations, and qualifications to this research............................ 17

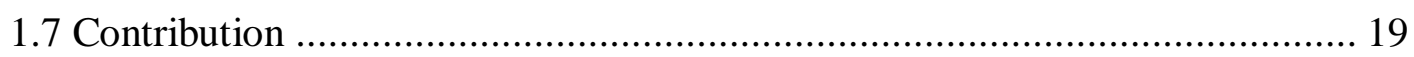

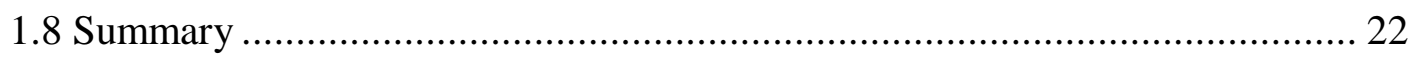

Chapter two: limits to market efficiency as an objective referent base .................... 24

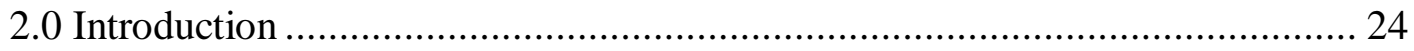

2.1 The basic elements of the Efficient Markets' Hypothesis .............................. 28

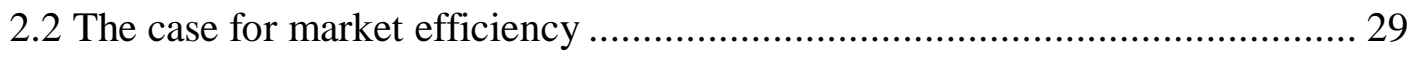

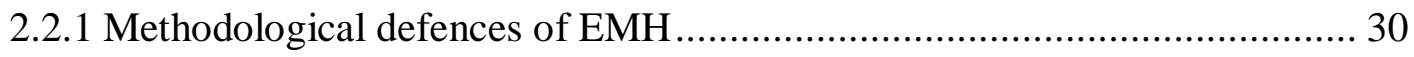

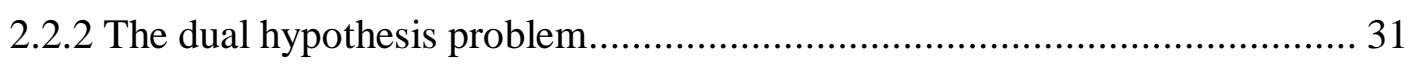

2.2.3 Under-developed trading rules as a defence of EMH ............................. 33

2.3 Challenges to market efficiency .......................................................... 33

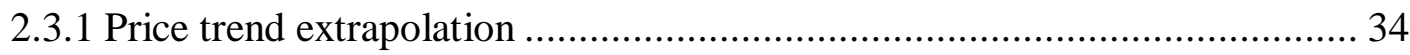

2.3.2 The tension between information and noise traders and the necessity of some

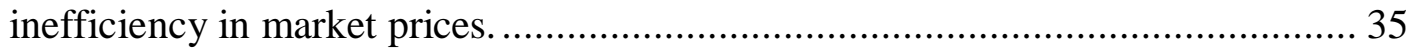

2.3.3 Bubbles as a challenge to market price objectivity ................................... 36

2.3.5 Precipitous market collapses as a key threat to EMH.............................. 43

2.3.6 The indeterminacy of risk-free rates of return and declining risk premia...... 48

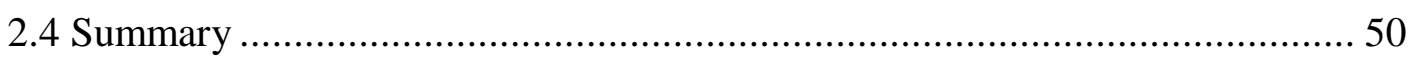

Chapter three: Theory: the inherent instability of capitalism and the implications of that instability for business and market cycles..................................................... 52

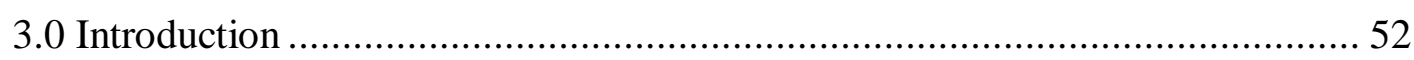

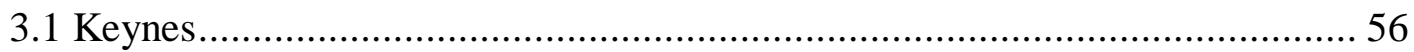


3.2.1 The central role of finance in the FIH view of capitalism's instability ..... 63

3.2.2 Extending Minsky's analysis of debt counter-party motivations .............. 67

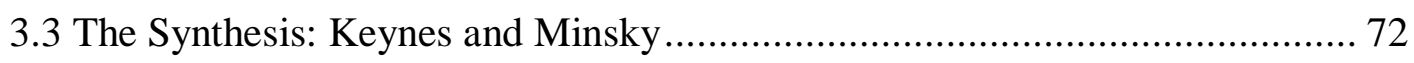

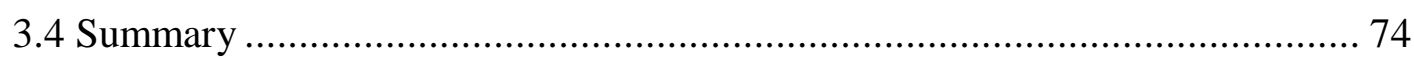

Chapter four: Light regulation, unstable markets and the FIH: An examination of the

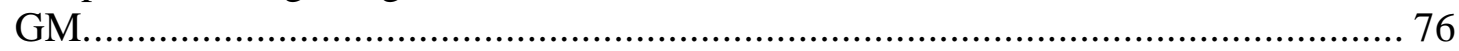

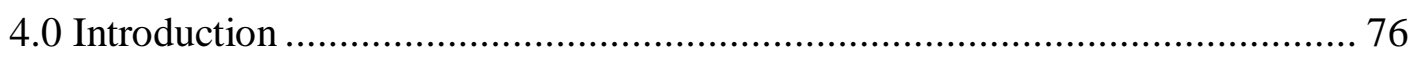

4.1The history and essential nature of business cycle endogeneity ...................... 78

4.2 Endogenous causes of the GM: Financial liberalization and the GM ............. 82

4.2.1 Domestic financial deregulation .......................................................... 84

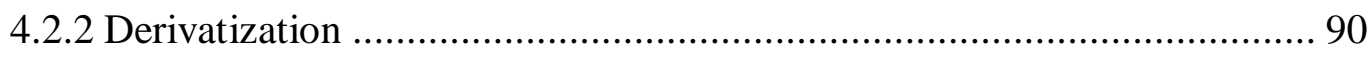

4.2.3 Corporations and their growing reliance on debt financing over the Great

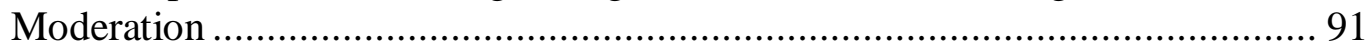

4.2.4 Changes in financing of the wider US economy over the period 1970-2011

4.2.5 International financial liberalization as an endogenous cause of macrofinanncial stability, foreign investment flows, and the GM......................... 96

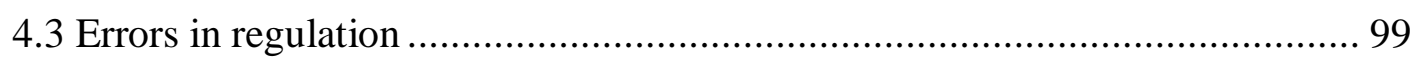

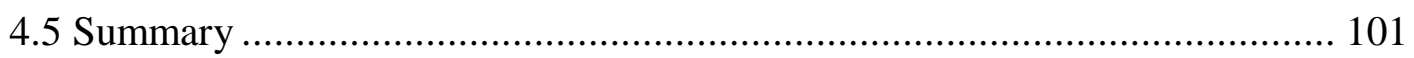

Chapter five: locating this thesis in contemporary corporate financing literature .... 104

5.0 Introduction 104

5.1 The Modigliani-Miller 'indifference' theorem as a starting point in corporate financing research

5.2 Theories relating to the role of company-specific factors in corporate financing

5.2.1 The broad theoretical frameworks of corporate financing structures ..... 114

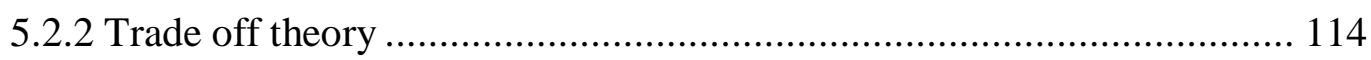

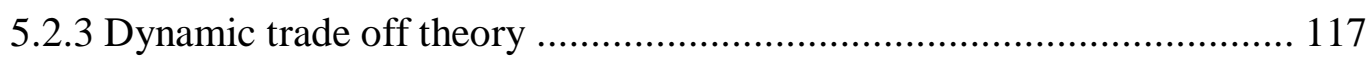

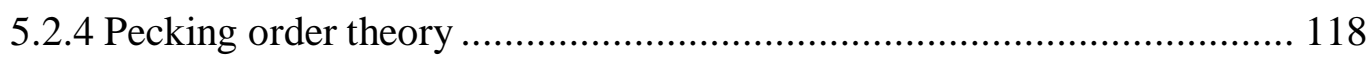

5.2.5 An alternative approach to traditional theories of corporate financing: the

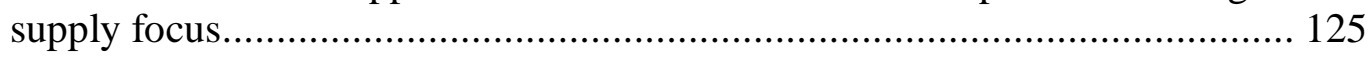

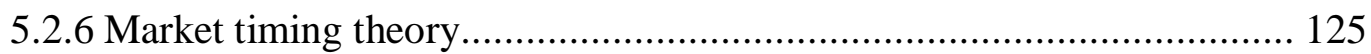

5.3 An empirical view of existing corporate financing theories ...................... 128

5.4 Observations about modern developments in corporate financing flows ....... 130

5.4.1 Why do conventional theories of corporate financial structure fail to explain modern-period observed cycles in corporate macro-financial flows?.. 132

5.4.2 Description of the relationships depicted in figure 15 ........................ 134 
5.5 Adding cyclical qualifications to existing structural qualifications to the Modigliani-Miller 'indifference' theorem

5.6 Can the proposed basis for active asset management overcome evidence that passive asset management systematically outperforms active management? ...... 141

5.7 Summary.

Chapter six: The 'extrapolative expectations' theory of corporate financing and positioning it in relation to existing forecast models

6.0 Introduction .....

6.1 Determining fundamental value under assumptions of market efficiency: the capital asset pricing model (CAPM) and Arbitrage Pricing Theory (APT) ......... 144

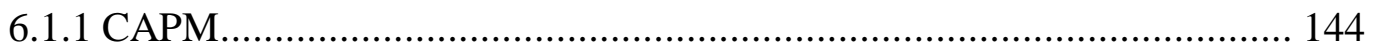

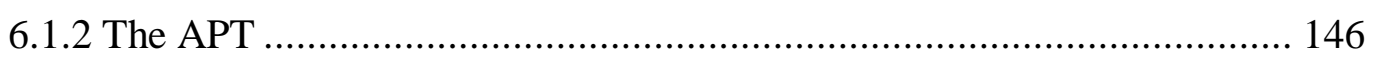

6.1.3 Other models: Extending CAPM with Fundamental factors.................. 149

6.2 Existing implicit and explicit models of market values under assumptions of market inefficiency ...................................................................................... 150

6.2.1 Minor departures from market efficiency ........................................... 151

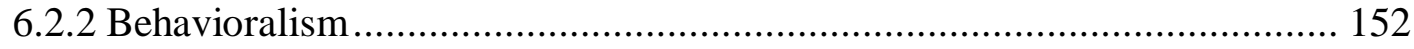

6.2.3 Money supply, credit, and liquidity as influences on asset prices .......... 153

6.2.4 Tobin's Q and imputed returns ........................................................ 155

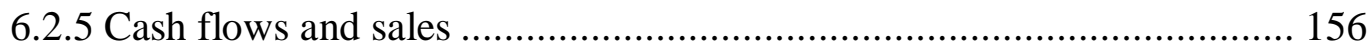

6.2.6 Quantification of sentiment .......................................................... 156

6.3 Alternative measures of fundamental value: Shiller's index …................... 157

6.4 Short term market prediction modelling ................................................... 160

6.5 Summary and implications for the current research ................................. 164

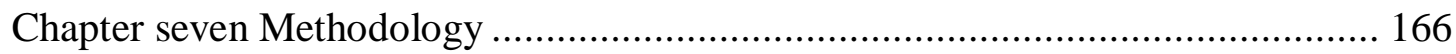

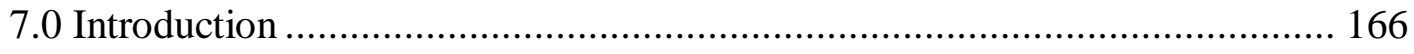

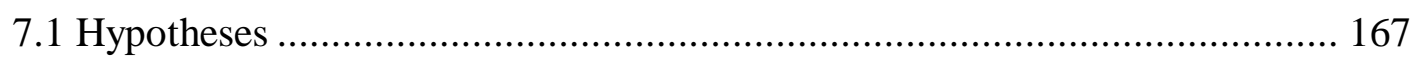

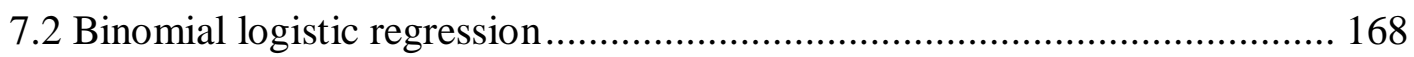

7.3 The forward stepwise approach to regression, multi-collinearity, and 'cut

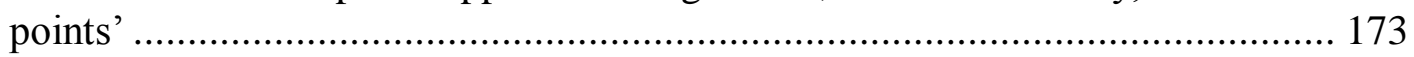

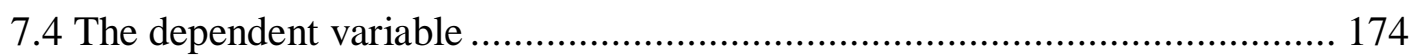

7.5 Minsky, the FIH, qualifications to these and adaptation of the framework to tailor it to this short term market forecasts .................................................... 175

7.6 reconfiguring the FIH-implied proxy variables identifying stability to accommodate criticisms of the FIH

7.7 Adaptation of the FIH-indicated variables to fit them to the focus of this research

7.9 The data: independent variables, their source, and construction ................... 185

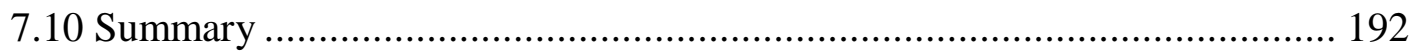




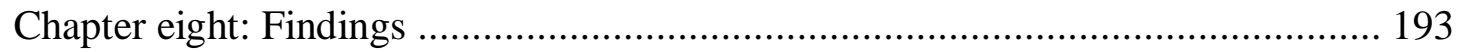

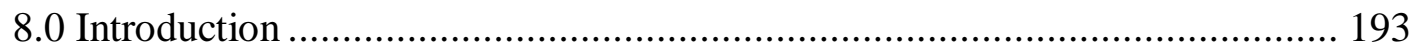

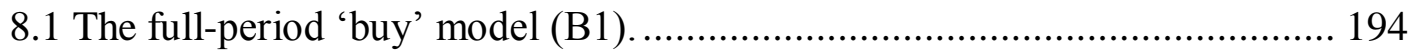

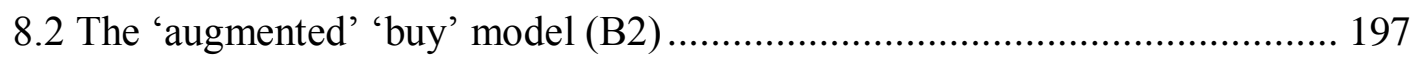

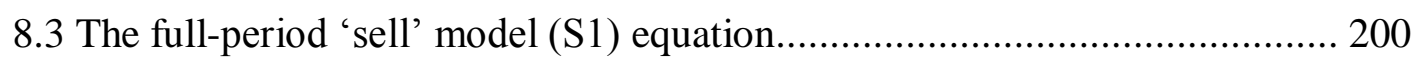

8.4 The sub-period 'sell' model (S2) or seven-variable model............................ 201

8.5 Variables failing to significantly contribute significantly to model development

8.6 Implied returns from defaults and different applications of the models developed in this research.

8.7 The respective model performances when applied to the 1970s S\&P 500 index

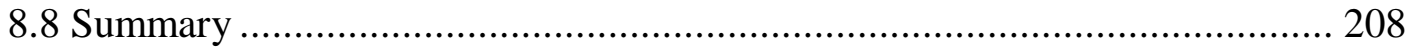

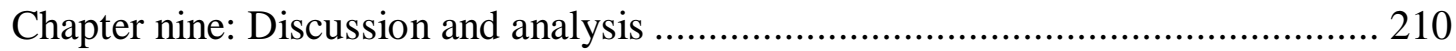

9.0 Introduction: the relationship of Minskian theory to market movements and market prediction model development in the post-1980 period in the US ........... 210

9.1 Key features of the period 1980-2012 …………...................................... 210

9.2 Major economic and external shocks and their influence on US markets ...... 213

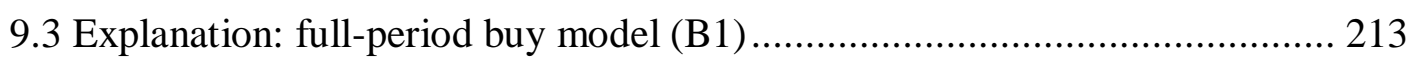

9.3 Explanation for the augmented 'Buy' model (B2) ..................................... 215

9.4 Explanation: full period sell model (S1) ................................................ 216

9.5 Explanation: short-period sell model (S2) ……………......................... 218

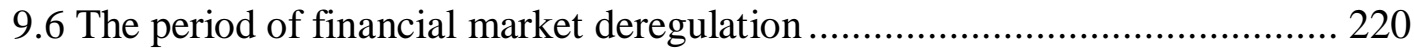

9.7 Why is the seven variable model (S2) so successful? ................................. 221

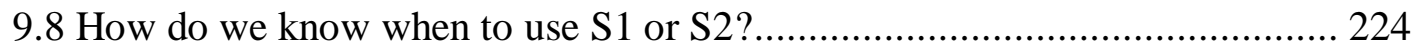

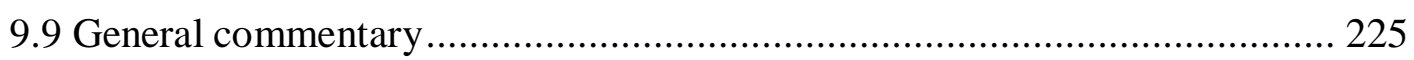

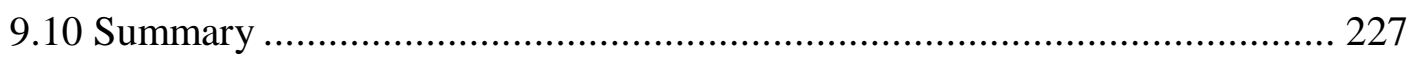

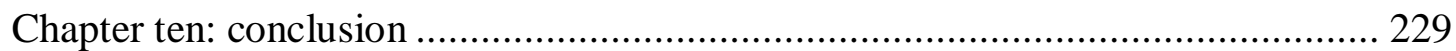

10.0 Introduction

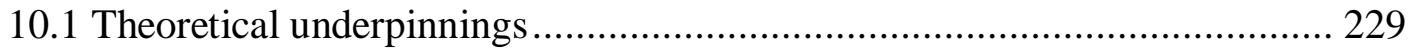

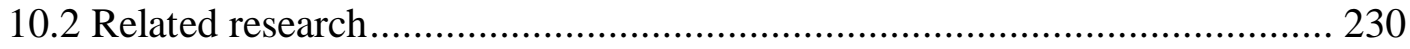

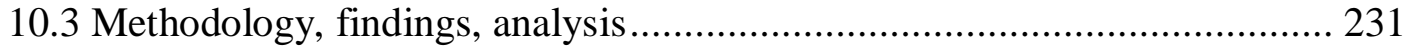

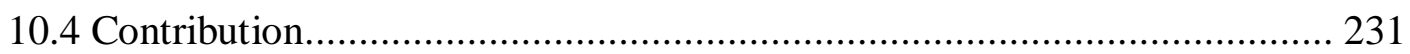

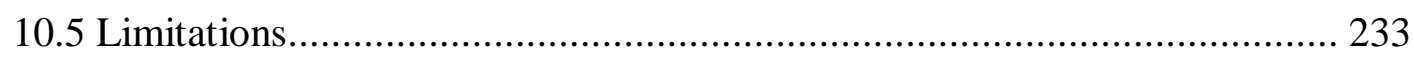

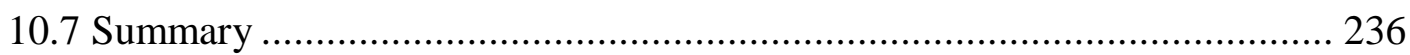

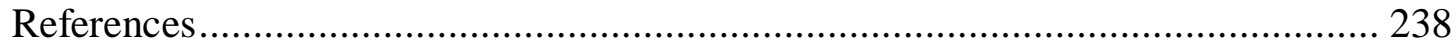

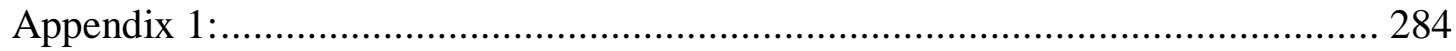

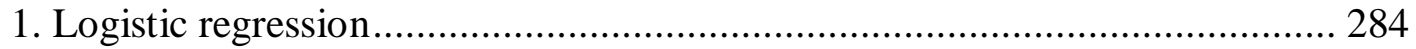




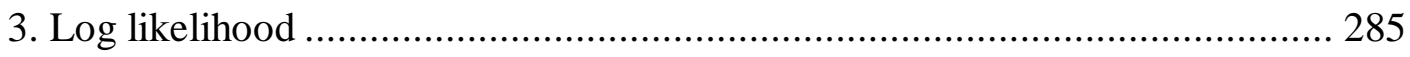

4. Pseudo-R squares: Nagelkerke ................................................................. 285

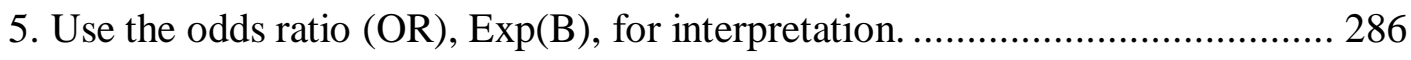

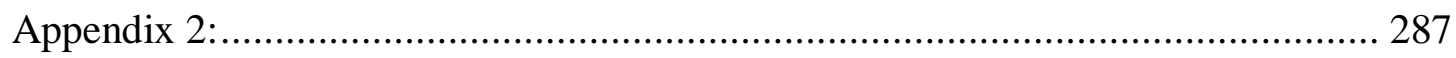

Appendix three: implied returns from default variants and plausible model applications

Appendix four: Timelines detailing major idiosyncratic events over the period 1970 to 2013

\section{Table of figures}

Figure 1: US corporate debt and equity flows (millions) 1980-2011 ...................... 25

Figure 2: Net US corporate debt and equity flows and the S\&P 500 index .............. 26

Figure 3: Changes in the percentage of 'money-manager' ownership of total corporate

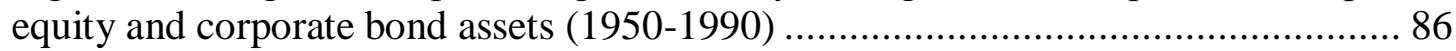

Figure 4: Patterns in corporate external financing composition from 1970-1980 ...... 92

Figure 5: Patterns in corporate external financing composition from 1980-1990 ...... 93

Figure 6: Patterns in corporate external financing composition from 1990-2000 ...... 93

Figure 7: Patterns in corporate external financing composition since 2000............. 93

Figure 8: The relationship of US Federal government deficits to GDP in the period

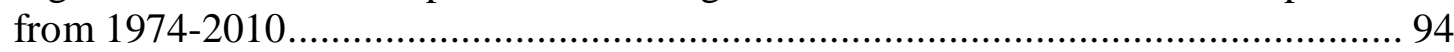

Figure 9 The progressive deterioration in the US current account situation from 1970

to 2008 .

Figure 10: The value of the firm in relation to corporate financing and risk and return

under the Modigliani/Miller indifference theorem................................................. 107

Figure 11: Trade off theory and firm wealth maximisation.................................. 116

Figure 12: The relationship between corporate dividends and corporate equity flows

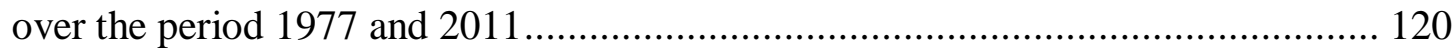

Figure 13: The secular decline in modern era US corporate dividend yields and its relationship to market index

changes.

Figure 14: Changes in corporate financing preferences due to Market movements in equity prices.

Figure 15: The relationship between S\&P 500 index movements and corporate debt

and equity flows over the period 1983-2008

Figure 17: Trends in US non-farm, non-financial corporate equity and market

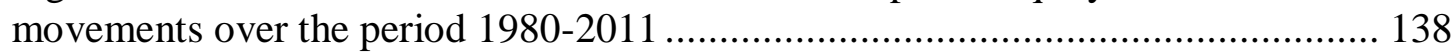

Figure 18: Quarterly changes in the S\&P 500 index after risk-adjustment .............. 175

Figure 19: Implied returns from continuous exposure to the market and different applications of the models developed in this thesis. ............................................... 207

Figure 20: S\&P 500 market movements and trends 1977-2011 ........................... 222

Figure 21: The 1980s and major idiosyncratic events influencing the US economy 296

Figure 22: The 1990s and major economic events influencing the US Economy .... 297

Figure 23: The 2000s and major events affecting the US Economy ...................... 298

Figure 24: Major idiosyncratic events affecting the US economy over the 1970s ... 301 


\section{Table of tables}

Table 1: A comparison of existing theories of corporate finance and the hypothesis advanced in this research

Table 2: The regression test variables, their equation codes, and source of data ..... 185

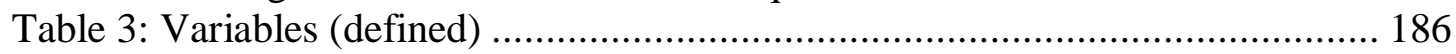

Table 4: The incidence of signs on integrated variables........................ 189

Table 5: Various economic and market forecast models.......................... 190

Table 6: Full-period 'buy' model (B1) variables, exponents, size and

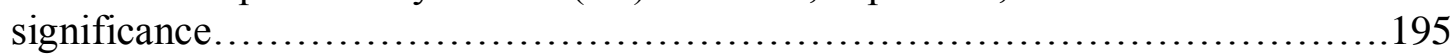

Table 7: Model goodness of fit, specificity, and sensitivity.................. 196

Table 8: "Augmented" buy model (B2) co-efficients, Standard errors, exponents, and statistical significance.

Table 9 "Augmented" model (B2) goodness of fit, specificity, and sensitivity.....

Table 10: Variables, exponents (odds ratios) size of effect, and statistical significance

for the 12-variable 'sell' model (S1).

Table 11: Full-period sell model (S1) goodness of model fit, specificity, and sensitivity....

Table 12: Variables, direction of influence, size and significance for the 'short period' 7 variable 'sell' model (S2) (1985-1999).

Table 13: Short-period "sell" model (S2) goodness of fit, specificity, and sensitivity....

Table 14: Arbitrating between Buy and Sell models when signals conflict.

Table 15: Results of the study-period 12 variable (B1 and S1) and 7 variable models (S2) and their components applied to the S\&P 500 index in the

Table 16: Changes from a base of 1 in each quarter and the forecast accuracy of different model applications.

Table 17: Raw and CPI-U deflated returns from continuous market exposure and different reasonable model applications. 


\subsection{Chapter one: Introduction}

An assumption prevalent in academic finance is that market cycles and movements are essentially unpredictable. This assumption provides the foundation for the notion of a 'random walk', precluding the possibility of reliable forecasts of market levels. This understanding is a derivation of the efficient market hypothesis but may be equally consistent with behavioralist explanations of markets (Barberis, 2003). Prevailing theory states that economic agents act rationally and operate on full (current) information sets that are uniformly available. This creates efficient markets which correctly price companies based on participants' aggregate estimates of those companies' future cash flows. Thus, markets are always correctly priced and sudden or large changes in market levels are due to new information-based adjustments to aggregate estimates of cash flows. On this view markets follow a random walk (with drift).

This thesis is motivated by a different set of assumptions. Economic agents are forced to act on incomplete information sets, and sentiment plays a key role in bridging the gap between what is known to the market and what market participants would hypothetically need to know to justify their decisions. On aggregate, sentiment is critically influenced by the phase of the market cycle and, even if imprecisely, sentiment may be identified by proxies for credit or liquidity availability and price. These proxies include corporate debt and equity flows and are measures of financial acceleration and systematic deviations from historical trend in risk assessments.

US market cycles are strong positive correlates of corporate debt flows and moderate negative correlates of corporate equity flows in the period since 1980 (Cooper, 2008). This thesis analyzes these correlations in terms of Minsky's (1986) financial instability hypothesis (FIH) and offers an interpretation of the observed corporate financing flows as an addition to existing theories of corporate financial structures. In particular, corporate financing flows, separately and integrated with market movements, are isolated as important signals of future market movements and are used in this thesis for market prediction modelling. Evidence for the positive claims of this thesis and its foundations is identified through an examination of US economic 
history from 1984-2007 (the era known as the Great Moderation (GM)), with some attention paid to the $1970-1983$ period $^{1}$.

The US is selected as the key focus of empirical analysis as it operates the largest, most developed equity markets in the world. As the world's largest economy and with a high market capitalisation relative to GDP, the US market presents as a compelling basis for investigation. US markets comprise a little more than $40 \%$ of global free-float equity market capitalisation and extensive governmental and nongovernmental data collection further support this market as the subject of this research. The Standard and Poors 500 (S\&P 500) index is widely regarded as the most representative major index in the US, justifying the selection of this market for investigation.

This thesis extends existing theory of corporate financing, identifying and explaining pro-market cyclicality in corporate debt flows and a counter-cyclical flow of corporate equity financing. It also surveys existing research into, and indices of, fundamental value and deviations from this as a basis for determining forecast models of equity market movements. The aim is to fill an identified gap in existing research into corporate financing theory. From this basis, market forecast models are developed, employing a theoretically supported set of macro-financial variables. These models incorporate corporate financing flows' variables, including dividend flows, and also financing prices (interest rates) as well as historical market volumes and levels. The objective is to forecast the direction of market movement in the following quarter $(t+1)$.

Given that markets rise in real terms over the long term, market forecast models developed with the view of improving market forecast ability and returns must improve outcomes over those returns obtainable by a buy-and-hold strategy. The present research is able to sufficiently improve the rate of return over such a default position by between three and five times using a series of plausible applications of the developed models. The aim behind the development of these models is to assist short term corporate financing and investing decisions.

\footnotetext{
${ }^{1}$ The GM later spread across the developed world. It exhibited low and stable inflation, low output volatility, and above historical trend growth.
} 
I develop two primary market forecast models. The models involve binomial logistic regressions. My research also explores the use of flows data, an area underdeveloped in economic and finance research. By these means the thesis constitutes an extension of our understanding of the role of market cycles in corporate financing decisions. A further goal is to provide enhanced information sets to investors.

\subsection{Market efficiency and its limitations}

Market efficiency has been and remains central to mainstream understandings of the operation of markets and market-based economies (Stiglitz, 2004; Ocampo, Spiegel, and Stiglitz, 2008). However, more recent understandings, including those of certain academics formerly confident of neo-classical economic prescriptions, have admitted qualifications to this confidence in markets' ability to settle at stable equilibria (see, for example: Prasad, Rogoff, Wei, and Kose, 2003). Stiglitz (2008) breaking with conventional wisdom, has argued against the applicability of market discipline in relation to developing countries in which many basic requirements for endogenous economic stability are not met. Thus, qualifications to market efficiency are developed in this research along Minskian lines and extended to market economies generally.

Specific geo-political, cultural, social and historical constraints on the ability of markets to operate as anticipated by neo-classical theory provide just some of the more obvious qualifications to market efficiency (Stiglitz, 2008). More fundamental defects exist in the notion that markets are essentially stable equilibrium-finding systems. The failure of markets to settle at endogenously stable levels is fundamentally due to the forces underlying the parable of the 'tragedy of the commons'. The tragedy of the commons predicts the commons would be over-grazed because the cost of that overgrazing is borne by the community yet its use is governed by individual utility. The rational individual utility is socially destructive without regulation to align individual and societal incentives. Although total or macro-economic utility would have been increased by allowing common pasture recovery this was driven beyond realisation by competing individual utility functions (Daniels, 2008). This economic 'parable' is analogous to forces operating through market cycles and found in the actions of bankers, lenders, and investors preceding the sub-prime crisis and global recession of 
2008-2009. These factors underline the fraught nature of regulator reliance on market discipline as occurred over the GM.

The notion of naturally stable-equilibrium market-based economies inducts the rationality of utility-maximising economic agents as a sufficient condition for that stability. This thesis does not rely on investor irrationality. In this sense it follows Bernanke (1983), advancing the view that the most productive approach is to push rationality to its practical limits. This is consistent with Minsky's explanation of agents' actions as observed without an ontological impost on those agents' irrationality. The central point is that inferences from the rational economic actor to natural stable states' macro-economic equilibria are invalid. Certain constraints on rationality limit the inferences possible from it. In the first instance, the effectiveness of its operation is, logically, strongly positively associated with the level of information upon which it has to operate.

Under Minsky's (1986) theory banks are compelled by competitive market forces to lend to borrowers they would not otherwise deem suitable credit risks as the market as a whole gravitated towards less stringent lending policies. The conservative banker forgoes profitable lending activity just as long as the markets against which the lending is secured continue to rise. The banker's choice is then aligned with avoiding under-performing a buoyant market. As the margins in banking business move towards greater risk over periods of economic expansion, supported by the successive validation of past debt contracts, the banker must move with the market. Progressive fragility will emerge in the macro-financial state but, at the margins, the banker's optimal strategy is to achieve a market-average position. She will be blamed for the failure to compete with the market but the market will be blamed for a general financial or economic crisis (Rajan, 1994; 2005). In this way the rational banker is able to internalise the benefit of a rising market, with an off-setting public cost. ${ }^{2}$ This trade off creates moral hazard by validating continued or expanded market exposure under conditions which individual bankers may identify as a bubble.

\footnotetext{
${ }^{2}$ The public cost was reflected from 2008 in the Federal Reserve Troubled Asset program (TARP), and claims on the Federal Deposit Insurance Corporation (FDIC) 
What is rational for the individual may not necessarily insulate economies from unhelpful outcomes ascribed by many economists to external shocks or marketdistorting government actions (Nasica, 2010). The discussion addresses this issue in relation to the rational actions of sub-prime-lending bankers and mortgagees. The argument is similar to that of Greenwald and Stiglitz (1987) in locating the non-sequitur of microeconomic rationality extended to infer stable macroeconomic equilibrium. Where Greenwald and Stiglitz identify price and wage rigidities and asymmetric information, I add a more pervasive market compulsion underlying the financial acceleration of debt inflation and deflation that emerges in sustained boom and bust periods. This compulsion lies in a market that subordinates absolute risk to realised risk and that extrapolates from past returns. The 'paradox' lies in that rationality can lead a banker to lend to a borrower who lacks the ability to repay the loan, while the borrower can rationally contract to meet loan obligations that ceteris paribus they cannot repay (Minsky, 1986; Wray, 2007b). The requisite conditions are: a recent history of completed debt contracts at a market-wide level; rising asset prices; and, the financial sector's progressive gravitation to 'new frontier' (more risky) marginal business in pursuit of colonising new business (Prosner, 2009). A number of other fundamental disruptions to stable market equilibration are also considered. These are sufficiently significant to support the synthesis of Keynes and Minsky, to describe the default state instability inherent to market-based, monetary economies.

The focus of modified neo-classical economics, the 'new market consensus', is on controlling inflation as the necessary and sufficient condition for macro-economic stability. Aggregate demand is discounted on this view as Say's Law (approximate to supply-side economics) fulfils the autonomous role of demand assumed in Keynesian analysis (Arestis and Sawyer, 2000; Laffer, 2004). However, the end of the GM-period of stable inflation and growth across the developed world (in late 2007) provides strong evidence that inflation control in isolation does not support economic stability. Instead, Minsky's view that stability is destabilising, gains traction as the longest period of macro-economic stability in US history has resulted in one of the longest periods of instability and below-trend economic growth.

As occurred through the 1990s (Spencer and Huston, 2006), when the Federal Reserve raised interest rates, it is reasonable to expect that, had the Federal Reserve 
raised interest rates from 2002, markets would have taken confidence in the monetary policy commitment to low inflation. As per the 1990s this is likely to have supported further asset price inflation. This contrasts with an important school of thought that the Federal Reserve's delay in responding to rising (although relatively low) inflation from 2002 was the principal cause of the housing price bubble in the US and subsequent financial crisis (Taylor, 2008; Schwartz, 2008).

In its most strident forms market efficiency is the view that markets always settle at their fundamental value. Proponents of this view have developed sometimes heroic defences, in particular, in relation to precipitous market crashes. Efficient markets' hypothesis defences typically involve the view that even small revisions in risk or expected returns may justify large equity price movements. Such an explanation is required when, as in 1987, there is no clear cause for the market decline. Chapter two argues that this defence is tenuous. However, evidence from the performance of managed funds of the failure of active management to deliver systematically superior returns to those obtained by passive fund (or index fund) investment is more compelling (Schwert, 2003a; 2003b). Nonetheless, its probative value is not of market efficiency in a fundamental sense but of the essential unpredictability of future market prices. An implication drawn from this is that fundamental value is elusive as there is no reliable reference value from which to adjust for idiosyncratic risk. The conclusion of this process (and chapter two) is that markets are reasonably efficient in the pricing of relative risk and expected returns within a class of investment assets but that they do not provide a reliable basis for determining absolute risk, creating the 'opening' for speculative bubbles to develop. This conclusion forms the basis for developing this thesis in terms of Minsky's (1986) FIH.

The non-sequitur of markets correctly identifying and settling on fundamental value is employed here as a basis to justify exploring under-identified market valuation inputs. Specifically, the role or signal of a series of macro-financial variables is employed. Key amongst these are corporate financing flows which may both influence and signal corporate financing choices. 


\subsection{The theoretical basis to this thesis}

This thesis' theoretical foundations are rooted in Keynes' (1936) concept of uncertainty and the central role of investment in the cyclicality of the economy and markets. Uncertainty causes economic agents to act on 'animal spirits' in the absence of complete information. This investment volatility means that cycles are an essential (and, therefore, persistent) feature of market-based economies. Investment will maintain an economy at or near full employment only as a transitory phase. Minsky (1986) adds to Keynes' (1936) investment theory of the business cycle a financial theory of investment, credit availability and liquidity.

Cyclical limits to economic growth arise as a function of the operation of investment uncertainty on effective demand, a position argued for by Keynes (1936). Technology shocks initiate business and market cycles expanding aggregate demand, and are a source of economic growth (Minsky, 1986; Schumpeter, 1938; 1954). These shocks result in efficiency increases which, in turn, fuel widespread reversion-period above zero economic profits to capital. These periods increase future earnings expectations, increasing asset prices. Subsequent to the technology shock, increased liquidity further supports economic growth, often exhausting new demand. The boom parallel to this development redistributes national income exhibiting a tendency to concentration. Whether this is transmitted through 'preferred' wage incomes, or through elevated profits, a cyclical increase in the prevalence of investment is initiated. These imbalances are arguably real variables that catalyse savings increases and, thus, fuel demand for financial (and other) assets, driving the prices of those assets higher. Progressively, rising profits motivate rising investment as the 'anchoring' function of consumption is destabilised. As investment begets profit, and profit begets more investment, the perpetuation of the cycle requires the progressive expansion of exports, capitalist consumption [and credit-financed household consumption], or rising government deficits to sustain profits (Toporowski, 1999). This interpretation is important in the current US context where the sustainability of government budget and current account deficits is uncertain, and where the relatively lower capitalist consumption propensity still holds, yet the recent boom has been substantially fuelled by consumption. Debt-financed consumption, in turn, increases the risks of a 'Balance Sheet' recession, as, in particular, the financial sector and household capital bases have become 'stretched' in the 2000s (Leijonhufvud, 2009). 
The key theoretical postulates of this thesis (as further outlined in chapter 3) follow Minsky (1986) and are that:

- Relatively narrow temporal parameters limit the information base for investors' rational operation, where perfect information is a premise of market efficiency, privileging current conditions in terms of fundamental value assessments (bounded rationality).

- In consequence, the objective character of market values is contingent. In a strict sense market prices are objective but only within the context of existing supply and demand dynamics. The marginal nature of market prices may allow them to deviate from fundamental value. To the extent it is possible, we should assess the influence of prevailing macroeconomic factors creating imbalances in market values.

- Markets and market-based economies are endogenously unstable. External shocks may exacerbate or mitigate that instability but they are not the primary cause of it. This distinguishes Minsky (1986) and Keynesianism more generally from prevalent New Market consensus views, those of neoclassical economics, and those of Real Business Cycle theorists who all see market-based economies as essentially self-stabilising, primarily and only temporarily disrupted by external shocks, aggravated or extended typically through inept government intervention.

- The financial sector of market-based economies comprises profitmotivated entrepreneurs who actively exploit opportunities to increase profits.

- This makes the financial sector a source of and transmission mechanism for instability in market-based economies. Light regulation of the financial sector creates the 'ideal' environment for subsequent instability (Minsky, 1986).

Minsky's FIH or 'Wall Street Paradigm' $(1986 ; 1992)$ provides an account of capitalism's evolution through cycles, driven by an inherently unstable financing 
structure $^{3}$ (Minsky, 1986; Wray, 2008). Minsky describes the inherent instability of capitalism as a result of prevailing institutional structures, but identifies an underlying instability that (counterfactually) would occur even without the complexity arising from the existing institutional framework (Pollin, 1997; Minsky, 1975). This is, in effect, the view that bankers are not merely intermediaries between savers and borrowers, but they are profit-motivated entrepreneurs (Minsky, 1986).

Minsky's theory of capitalist instability draws on previous theoretical traditions of Veblen, Wicksell, Fisher, Schumpeter, and Keynes, developing a version of postKeynesianism referred to as Financial Keynesianism (Wray, 2008; Dimand, 2004). Part of the expository element of this thesis involves establishing the basis for the inherent nature of the instability of market-based economies, extending beyond current institutional structures. This posits a market-based economy with money as a store of wealth as a sufficient condition for financial fragility. However, this base of instability only becomes problematic for Minsky (1986) when aggravated by the financial system and it is this that forms the focus of this thesis. From this foundation it is necessary to establish regularities (or at least recurrences) in the instability of capitalism. Such regularities are identified in the work of Kindleberger (2000).

Kindleberger (2000) provides historical empirical support for Minsky's basic propositions that asset price bubbles are persistent features of the economy due to their causal nexus with human behaviour (Filardo, 2004). Following Minsky's proposition that bubbles are instigated by an exogenous factor, such as a technology shock, financial liberalization, or political outcome, which create new profit opportunities, he argues that such developments are self-sustaining and reinforcing, subject to limits (Filardo, 2004). Elastic credit creation then interacts with the shock factor. This leads to a progressive expansion of the bubble which meets demand constraints, and progressively observes a widening gap between speculatively-fuelled asset prices and

\footnotetext{
${ }^{3}$ Fractional reserve banking is the retention of a small portion of deposits as reserves against money lent. The effect of fractional reserve banking is that a single deposit enables the financial system to extend credit in some multiple of the original deposit as the lent money cycles back through the system to provide more reserves and greater ability to lend on the basis of those increased reserves. This does not entail that available reserves determine money supply but it creates greater scope for money supply to grow on the back of increased demand.
} 
fundamentals. Ultimately such bubbles must collapse, returning markets to a stable equilibrium level at substantially lower levels (Minsky, 1986).

Prevailing short term stock market forecast models are also considered. As the focus of this research is quarterly market movements this process aids the adaptation of Minksy's (1986) FIH which details the anatomy of complete business cycles. Beyond sharpening the focus of Minsky's use of leverage levels through the examination of flows' data, in this research short term forecast models support the use of 'technical' indicators. Technical indicators include market trading volume and price history data and are consistent with a Minskian understanding of market and investor behaviour. Specifically, given the focus of short term forecast models on such indicators, market movements and volumes data are incorporated into the selected test variables. Notably, notwithstanding the extensive use of technical prediction models by many market participants this approach is largely rejected by academic sources. In general terms academia regards short term market movements as a random walk which precludes reliable predictions.

\subsection{Corporate financial structures, preferences, theories about these, and the limits of those theories, and an alternative theory}

The specific theoretical structure developed from the key propositions outlined above starts from a default position of the Modigliani and Miller (1958) (MM) 'indifference theorem' and inter alia Gordon's (1989) corporate financing structural qualifications to that theorem. These foundations form the basis for the implied optimality of parallel relations between corporate equity and debt financing. That is, either debt or equity may be greater than the other as a source of corporate financing but there is no basis for this to change cyclically. Gordon's (1989) qualifications to MM (or the violation of one of the MM assumptions) determine a shift in the curve (line) describing the optimal configuration of a company's external financing, without fundamentally undermining the theory. That is, the relative mix of corporate debt to equity is objectively determined at a structural level and, therefore, cyclical variations should not arise. The observed macro-financial cyclical divergence between corporate debt and equity funding flows is identified in this thesis as a sub-optimal deviation in which risk is incorrectly priced. The underlying structural preference for debt finance over equity is augmented by a pro-cyclical and unrelated bias. This view, that cycles in 
corporate financing composition are related to market cycles, is Minskian in derivation, proxying the contraction of lender margins and the expansion of borrower margins over booms is often described as the 'systematic mis-pricing of risk'. Such mis-pricing may be expected to manifest in finance flows and prices as potential indicators of market direction.

From the MM starting point this thesis proceeds to evaluate alternative theories of corporate financial structures and preferences. Amongst these are: trade off theory, dynamic trade off theory, pecking order theory and market timing theory. A range of other factors are considered including: company size, profitability, cash flows, the stability or volatility of profits and cash flows, and industry type. There is no current theory able to explain the cyclical movements in corporate debt and equity flows identified above (and depicted in figure 1) without recourse to a (questionable) dual hypothesis; that of the objectivity and rationality of extrapolative market price trend expectations. That is, in particular in relation to rising markets, an additional hypothesis is required that if recent market price trends are to support inference to future trends then it is necessary for markets to continue to rise (indefinitely). The confidence in trend extrapolation functionally precludes market cycles but cycles are demonstrably persistent features of markets. No theory involving other than severely truncated agent rationality can rely on a dual hypothesis that specifically entails the systematic irrationality of agents or that assumes recurrent historical patterns are unlikely to be repeated at any point in the future. Both trade off theory and pecking order theory rely on agent rationality as a key assumption. In the case of market timing theory empirical observation appears to contradict the central elements of that theory in the period 19802012, as equity issuance, on average, declines as markets rise and is frequently negative at such times. For these reasons there is a substantial gap in each of the three key current theories of corporate financial structure. Cycles in corporate financing flows are recurrent phenomena in recent history. Moreover, this empirical observation can contribute to theory as well as offering potential signals for future market forecasting models.

Chapter five describes the gap identified above and indicates scope for an alternative (or additional) theoretical view of corporate financing. This research advances the role of market price trend extrapolation and of the parallel higher implied 
cost of equity financing relative to debt financing as drivers of corporate financial structures over market expansions. The observation of increased corporate debt inflows and corporate equity outflows, which parallel rising markets, may be no more than corporate re-balancing of its financial structure to account for increases in equity due to retained earnings and asset price rises. However, evidence of sharp reversals in corporate financing flows after market falls, especially when substantial and sustained, seem to imply a different conclusion. Equity issuance in the aftermath of a market fall (counter to market timing theory) is costly as the reduced market price of equity is compounded by an increase in supply. Instead, Minsky's (1986) view of the need for corporations to consolidate their balance sheets appears to offer a more plausible explanation of observed corporate debt and equity flows in the period subsequent to 1980. These factors provide the basis to posit the market price trend extrapolation theory of cycles in corporate financing flows and structures.

The hypotheses for the chapter five development of a theory of corporate financial structures are that:

HO: Existing theories of corporate financial structures fully explain corporate macro-financial flows in the US in the period 1980-2011.

H1: Cyclical US corporate macro-financial flows in the period 1980-2011 are not explained by existing theories of corporate financial structures and preferences.

Hla: Deductive inference supports an alternative Minskian interpretation of observed corporate macro-financial flows; that prior market price trend extrapolation supports corporate preferences for debt or equity at different points in market cycles.

The methodology employed here to advance the alternative hypotheses is based on empirical observations and deductive inference from those observations. This involves examining observations within the framework of existing theories of corporate financial structures and preferences and then isolating the deficiencies of these theories in terms of observed corporate macro-financial flows in the modern period. The result of this 
process is that modern period observations appear to contradict pecking order theory and market timing theory. Further, trade off theory provides an implausible explanation for cyclicality in corporate macro-financial flows and must tacitly abandon its assumption of optimisation as the foundation of corporate financing choices. The alternative hypothesis identified above is the generative basis for the primary hypothesis of this thesis, as given in section 1.5. If existing theory fails to account for a substantial cyclical pattern in corporate financing flows then scope exists to identify the forces behind those cycles. It is also reasonable to assume that those flow cycles have not had sufficient importance attached to them within existing corporate financing theory. Further, I advance the case that variables determined on the basis of the theory developed in chapter five of this thesis have market forecast potential.

\subsection{The indicator approach}

Proceeding from the theoretical base detailed in chapters two through five, chapter six surveys and assesses existing models of fundamental value and indices of financial fragility (or deviations from fundamental value). Such research isolates a number of variables, measures and proxies for the valuation or mis-valuation of assets, with some of these measures developed to identify when there is an elevated risk of economic recession. This survey is conducted to inform and position the present research relative to existing research and literature in the general area.

There has been a general increase in interest in (leading) business cycle indicators around the world in recent years, but in the US a progressive reduction of focus on these indicators has occurred (Klein, 2001). These indicators include leading, coincident, and lagging factors. Amongst these are rates of, and changes in the rates of, employment, incomes, inventories, expectations, and markets. Prevailing thought involves the tacit rejection of Mitchell and Burns's (1938) observation that, although each business cycle is unique there are regularities in the sequences of phenomena surrounding them. This tacit rejection of broadly recurring general features of business cycles is predicated on a number of dubious assumptions (Mullineux, 1990). These include: the low value attended to identifying what are viewed as largely exogenous shocks; the greater value attached to more sophisticated econometric forecasting; the argued for relatively minor nature of business cycles as normal adjustment processes; 
and, the declining usefulness of business cycle indicators since the Second World War (Klein, 1976; 2001).

\subsection{Methodology: variables, time span, and empirical foundations of this research}

The hypotheses are stated thus:

H2: Future market movement forecasts cannot be improved over those implied by a random walk.

H3: A number of macro-financial variables may improve forecasts of market movements over those implied by a random walk.

H3a: H3 can be employed by corporations in their short term financing and investing decisions to increase the efficiency of such operations.

Evidence for $\mathrm{H} 3$ relies on the ability of the models developed in this thesis to provide increased implied returns over those achievable by a buy-and-hold strategy for the period 1980-2012. Because markets rise above risk-adjusted levels over the long term, a successful forecast model must be able to improve returns over those that assume the unpredictability of markets. Due to certain variables included in the models being just one lag (one quarter) from the predicted period the models are limited to predicting $(t+1)$ or the quarter ahead only.

The methodological approach adopted in this thesis involves the use of binomial logistic regressions to identify which theoretically indicated variables are able to improve forecasts of market movements. The use of this method is the result of the need to divide the dependent variable into 'buy' and 'sell' classifications. In simple terms the same set of predictor variables cannot be expected to predict alternative outcomes from a single linear regression. For this reason the dependent variable has been drawn as a dichotomous variable representing market rises (1) or no rise (0). Alternatively, a separate model is developed using quarterly market declines in which a quarter of decline is denoted 1 and a quarter of no decline is 0 . A threshold is employed on minor increases and decreases to ensure that the implied risk-free rate do not invalidate translation of the forecast or prediction model into a decision model. 
The use of binomial logistic regressions in preference to a linear regression is also predicated on an assumed level of imprecision or incompleteness in the models developed. It would be heroic to assume the tested variables were exhaustive of causality on stock prices. For this reason a dichotomous dependent variable makes less onerous demands on the predictors than would a linear approach, assuming a more 'approximate' ability to explain the dependent variable. An additional advantage is that by setting up two distinct (buy and sell) models it is possible to extend or diversify the potential applications of the models. This is due to the binomial logistic regression (and Hosmer-Lemeshow test) ability to determine odds ratios which, when different models offer competing signals, enables the arbitration of that competition by reference to investor preferences. In the case of this thesis, the creation of distinctive 'buy' and 'sell' models results in two sets of predictions which conflict in certain periods, allowing the selection of the signals with the greatest probability. This further adds to the decisionusefulness of the approach adopted here.

A binary logistic regression is employed to assess the incremental value added to the model of risk by each of the explanatory variables. Binary logistic regression crystallizes an essentially neo-classical, market-efficient position on the unpredictability of future market movements. That is, in each period it is equally likely that a dependent variable event will occur, based on historical incidence and time. Further, there is little likelihood of more than one event occurring in a single period and, thirdly, each event is independent of preceding events. These assumptions are not held true in terms of the theory of this thesis. Instead, they describe a default starting point from which significant coefficient values define an improvement in the basic assumptions of market efficiency. If the models improve returns over those achieved by the assumption that markets correctly price all relevant information through the aggregate operation of knowledgeable, rational, risk-averse economic agents eliminating abnormal, risk-adjusted returns, then they can be said to be successful.

The macro-financial independent variables employed for testing for market forecast efficacy are determined on the basis of the theory previously outlined and include:

1. Broad changes in share prices, proxied in the case of the US by the S\&P index

2. Net corporate debt flows 
3. Net corporate equity flows

4. The relationship between these flows

5. S\&P 500 market price (level) history

6. The relationship between corporate financing flows and the S\&P 500 index

7. Market trading volumes

8. Dividend flows

9. Real interest rates

10. Nominal interest rates

11. The Federal funds rate (FFR)

12. The Discount rate

13. The Current Account deficit

14. Inflation

These variables are assessed at up to ten lags (quarters) each to determine those most productive in terms of reliable occurrence precursory to substantial changes in market levels.

Following the FIH, the hypothesis is advanced that, as booms extend, previous asset price rises cause a contraction in risk assessments. Shiller (2005) argues that this is due to a simple process of trend extrapolation. Clearly, the longer and more persistent the boom, the longer and more consistent the history of asset price rises, the greater the evidence for the extrapolation of future increases. This defines a default floor in typical assessments of risk in debt contracts (for the lender) as contract performance is supported by the appreciation of collateral backing debts. In this way rising asset prices are self-validating, supporting increased borrowing against assets, further supporting rising asset prices.

While the principal focus of this research relates to the changes in the level of financing by external corporate debt relative to corporate equity as sign of asset price bubbling, a body of research causally links the expansion of broad credit aggregates with either inflation in consumer prices or, where not this, inflation in asset prices (Becker, 2007; Borio and Lowe, 2002; Goodhart and Hofmann, 2008; Palley, 2008). Sharpening this focus from broader aggregates informs the approach taken here in analysing the role of cyclical corporate credit growth, relative to corporate equity. 
Simply, there is no plausible reason to assert a utility optimizing reconfiguration of debt-to-equity that is observably pro-cyclical without a companion assumption that risk is systematically mispriced, reduced at certain points in the cycle and increased at other points, or that it is primarily a function of trend extrapolation.

The empirical evidence of the positive claims of this thesis requires an examination of historical data sources. In contrast to the preference articulated by Reinhart and Rogoff (2008), the period is relatively brief, spanning the period from 1980-2012. The relatively longer period (of eight centuries) preferred by Reinhart and Rogoff (2008) to eliminate the risk of deeming events rare or improbable that are likely to occur over longer sweeps of history, is not suitable in the present context. Three key factors resist such a longitudinal approach. Firstly, modern corporations and active secondary markets are limited in history to the period from the late 1700s. Secondly and more importantly for defining historical parameters to the relevance of time series, economic epochs are substantially defined by the institutional structures particular to them. In this context a descriptive account of the current period is necessary to define its nature. Thirdly, data availability improves over time, recommending recent economic history.

\subsection{Problems, limitations, and qualifications to this research}

Minsky's theoretical framework has been criticised inter alia for its silence on wealth distribution as a causal link to business cycles and, concomitantly, asset market cycles. Dickens (1999), Dymski (2002), and Rasmus (2008), have identified this as a deficiency in Financial Keynesianism. Arguably then, Minsky's 'financial' theory of business cycles identifies just one of the signs of financial fragility. This objection indicates that underlying business cycles are cyclically coincident with changing wealth and income distribution. By extending Minsky's analysis to the tension between labour and capital, a fuller understanding of business cycle causation may arise. However, this thesis focuses on corporate valuations. For this reason any companion trend of growing inequality in wealth and income with booming markets and elevated relative levels of profitability is of secondary importance. The FIH is able to provide proximate causation. For the purposes of developing forecast models for equity markets the FIH provides a sufficient theoretical basis. 
The research is necessarily limited in its consideration of economic variables endogenous with macroeconomic and market cycles. In the same sense that market efficiency is argued in this thesis as constrained by the limits to rationality as an operation on information, the research must describe limits in its domain. This does not preclude economic implications due to exogenous shocks, such as war or disease. The position here is that the incidence and magnitude of such events cannot be anticipated from economic information and, thus, such information cannot inform a calculus for the predetermination of market disequilibration relative to the valuation implications of exogenous shock factors.

An issue in relation to the operation of the models developed in this thesis is that they operate on a well-specified economic and financial institutional environment. This is the de-regulation of the US domestic economy (although some generalisability to other developed countries may be possible, if later in occurrence) and the freedom of global financial flows that have extended this economic liberalism around the developed world. In the US the period of deregulation began from the 1970s. In other countries it was somewhat later. For example, the origin of the deregulation of the UK financial sector has been isolated to 1986, and it occurred more precipitously than in the US. This is similar to New Zealand's experience, beginning in 1984. Arguably, this forms an important element in model specification and it might be expected that the models would perform less well in a significantly altered environment. Given this, there would be a need to re-visit the models, modifying them, in the event that the era of light regulation of financial markets and economies was to change. Light regulation is also paralleled by a focus on monetary policy and the focus of that policy on inflation control, augmented by a separate concern for asset market stability. Despite signalling this issue it is one that has recurred in the field over time and is no different to that identified by Mitchell and Burns (1938) when they developed the NBER basis for leading, coincident and lagging business cycle indicators. Some measures will wane in importance, some will cease to be relevant, new variables will acquire relevance. This is more an issue of identifying the need to maintain the currency of such measures and models, rather than an inherent flaw. 


\subsection{Contribution}

Contemporary positivist research is typically based on an assumption of market efficiency or on establishing incremental proof (or disproof) of market efficiency (Whittington, 1985). Ball (1989) provides a Kuhnian description of 'normal science' as relevant to the evolution of the efficient markets' hypothesis. Qualifications to market efficiency have gained some currency as a result of successive challenges to the efficient market hypothesis. However, the dual hypothesis problem (alluded to in chapter two) that confounds categorical proof of market efficiency has also preserved the hypothesis against rejection. This is amongst the reasons that the EMH remains at the core of contemporary economic and financial market theory. A consequence of this is that alternative generative assumptions, including that markets are not reliably efficient, have been (relatively) under-explored as the basis for research. This is all the more so where the assumptions involve fundamental departures from market efficiency as inherent features of market-based economies.

The failure of equilibrium economics to account for market crashes is problematic for the more rigid views of market efficiency held by (amongst others) Fama (1970; 1998), Fama and French (1992; 1995), Kothari (2001), and Schwert (2003) (Cooper, 2008; Tvede, 1997). In particular, the failure of the market to provide reliable fundamental valuations of companies seems too important to discount. The contribution I make here is an interrogation of prevailing arguments for market efficiency and what inferences for the objectivity of market values we may draw from them. The case is made that market efficiency has effectively survived in its more parsimonious forms but it does not tell us markets deliver accurate assessments of fundamental value. Instead the case is made that the efficiency of markets best supports the view of markets efficiently delivering relative company valuations. Stipulating this lesser claim, the presumption of the objectivity of market values requires qualification.

This research adds to the literature by developing theory based on fundamental departures from market efficiency. By following, applying and extending a broadly Minskian approach to the operation of market economies, a well-grounded basis for positing a challenge to market efficiency at a fundamental level is advanced. This approach expands on re-newed interest in Minsky's (1986) FIH that arose around the time of the sub-prime crisis and ensuing global financial crisis and recession. Minsky's 
(1986) FIH seemed to provide convincing explanations of events that more prevalent theories were silent on or that those more mainstream theories provided less compelling explanations for. The apposite nature of Minsky's work was reflected in something of a renaissance of the FIH, including the commentary and articles of Bellofiore, Halevi, and Passarella (2010), Cassidy (2008) Dymski (2010), Fernandez (2008), and Kregel (2007) The recent financial crises are difficult to explain within the framework of rational economic agents, acting with full knowledge to maximise their utility, and entailing the inherent stability of market-based economies. These developments provide a sound basis to introduce and investigate an alternative understanding of markets, their financing structures, operation, and the implications of these factors for future market prices.

A further contribution is the use of flows' data. This contrasts with prevalent approaches that focus on stocks or 'fundamentals'. In particular, Shiller (2005), who is prominent amongst economists challenging macro-economic stability as an outcome of micro-economic rationality, uses fundamentals to determine the stability of financial and housing market pricing levels. In relation to equity markets Shiller uses price-toearnings ratios (PERs). There are several reasons to resist this approach and to develop alternative bases to those employed by Shiller. PERs are not constant measures over time; fair value accounting measurement has substantially superseded historical cost accounting measurement that was used to determine earlier PERs. This development confounds reliable comparability of PERs over time. Equally, intangibles have become increasingly important in the modern corporate context and accounting convention, determining the calculation of PERs, precludes the capitalisation of internallygenerated intangibles, further confounding PER comparability over extended periods due to changes in the underlying commercial environment that accounting numbers describe (Short, 2013). This becomes relevant when we consider average PERs in the late 1920s, preceding the Great Depression, of approximately 30, compared with PERs of almost 45 in the late 1990s. The recession and market decline of the latter period of 'stretched' fundamentals was brief and minor relative to the Great Depression yet the 'signal' of market fragility was stronger in that period. It can be seen that Shiller's measures are very general and long term in nature. 
Flows' data offers the prospect of 'sharpening' the focus of 'predictive' modelling, aiming at more specific, short-term forecasts. Instead of focusing on cumulative effects it may be possible to enhance the immediacy of predictive modelling by avoiding the use of 'fundamental' measures of financial market stability and by rejecting the use of stocks' measures. In both cases an additional (potential) advantage is that the feedback effects of market cycle phases may be reduced through flows' data. In particular, debt-to-equity, PERs, and cash flows' measures are all influenced by cycle phase. To an extent, asset mis-pricing is self-justifying as rising or falling prices feedback into stocks and fundamentals. This is less clearly a confounding issue with single period single period flows' data.

The use of flows' data also involves an adaptation of the FIH to fit its insights to the modelling of market movements over periods shorter than the business cycle that was Minsky's (1986) focus. The use of flows is augmented with more typical short term market prediction variables. These variables include historical market volumes and levels. In contrast to standard applications in short term market prediction models the use is made of historical quarterly data as opposed to the daily data of the shorter term models (Atsalakis and Valavanis, 2009). This modification is made to tailor Minsky's (1986) central insights to quarterly prediction modelling.

The purpose of the preceding considerations is to create a model capable of forecasting short term market movements. This adds to the literature by filling a gap in a presently thin field of research. The nearest similar research I have been able to identify is that of Shiller (2005). Shiller's research provides credible (and historically validated) long range forecasts of market movements that are of a very general nature (as noted above). Shiller's model allows him to anticipate market levels in ten years' time with reasonable success but it is unable to elaborate that outcome in terms of the progress towards that future point. This result is of value to very long term investors but many investors have shorter time horizons in focus.

A further contribution of this thesis is embodied in the extension it makes to existing theories of corporate financial structures. The basis for this extension of existing theory is the observation that corporate debt inflows and corporate equity flows decrease or outflows typically accompany rising equity markets. The direction of these 
flows reverses with market falls. This set of observations is highly consistent for the S\&P 500 index over the period 1983 to 2012.

Existing theories of corporate financial structure do not readily lend themselves to the observations outlined above. This gives rise to an 'extrapolative expectations' theory of corporate financing which better accords with observed corporate financing flows. This theory approximately contradicts market timing theory. However, it is not a complete theory of corporate financial structure. Inter alia firm-specific factors also have a role. The industry type, cash flow stability, firm size, and profitability all influence corporate debt and equity financing preferences. Further, existing theories (with the possible exception of market timing theory) offer some insights into corporate financing. What the extrapolative expectations theory aims to do is provide an explanation for cycles in corporate financing preferences by adopting a macro-financial approach to understanding this area.

\subsection{Summary}

This thesis builds on a subsidiary line of economic theory to argue for a fundamental break with the efficient market hypothesis. The approach involves exploring the Keynesian roots of Minsky's (1986) FIH, and the FIH itself, to expound a case for markets that are endogenously unstable. Notwithstanding endogenous instability, these markets are dampening or inherently stable in processing external shocks through flexible prices. The endogenous instability of markets is transmitted through its financial system and is, in part, reflected in the cyclical flows of corporate debt and equity external financing. Further, patterns in these financing flows may provide market signalling potential. Arguments for these propositions are developed in chapters two, three and four. An alternative (to existing) theory of corporate financial structures is developed in chapter five which outlines the case for an extension to existing theories. These theoretical foundations support the development of models which aim to forecast future market movements. Chapter six then assesses existing forecast and equity valuation models to situate this thesis within that literature.

This thesis develops models (in chapters seven and eight) based on the theoretical foundations described above. These models target quarterly $t+1$ predictions (predictions for the quarter ahead) of market rises or falls. Using test variables indicated 
from the preceding theoretical foundations separate buy and sell models are developed using binomial logistic regressions. These models are set against a default of historical incidence over time. More demandingly, assuming a random walk and the long term risk-adjusted rise of markets, a second comparator is provided by a default buy-andhold strategy. The performance of the respective 'buy' and 'sell' models is assessed against these proxies for a random walk around a secular rise in the market. The results of these tests are that combinations of the tested variables improve on the outcome of proxies for unpredictable markets. Findings are presented in chapter eight and chapter nine discusses and analyses these findings. 


\section{Chapter two: limits to market efficiency as an objective referent base}

\subsection{Introduction}

This chapter examines the concept of market efficiency to determine limitations to its positive statements about market values as a reflection of objective fundamental values. This issue is examined as a basis for determining the extent to which asserting that the cyclical flows of corporate debt and equity finance are explicable in Minskian terms (as further discussed in chapter five). Minsky $(1986 ; 1991 ; 1992)$ is used as a theoretical basis for this thesis and the theoretical framework is presented in chapter three and four as the FIH identifies an ecomony's gravitation towards greater reliance on debt over periods of economic (and market) expansion, fitting with observations. In terms of corporate financial structures this reliance and observed financing flows may be explained as a rational response to increased equity (and declining leverage levels) through retained earnings and asset revaluations. However, empirical analysis shows (see: figure 1 below) what appear to be debt and equity substitutions, the extent and timing of which may not be entirely rational (as is discussed further in chapter five). This substitution may be able to aid the forecast of equity market price movements. This does not entail the abandonment of an FIH framework but, instead, argues for the modification of that framework.

Figure 1 identifies macro-financial corporate debt and equity flows in the US from 1980 to 2011. Debt flows are the inflow (and occasional outflow) of net corporate debt across the market. Net equity flows are changes in the external equity financing position of corporations across the market. As these equity flows are predominantly negative (net outflows) they typically reflect the excess of share buy backs over new equity issuance. The source of this data is the Board of Governors of the Federal Reserve Board, series Z.1. Figure 1 shows what appears to be the (approximate) substitution of debt for equity.

Rational corporate financing choices imply wealth maximisation. For this reason rationality fails as an explanation of the observed flows because market movements are more liquid than changes in corporate financial structures, and Balance Sheet consolidation requires companies to issue new shares at low prices after large 
stock market declines as is shown in figure 2. Companies are, therefore, transferring a greater share of corporate wealth to new investors that if they had sold equity at higher market levels. Because such falls are recurrent features of markets it is unlikely that the optimisation of corporate financial structures that rationality entails could result in the pre-crash corporate financing substitution of debt for equity. During periods of market decline and consolidation, equity is substituted for debt and these equity financing flows are invariably comparatively expensive as equity market prices are falling or have fallen substantially. These flows in external corporate financing provide a challenge to market efficiency as they indicate lengthy periods of sub-optimal corporate financial structures. Instead of rational (and therefore efficient) aggregate corporate financial structures it is plausible to identify disaster myopia as a driver of corporate financing over expansions. ${ }^{4}$

Figure 1: US corporate debt and equity flows (millions) 1980-2011

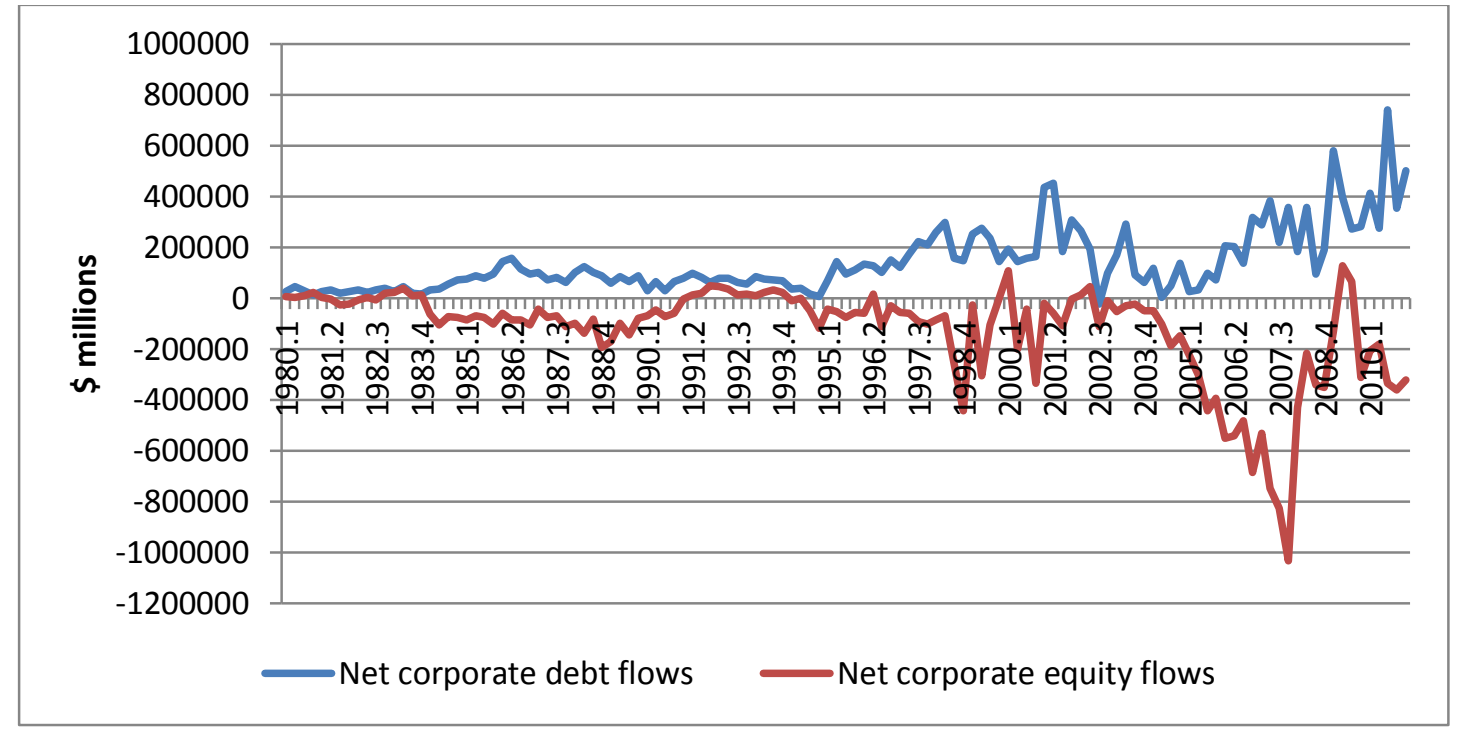

This chapter builds the case for a parsimonious form of market efficiency, that of markets' relative pricing efficiency. Relative (company) pricing efficiency is the view that market levels may not be justified but companies are broadly efficiently priced when compared with each other. An implication of this is that market values may not be solely products of the operation of rational expectations of future cash flows. In

\footnotetext{
${ }^{4}$ The subsumption of total risk evaluations by realised risk evaluations results in growing complacency that latent risks will not be realised. This leads investors to discount comparatively small risks (in any period) of a large and sustained decline in market values. As markets rise this approach gains successive empirical support.
} 
line with Minsky (1986) and Pepper and Oliver (2002), investors' sentiment and liquidity may move markets away from fundamental value. These propositions theoretically ground this thesis' case that US corporate financing flows are influenced by non-rational reactions but also macro-financial forces that cause markets to become mis-priced. Adopting a view espoused by Pepper and Oliver (2002) credit availability is a separate determinant of asset market pricing that inflates or constrains those prices, respectively above or below fundamental value. Such mis-pricings are points of abnormal risk to market values and bring an increased likelihood of short-term trend reversals.

The aim of this chapter is to provide the basis for an increased understanding of the nature of forces effecting asset market prices, as a basis for better informing corporate financing decisions, investor decision models and, in chapter five, developing a theoretical understanding of corporate financing decisions that augments existing theories and that links to corporate (equity) financing and asset pricing.

Figure 2: Net US corporate debt and equity flows and the S\&P 500 index

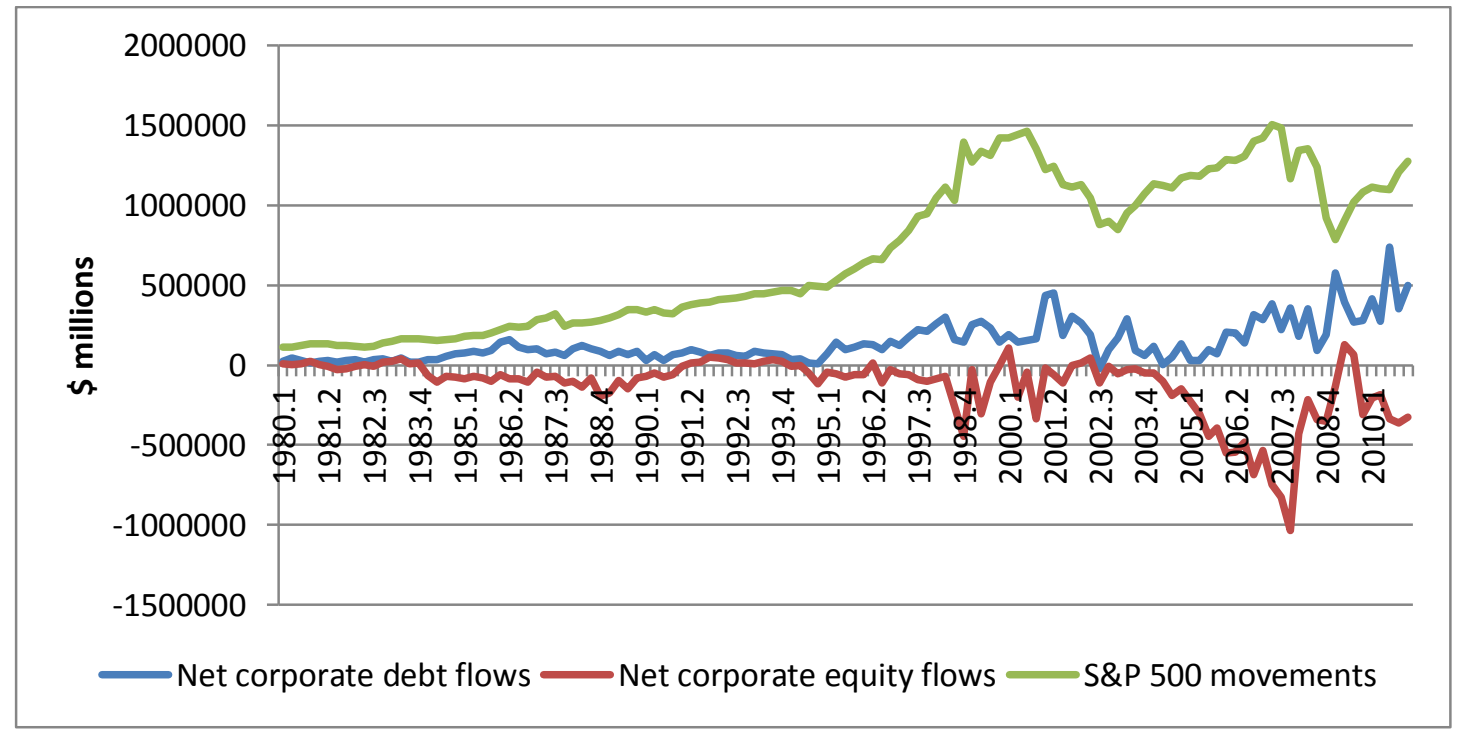

Figure 2 adds (to figure 1) movements in the Standard and Poors (S\&P) 500 index to corporate debt and equity flows. It reflects broadly positive movements in debt and the index (correlation: $0.60 ; \mathrm{R}^{\wedge} 2$ 0.37), along with a broadly negative relationship between these times series and corporate equity flows (correlation: $-0.55 ; \mathrm{R}^{\wedge} 20.31$ ). In general, a rising market is matched by corporate equity outflows. A lengthy period of consolidation is also observable in the early 1990s, with a reduction in corporate 
reliance on debt and a period of corporate equity inflows. Notably, this extended period of balance sheet consolidation was followed by the 'Super Bull Run' of the 1990s. The relationship between market movements and corporate debt and equity flows corresponds with Minsky's (1986) view that sustained economic expansions are accompanied by progressively risky corporate financing structures as increasing debt is assumed by companies.

The treatment of market efficiency is developed here in terms of arguments for and challenges to the efficient markets' hypothesis. The chapter then proceeds to show how specific challenges to market efficiency of particular relevance to this thesis form a basis for the acceptance of the relative pricing efficiency only. That is, market efficiency prices assets of a class (such as equities) effectively relative to each other but this does not entail that these prices are true reflections of fundamental value. The market in toto may be mispriced. The issues have been covered extensively in past literature (including: Ball, 1989; Dimson and Mussavian, 1998; Kothari, 2001; Malkiel 2003a; 2003b; Schwert, 2003a; 2003b) which has, on balance, been inconclusive. Simply, proofs of market efficiency have been met by disproofs of the same and the respective arguments rely on assumptions that are not self-evident. Certainly, there is no compelling basis to assert that markets reliably reflect fundamentals alone, without independent influences on price formation from sentiment, liquidity, and constraints on equity supply, in part caused by stock repurchases. For this reason, and cognisant of Kothari's (2001) observation that the efficient market hypothesis is the best (wellspecified) theory we have, this chapter argues against general (macro-level or marketwide) market efficiency but accepts the ability of markets to deliver relative pricing efficiency.

Without a superior theory, the limits to market efficiency identified here do not describe its inherent weakness but its over-extension in application. The case presented is that market efficiency does not, or need not, entail that those markets reflect fundamental value. Its more parsimonious, credible forms state that security prices will move appropriately (relative to each other) to new information entering the market (Campbell, Lo, and MacKinlay, 1997). Without a conception of a true equilibrium value it is unclear that the appropriate behaviour of particular prices relative to other prices in response to information flows delivers true equilibrium values as opposed to 
correct relative equilibrium values (Summers, 1986). This position is similar to that of Borio, Furfine, and Lowe (2001), who argue that relative risk assessment is more accurate than absolute risk assessment. That is, Borio's, et al, (2001) position is that markets' core competency lies in their ability to appropriately order the value of risk assets in relation to each other, without providing an objective measure of that value.

\subsection{The basic elements of the Efficient Markets' Hypothesis}

The efficient markets' hypothesis was developed over the late 1960s and formally presented in Fama's (1970) survey of the research. Initially, the evidence about the efficiency of markets overwhelmingly supported the proposition that markets move rapidly to reflect fundamental values, updating prices as new information becomes available (Schwert, 2003a). However, as the publication of further proofs of market efficiency declined, the research focus changed to anomalies or empirical evidence contrary to market efficiency (Ball, 1978). ${ }^{5}$ Despite these challenges, and evidence of them, market efficiency, albeit sometimes qualified, has remained at the core of orthodox understandings of the operation of markets. This factor is noted by Temin (2008) as a constraint on the ability of economics to identify bubbles and forecast the subsequent bursting of those bubbles.

The basic tenets of the efficient market hypothesis are that, on aggregate, markets comprise fully-informed, rational, utility-maximising economic agents. These rational agents rapidly incorporate all new information into securities' prices as that information becomes available (Ball, 1978). This process eliminates the possibility of abnormal returns from information trading (Keane, 1983; Schwert, 2003a). A stronger claim made by market efficiency proponents is that it delivers market prices fully reflective of fundamental value. The foundation of these views is that securities' prices arise from the market's expectations about the distribution of future cash flows attributable to a security. Further, pricing updates accurately reflect the affect of new information on future cash flows. On this view only revisions of cash flows estimates based on new information will affect a security's price.

\footnotetext{
${ }^{5}$ Ikenberry and Lokinshok (1989) provide a survey literature identifying temporal anomalies. Amongst anomaly research is that of Ariel (1988); Banz (1981); Basu (1977); Cross (1973); and Debondt and Thaler (1985). Each of these researchers identified different anomalies, some of which were later implicated in risk models by efficient markets' proponents.
} 


\subsection{The case for market efficiency}

The most compelling evidence for market efficiency is that active funds' management persistently fails to deliver better returns than the underlying indices against which they are benchmarked (Findlay, 1977; Schwert, 2003a). Evidence of this type supports the view that information trading does not deliver abnormal returns in the long run. This evidence establishes that markets are not predictable or, at least, that current techniques are not capable of producing reliable predictions. However, it does not support the stronger claims of market efficiency proponents, that markets reflect fundamental value. Furthermore, behavioralist explanations of market movements may equally explain the random walk in stock prices (Dreman, 1977; Scharfstein and Stein, 1990).

A well-established feature of asset management is that active management on average systematically under-performs passive management (Fama and French, 2010; Grinblatt and Titman, 1989; 1992; Malkiel, 1995). In large part this is not a function of active fund management incompetence but of higher management fees charged (than is the case for low-fee passive funds), the greater number of transactions and concomitant transaction costs, and either broadly efficient markets or, at least, broadly unpredictable markets (Fama and French, 2010). The general under-performance of actively managed funds against their targeted indices led to a funds management revolution forty years ago through the progressive development and growth of passive funds.

Against such research conclusions, Avramov and Werners (2006) identify the possibility of fund out-performance by managers either timing investment in specific sectors during an economic cycle or by selecting funds on the basis of past outperformance. Cuthbertson, Nitzsche, and O'Sullivan (2008) find that between 5\% and $10 \%$ of the best performing funds achieve returns reflecting skill rather than mere luck. Further, returns persistence is more prevalent amongst poorly performing funds. That is, poor performing funds tend to continue to deliver poor returns more reliably than other funds repeat their performance. Thus, by qualifying the findings of many studies in this area that average active fund management performance falls below that of benchmark indices (and index funds), it is possible to select for out-performance. 
Malkiel (2003a) provides an example of a key argument for market efficiency which is essentially experimental but arguably it is not translatable as a sequitur of markets and market participant behaviours. He cites evidence of students' superior aggregated predictions (analogous to the market) of academy award winners, compared to their individual predictive ability. He describes a situation in which the average survey participant's predictive success was five of twelve categories, yet aggregated results picked all twelve categories for a particular year. This result, although interesting, only supports survey participants' (extended to market participants') ability to select, on aggregate, between contemporary alternatives with finite and clearly defined alternatives. The survey responses are either correct or incorrect yet an infinite or at least wide distribution of values may occur in terms of future securities' prices. Malkiel's (2003a) survey evidence does not support inferences to inter-temporal comparison. The key objection to this argument for market efficiency from Malkiel (2003a) is that although markets are relatively efficient in identifying the value of near term prices they are less capable of identifying those that are in the distant future. In this sense greater discounting of the future is an inherent aspect of rationality (Kamarck, 1983). This analogy better supports the relative pricing efficiency argued for here than for systematic pricing based on fundamentals alone because it identifies the aggregate success of predictions of single-period alternatives.

\subsubsection{Methodological defences of EMH}

An element of Fama's (1998) defence of market efficiency suggests that methodological concerns confound most research which locates anomalies in the efficiency of markets. He takes the view that where reasonable alternatives to the methodologies identifying anomalies result in the disappearance of those anomalies (such as the January effect), it is reasonable to suggest such anomalies are an illusion. In simple terms, Fama prefers a default presumption in favour of his theory. Moreover, Fama (1998) offers promissory empiricism, stating that most anomalies are doubtful due to their failure to meet robustness and replication checks that follow initial publication. Fama (1998, p. 303) presumes that all anomalies, "will likely fall prey to the same process". This position is one identified by Ball (1978), who suggests that evidence of market inefficiency may indicate the need to improve the model of risk. This defence becomes circular as evidence of market inefficiency can always be 
deemed to be flawed in some regard or evidence of something other than the efficiency of markets (Summers, 1986).

Fama (1998) argues that market overreactions and under-reactions exhibit an approximate equivalence. For example, post-earnings announcement price drift, identified by Beaver (2002), and Jegadeesh and Titman (1993), as evidence of underreaction, is countered by evidence of overreaction events. This includes the price trendreversal findings of DeBondt and Thaler (1985). Fama's case is predicated on the basis that the identified reaction biases are temporally and causally unrelated. However, counter-valence does not neutralise potential abnormal returns from trading on each of the anomalies. Fama's (1998) suggestion, that overreactions and under-reactions broadly balance each other out, producing the kind of unpredictability anticipated by market efficiency, ignores the discrete nature of the various reaction biases, the EMHinexplicable length of these movements, and their identifiability. What market efficiency requires here is that returns' deviations from particular classes of anomalies will approach zero, so that equal probabilities and magnitudes of price increases and decreases occur in relation to each 'anomaly'.

Summers (1986) argues thattests of market efficiency often lack power, fail to identify many cases of inefficiency, and that this is the cause of the failure of anomaly research to survive the robustness and replication checks that Fama (1998) identified as essential tests of the existence of an anomaly. That is, the failure to reject market efficiency has been inducted as de facto evidence of market efficiency. Summers contends the low power of such proofs may fail to locate market inefficiencies, in particular, frustrating arbitrage elimination opportunities that cannot be statistically located. These proofs are prone to a high rate of type 2 errors, potentially suppressing evidence of market inefficiency. This supports the conclusion that while systematic abnormal returns may not be obtained by trading on public information, the stronger claim of market efficiency, that market prices are rational assessments of fundamental values, cannot be sustained (Summers, 1986).

\subsubsection{The dual hypothesis problem}

A fundamental problem with the efficient markets' hypothesis is the dual hypothesis problem (Fama, 1970; Summers, 1986). This problem arises in the need to 
rely on a model of risk to test market efficiency. For this reason conclusions about market efficiency are qualified by the assumption of correct risk specification. The dual hypothesis problem admits a tautological defence, but such a defence renders the hypothesis unfalsifiable. Logically then, market efficiency relies on its incumbency and, as Kothari suggests (2001), it is all we have and, thus, the best we have. Fama (1998, p. 284) makes a similar point, that market efficiency "can only be replaced by a better specific model of price formation [and that no such model exists]".

Market efficiency is secure if we accept a tautological interpretation of it, and some evidence of this has occurred, with the retreat into ad hoc defences (Dyckman and Morse, 1975). Arguably, some of the more tautological defences have been made by the progenitor of the efficient markets' hypothesis, Fama (1998; Fama and French, 1992; 1995). Fama made the case that the capital asset pricing model (CAPM) (as the original model of risk against which many original proofs of market efficiency were established) was misspecified in isolating beta as a single measure of risk.

Improved correlation between nominated risk variables and returns could be found by adding company size and price-to-book value as risk factors. Aside from the limits to the improvement of correlations between risk and returns that this augmented model provided (Schwert, 2003), there is no explanation provided why, in particular, high book value to price would recommend itself as an indication of elevated risk (Ball, 1989). In essence, ad hocery is implicit in the tenacity of this defence of market efficiency in which otherwise inexplicable anomalies are swept into the model of risk. Moreover, there is evidence of more persistent anomalies such as abnormal momentum returns and post announcement price drift (Jeegadeesh and Titman, 1993), the inclusion of which in risk models would almost certainly further improve correlations between risk and return and, thereby, support market efficiency. To the extent that this occurs, without a sound theoretical basis for inclusion of diverse variables in the model of risk, market efficiency becomes a tautology.

Extended CAPM models do not demonstrate the same efficient market theoretical coherence of company price beta alone and so they also may be viewed as ad hoc defences of market efficiency. Companies securites' price volatility as a relation to broader market (or industry) volatility must, presumably (in the context of market 
efficiency), link to a market estimate of degrees of risk relating to the certainty of expected future cash flows of those securities. If securities' prices are to be viewed as objective referents we would expect to find elevated betas perfectly correlated with, for example, low price-to-earnings ratios to the extent that low price/earnings ratio firms' outperform the market yet we do not. Thus, abandoning CAPM and, moreover, discounting its earlier EMH-probative value, appears to have suspect motivation. This may be qualified, to the extent that we allow the position of Grossman and Stiglitz (1980) (this is discussed in section 2.3.2); that volatility is confounded necessarily as an estimate of risk due to the influence of noise traders. The case for supplementing beta could then be theoretically justified, but with potentially negative implications for earlier evidence of market efficiency generated from CAPM.

Chapter six identifies key efficient markets' valuation models in greater detail. The point here (and a point touched on in chapter five) is that it is possible to characterise risk and risk modelling in such terms that markets are always (defined as) efficient. If, as Fama and French (1995) imply, evidence of market inefficiency is simply an indication that risk is mis-specified, then market efficiency is central to the measurement of risk and it becomes an empty truism. Fama and French (1995) do not infer a reduction in market efficiency from the mis-specification of risk but that this mis-specification creates the false identification of instances of market inefficiency.

\subsubsection{Under-developed trading rules as a defence of EMH}

\subsection{Challenges to market efficiency}

Challenges to market efficiency have, to this point, adopted a variety of approaches. They are broadly divided between rational explanations for market inefficiency and behavioralist explanations (Hafer and Hein, 2007). The former tend to identify more limited qualifications to market efficiency that still assert collective rational market participant action. The latter speak in such terms as herding and mass psychology. As yet, neither of these approaches has been fully theoretically developed and this, to some degree, leaves market efficiency as the default position (Fama, 1998; Kothari, 2001). Notably, unpredictability or the absence of abnormal returns from information trading is (or may be) consistent with behavioural explanations of market movements. 
The key areas of challenge to market efficiency relevant to this thesis involve trend extrapolation, the absence of an observable basis to determine fundamental value, and resulting bubbles. Investors prefer the recent past when estimating future prices, creating a feedback loop, and they focus on current prices (equity, dividends, and interest rates) to determine relative financial (or substitute) values (Shiller, 2005). These features are discussed in the following sections to establish the mechanism through which markets may be broadly fundamentally mispriced, without compromising their relative pricing efficiency. Simply, assets may be broadly mispriced in fundamental terms but correctly priced relative to each other, at least within a class of assets. This does not entail that bubbles are necessarily homogeneous across an asset class but that where this occurs there are existing, identifiable signs of such relative pricing inefficiency. Instead the focus of this thesis is on less identifiable, more generalised mis-pricing.

\subsubsection{Price trend extrapolation}

Markets privilege temporally proximate variables in valuing securities (Shaw, 1988; Kent and D'Arcy, 2001; Herring, 1999; Rousseas, 1992). This issue links with the preceding discussion on the irrationality (or bounded rationality) of investors' estimates of future cash flows. Investors (must) rationally prefer the certainty of current or 'near' information (about cash), either of the recent past or estimates of the near future, over temporally distant information of lesser reliability to determine individual equity valuations (Sawyer, 1989). In contrast to theories of cognitive dissonance or 'disaster myopia' (canvassed by Borio, Furfine, and Lowe, 2001), it is not obvious that irrationality is indicated in investors' discounting of low-probability, high-loss events (Kamarck, 1983). By assigning very low-probability events a percentage chance of occurrence in any period, investors can only marginally adjust their valuations in all periods but such events are discrete and occasional occurrences, typically assuming the independence of occurrences. Thus, Keynes (1936) emphasis on convention and uncertainty in forming asset prices complete agents' decision processes providing reason to question the objectivity equity market pricing.

Investment or divestment decisions must be based on at best a contingent objectivity (Borio, 2003; Herring, 1999; Keynes, 1936; Veblen, 1904). Keynes (1936) 
held that firms and wealth holders could never have all the information necessary to make investment decisions and so, must fall back on convention and psychological criteria as a substitute for information. This position contrasts with the dominant view of asset prices formed by the rational application of correct processing to full information sets that reflects the capitalisation of the distribution of aggregate expectations of risk-adjusted future cash flows. For this reason in as far as it is possible to do so, the case arises for qualifying market values for imbalances in the prevailing economic environment.

Price-trend extrapolation (or extrapolative market pricing expectations) is of particular significance in the present research as it becomes self-reinforcing, creating an independent source of 'bubbling'. It is also predictable under Minsky's (1986) view of market prices as self-reinforcing. If market rises spur the corporate substitution of debt for equity and this, in turn, drives prices higher by building an independent source of demand for equity, it follows that a rising market is locked into a feedback loop. Thus, even if corporate financing flows follow rational imperatives of shareholder wealth maximisation, those flows become inherent to the supply and demand equation. For this reason it appears reasonable to assume such a feedback loop must have some role in building an asset price bubble. This argument isolates credit-created liquidity as an independent source of demand for equity as identified in Pepper and Oliver (2002). If liquidity is an independent source of equity price formation, and signs of it are evident, then a buy-and-hold strategy is sub-optimal as it fails to respond to future pricing information contained in funds' flows.

\subsubsection{The tension between information and noise traders and the necessity of some inefficiency in market prices.}

More recent challenges to market efficiency view markets as constantly striving towards efficiency without ever attaining perfect efficiency (Grossman and Stiglitz, 1980). The action of information arbitrageurs is frustrated by 'noise' traders. Black (1986) makes a similar point in identifying the essential function of noise trading as a precondition for the existence of markets. This must ultimately be a post-mortem analysis given that the noise trader is one who is defined as trading on pseudoinformation and this is only determinable as information that is not later reflected in appropriate cash flows (Grossman and Stiglitz, 1980). The position advanced by 
Grossman and Stiglitz does not describe variations of great magnitude from true equilibrium. It provides us with an explanation for short term volatility and liquidity, addressing concerns such as those raised by LeRoy and Porter (1981) and Shiller (1981). However, it does not explain or identify substantial or sustained deviations from fundamental value; and the occurrence of such movements is the most plausible explanation of market crashes. As such periods of market breakdown have been a continual, periodic feature of asset markets since the development of those markets, it is reasonable to expect any theory of asset market price formation to provide a plausible explanation of these movements.

\subsubsection{Bubbles as a challenge to market price objectivity}

Market bubbles are an area of some contention in academic circles. For the purposes of this research a bubble is a sustained rise in asset prices above a level justified by fundamentals. This definition is itself fraught in that 'sustained' and 'fundamentals' are loosely defined. Bubbles (as per Minsky, 1986) involve the operation of markets on fundamental catalysts; typically a technology shock. Markets rise on the back of a technology shock, reflecting an unbiased response to elevated but temporary greater returns to capital. As economic and market expansions grow in duration, liquidity and trend extrapolation carry those expansions beyond the temporary shift in fundamentals caused by the technology shock (Minsky, 1986). A financial channel serves as an independent source of momentum. This is a bubble. Due to the anatomy of a bubble and different primary forces operating over the duration of an expansive phase it is difficult to identify precisely when an increase in markets is a rational response to changing fundamentals and when it becomes a bubble.

Rational bubbles' models assert that bubbles are consistent with market efficiency. These models fall into two main classes; bubbles that occur under the assumption of homogeneous and rational expectations, and those occurring under assumptions of rational and heterogeneous expectations. In both cases information symmetry or asymmetry may be assumed. All bubbles under rational expectations' assumptions also hold that on aggregate agents believe that the asset is over-priced in fundamental terms and that the bubble must exist from initial allocation. If this was not so, then buyers would be unprepared to pay a premium (to fundamental value) for an asset initially allocated at a Pareto efficient level, as this would involve a deliberate 
overpayment by the buyer. Bubble rationality is based on aggregate agent expectations that an asset's price growth will continue and will accelerate to compensate agents exposed to the risk that the bubble bursts. In this sense the rational bubble is effectively a particular specification of the 'bigger fool' theory. It follows that aggregate expectations are that all bubbles will burst at some future point.

To derive the rationality of bubble investment it is possible to consider bubbles per se as indeterminate, but this narrowly defines rationality so that it approximates the herding of behavioralism (Keynes, 1936; Wray and Tymoigne, 2008; Zarnowitz, 1998). Determinacy implies that an (exogenous) shock-induced deviation from true equilibrium value would entail a rapid price reversion to equilibrium, subject only to investor knowledge of market bubbles, yet this does not occur (Shiller, 2005). Moreover, bubbles analytically occur by magnitudes greater than can be plausibly explained by tension between, and the variable strength of, information and noise traders. We can deduce the indeterminacy of bubbles as a property of them due to their extended interaction with, and action upon, booms (Bernanke, 2002; Bernanke and Blinder, 1988; Bernanke and Gertler, 1989; Kaufmann and Valderama, 2007). Moreover, bubbles build around confluences of variables particular to each bubble (Mitchell and Burns, 1938). For this reason investment in bubble markets is justified by extrapolation from short term valuation trends only to justify overpayment in fundamental terms. That is, it is reasonable to pay more for a stock than its fundamental value provided only that the investor has a reasonable expectation that the stock will become even more over-valued and by an amount that justifies continued exposure to the bubble and the risk of that bubble bursting. It follows that bubble returns and expectations of those returns must accelerate as the bubble progresses. Under such conditions it is consistent with the market efficiency assumption of investor rationality (Shiller, 2005). Thus, the market price need not reflect true value at any point but only that errors are unbiased and uncorrelated with any observable variable (Mauboussin, 2002). Sufficient conditions consist in the indeterminate nature and lifecycle of the bubble. $^{8}$

\footnotetext{
${ }^{8}$ Not even typical rational bubble models assume the duration of bubbles can be known, although they do assume the extent of 'bubbling' is known (Lansing, 2007). In contrast, the case made here is that bubbles feed off and into changing fundamentals and are, thereby, less determinate than is implied by rational bubble theories.
} 
Notwithstanding the assertions of rational bubbles proponents, market efficiency logically precludes the formation of asset price bubbles. The key failure of rational bubbles' models to fit an explanation of bubbles within an efficient markets' framework lies in those models' requirement that, on aggregate, investors correctly weigh risk to determine the required rate of return (speed of bubble acceleration). That bubbles increase at a sufficient rate to justify investor exposure to the risk of the bubble bursting is not something that can be established empirically without a circular definition of risk and return in an objective relationship with the trajectory of the bubble. Further, challenges lie in rational bubbles' models' assumptions that bubbles necessarily burst. Often bubbles deflate (Brunnermeier, undated; Diba and Grossman, 1988). Further, the price bubbling of former 'penny dreadful' mining stocks that added dotcom to their names in the second half of the 1990s is inconsistent with an assumption of rational bubble proponents that the bubble must exist from initial allocation (Cooper, Dimitriov, and Rau, 2001). Even if the case for rational bubbles is accepted those bubbles still indicate market inefficiency.

The basis of market efficiency is that markets will always clear supply and demand imbalances through the price mechanism (Lydall, 1998). Where, for example, demand for a good exceeds supply, the price will rise, stimulating supply while decreasing demand. However, equity markets do not typically follow the pattern assumed in conventional supply/demand analysis (Cooper, 2008; Galbraith, 1990; Toporowski, 1993). Supply will not necessarily increase in response to demand pressures. The scarcity of stock recommends that corporations undertake debt-funded expansion; further, high and rising prices stimulate demand for equity, in part due to the increased ability of current shareholders to leverage their holdings (Cooper, 2008). Evidence of share buy-backs growing in frequency and magnitude over expansionary economic periods, with equity markets rising strongly, support this position (Finfacts Team, 2006; Friedman, 1992). The role of increasing liquidity when coupled with reduced supply due to stock repurchases by companies, establishes sufficient conditions for asset market bubbles when operated on by the expanding availability of credit.

Some economists have produced elaborate ex post rationalisations to refute historical evidence of bubbles (Cooper, 2008; Rudenbusch, 2005; Santoni, 1987). 
Garber (2000) is amongst these, arguing that historical instances described as bubbles, including the seventeenth century tulip 'boom', were rationally founded on expected cash flows. Flood and Garber (1994) reject bubbling in the period of German hyperinflation. Garber (1994) interprets those asset market rises assigned the status of 'bubbles' as fundamentally justified, making the case for the prudentiality of market participants' actions. To the level Garber pushes his argument he tautologically and analytically precludes bubbles. Similarly, Pastor and Veronesi (2006) make the case that the rapid rise in the index of the National Association of Securities Dealers Automated Quotations (NASDAQ) through the latter half of the 1990s may have been justified on the basis that, under certain conditions, uncertainty may support price rises. The ex ante justification for this counterintuitive assertion appears to rely only on high levels of volatility (realized during the NASDAQ boom), consequent upon the greater dispersion of future expectations. Uncertainty is sufficient to explain volatility but it less clearly explains the positive bias of the realized market levels or their subsequent precipitous decline, whatever the dispersion of future values may have been. If the posited explanation is that market levels could settle at any point across the range of future value dispersion, then it seems to provide no more than a tautological rejection of bubbles on definitional grounds. Notably, (qualified) efficient market proponent Malkiel (2003a) identifies the NASDAQ of the late 1990s as a bubble. He takes a different approach, holding that market efficiency does not require that the market is systematically correct at all times. This is an implicit argument for the relative pricing efficiency of markets.

There is a general acceptance that bubbles can and do occur, but that their occurrence is difficult to determine ex ante (Bernanke and Gertler, and Gilchrist, 1999; Cotis and Coppell, 2005; Detkin and Smets, 2004; Fuhrer and Schuh, 2008; Trichet, 2005). The types of arguments employed in support of the 'no bubble' proposition indicate a tautological defence of market efficiency. It is at least plausible that we can describe a possible world in which any market's price-implicit forecast of the future was justified. Kindleberger's (2000) description of rapid market price rises preceding a crash is the phenomenon described here. By identifying general conditions leading and coincident with bubbles (Mitchell, 1938), the identification of those bubbles seems more productive than their ex post denial. 
The research of Smith, Suchanek, and Williams (1988) develops a case for speculative bubbles as a result of a series of experiments they conducted. Gaginalp, Porter and Smith (2000) develop their earlier experiments in asset price bubbles, allowing that fundamentals play a role in determining asset prices, but also that momentum trading is a factor. In each experimental design fundamentals are welldefined and known to the subjects (with some outcome volatility introduced to mimic more realistic scenarios). As in the later research of Porter and Smith (2003), experience (subjects repeating the experiment) reduces bubbles. This conclusion, that investor behaviour approaches that anticipated by rational expectations models, is supported by temporal distance between actual market bubbles and crashes (Porter and Smith, 2003). In simple terms, it seems to provide the mechanism for Galbraith's (1989) observation that each generation (approximately every twenty years) repeats the mistakes of the past (paraphrased). Under these experiments bubbles arise due to uncertainty about the behaviour of others and are not due to uncertainty about (known) fundamentals.

Successive experimental research in this vein has controlled for a variety of complicating (real world) factors. Transaction costs have been added, inexperienced traders have been augmented with experiments including more experienced traders, short selling has been introduced, and capital gains taxes applied. Consistent findings are that subject inexperience increases trade volumes and bubble magnitudes. The trading of more sophisticated investors closely follows fundamentals, with limited 'scalping' that, in effect, exploits small deviations from fundamentals (Smith, et al, 1988). The general conclusion of this line of experimental research is that bubbles are a function of divergent agents' expectations (Porter, and Smith, 2003).

The evidence from investor behaviour experiments gives rise to the potential for speculative bubbles to occur. Inexperience in terms of the actual market is not the inexperience of investors new to investing, although such investors typically do participate in markets in greater numbers in the late stages of expansions (Galbraith, 1990). The 'newness' of market participants is more general in the sense of their distance from, and inexperience of, previous market cycles (Galbraith, 1989). Simply, given enough distance from a market slump, investors become progressively accustomed to markets rising and largely discount substantial reversals (disaster myopia). Perhaps more pointedly, investors discount the possibility of other investors 
including the prospect of market reversal in their valuations of equities (Shiller, 2003). This behavioural element is necessary for the emergence of a speculative bubble, but not sufficient. It is through financial channels, the creation of credit, and the demand pressure that this creates on equity prices that result in the bubble. This financial channel is intensified by corporate profitability in late-stage expansions along with low dividend payouts (in the modern era) and reduced new investment opportunities. These factors aggregate in increased corporate demand for their own equity, further adding to an equity price 'spiral'.

The position adopted here is not to unequivocally reject market efficiency but to establish the boundaries to that efficiency. This is because there is no compelling reason to abandon a basic underpinning of market efficiency; that economic agents are utility-maximising, and rational. In a sense the central thesis of this paper isolates an anomaly, that is, bubbles in market (price) levels fuelled by sentiment as a supplement to incomplete information and financing flows. The equal likelihood of over or underperformance of individual stocks explicit in market efficiency extends to market levels, consistent with positive and negative bubbles, precisely because ex ante knowledge of the duration and magnitude of bubbles is not possible (Allen, 2005; Allen and Gale, 2000; 2006; Bernanke and Gertler, 2000; Fuhrer and Schuh, 2008; Kent and D'Arcy, 2001; Lansing, 2007). Against the view that bubbles are hard to identify Cecchetti (2003) argues that it is no more difficult to locate asset price imbalances than it is to estimate potential GDP, a common tool of monetary policy central to the determination of the output gap. This assertion by Cecchetti is not equivalent to identifying the predictability of bubbles in terms of magnitude and duration but merely their existence. Notwithstanding the difficulty in identifying bubbles their existence supports the view that related data have not been fully recognised by markets and that, therefore, cannot be said to form part of the investor information set. In a link to the preceding discussion, information must not only be known to the market, its relevance must also be recognised.

The most logical way that a bubble can be identified is by the process of it bursting. If markets never crashed it would be difficult to make the case for bubbles. A number of substantial market crashes have been identified as important challenges to market efficiency. The two most prominent of these are the 1929 crash, the so-called 
Babson Break, preceding the Great Depression of the 1930s, and the 1987 stock market crash. ${ }^{9}$ The system-wide gravitation towards fragility provides a separate challenge to market efficiency in terms of how a rational financial institutional structure could have behaved in such a way. They, and in particular the $1987 \mathrm{crash}$, have resulted in some of the more tenacious and questionable defences of market efficiency.

An extensive body of economic literature identifies the difficulty of isolating bubbles (Bernanke, 2002; Bernanke and Gertler, 2000; Greenspan, 2002; Mishkin, 2007; Trichet, 2005). In part, this is because bubbles operate endogenously with booms, being fuelled by fundamentals but interacting with these fundamentals to create the bubble that leads to a widening gap between fundamentals and asset prices (Becker, 2007). When this complex interrelationship is complemented by the temporal constraints on rational calculus and its prioritization of more certain, temporally proximate data, the market is not clearly in a rational bubble but the rationality of discounting indeterminate variables (Keynes, 1936). From this position, the model may be improved, not by challenging investor rationality, but by increasing the determinacy or specification and suite of the factors informing the investor's value calculus. The results of this process may then be employed in companies' stock repurchase decision models.

Different agents experience variable exposure rigidities. For example, financial institutions and fund managers, and companies operating in competitive markets, have the choice of following market trends, seeking marginal business, or compromising their competitive position by withdrawing from the market. By withdrawing from the market, an individual financial institution accepts greater than market average variation in potential outcomes. For this reason the rational financial institution can continue to write business at any level of underlying market risk. If we add to this consideration the fixed costs of providing banking infrastructure then the leverage from increased activity levels further supports this proposition. Finally, financial institutions have to consider risks to their existing debt assets that have endogenous determination with their failure to extend their financing operations as well as moral hazard considerations.

\footnotetext{
${ }^{9}$ Importantly, although the 2008 sub-prime crisis and ensuing global financial crisis and recession were a substantial (series of) events, they are distinct from the events identified above because there was a readily identifiable source of adverse news in the deterioration of home loan performance.
} 
Allowing that a positive shock, such as new technology, will lead to a temporally specific disruption to the assumption of zero economic profit in competitive markets, such abnormal returns will progressively revert to zero as the market adapts to the shock (Solow, 1970). It is in the period of supernormal profits and, most significantly, in the timing of future cash flows that elevated asset prices are justified. The problem inherent in this scenario is that investors will typically extrapolate from the higher certainty of 'near' cash flows, attracting lower discount factors and justifying some premium for implied (possibly putative) fundamental reasons (Shiller, 2005). Likewise, in depressed economic times we would expect the discount factor to be greater, and from a lower set of base assumptions (proxied by prevailing prices). Kent and D'Arcy (2001) draw this inference from the realization of risk, rather than the actual level of risk, as an important determinant of bank and investor behaviour, leading to pro-cyclical excesses of optimism and pessimism. These considerations will be exacerbated by the financial accelerator which is inherently pro-cyclical in its influence on asset prices (Boyer, 2007).

\subsubsection{Precipitous market collapses as a key threat to EMH}

The Great Depression has been viewed as a fundamental challenge to the neoclassical economic assumptions of a Walrasian equilibrium-finding system in which markets inexorably move towards clearance through the price mechanism. Lucas (1980) described the Great Depression as a phenomenon that was not amenable to equilibrium analysis. More recently Real Business Cycle theory (RBC) has sought to rehabilitate neo-classicism in relation to the Great Depression, offering explanations for its severity and longevity (DeVroey and Pensieroso, 2005; Pensieroso, 2005). RBC incorporates an amalgam of the operation of (typically technology-based) external shocks as an impulse, and inept government responses or actions as the propagation mechanism (Kydland and Prescott, 1991). Further, an important element of RBC theory is that there is a trade off between economic growth and volatility. Altman (1992) has demonstrated that there is no significant relationship between these two factors. Methodologically it has generated a range of particularist, closed-economy models as 'sufficient' proxies for an increasingly autarkical depression-era 1930s. Pensieroso (2005) and Temin (2008) express scepticism about the robustness of this explanation. Independent of their methodological concerns, it is unclear that the causal flow was 
from the autarky (protectionism) of the 1930s and the widespread economic malaise of that period. RBC reduces an analysis of the Great Depression to closed-economy models and, thus discounts the more plausible of causal relations to advance tractability with real-world complexity assumed away.

Lucas (1980) argues that the Great Depression, often seen as an event elongated and intensified entirely by inept government intervention, and as an inappropriate response to an exogenous shock, cannot be explained this way. RBC interprets business cycles as efficient responses to changing factorial productivity induced by a series of exogenous shocks. Such economic disruptions are aggravated into extended periods of recession or depression by government intervention only. Notably, this interpretation discounts the frequency and severity of business cycles in the latter half of the 1880s and early 1900s, which pre-dates large government interventions in the economy or the existence of a central bank.

The case that market levels can be systematically incorrect is supported most vividly by precipitous market collapses (Cajueiro and Tabak, 2006; Pratten, 1993; Shiller, 2005). The US stock market crashed on October 1987, falling 508 points or 22.6\% (Malkiel, 2003; Miller, 1990; Shiller, 2005). Shiller (2005) surveyed media for potentially relevant news preceding the collapse, finding little to explain such a drop. Mitchell and Netter (1989) note that proposed anti-takeover legislation of October 13th caused a market decline of $10 \%$ on the $16^{\text {th }}$ of October but provide no account for the greater decline on the $19^{\text {th }}$ of October. Similarly, new, favourable information cannot explain the 83\% US market rise between July and August of 1932 (Shiller, 2005). For this reason, deduction supports the inference that the market in toto is incapable of distinguishing a reliable referent for its true, fundamental equilibrium level.

The basic premise of market efficiency is that informed markets move rapidly to reflect investor expectations of future cash flows. On this view the market is continuously updating to reflect all new information, impounding that information into market prices as a reflection of fundamental value. Yet the 1987 stock market crash is seen as a significant threat to the view that markets accurately reflect all new information instantaneously, as that information becomes available. The standard argument from market efficiency is that small variations in the discount rate used (or 
measure of risk), or in companies' expected future cash flows, may have a large impact on share prices. This appears to be the means by which efficient markets' proponents address the absence of any significant new (and adverse) information preceding a market crash. However, it does raise doubts about the view that markets accurately reflect fundamental value if that value is highly sensitive to even minor changes in fundamentals. Equally, such a large apparent shift in fundamentals (as was implicitly the case in October of 1987 on a 'change in fundamentals' view) should have clear indications of what that deterioration in fundamentals was. Markets arrive at efficient prices, if at all, by the aggregate weight of market participants' expectations of future cash flows. It is inconceivable that this could be correct without a general awareness of the deteriorating fundamental/s in question.

Roll (1988) contends that while there is no statistically significant evidence supporting the role of institutional features in the cause of the 1987 stock market crash there is evidence of a high international correlation between market movements at this time. This he interprets as evidence of markets' response to an (unidentified) shift in global expectations of global industrial activity. His evidence for this was that there was no sustained recovery of global equity markets in the four months following the October market crashes. Roll (1988) argues that, had the stock market crash been due to the (often claimed) bursting of a speculative bubble, then the overreaction in the bubble's bursting would have seen a strong and near-immediate recovery. However, many major markets, including the US, did rebound strongly shortly thereafter, through 1988. Equally, global economic growth did not collapse (as would be implied by the 1987 stock market crash if it was a reaction to a fundamental cause) in 1988 or 1989. It was only towards the end of 1989 and into the early 1990s that economies moved into a brief (two quarter) and shallow recession. So, in contrast to an efficient markets' view, the crash implies markets mispriced the future cash flow generating capacity of stocks as it was not followed by a sustained deterioration in fundamentals.

The key issue this discussion raises is that the case for a speculative bubble, although unproved, is no less plausible than conventional explanations of the crash. Proponents of the 'fundamentals' view', that either risks or returns' assessments adjusted with large valuation implications, have dominated academic analysis of the event (see, for example: Fama and French, 1987a; 1988b; French, 1988; Miller 1988; 
Roll, 1988). In contrast, theories of the crash starting from the position that the market was overvalued have been less prevalent in the academic literature with Shiller (1987; 1989) as an important contributor to the alternative hypothesis. Given the plausibility of the position that markets may be systematically mis-priced at any point, and the paucity of identifiable news of adverse fundamental developments immediately preceding the 1987 stock market crash (Shiller, 1987; 1989) there is reason to further explore this interpretation of the events with a view to generalising (or assessing its generalisability) to market breakdowns simpliciter. This argument forms part of the basis for the approach pursued in this thesis.

Miller (1990) and Santoni (1987) argue that, although there was no bad news commensurate with the magnitude of the 1987 stock market collapse, anticipated cash flows are important and valuation models are highly sensitive to small changes in growth rates. This response is strained. The implication that markets could revise their valuation-model estimates so precipitously, absent new information, is implausible. It is hard to understand how this can support a view of valuation models that are other than too speculative and tentative to form a reasonable, rational basis for valuation. Miller (1990) argues that the cumulative weight of negative news, including the progressive rise in long term bond interest rates over several months preceding the crash, proposed anti-merger legislation, and the Secretary of Treasury's threat to force dollar deflation, caused the 1987 crash. Again, this is strained as the efficient market presumption must be that the market would adjust as the information entered the market. Further, it does not account for similarly precipitous declines in overseas markets, less directly impacted by the suite of adverse developments. The issue that arises here lies in the recurrence of speculative bubbles as distinct from fundamental drivers of prices.

Galbraith (1990) further argues that if the threat of US dollar devaluation, in particular against the German mark, had been the substantive cause of the 1987 stock market crash, then the crash would be more plausibly placed in 1985 when the Plaza Accord provided reason for financial markets to test the ability of the US to achieve a gradual devaluation of the US dollar. Similarly, Galbraith observes that, where growing US fiscal deficits have been ascribed causation; these had been persistent and growing over the six years preceding the crash. The suggestion that the market collectively 
arrived at a realization that such deficits entailed negative consequences in October 1987 does more to undermine market efficiency, than to validate it because they did not incrementally reflect the deficit trend in market prices as this information became available but, instead, precipitously and belatedly impounded it into those prices.

The argument that a suite of factors aggregated to cause the 1987 stock market crash must state that the identified suite of causes of the crash, or at least similar factors, occurred contemporaneously across international markets. The only alternative is that the US market crash was the cause of other markets to crash. It seems odd to suggest that the flow-on effect of a US stock market crash could be the catalyst for other overseas markets to instantaneously re-rate companies' expected future cash flows or risks to these. This is even less convincing given a number of the identified 'causes' of the crash are US-specific and many overseas markets fell by as much as or more than the US market. It is even less convincing when one key factor identified as having caused the US stock market crash in 1987, the threat of the devaluation of the US dollar, might reasonably be expected to have had an inverse effect on overseas markets compared to its effect on US markets. The movements of overseas markets immediately following the US stock market crash provides a significant challenge to prominent explanations of the US collapse.

Precipitous market falls in the absence of identifiable new and adverse information appear to contradict stocks being priced on the basis of fundamentals. For this reason the view that market values are fundamental values is rejected. This is not changed by the view that small movements in long term forecasts, discounted back to today, tell us why relatively minor new information may have unexpectedly large impacts on the market (such as the 1987 crash). The method itself implies a precision in its assumptions. The question here is not even one of what better approach we may take. Simply, there is nothing reliable about such valuations. If all of the assumptions employed are sufficiently accurate and discounted cash flow valuations are respected by the market, then there is little more to be done. The market price is the fundamental price. However, if we can anticipate risks of an event such as a market crash before it happens, this suggests inter alia that we can increase the information set upon which future cash flows are forecast. 
Without preferring either pre- or post-crash values as representative of fundamental value, and allowing that neither may reflect true value, the movement between two levels implies the difficulty for the market in determining absolute market values (Shiller, 2005). This problem arises due to a complex set of variables determining inter alia the risk-free rate, risk premia attached to various assets and asset classes, inflation expectations, and expected returns from assets (Gruen, 2005; Keynes, 1936; Minsky, 1986). The array of influences on risk-free rates further frustrates valuation objectivity as it influences the rates at which future cash flows are discounted. Such rates can be heavily influenced by short term factors and, so, cannot be a sound basis to discount cash flows beyond the very short term. This gives rise to the indeterminacy of the risk-free rate as an independent source of threat to market pricing as a reflection of fundamental value. If risk-free proxies are determined by policy considerations that are separate from risk than they form a dubious basis for calculating total risk.

\subsubsection{The indeterminacy of risk-free rates of return and declining risk premia}

The Great Moderation (GM) has tended to undermine the value of the Federal Funds Rate (FFR) as a risk-free reference. 'Hair trigger' use of adjustments to the rate by the Federal Reserve Board in response to perceived threats of inflation or deflation (unemployment, output declines) has left a rate that is too volatile to serve any measurement objective (Brousseau and Detkin, 2001; Detkin and Smets, 2004; Friedman, 1999; Muusa, 2003; Spencer and Huston, 2006). From February 1995 to February 1996 the Federal Reserve Board increased the FFR from 3\% to 6\%, without any evidence of building inflation pressures (Spencer and Huston, 2006). This, in turn, has supported the credibility of the Federal Reserve as it was seen to take robust action in response to even the risk of future inflationary pressures. This, in turn supported a persistent trend in overinvestment across investment categories but notably in housing stock in the period immediately prior to the sub-prime crisis as it provided an assurance about the Federal Reserve Board's commitment to low inflation and, therefore, low interest rates. For this reason the use of the FFR as a risk-free rate is questionable and, from this, risk premia cannot be reliably determined. Evidence of a general contraction in risk spreads is reflected in emerging market bond spread contraction relative to US Treasuries. From 2002 to 2004 the spread fell from 900 basis points to 300 (or 3\%) 
(Goldstein, 2005). To this we may add that long term interest rates in the US have become less responsive to the FFR due to the 'safe haven' effect (Wray and Tymoigne, 2008). That is, recent experiences (the 1997 Asian crisis and 1998 Russian bond crisis) have taught international (Asian) investors that the US is a safe haven, thus large international capital flows have been directed towards the US, essentially primarily as a currency hedge (Perelstein, 2009). On this basis, the GM appears more clearly as a cyclical 'smoothing' based on progressively expanded debt. The central question about this consists in whether such a development is sustainable.

Standard proxies for riskless investment are in one sense a measure and in another, a policy tool. There is no objectivity to the measure unless its instrumentality is adjusted for. This is in evidence in 2002-2004, when the FFR in the US was reduced to $1 \%$ in an environment where inflation was in excess of $3 \%$ (Schwartz, 2008). Such a negative real risk-free rate, apart from being oxymoronic, cannot realistically serve as a base value referent. Jensen and Johnson (1993) observe uniform responses in equities' pricing to discount rate changes, independent of the motivation behind those changes. Market inferences to trend indications from observed monetary authority interest rate changes further increase stock price responses (Jensen and Johnson, 1993). This suggests that more than just a suspect risk-free base, risk premia are also positive correlates of discount rate changes. If such a base informs the calculus from which risk premia (spreads) are calculated for risky assets, inference supports the absolute mispricing of risk assets in general. Thus, without a reliable risk-free rate, riskadjustment lacks a reliable starting point.

In terms of the GM, a period of abnormally low inflation and output volatility since the early 1980s, risk premia contracted (Bean, 2003; ECB 2004; Sardoni and Wray, 2005). This phenomenon was evident with the progressive contraction of risk spreads up to 2007 (Wray, 2008). Minskian analysis of business cycles predicts such developments. Central Bank credibility in controlling inflation was influential in this risk spread contraction (Sardoni and Wray, 2005). The progressive decline in risk spreads further stimulated the assumption of risk, where profits accrued to those who borrowed to fund business or housing consumption. This phenomenon is described and explained in greater detail in the examination of Minsky's instability hypothesis (in chapter three). In an environment in which the risk-free rate is ill-defined and in which 
risk premia are volatile, the movement of markets from fundamental value is a predictable outcome. Minsky argues that such movements are the default state of markets. Using Minsky's FIH as a basis this thesis advances the case that market-wide departures from fundamental value are identifiable. These deviations from fundamental value should be made available as part of the information set for market participants to operate on.

The overall level of interest rates is determined separate from an estimate of risk in the economy. Moreover, realised risk has a strong impact on interest rates whereas potential risk is substantially under-priced (Borio, 2003). The combination of interest rate proxies for default-riskless investment and expansion-era contractions in creditor pricing of idiosyncratic risk undermine markets' ability to identify fundamental value. These factors form independent inputs into stock market prices because these prices are influenced by interest rates as substitutes for equity investment. These considerations are compounded contemporaneously by declining borrower margins (reflected in rising asset prices).

\subsection{Summary}

The purpose of this discussion was to advance the case that markets are not reliably efficient. Successive research findings support the view that: a) there is a certain necessary level of market inefficiency to achieve general efficiency (Grossman and Stiglitz, 1980), and, b) markets may deviate from true equilibrium values, without disrupting the assumption of their broad relative pricing efficiency (Malkiel, 2003b; Summers, 1986). Allowing a narrower view of market efficiency than many of its proponents defend, relies on the identification of recurring macro-financial variables (or alternative unrecognised signals) able to improve the ability to forecast future market levels. A key element of the case for rejecting broad market efficiency is the occurrence of precipitous market level changes in the absence of market efficiencyrequired new information. In this sense this thesis identifies a hitherto unrecognised anomaly; the market's inability to draw future price movement inferences from movements in macro-financial variables.

The conclusion of this chapter, that market efficiency overstates the perfection of markets, provides the foundation for the introduction of Keynesian/Minskian 
analysis in chapter three as a theoretical basis for this thesis. This chapter discounted the non-sequitur of inference from micro-economic rationality to rational macroeconomic outcomes. An entailment of this approach is that asset markets are not able to reliably reflect fundamental value and may be moved into bubble states, propelled by future uncertainty and credit transmission mechanisms. These themes are explored in the following chapter through an outline of Keynes' contribution to economic theory and specific developments and extensions of this provided by self-described financial Keynesian, Hyman Minsky.

Establishing limits to market efficiency forms the foundation from which to examine recent history in terms of Minsky's FIH. Recent trend extrapolation approximates Minsky's (1986) view that past debt contract completion building expectations of future debt contract completion and leads to a contraction in lender and borrower margins. These developments are central to Minsky's view that stability creates instability. Such extrapolation is further reinforced by the feedback loop of equity repurchases over periods of rising markets. Such feedback loops provide an independent source of demand for equities, further supporting subsequent share price rises. That these developments are unsustainable over an infinite time horizon is supported by periodic market crashes and periods of consolidation. Further evidence that the identified developments constitute bubbles was identified in graph 2.1 in which corporate debt and equity flows reverse sharply during market falls and in the period of market consolidation at levels substantially below pre-crash levels. It is reasonable to infer that markets became overvalued in the pre-crash, expansive period and that balance sheet consolidation as described by Minsky is required with the issuance of new equity and the decline in corporate debt financing. Where preceding market runups are large and the previously described underlying corporate financing flows are large, observation supports the view that market external financing flows will also be large. 


\section{Chapter three: Theory: the inherent instability of capitalism and the implications of that instability for business and market cycles.}

\subsection{Introduction}

The preceding chapter identified certain limits to market efficiency theory, describing the persistence of economic and market cycles and identifying this as evidence of stock markets' tendency to instability. The argument was made in chapter two that the recurrence of cycles is evidence that markets persist in an endemic tendency to mis-price assets. These mis-pricings reflect, at different points in each cycle, an excess of optimism or pessimism, as well as associated ease of or constraint of credit availability. In particular, precipitous and large asset market declines in the absence of significant adverse news are difficult to explain in terms of an efficient market assumption that asset markets are valued on the basis of the discounted value of future cash flows. As a de minimus there is a need to infer a collapse in sentiment coupled with herding that treats declining market prices as an independent input into future price declines (Keynesian 'animal spirits'). These propositions require an alternative explanation that is able to account for deviations in market values from fundamental values. These issues are addressed in this chapter from a Keynesian perspective. This chapter outlines elements of Keynes' (1936) theory of the role of investment in the failure of market-based economies to settle at stable full employment equilibrium under conditions of uncertainty. Investment therefore determines business cycles in market-based economies. These insights of Keynes are further refined by use of Minsky's (1986) Financial Instability Hypothesis (FIH) which identifies the effect of credit on investment. The Keynes-Minsky theoretical base is developed exploring the FIH to identify such economies' financial structures and institutions as the transmission mechanisms and key sources of financial instability. The identified theoretical foundations are then adapted and further augmented by short term technical indicators.

This thesis synthesises economic theories identifying the natural or default state of capitalism as one that moves through equilibrium only in the course of successive imbalances which reverse preceding disequilibria (see Fisher, 1933). This view 
identifies business cycle recurrence without an assumption of cycle predictability but allowing that there are sufficient regularities from which to identify periods of elevated risk of cycle phase change (Mullineux, 1990). Such a position is contrary to the "new classical consensus' (Leijonhufvud, 2009; Shaw, 1988). By hypothesis, extended periods of economic boom, followed by busts, do not readily lend themselves to a view of markets efficiently allocating resources on the basis of rational expectations of future returns, (or) based on full information (Kregel, 2009; Leijonhufvud, 2009; Minsky, 1986; Morgan, 2009; 1992; Sylla, 1991). Inefficient allocation in the context of the chapter two argument that markets are efficient in relative pricing refers to a general mal-investment (over- or under-investment) driven by credit supply. If markets can be said to achieve equilibrium at all, the conception must be of the very long-run in which excesses inevitably reverse, meeting terminal limits and countervailing excesses. This thesis employs these insights to extend our understanding of market movements and influences on corporate financing decisions.

This chapter establishes the general condition of market-based economies' instability as a foundation for extracting the implications of this for corporate financing structures. The essential market characteristic of endogenous instability, principally through instability in investment's contribution to aggregate demand, underlies the essential relationship of the business cycle to market economies. This relationship, in turn, results in market cycles. Minsky (1986) emphasises the role of financing structures in cycles. These are proxied in this thesis through corporate finance flows and the case made that these flows are influenced (and influence) these cycles. These features connect the general features of market-based economies identified by Keynes (1936) from economic cycles, to market cycles, to corporate financing flows and preferences.

Frequently, exogenous shocks have been the preferred explanation of economic instability (Morgan, 2009; Wade, 2009). Dominant trends in contemporary economic literature are towards an increased emphasis on aggregate supply, a renewed assumption of markets clearing through the price mechanism, and the use of rational expectations as a substitute for perfect foresight. This clustering of assumptions appears to be motivated by its mathematical tractability rather than by its descriptive accuracy (Zarnowitz, 1992). Some part of the popularity of this approach is an aversion to revolutionalizing the microeconomic foundations of macroeconomic theory; that 
economies comprise utility-maximizing agents. However, the abandonment of macroeconomic equilibrium assumptions does not entail a necessary rejection of investor (agent) rationality but it does imply that individual investor rationality does not create stable equilibria in market-based economies (Minsky, 1992). We can still have individual utility-maximizing economic agents without extending this microfoundation to an implication of macroeconomic stability. This thesis rejects (singular, necessary) exogenous business cycle causation. Instead a hybrid of traditional (endogenous) business cycles based on overinvestment and the accelerator/multiplier models of more recent theories in economics is hypothesized implying the priority of financing in the economic instability described by Minsky (1986), Zarnowitz (1992), and the impact of sentiment on financing (Akerlof and Shiller, 2008).

The theoretical predicates underpinning this thesis draw on a long tradition, not universally acknowledged by successive theorists in the 'chain'. Broadly, the lineage includes: Veblen (1904), Fisher (1933), Mitchell and Burns (1938), Schumpeter (1939; 1954), Keynes (1936), Kalecki (1968), and Minsky (1986) (Dimand, 2004). This list of theoretical antecedents (or contemporaries) to Minsky may be extended to include Wicksell, Bagehot, and Kindleberger (Formaini, 2004; Prychitko, 2009). The intention in this chapter is not to create a 'grab bag' of eclectic parts but to briefly identify the apparent heredity of Minsky's FIH; the position that capitalism's inherent instability is due to its financing structures. Although Minsky clearly identified himself as a Keynesian, and he was a student of Schumpeter, he did not explicitly acknowledge the influence of certain other theoretical strains that appear to inform his FIH, including Veblen and Bagehot (Dimand, 2004).

The discussion in this chapter centres on Keynes and Minsky, adapting a broadly Keynesian framework to the latter theorist's developments of ideas in, or consistent with Keynesianism. Beyond exogenous shocks, this position argues 'errors' in regulation cause market dysfunctions, often with perverse implications, to qualify markets' 'invisible hand' operation, with more limited qualifications by clear-cut market dysfunctions (Dillard, 1988). Notably, errors are biased through different phases of the business cycle implying a level of determinism not emphasised in Minsky's (1986) FIH (Spencer and Huston, 2006). The basis for the choice of a Minskian theoretical scheme is that market breakdowns and business cycle recurrence are 
inexplicable, or merely implausibly explicable, unless the chosen theory centres on the inherent instability of capitalism (Dillard, 1988; Fender, 1981;Vicarelli, 1984).

Proceeding from a review of his Keynesian theoretical roots in this chapter, consideration is focused on Minsky. Where Keynes identified investment as a factor aggravating financial instability, Minsky charts the progressive financial fragility of microeconomic units through expansionary periods of the business cycle, in which financing structures play a central role. Minsky's focus is primarily on business financing. For the purposes of this discussion, with the recent role of US residential housing in financial instability in mind, Minsky's focus may be extended to all investments in the economy involving significant shares of debt, and which allow progressively more risky borrowing and investing.

Minsky does not explicitly identify the relationship between economic booms and income transfers from workers (wages) to capital (profits). However, (empirically) profits represent a growing percentage of national income during booms. The ability to subdue interest and wage imposts on profits sustains asset markets as future profit expectations are built on presumptions of sustaining or increasing the present efficiency of capital (Mott, 1988; Murphy and Welch, 1991). This more complete view of the causes and effects of business cycles reinforce the endogeneity of instability to capitalism. This conclusion is, although plausible or empirically identifiable, of secondary importance to this thesis. As per Minsky (1986), it is possible and productive to focus on the more proximate relationships rather than a fuller set. Minsky's FIH is applied here more particularly to broad market valuations.

The implications of Minsky's (1986) FIH are adapted from a description of business cycle evolution to provide a focus on short term (quarterly) market movements. Part of this process involves the incorporation of independent variables in market prediction models consistent with Minsky's FIH but that are more explicitly associated with prevailing technical analysis. These include trade volume and market price histories. 


\subsection{Keynes}

Keynes expounded a key concept underpinning the theoretical approach adopted in this thesis in his inversion of Say's Law (Keynes, 1936; Shaw, 1988). Where Say's Law defined earlier economic orthodoxy in stating that supply created its own demand, Keynes argued that demand preceded supply, that is, that demand was the only essentially autonomous macroeconomic variable (Keynes, 1936). On the classical view, the aggregate demand price of output would always equal the aggregate supply price for all volumes of output, thus presenting no obstacle to full employment (Fender, 1981). This general condition was granted by Keynes of poor communities where output equalled consumption (i.e. that there was no savings).

In wealthier communities, Keynes (1936) argued that supply could not rely exclusively on consumption demand. Such societies require a level of investment equalling the excess of the supply price of total output from full employment over consumption at the same point to maintain full employment equilibrium (Robinson, 1938). From this, Keynes argued that only one level of employment was consistent with the equilibrium of supply and demand and that this could not be greater than full employment. This entails that, contra-Say, full employment is just a special case and not a point that market-based economies inexorably move towards (Keynes, 1936).

Keynes' theory states that beyond subsistence economies effective demand is determined the marginal nature of investment and that uncertainty makes stable full employment equilibrium impossible Keynes isolates the central role of investment in determining aggregate demand. Interest rates combined with uncertainty determine investment. The key determinants of investment are the marginal efficiency of capital and expectations of such efficiency (Karose, 2004; Sardoni, 1992). This investment function is influenced by 'animal spirits' or the will to act under conditions of uncertainty. Consistent with Sawyer's (1989) interpretation of Keynes, the understanding applied here is that the key distinctive feature of Keynes' theory is uncertainty concerning the future. On this basis earnings' expectation validation or disappointment may be expected to heighten the volatility of investment, relative to aggregate demand in toto. This function of investment is of central importance with the growing wealth of societies, thus it is importantly linked to the secular accumulation function of capitalist economies. Further, aggregate consumption propensity changes 
(counter-cyclically) at different levels of employment, increasing the significance of investment sufficiency to total effective demand over booms (Brown, 2004; Larsen, 2002). This theme has been developed more recently by Akerlof and Shiller (2009).

Following from this, the central drivers of aggregate demand (and thus the business cycle) are those factors that stimulate investment (Kalecki, 1932a; 1968). Keynes argued that expectations of future profits, and the marginal efficiency of capital (MEC), although influenced by interest rates, were centrally determined by 'animal spirits'. These 'animal spirits' are the product of unpredictable waves of optimism and pessimism (Keynes, 1936). The interest rate itself is determined exogenously, with dependence on monetary factors, including liquidity preferences and supply (King, 1994). Thus, full employment levels of aggregate demand need not arise from investment under conditions of uncertainty. Thus demand for investment is determined by supply conditions in investment goods markets, ${ }^{10}$ future profit expectations, and interest rates (Sardoni, 1992). Significantly, profit is the most volatile element in aggregate income, supporting its nexus with investment volatility, as both are residual (Zarnowitz, 1999). Banks stretch and consolidate their balance sheets at different points in the business cycle. On this analysis an increase in aggregate demand would increase profit shares and, thereby, increase employment, reducing real wages. The central concern of Keynes was that the MEC is exogenously determined and, therefore, could not reliably support full employment equilibria as a natural state (Sardoni, 1992). Simply, the equality of savings and investment is, at best, a long-run equilibrium (Evans and Makepeace, 1979), and, potentially, this long-run is further extended beyond its closed economy modelling in an era of globalisation (Kaufman, 2009). That is, borrowing and lending between countries plays an important role in net debtor nations' ability to sustain aggregate demand for lengthy periods without any necessary equality nationally between savings and investment.

In précis, Keynes makes the case that the nature of money and liquidity demands allow the persistence of involuntary unemployment (Fender, 1981). In contrast to Walras's Law, there may be an excess of labour supply that is not offset by excess demand for labour elsewhere (Sargent, 1987). Keynes does not assume market

\footnotetext{
${ }^{10}$ Independent of price (interest rates), availability of finance is pro-cyclical.
} 
imperfections are prerequisite to the failure of the capitalist economic system to support full employment equilibrium (Davidson, 2002). The exogenous nature of expectations surrounding the MEC removes any necessary unitary relation between supply prices and demand levels, as forms the basis of Say's Law (Sardoni, 1992). On this view full employment equilibrium is a special case which is unstable (Keynes, 1936). The recurrence of the business cycle means that full employment is only one point on a spectrum and that the economy is typically not at full employment equilibrium. This feature compounds Keynes' fluctuations in investment as unemployment undermines the contribution of consumption to aggregate demand. Although appreciably more stable than investment, pressures on consumption and consumption growth may have a major impact due to its dominant role in aggregate demand, especially for developed countries (Hall, 1986).

In terms of this thesis and its implications for corporate valuation and financial reporting, changing income distribution influences conditions underlying aggregate demand resulting in financial fragility. Growth in income inequality implies a growing burden on investment to complete aggregate demand at levels that support economic expansion. The following discussion of the destabilization of aggregate consumption's contribution to aggregate demand extends Keynes and Minsky. Present economic developments indicate the need to include a role for domestic consumption in destabilising the economy as households are influenced by access to similar financing structures as those available to business (Akerlof, 2008; Acemoglu, 2009). Undoubtedly Keynes could not have conceived of the 'democratization' of debt, entailing the widespread access to loans that marks the current situation. Equally, such developments, although emerging in Minsky's time, had not then fully developed and were not, in any event, the focus of Minsky's concern. This section suggests that consumption stability was, beyond its essential nature, reinforced by historic institutional structures in the post-2000 period (Gerstad and Smith, 2009; Lavoie and Stockhammer, 2012). With change in those structures the bubbling of consumption is eminently possible, even if less so than investment. The inclusion of consumption completes the set of preconditions of economic fragility in recent history, manifesting eventually in recessions and market breakdowns Krugman, 2000; 2006). 
In earlier writings (The Economic Consequences of Peace), Keynes explicitly identified the inequality of income distribution as a significant cause of capitalist instability (Rousseas, 1992). In his General Theory (1936), Keynes stepped back from this, arguing that the requisite marginal efficiency of capital to ensure full employmentsustaining levels of investment necessitated income inequality. Although Keynes (1936: 372) [1973] describes the "arbitrary and inequitable distribution of wealth and incomes...[as one of two]...outstanding faults of [capitalism]", he seems to hold this position on purely ethical grounds. He does not appear to suggest implications for effective demand, isolating uncertainty around investment as the important proximate cause of economic and financial market volatility. The difficulty here is that the assumptions of Keynes give no specification to the 'appropriate' degree of income inequality necessary to incentivise investment as the issue was subsumed by the priority he afforded investment (in)sufficiency as the driver of business cycles. For Keynes (1936) investment in rich (non-subsistence) societies to complete aggregate demand at full employment requires an optimal level of inequality. Inequality beyond a certain (possibly indeterminate) level must, presumably, lead to decreases in the absolute level of current demand for consumption goods that have been supplied by prior increases in investment goods. This connects the MEC to the Marginal Propensity to Consume (MPC). ${ }^{11}$ Arguably Keynes's approach prioritizes the proximate cause of business cycles at the expense of a more comprehensive analysis of causal relations (Rousseas, 1992). However, this is not a disadvantage for this thesis which aims to extract signs or causes of future market values rather than to provide a comprehensive explanation of those movements.

Keynes may understate the risks to prevailing levels of aggregate demand posed by insufficient or unsustainable consumption (Brown, 2004; Lavoie, 2006; Maffeo, 2001). This possibility is plausible in terms of explaining recent events in which elevated household debt, to an important degree, sustained a consumption-led boom from 2003 (Leijonhufvud, 2009). Real wages do not reliably follow changes in the marginal productivity of labour as Keynes held (but later had doubts about) and subsequent empirical research challenges Keynes' position in this regard (see, for

\footnotetext{
${ }^{11}$ The MPC identifies the relationship between income levels and its influence on consumption and savings. Typically the lowest paid workers consume all of their income, with progressively increasing levels of saving (of income residual to current consumption) as income rises.
} 
example Acemoglu, (2001) and Arpaia and Pichelman, (2007) and Gottschalk and Smeeding (2000)). Nevertheless, this underlying assumption of market clearance at wage rates commensurate with labour's marginal productivity is an element of Keynes's assumption of markets finding equilibrium (Davidson, 2002).

For Keynes the variable consumption and savings propensities at different levels of employment and income seem to be determinants of (at least) the composition of aggregate demand. Keynes explicitly identifies consumption insufficiency as an influence on the stability of demand, stating that a low marginal propensity to consume at other than full employment levels holds back economic growth (Keynes, 1936). Keynes (1936, p. 373) goes further, stating that, "in existing conditions saving by institutions through sinking funds is more than adequate and that ...[income redistribution that increases the marginal propensity to consume] ....may [increase] the growth of capital." Despite this a widely held view of Keynes theory was that he was silent on consumption's contribution to aggregate demand (Hartwig, 2004). Keynes' theory of investment uncertainty provides a non-trivial business cycle catalyst but postulating preconditions heightening the importance of investment as a component of aggregate demand may be productive.. The investment volatility relativity to these variables is a matter of empirical fact (Allen and Gale, 2006; Backus and Kehoe, 1992; Basu and Taylor, 1999; Zarnowitz, 1992; 1999). The failure to investigate consumption dynamics directly appears to assume their (substantial) autonomy, relative to the business cycle. Keynes' (1936) paradox of thrift, by which savings increase beyond a certain point (determined by the level of investment), resulting in declining accumulation (profits), implies a central role in aggregate demand for income distribution. That is, greater proportions of profits and high wage incomes are saved relative to the savings of those with low incomes. For this reason the increase in profits as a percentage of total income that typically accompanies economic expansions progressively destabilises aggregate demand. This assertion requires only variable marginal propensities to consume over different income strata, and between capital income and wage income (Robinson, 1938). Logical coherence indicates Kalecki's (1933) income distribution priority should, at least, be included amongst the posited causes of capitalist instability. 
Granting that the MPC is greatest from workers' incomes, and unitary with income for the lowest paid workers (Kalecki, 1946; 1933), it is a logical extension to conclude that the wage share of income is an important determinant of the stability or sufficiency of consumption's contribution to aggregate demand (Robinson, 1938). We do not need the stylized fact of a unitary relationship between wage income and consumption to support this position, just the inverse consumption propensity as a relation to income levels. This is salient in the modern context where economic growth in many developed countries has been substantially composed of consumption in the context of an environment where wage shares have been contracting and real income distribution inequality has been growing (Lavoie and Stockhammer, 2012; Maffeo, 2001; Papadimitriou and Wray, 2001; Treeck and Sturm, 2012). The sustainability of consumption became doubtful in the US through the early 2000s with progressive increases in consumption-driven household debt (Greenspan and Kennedy, 2007).

Investment relies on profit and profit depends on current consumption. Where we can stipulate that a degree of income inequality may be necessary to motivate investment, in light of variable consumption propensities determined by income levels, there must be parameters beyond which wealth inequality motivates overinvestment and under consumption (Robinson, 1938). This implies that there are objective conditions that determine the bias of 'animal spirits' at any given point in the cycle which, thereby, determine expectations for the MEC. That consumption is observably stable relative other aggregates is no clear indication of its inert nature, as even a small movement in consumption may have a large impact on investment.

\subsection{Minsky and the FIH}

Minsky's (1986) FIH is combined here with Keynes' theory of the inherent instability of capitalism. Where Keynes established an investment theory of fluctuations in real demand, Minsky adds a financial theory of demand for real investment (Erturk, 2007). Minsky's hypothesis is clearly a development of Keynes' position (Wray and Tymoigne, 2008). The FIH is an elaboration and extension of the Keynesian priority of investment in terms of capitalist instability (Cassidy, 2008). Minsky's (1986) theory is a disequilibrium theory of business cycles, with strong endogenous elements (Zarnowitz, 1992). Keynes does not directly link uncertainty to consumption but, instead, argues that investment insufficiency, anchored in the 
uncertainty surrounding the marginal efficiency of capital (influenced by 'animal spirits'), may unseat an assumption of stable full employment equilibrium in capitalist economies (Keynes, 1936; Minsky, 1986). The case has been made that consumption insufficiency creates pressures on investment sufficiency, increasing the instability of aggregate demand (Hein and van Treeck, 2007; Rasmus, 2008). The link between demand insufficiency and Keynesian and post-Keynesian indications of financial instability arises in the evolving financing arrangements and institutions of capitalism. This introduces the Minskian FIH, connecting and inter-relating real and financial variables (Crotty, 1990).

The standard view is that business cycles are not inherent to capitalism but are imposed on an otherwise stable system by external shocks, including government intervention (Fuhrer and Schuh, 2008; Lydall, 1998; Temin, 2008). Without denying the potential for external shocks to impact economies this thesis follows a tradition established by Veblen (1904), Fisher (1933), Keynes (1936), and Minsky (1986), that business cycles are endogenous to capitalism. This view was clearly articulated by Minsky (1986, p. 172) when he stated that:

“...our economy is not unstable because it is shocked by oil, wars, or monetary surprises, but because of its nature”.

That is, within the conceptual scheme of capitalist economies operating without external shocks (or their possibility), economic and asset market cycles would still occur. Markets do not automatically clear and cyclical expansion and contraction of credit money is central to this failure of markets to clear (Minsky, 1986). This challenge to an endogenous steady state capitalist equilibrium questions the presupposition that credit is automatically balanced at optimum levels.

The central disagreement between the FIH and prevalent economic views arises in the endogenous nature of instability in market-based economies that forms an underlying assumption of Minsky's theory. Market efficiency allows space for market crashes provided that their cause is wholly a short term response to external shocks. Typically, where this position needs to accommodate longer term market dysfunction or where no obvious external shock is evident, failures of governments or central banks are the preferred explanation (Lydall, 1998). External shocks should not result in 
sustained disequilibria. Markets would, on this view, move relative to the shock to stabilise at a new equilibrium through flexible prices. Conversely, Keynes argues that markets do not naturally or necessarily clear (labour markets in particular) and that sustained periods of instability and elevated unemployment may occur. Given the history of financial crises preceding central banks' development, or arising independent of any necessary shock, and not clearly caused by government interference in markets, the role of government intervention is not compelling (Fuhrer and Schuh, 1998; Romer, 1993; Temin, 2008).

Extended periods of economic expansion give rise to the view that the business cycle is an historic artefact (Galbraith, 1990; Klein, 1976; Persons, 1930; Zarnowitz and Moore, 1986). As noted in section 2.3.4, Galbraith (1990: 89) suggests that generally no longer than every twenty years a new generation becomes impressed with its own "innovative genius", completing a cycle from "illusion to disillusion and back to illusion" (Galbraith, 1990:88). That is, each generation is fated to repeat the mistakes of the past and each experiences the hubris that is due to their inexperience of the previous cycle. In particular, explanations for the Great Moderation suggest progress made in addressing business cycles should render them obsolete (Borio, 2006; Cooper, 2008; Tvede, 1997; Zarnowitz, 1998). Notably, Persons (1930) details the central role of rising debt over the 1920s, leading to the Great Depression. He also observes the central tendency to gratulatory assertions that historic lessons have been learned during economic expansions fuelled by debt. The rise in debt during booms is central to Minsky's view of endogenous economic instability. The description supports flows of debt as indications of the movements towards fragility in an economy.

\subsubsection{The central role of finance in the FIH view of capitalism's instability}

Minsky elaborates and specifies the inherence of capitalism's progressive gravitation towards financial fragility over economic booms (Cassidy, 2008; Ferri and Minsky, 1991; Minsky, 1992; Wray, 2007b). He identifies an endogenous process of increasing risk due to the validation of previous expectations (Kregel, 2007). Research supporting this interpretation includes Borio and Crockett (2000), Gertler and Lown (2000); Gorton (1988), and Wood (1999). Signs of elevated risk-aversion arise in a contraction of lender margins comprising collateral requirements, debt maturity lengths, and interest rate spreads, and an expansion of borrower margins (reflected in 
rising asset prices). Credit spreads observe a strong negative correlation to the business cycle (Borio, et al, 2001). This is consistent with Keynesian theory, as it entails a fragility that supports the failure of investment to sustain a level of aggregate demand sufficient to stabilise the economy at full employment (Keynes, 1936). Minsky (1993), following Keynes, identifies the 'two price system' as central to capitalism's instability. These are prices for current consumption goods and distinct prices (current market) for investment goods. The value of investment goods is determined by current and expected prices for consumer goods, introducing volatility to investment (Minsky, 1993). Minsky holds that declining investment precedes declining profitability and that this is significantly influenced by interest rate rises. The FIH describes financing structures composed of hedge units, speculative units and Ponzi units (Kregel, 2007; Minsky, 1986).

The FIH identifies three broad types of debt finance. These are defined by the level of risk implicit in the business or project being financed. The hedge unit is the most stable of these three in that all cash flow demands under debt contracts are met by investment cash flows, including principal repayments (Ferri and Minsky, 1991). Such debt contracts only require the normal operation of factor markets and are not vulnerable to financial market dysfunctions (Pollin, 1997). Economies' financing arrangements are typically dominated by hedge units in the early stages of growth cycles as the precedent cash flow expectations and achievements are conservative (Mullineux, 1990; Rousseas, 1992).

Minsky (1992) identifies the role of increasing yet unrecognised risk in debt contracts during economic expansions. This fact is implicit in the generally accepted declining margin spreads over booms and relates to the risk inhering in the "existing liability structure" (Farazzi, 1992; Ferri and Minsky, 1991). Further, evidence provided by Borio and Zhu (2007) and Rajan (2005) supports Minsky's position indicating increased risk-taking during periods of low interest rates. In contrast to the continuous market clearance described by equilibrium models, the perfect arbitrage this assumes depends on perfect liquidity in credit markets. This is compromised by increasing gearing (Toporowski, 1999a). Restricted credit reduces cash flows, reducing borrowers' ability to service debt (Minsky, 1986). Prior to this stage banks must expand finance to maintain market share in their competitive environment (Wray, 2007b). This, 
coupled with the progressive validation of prior future cash flow forecasts, expands credit availability, extending debt-driven booms. This argument implies Keynes's and Minsky's position that stability is destabilising as it provides a progressively increasing empirical basis to justify greater exposure to risky investment due to the successful performance by debtors of past debt obligations (Demski and Pollin, 1992).

The FIH asserts that, under capitalism, the volatility of private investment is magnified by expansion-period leveraging and recession-period de-leveraging which creates an inherent economic instability. Minsky's position is that capitalist investment relies on expectations of future cash flows, discounted at nominal interest rates, thereby determining the profitability of investment, to establish future investment. Farazzi (1992) holds that this supports sufficient or stable growth levels of aggregate demand in Minskian terms. Minsky's (1986) identification of the essential stimulus of investment in the two-price system, in which the price of capital goods must be less than the value implied by their discounted cash flows, is critical to the stability of market-based economies. This is consistent with Tobin's (Q) conception, although Minsky adds the autonomous role of finance in investment fluctuations to Tobin's view that an excess of financial market value over the cost of capital goods will stimulate investment (Farazzi, 1992; Pollin, 1997), incremental to technology developments (Wray and Tymoigne, 2008).

Minskian analysis assumes an essentially demand-driven liquidity supply, discounting the view of banks' role in the passive intermediation between savers and borrowers, simply matching deposit supplies with demand for funds up to the limits of their reserve-based lending capacity. Evidence and a priori logic support banks' ability to innovate, reducing reserve requirements, to meet any profitable demand for funds (Choi, 2000; Minsky, 1986; Wray, 2007a). Further, the control sense of central bank money supply assumes central bank independence from pressures to maintain expanding liquidity. This pressure largely arises in the fait accompli that existing liquidity demands create for generally accommodative stances by central banks. In this sense central banks' tendency is to do no more than 'lean against bubbles', lest more aggressive action precipitates a financial crisis (Bernanke and Gertler, 2000). Notwithstanding these limits to central bank power the Federal Reserve Board has 
considerable influence over liquidity conditions through its control of short term interest rates and base money supply.

As the boom progresses, cash flow expectations are validated by the fulfilment of preceding expectations, supported by increasing aggregate demand and increasing profitability, concomitant with fuller capacity utilization, leveraged off the elimination of inefficiencies that build through booms (Borio and Lowe, 2002; Rousseas, 1992). These factors, in turn, contract lender margins. Similarly, borrower margins contract with higher prices paid for assets, also validated by the satisfaction of prior cash flow expectations (Minsky, 1986). These preconditions presage the growing reliance of microeconomic units on speculative finance (Mullineux, 1990; Minsky, 1986). Further borrowing is supported by rising collateral levels, establishing the impetus behind rising asset prices (Kiyotaki and Moore, 1997). The 'balance sheet' financial accelerator/multiplier effect is also identified by Schwartz (2002). The observation that booms interact with financial acceleration dates to at least Veblen (1904). However, the origins of this idea may be interpreted in Smith (1776) [1952]. Increasingly, over economic expansions, financing is composed of greater levels of speculative units, where interest costs are covered by investment cash flows but repayment of loan capital requires a roll-over of existing debt into new loans.

Subsequent to this stage is the progressive increase in Ponzi unit debt financing of microeconomic units (Minsky, 1986; Rousseas, 1992). These Ponzi financing arrangements are still more fragile than speculative units as debt contracts entail negative cash flows. These can be satisfied only by drawing new debt. These loans rely on the continuing rise in asset prices to repay initial and subsequent borrowing (Mullineux, 1986). At no point during the project life are cash flows sufficient to meet even the interest payments under such loans. Typically, when speculative and Ponzi units come to dominate the financing in an economy its fragility is such that the preconditions for elevated uncertainty and concomitant increases in lender margins arise. One important manifestation of this process is an increasing spread in maturities, between financing and investment horizons, principally through the reduction of loan duration (Zarnowitz, 1992). The manifestation of interest rate rises curtails investment, dislodging the key driver of future profits (Minsky, 1986). Evidence of this effect was 
forthcoming during the Great Depression when the yield gap between US Treasuries and Baa rated corporate bonds spread to $8 \%$ in 1932 (Bernanke, 1983).

\subsubsection{Extending Minsky's analysis of debt counter-party motivations}

Barnes $(2007 ; 2009)$ offers a critique of Minsky's FIH, identifying the role of information asymmetry between companies' managers and owners. Minsky is silent on this issue. Barnes proceeds to identify instances in which clear evidence of information asymmetry aggravated Minsky's 'euphoric' phase and, therefore, exacerbated the ensuing crisis. Barnes (2009) identifies the role of misleading accounting treatments in financial instability. It is not clear that Barnes' concern constitutes a substantial challenge but, more realistically, it may be held to isolate a subordinate factor in the anatomy of the business (and market) cycle. Minsky does not discount the role of information asymmetry; he simply denies such asymmetries are necessary preconditions for market instability. Euphoria would occur and crisis would follow in the absence of information asymmetries on Minsky's view.

Dickens (1999) offers a different criticism of Minsky's FIH, arguing that the build-up of debt in the US economy over the 1960s does not explain the occurrence of the 1966 financial crisis. Instead, Dickens contends that intra-class conflict between the New York banks' demands for interest rate increases (responding to high inflation) and the large regional banks, who sought to maintain interest rates at their then present level, was the source of the 1966 financial crisis. This issue has attracted a range of views (see: Dickens, 1999; Epstein, 1999; Wolfson, 1994; 1999; and Wray, 1999). At its core the debate has isolated the proximate cause of the crisis without necessarily eliminating underlying causes. The exception is Wray (1999), who argues in defence of Minsky that debt built up between 1961 and 1966 and that this expansionary extension of credit to corporations was a precursor and precondition of the crisis. That the crisis was precipitated by tension between banks, the actions of government, or the Federal Reserve, more describes the crisis than it does explain it. More importantly, Minsky's (1986) FIH does not presuppose the absence of an effect from partially or wholly exogenous shocks impacting the economy; Minsky simply questions their necessary role in capitalist economic cycles. 
Lavoie and Seccareccia (2001) observe that Minsky's formalisation of the evolution of the business cycle is based on micro-economic premises, including internal cash flows and leverage levels related to business cycle phase. Investment decisions are based on these two factors and, although not included in his formal articulation, Minsky identified a feedback role for macro-financial factors on corporate cash flows. Lavoie and Seccarrecia (2001) contend that Minsky neglected the effect that one firm's increased debt is another's income, leaving aggregate debt levels stable. They argue that this is a key weakness of Minsky's FIH. Against this criticism Caverzasi (2013) argues that this 'fallacy of composition' argument relies on a rarified set assumptions, including: that firms do not distribute profits or that households have no marginal propensity to save any part of distributed profits.

Farazzi (1992) holds that private investment, conditioned by financing structures, completes the level of aggregate demand in Minskian terms. Minsky (1992) identifies the role of increasing yet unrecognised risk in debt contracts over economic expansions which increases the fragility of aggregate demand. This relates to the risk inhering in the "existing liability structure" (Farazzi, 1992; Ferri and Minsky, 1991). That is, investment is able only to support full employment through progressive increases in risk and increased financial fragility over economic expansions In contrast to the continuous market clearance described by Walras the perfect arbitrage this assumes depends on perfect liquidity in credit markets. This is compromised by increasing gearing (Toporowski, 1999a). Restricted credit reduces cash flows, reducing borrowers' ability to service debt (Minsky, 1986). These factors, at different points in the cycle, create constraints and excess in the provision of credit to corporations.

Rasmus (2008) has suggested that Minsky (1986) does not explain the motivation behind the gravitation towards increasing financial fragility. While there is some truth to this claim, Minsky does explain banks' motivations. In contrast to prevailing views of bankers as passive intermediaries between borrowers and lenders, Minsky (1986; 1992) views them as more than aggregators of short term deposits, arbitraging differential temporal parameters, to supply long term loans. Banks occupy an active role of entrepreneurial capitalist in Minsky's hypothesis, actively searching for profit opportunities through progressive innovation (Minsky, 1992). This innovation is clearly in evidence in the securitization industry through which banks 
develop products to compete in deregulated financial markets with less-regulated intermediaries, generating fee income. Banks respond to money demand by economising on reserve requirements through devices such as sweeps. In Minskian terms banks are active in accommodating demand for money anywhere that such demand offers profits to the bank.

The less clearly expounded motivation is that of the borrower. Rasmus (2008) observes that Minsky has not explicitly identified the debtor's motivation for assuming Ponzi finance obligations. The underlying assumption of investors' desire for the maximisation of risk-adjusted returns still remains (Fazzari, 1999). The explanation is found in the elevated return on equity that may be obtained from greater leverage. Where minimal or no equity is demanded to fund investment and where the implications of default are contractually or functionally limited to rights over loan collateral (in which the borrower has no equity), risk transference to the bank (and savers) justifies the borrowers' ostensibly irrational choice. In essence, the potential for default limits the downside risk for the mortgagee (Allen and Gale, 2000; Jensen and Meckling, 1976; Stiglitz and Weiss, 1981). Equally, the central bank "credibility paradox" reinforces low inflation rates, supporting household expectations of long term interest rate affordability (Bean, 2003). Rasmus (2008) suggests that the return on equity is increased when companies are funded by, minimal equity, and that this satisfies investors' returns'-based priority. Regardless of the precise reasoning process that informs the individual assumption of Ponzi debt obligations, sufficient plausible grounds exist for this assumption of debt, suggesting inclusion of this issue is essentially about completing a conceptual set rather than an inherent deficiency in Minsky's analysis.

Identifying the borrower's motives does dictate the need to elaborate the dynamics behind a bank's incentive to provide progressively risky debt. The essence of this motivation lies in the Keynesian proposition that it is better to fail conventionally than to succeed unconventionally. The individual rational choice (or individual bank choice) is to maximise returns relative to any given level of risk. For the bank, a preexisting exposure to creditor risk exists in that their business involves lending to debtors. Where the market margins gravitate towards progressive increases in risk, market average returns support movement to the margins. The alternative is to stand 
aside from the market, rejecting elevated market-average risk over some theoretically more comfortable level of risk (Crotty, 2009). The problem of withdrawing from an increasingly risky loan market is that in pre-empting market breakdown the investor foregoes profits as long as the market holds up. Given the progressive mobility of capital in the era of globalization such a course dictates immaculate timing. This explains recent bank behaviour, making former Federal Reserve Chairman Greenspan's perplexity over banks' failure to limit risk inexplicable. He ascribes this to a fundamental failure of the market (Warner, 2008), yet Minsky might have argued that it was a predictable failure of rationality to deliver (typically) expected benefits of stability.

Bankers have a continuous exposure to banking business and constant fixed costs attached to this exposure. Along with investors' reluctance to forgo returns these factors underwrite continued and increasing exposure to the risks of growing credit and liquidity imbalances. This basic feature of capitalism and competitive markets was summed up by the head of Citibank, Charles Prince, who conceded he was aware of the increasing risk of widespread defaults from progressively riskier lending but had no alternative (Crotty, 2009). This is a feature of declining investor time horizons identified by Minsky (1986).

Furthermore, the impossibility of the situation facing banks preceding the subprime meltdown was aggravated by the endogeneity of causation. Allowing that large, privately-owned banks would have faced an already impossible task of extricating themselves from active provision of loan finance at the loans market margins, had any been able to do so, it is doubtful they would advance their extrication to any significant level without precipitating an already predetermined market dysfunction. So, without saving themselves from any significant losses they would encounter political costs. Moreover, the propensity to blame bank management is observed to decline in an environment where losses are widespread (Rajan, 1994), and the increased likelihood of central bank assistance to banks at such points justifies the banker's choice (Borio, et al, 1994). Under such conditions the conservative bank's 'retreat to cash' foregoes the advantage implied by the moral hazard created by implicit Central bank guarantees, only so long as the bank is not too much more exposed than the market-average. 
Nowhere is the need to replace the asymmetric information advantage explanation more evident than in its role as a plausible explanation of the sub primeinduced market breakdown. Suggestions have been made that differential awareness of individual credit risks favoured borrowers of subprime loans over their bankers. This depicts banks as guileless victims of unsophisticated aspiring homeowners with minimal assets, modest income and no systematic prospect of changing these circumstances. It seems more plausible to view banks' pre-commitment to the loan market due to rigidities implied by the intensity of competition in a deregulated financial sector. Writing new loans functionally validated existing loans, supporting house prices. The "asymmetrically information-disadvantaged banker" explanation fails satisfaction of plausibility criteria (Wray, 2008). Competitive pressures for returns coupled with moral hazard identified by Prosner (2007) offer a more plausible explanation for the behaviour of bankers.

Fazzari (1999) states that Minsky did not rely on asymmetry as a determinant of financing constraints on firms' investment decisions. Fazzari, however, argued that the introduction of information asymmetries between borrowers and lenders usefully explains firms' inability to attract finance. His argument is that good projects may be left unfunded and that this requires explanation. Conversely, as noted by Minsky (1986), much lesser quality projects find finance as economic expansions progress. Loose monetary policy over expansionary periods lowers interest rates and generally it increases business equity, improving balance sheets and, thereby, increases the ability of businesses to borrow. This borrowing costs less as 'strong' balance sheets reduce perceived risk (Fazzari, 1999). A decrease in asymmetric information is not indicated by the perception of reduced risk, but an increasing margin of safety is perceived by lenders in the absolute level of firm equity, and in the general direction of prices. Given that there is no reason to believe declining asymmetries occur over booms, it is unclear that information asymmetries can form an important part of the explanation for underfinancing prior to boom periods (Farazzi, 1999).

Separate from Minsky's argument of the role of financing in capitalism's instability, capitalism has a default requirement of economic growth. Where standard neo-classical assumptions conclude that increased production and the growth of 
productivity in particular support rising living standards, its foundation for this proposition does not disaggregate the incidence of national income growth by distribution (Robinson, 1938). Sustained economic growth is necessary to maintain full employment if productivity growth results in wage income lagging profit income as shares of national income over booms. Total economic growth and production must increase to absorb labour displaced by productivity gains. A further standard condition is that profits fuel investment (realised or expected) and investment is sustained over booms by rising profit shares which, in turn, capitalise and rationalise further investment (Fellner, 1969; Minsky, 1992; Keynes, 1936). This investment is accompanied by a growth in money wages. However, the relation of labour incomes to capital incomes alters in capital's favour due to the differential speed of increases in income.

It follows from this that income progressively concentrates over booms and destabilizes consumption demand (Brown, 2004; Lavoie and Stockhammer, 2012; Robinson, 1938). This Cambridge School ${ }^{12}$ argument is that the incidence of income is not neutral and, thereby, determines savings rates (Stiglitz and Uzawa, 1969). As a simple identity savings equal investment. As discussed previously, evidence of progressive income inequality over booms suggests varying priorities afforded consumption and investment over economic cycles. This is important because factors destabilising consumption as a component of aggregate demand place greater priority on investment to sustain demand (Brown, 2004; Lavoie and Stockhammer, 2012; Robinson, 1938). From Keynes (1936), the uncertainty concerning returns to capital makes it the most volatile part of aggregate demand. Thus, a growing income inequality is inferred as an early sign of systemic economic disequilibrium.

\subsection{The Synthesis: Keynes and Minsky}

Keynes's view of the influence of uncertainty on investment establishes the conditions of capitalism's inherent instability. Minsky's FIH provides an extension of Keynes's basic case for business cycles driven by insufficient aggregate demand. It provides and focuses on the financial system as the principal transmission mechanism

\footnotetext{
12 The Cambridge school identified markets in partial equilibrium, including the notion of diminishing returns. The role of market imperfections is central to the Cambridge School qualifications and its focus on market failures, along with attention given to labour market imperfections by Robinson relate it to this aspect of the present research.
} 
of the fundamental instability identified by Keynes. The key distinction is in the greater focus Minsky attaches to the financial system. For Keynes these structures could aggravate instability but they were neither central nor necessary to instability. Investment itself was subject to uncertainty and it is in this uncertainty of the MEC in the future that undermines sufficient aggregate demand to support economic stability. Arguably, Minsky (1975) concurs with Keynes in denying the necessity of fractional reserve banking for the endogenous instability of predominantly market-based economies. The financing structures of capitalism interact pro-cyclically with aggregate demand, as identified by Minsky's analysis of an entrepreneurial, competitive financing sector, fuelling investment and consumption. This aggravates business cycles through debt inflations and deflations. Consistent with Keynes and Minsky, the operation is most pronounced on investment (Basu and Taylor, 1999).

The discussion to this point has centred on effective demand drivers as an explanation of the business cycle, particularly in relation to Keynes. The focus here is not, however, on the implications for full employment in capitalist economies and their systemic failure to stabilize at full employment, but on the signs indicating the propensity of markets to move away from equilibrium value as a function of aggregate demand cycles. The theoretical focus to this point has identified two key variables causally linked to macroeconomic cycles. These are the growth of income inequality and the progressive rise in debt over booms. I have indicated the link between income inequality and household debt levels in the current economic environment. This link supports the importance of income inequality and consumption as causes lying beneath Keynes's and Minsky's proximate causes of business cycles. In relation to Minsky the extension is minimal; it simply accommodates the prevailing institutional environment in which house price rises, supported by loan access, extend Minsky's conditions of financial fragility from business to the household sector.

The theoretical connection between economic cycles and market cycles arises in the common conditions destabilising effective demand and future profits (BIS Annual Report, 2001; Gatti, Galleti, and Galleti, 2005; Zarnowitz, 1999). Future cashflow expectations are subject to change and this links equity market cyclicality to macro-economic cyclicality advanced in Keynesian-Minskian analysis. Macroeconomic cycles are driven by investment and investment drives profits. Further, the 
forces driving profits and future profits also drive borrower margins, reflected in asset prices (Borio, 2003). The logical and empirical basis to this position is supported by the research of Hamilton and Lin (1996), Chen, Roll and Ross (1986), Fama (1990), Schwert (1990), and Chen (1991). These researchers conclude that fluctuations in economic growth are a central determinant of stock returns and they are positively related. This completes the link between Keynes' theory of effective demand and asset market cycles.

Instances of market volatility may occur at points that do not satisfy the basic parameters identified in this discussion. It follows that truly, substantially exogenous shocks will not be assessed as holding important implications for broad market valuation stability. Markets cannot assign valuation implications to random events. Allowing that large exogenous shocks may impact markets the substantially endogenous models developed in this thesis must be qualified under conditions in which the economy and markets are affected by large shocks. The central function of the identification of business cycles with endogenous causes is to identify these cycles with recognizable signs which build in the economic system itself. These are signs of asset price inflation through financial acceleration, operating through an 'excessive' debt mechanism.

\subsection{Summary}

The theoretical framework adopted by this thesis coheres around central determinants of instability in modern capitalist economies. The relation between macro-financial variables and asset market cycles is analyzed through a Keynesian/Minskian framework. With investment uncertainty, as the cause of endogenous capitalist uncertainty, specific elements identified as aggravating economic and asset market price cycles under fractional reserve banking are cycles in credit growth and destruction (debt inflation and deflation). This relation, and the mechanisms creating it, are described in Bernanke (1983), Kiyotaki and Moore (1997), Bernanke, Gertler and Gilchrist (1999), and Allen (2005). The Minskian extension to Keynesianism relates to the role finance plays in creating instability in the capitalist system. In contrast to Keynes, Minsky identifies capitalism's financing structure as the central cause of systemic instability; it is not merely an aggravating factor. Underlying this cyclicality is the aggregation of expansion-era income benefits to particular classes 
of specialised labour and to capital. This is reflected in a growing proportion of national income reflected in profits. This, in turn, places greater demands on investment to complete high (economic expansion-sustaining) levels of effective demand and, thereby, heightens the significance of investment's volatility on the economy and asset markets.

From existing theoretical and empirical research identified in this and the following chapter, the underlying assumptions of the necessary recurrence of business cycles and the co-movement of aggregate demand and asset prices form the basis from which the endogeneity and identifiability of the level of equity market stability is asserted. These propositions are extended to their implications for the potential to forecast equity market investments through changes in corporate financing structures. From the base of the argued theory deviations in the movement of corporate debt (procyclical) and corporate equity (countercyclical) from each other offer a potential leading indicator of asset market trends.

Chapter four identifies the essential endogeneity of business and market cycles, making the case for identifiable factors implicated in those cycles. This argument forms the basis of the case advanced in this research that by recognising relevant signs related to asset markets it may be possible to anticipate future market movements. This process links endogenous market cycles with the financial infrastructure in what is a Minskian analysis of the relationship between markets and the financing structures of companies. 


\section{Chapter four: Light regulation, unstable markets and the FIH: An examination of the GM.}

\subsection{Introduction}

This chapter builds on chapters two and three to link the essential nature of market-based economies' endogenous instability to the operation of the financial system as identified by Minsky (1986). Aggregate demand is temporally promoted over booms, causing a credit constraint in the aftermath of economic expansions. The role of financial de-regulation is identified in recent US history over the period known as the Great Moderation (GM). Moreover, the cycles in regulation are recurrent. Features of the financial sector that evolved over the research period (1980-2012) are considered as causes of the GM and of the end of it. Minsky's (1986) FIH is adapted (from its chapter three presentation) to accommodate developments in the modern period. The chapter concludes that inter alia corporate debt and equity flows are indicated as test variables for use in predictive models of market movements, as well as market trading volume and price history.

Following Minsky (1975; 1986; 1990: 1992) the argument is developed that markets are independently driven by self-reinforcing changes in the availability of credit, leveraging gains initially fuelled by changes in fundamentals. It is hypothesized that the economic and market growth of the GM reduced agents' estimates of risk and increased their expectations for returns. These forces operated to increase the availability of credit and created a political pressure on regulation and regulators to adopt a growth-accomodative stance, supporting the 'light-handed' approach to regulation observed progressively over the GM (Spencer and Huston, 2006). Likewise, the credit rationing of the GFC caused banks to retain $\mathrm{TARP}^{13}$ funds as reserves rather than increasing credit availability to businesses that were financially constrained in 2008 and 2009, with credit availability easing only after the real economy suffered significant damage (US Department of Treasury, 2008; Black and Hazelwood, 2012). The rationing of credit during periods of financial distress and recession is also expected under the FIH.

\footnotetext{
${ }^{13}$ TARP was a US federal Government fund established under H.R. 1424 enacting the Emergency Economic Stabilization Act of 2008. It provides funds for the purchase of 'troubled' securities, such as mortgage-backed securities. TARP is an acronym for the Troubled Asset Relief Program.
} 
In contrast to Minsky's (1986) expectations, from 2003 financial markets rose and the economy expanded until late 2007, but without significant new investment or increasing corporate leverage (Bellofiore, et al, 2010). This, along with observations detailed in chapter five and the short term forecast (of equity markets) focus of this thesis, indicates adaptation of test variables to fit a more approximate context. These considerations support the use of flows' data over the stocks' data (total debt-to-equity or leverage levels) that Minsky (1986) argued was most productive as they related to economic cycles. The greater liquidity of equity markets when compared with the wider economy further recommends this approach. Equally, and consistent with the FIH, current short term market financial flows' data may be expected to be of greater relevance to predictions of equity market movements.

The key hypotheses advanced in this chapter are that:

- History supports business cycle endogeneity as an essential feature of modern market-based economies.

- The temporal displacement of aggregate demand is an essential feature of business cycles.

- The financial sector is central to economic and market instability.

- Aggregate demand is the key to financial market buoyancy with expansion and contraction influenced by credit availability and demand which are both influenced by cycle phase.

- Recent US history combined a de-regulated financial sector with monetary policy relying on limited regulation augmented by market discipline to constrain agents' actions. This exacerbated economic and market instability, increasing the amplitude of movements, while supporting elevated growth in asset markets and the economy in toto.

- Thus, financial variables are indicated as signs of market direction and stability.

- Stocks (leverage) are endogenously determined, in part, by market levels and movements and, so, they are unsuited to signalling economic or market direction. This entails adapting Minsky's focus on leverage to one on flows. Adapting the FIH to the focus of this research indicates flows' data versus stocks' data. This conclusion is supported by 
observed financing flows' movements over the study period (see chapter five).

- Common features of current short term market prediction modelling that are consistent with Minsky's (1986) FIH are viable for inclusion in model/s testing of independent variables to bridge the gap between the business cycle focus of the FIH and the very short term focus of current technical analysis.

These propositions are elaborated in this chapter which concludes with the IVs indicated on the basis of this process.

\subsection{The history and essential nature of business cycle endogeneity}

Business cycles as recurrent and endogenous features of the economic system became more pronounced only in the latter half of the eighteenth century (Entov and Poletayev, 1991; Kleinknecht, 1981; 1987; Rothbard, 2003). In the UK in the Middle Ages there were lengthy periods of variously, good, bad, and indifferent economy. ${ }^{14}$ Rothbard (2003) describes the fourteenth and fifteenth centuries as a broadly singular period of secular economic decline. From time to time a large external shock would jolt the economy into a major shift (period of elevated growth or decline), with the directionality determined by the nature of the shock (North and Thomas, 1970). What emerges from the feudal era is the complete lack of periodicity of general changes in the economic environment and that external shocks had a functionally exclusive role in adjustments in the economy. At the least, business cycles became less obviously, exclusively linked to the operation of external shocks. This situation of a comparatively stable environment persisted in predominantly subsistence agrarian societies, prior to the widespread development of market economies. Notably, even within agriculturallydominated countries active in international trade, relative stability prevailed (Stock and Watson, 2003). The distinguishing features of these agrarian economies included: the perishability of production and, in consequence, constraints on the ability of these economies to overproduce in a sustained manner; seasonality and varied weather patterns further regulated production without systematic bias endogenous to the economic system; the resultant brevity of cycles, exogenous to the system of economic

\footnotetext{
${ }^{14}$ Malthusian business cycles involved fluctuations in demand and supply but they were subdued relative to those in modern-era capitalism. Constraints inherent in the institutional ability to create credit limited the amplitude of these cycles (Commons, McCracken, and Zeuch, 1922).
} 
organisation; and, the relative nascence of their development, restricting the accumulation of wealth.

Central to the business cycle endogeneity of capitalism is the cyclical tendency of market-based economies to build excess production capacity. This 'excess capacity' is integral to the central cyclical tendency of capitalism to lag wage increases relative to productivity gains over booms (Azmat, et al, 2007; Baker, 2007; Dymski, 2002; Finfacts Team, 2006; Keister and Moller, 2000; Krugman, 2000; 2006; Minsky and Whalen, 1996-97; Lavoie, 2006; Papadimitriou and Wray, 2001; Willis, 2003; Wolf and Zacharias, 2007). This basic phenomenon informs the Kondratieff system of 'long waves'. From time to time major new labour-saving innovations impact society and these rapidly increase productivity. This view of periodic technology shocks as the catalyst for business cycles is broadly consistent with the interpretations of Schumpeter and Keynes. Kondratieff identifies capitalism's regenerative tendency. Variously, the cotton gin and clothing manufacture (1800-1850), the age of steam, steel and railroads (1850-1900), and petrol chemicals, the car (internal combustion engine), and electrification of assembly lines (1908-1947), fuelled major productivity gains. In the last of these three major labour-based innovations, the electrification of assembly lines led to increases in productivity on declining total employment. This, in turn, reduced wage employment and incomes relative to productivity and national income. Arguably, the influence of globalization debased the monetary value of developed country labour, and exacerbated the trend to the casualisation of those labour markets (Willis, 2003), constituting a wage income-to-productivity and total production constraint easily as great as the previously described historical labour-based innovations. In simple terms, declining real wages in the US since 1973, due to the de facto internationalisation of labour markets, constitute a major labour market innovation of at least similar magnitudes to prior innovations (Willis, 2003). This effect produced what Keynes referred to as a period of secular stagnation (Broadway, 1998).

The discussion to this point identifies labour-based innovations as the impulse and propagation mechanisms initiating business cycles. The 'New Long wave' identified by Broadway (1998) moves beyond external shocks. He states that the postWorld War II boom occurred without labour-based innovation. Keynesian government debt switched to rising private sector debt to create the 'Long Debt wave'. This stalled 
between 1970 and 1983 but was restarted with an expansion of (US) debt from 175\% of GDP (1981), to $250 \%$ of GDP (1987). With the arrival of Greenspan as chairman of the Federal Reserve System in 1987, recessions and recessionary risks were met consistently with increased liquidity supplied by the Federal Reserve. This point marks the transition from the era of 'Big Government' to the era of 'Big Bank' (Papadimitriou and Wray, 2010; Wray and Tymoigne, 2008).

Importantly, this is not an argument for Kondratieff Waves. Kondratieff's theory relies on a degree of determinism implied by the approximate regularity of his hypothesized fifty-four year cycle (Rothbard, 2003). This implicit regularity is most useful as a descriptive account of the sources of business cyclicality rather than as a predictive tool. However, the positive claims made by Kondratieff are confounded by the heterogeneous nature and range of causes and magnitudes of successive cycles. Successive cycles will necessarily be, at least in part, a function of the preceding cycle (consistent with the views of Fisher, 1933), and thus, indeterminate a priori over such long periods of history as is explicit in the Kondratieff Wave theory. Part of the foundation for this assertion is the temporal distance from the growth in government and regulation during and following the Great Depression, and its subsequent contraction and repeal (respectively) in the modern era of financial liberalization.

Sims (1998) observes the minor role of monetary policy in generating business cycles, independent of the argument for monetary policy endogeneity. This issue assumes relevance when governmental and quasi-governmental errors are introduced by the mainstream as explanations for sustained or intense recessions when markets fail to clear as classical economics indicates they would. ${ }^{15}$ Supporting this argument, Romer (1993) contends that the 1930s depression was not caused by the 1929 stock market crash (as an exogenous shock), because the economy had been contracting significantly prior to the crash. Further, monetary policy cannot be implicated as the cause of the Great Depression as base money supply growth did not slow significantly

\footnotetext{
${ }^{15}$ During the Great Depression assumed errors included the US Federal Reserve Bank constraint of credit availability and money supply (Friedman and Schwartz, 1965) and, in the 1990s-2000s, Wallinson (2009) argues that the Congress-backed 'democratisation of debt' forced the financial sector to issue unsound loans.
} 
and real interest rates declined after 1929. Similarly, the Federal Reserve Board behaved typically, thereby creating no departure from expectations.

Real Business Cycle theories identify the role of exogenous, real factors as central to economic fluctuations. In particular the 1974-1975 downturn is attributed to poor harvests and the 1973 oil supply shock, diminishing supply respectively of food and oil and increasing prices (McHugh, 1986). Other factors operating as shocks on the economy include technological innovations. Without discounting the impact of exogenous shocks it is doubtful that technology shocks could be adopted with sufficient speed to create a 'shock' to the economy. Major innovations operate progressively over time to support economic expansions (Fuhrer and Schuh, 1998). This is consistent with the function of technological innovation in Minsky's theory. They induce a period of economic expansion. Equally, the more acute shocks of the mid-1970s that undoubtedly played a role in the business cycles of that period do not signify systematic disequilibration of asset market prices.

Against the view that exogenous shocks are important determinants of business cycles this thesis follows Minsky (1986) by arguing for the relatively peripheral role of such shocks. Instead, financing structures play a central role by carrying fundamentalsbased growth beyond the limits of productivity increases and product innovation. Financing structures gravitate towards greater financial fragility as credit availability extends the economic expansion. This is aided by economic liberalisation as the immediate benefits of expanded credit availability are substantial and possibly irresistible. These considerations support the use of corporate financing flows and prices as prediction model variables.

In précis, the following discussion identifies the substantially endogenous nature of factors causing the modern-era GM. In this sense financial liberalization is not an external influence on an otherwise stable system. It is endemic to the broader socio-historical context of an economic system in which markets are driven by incentives and competitive pressures on economic actors. This view also holds that monetary policy is essentially endogenously determined. On any account monetary policy showed no systematic bias other than to support persistent economic growth through the GM (Checcetti, 2003). Even in the Greenspan era 'leaning against the 
bubble' approaches to monetary policy tightened monetary conditions only when financial markets were performing strongly and with the aim of suppressing bubbles (Spencer and Huston, 2006). A view of monetary policy substantial endogeneity need only look to markets, capitalists, workers and society as a whole holding a preference for profit, wage, and job growth to the deficit of these things for plausible support. In essence, monetary policy is largely influenced by the prevailing environment (Shiller, 2012; Spencer and Huston, 2006). Primary causation attributed to external shocks is rejected. These external shock factors are largely incidental and operate on the economic system as they find it. The dampening or exacerbating response of the economic system depends substantially on the cyclical phase it occupies when acted on by the external shock factor. Thus, after long periods of stability, especially where light regulation fails to constrain unstable growth, the build-up of endemic instability could leave the economy so fragile that an external shock is the catalyst for economic and financial market dysfunction.

\subsection{Endogenous causes of the GM: Financial liberalization and the GM}

The financial sector and financial market liberalisation were important preconditions of the GM. Financial market deregulation occurred progressively from the 1970s and involved unwinding the Depression-era regulation of the 'New Deal". The succession of regulatory changes detailed in this section show a systematic bias towards reduced regulation over the period 1970-2007. In this light arguments for regulatory 'mistakes' (see, for example, Shiller, 2012; Taylor, 2008) imply a series of very many 'mistakes'. The case is made that such an interpretation is tenuous and that the socio-economic and political environment provided the foundations for the broad direction of regulation and that regulation is a natural product of its environment rather than an independent influence on that environment.

This section advances the view that the GM was substantially due to the era of financial liberalization (see: BIS Annual Report, 2001; Cecchetti, Flores-Lagunes, and Krause, 2005; Dynan, Elmendorf, and Sichel, 2005; Kaminsky and Reinhart, 1999; Nakov and Pescatori, 2007; Summers, 2005). In the post-Bretton Woods era, from 1971, floating exchange rates interacted with domestic financial market liberalization to fuel a rapid loosening of credit availability, the rapid increase in international capital flows, and rising financial market instability (Bibow, 2008; Ferri and Minsky, 1991; 
Kose, Otrok and Prasad, 2008; Lewis, 1993). The availability of credit greatly increased in this period (Rowbotham, 1998). Over the GM, deregulation led to a decline in traditional bank shares of the US loans market (Friedman, 1999). This inter alia reduced central banks' power, as an increasing share of this market fell outside of the reserve system (Thoma, 2009). Along with the declining control of monetary authorities, rising debt levels of microeconomic units in many developed countries further limited central banks' options, heightening risks to financial stability. Similarly, evidence of rising systematic risks emerged, due to the growing reliance on debt-fuelled consumption as the key stimulus to aggregate demand (Cynamon and Farazzi, 2008).

Parallel to the rise in international capital flows was the growing volatility of exchange rates, providing what has been argued as a trade-off of financial market stability against increased domestic macroeconomic stability (Crockett, 2003; Guise and Tuxen, 2008). Increasingly, economic imbalances were suppressed or absorbed through shifts in currencies' relative values. For this reason floating exchange rates were the first phase of financial deregulation contributing to the GM, allowing the greater flow of capital internationally and, thereby, supporting imbalances reflected in the international capital flows' paradox (Bernanke, 2005). ${ }^{16}$

Securitization accelerated global capital flows, along with floating currencies, allowing opportunistic foreign investors to move between asset markets, increasing the volatility of those markets (Kaufman, 2009). This trend expanded internationally from the US, increasing financial market liquidity, allowing the investor to easily exit security holdings. This was further compounded by the credibility of progressively tightened securities regulations, matched by the loosening of banking regulations. Amongst tightened regulations were those controlling insider trading and disclosure and the Sarbanes-Oxley Act (2002), increasing the regulation of corporate governance. Typically, managed funds have hundreds of sub-ten percent holdings, to avoid falling within the provisions of insider trading regulations and to comply with portfolio theory. These developments encouraged a shortening of average company stock holding

\footnotetext{
16 The international capital flows' paradox is the flow of net capital from developing countries to developed countries. It is described as a paradox because prevalent economic theory cannot explain this flow. On conventional views of economic theory the flow should always be towards less capital sufficient (developing) countries, from developed countries.
} 
periods to less than a year, supporting the position that exit was the best strategy if a company failed to perform. Effectively, this led to lowered monitoring costs and increased volatility as free-riding came to dominate equity markets, reducing the due diligence previously undertaken (Bhide, 2009).

\subsubsection{Domestic financial deregulation}

Domestically (in the US and other developed countries), the liberalization of exchange rates was followed by deregulation of financial markets and the banking industry (Kregel, 2007). This occurred through the 1970s and 1980s. Until the 1970s the US banking industry was heavily regulated. Restrictions had been applied to banks' geographical spread, interest rates they could pay, and investment activities they could undertake (Strahan, 2003). Progressively, deregulation relaxed constraints on banking to allow state-wide and later interstate branching (Stiroh and Strahan, 2003). A succession of legislation supported financial deregulation, including: The Depository Institutions Deregulation and Monetary Reforms Act (1980), the Garn-St. Germain Act (1982), and the repeal of the Glass-Steagall Act (1933), with the Gramm-Leach-Bliley Act (1999) (Tregenna, 2009; Wray, 2007a). Deregulation reduced banks' reserve requirements, increased competition in financial services provision, facilitated consolidation in the financial sector, loosened constraints on banks' investing activities, removed caps on interest rates payable on deposits, and increased Federal guarantees of bank-held deposits, while increasing access to the Federal Reserve discount window for overnight borrowing (Kregel, 2007). Deregulation expanded banks' and financial institutions' ability to generate credit and reduced the absolute risk of doing so through access to the discount window and Federal Deposit Insurance Corporation underwriting, respectively mitigating liquidity and credit risk and, jointly, increasing moral hazard.

The effectiveness of relationship banking and its disciplines declined and were replaced by statistically-driven risk management (Friedman, 1999). Due diligence and monitoring was largely replaced by modelled risk assessment, pooling, and diversification as risk management tools (Acharya and Richardson, 2009). ${ }^{17}$ The higher cost structure of relationship banking led banks to develop the securitization market,

\footnotetext{
${ }^{17}$ In particular, institutional investors reduced their activism, instead relying on market discipline and diversification as risk management tools.
} 
substituting fee income for interest income. Securitizations involved an 'initiate and distribute' approach to meeting lenders' demands for finance: a system which introduced systemic risks, as non-performance risks were passed on to investors in the securitizations. Minsky's (1986) position that banks are effective in circumventing regulation designed to constrain money supply was validated and compounded by competitive pressures imposed on banks by deregulation, including margin erosion and mispricing of risks by marginal banks (Mullineux, 1990). Notably, these developments were compounded as banks were forced to retain exposure to risks associated with securitizations through guarantees. Such guarantees were necessary to sustain further issues. Minsky (1992) observed the origins of the securitization market in the 1980s, identifying it as a new, significant source of risk to economic stability (Whalen, 1999; Wray, 2007).

Money market funds, banks, and pension funds exist in a competitive returns' market. Therefore, they face pressure to arbitrage deposit and debt maturities to a progressively greater extent. The growing role of managed funds is depicted in figure 3. Banks' increasingly relied on the overnight repo (repurchase agreement) market to finance their balance sheets (Brunnermeier, 2008). Bank financing, using overnight repos, increased from $12.5 \%$ (2000) to $25 \%$ (2007) (Brunnermeier, 2008). This development was forced by low short term interest rates. The flood of funds to longer term debt, in turn, pushed down long term interest rates (Samuelson, 2005), heightening both liquidity and credit risks. The importance of 'money manager' equity and debt ownership can be seen in figure 3, depicting the growth in the percentage of institutional ownership between 1950 and 1990. 
Figure 3: Changes in the percentage of 'money-manager' ownership of total corporate equity and corporate bond assets (1950-1990)

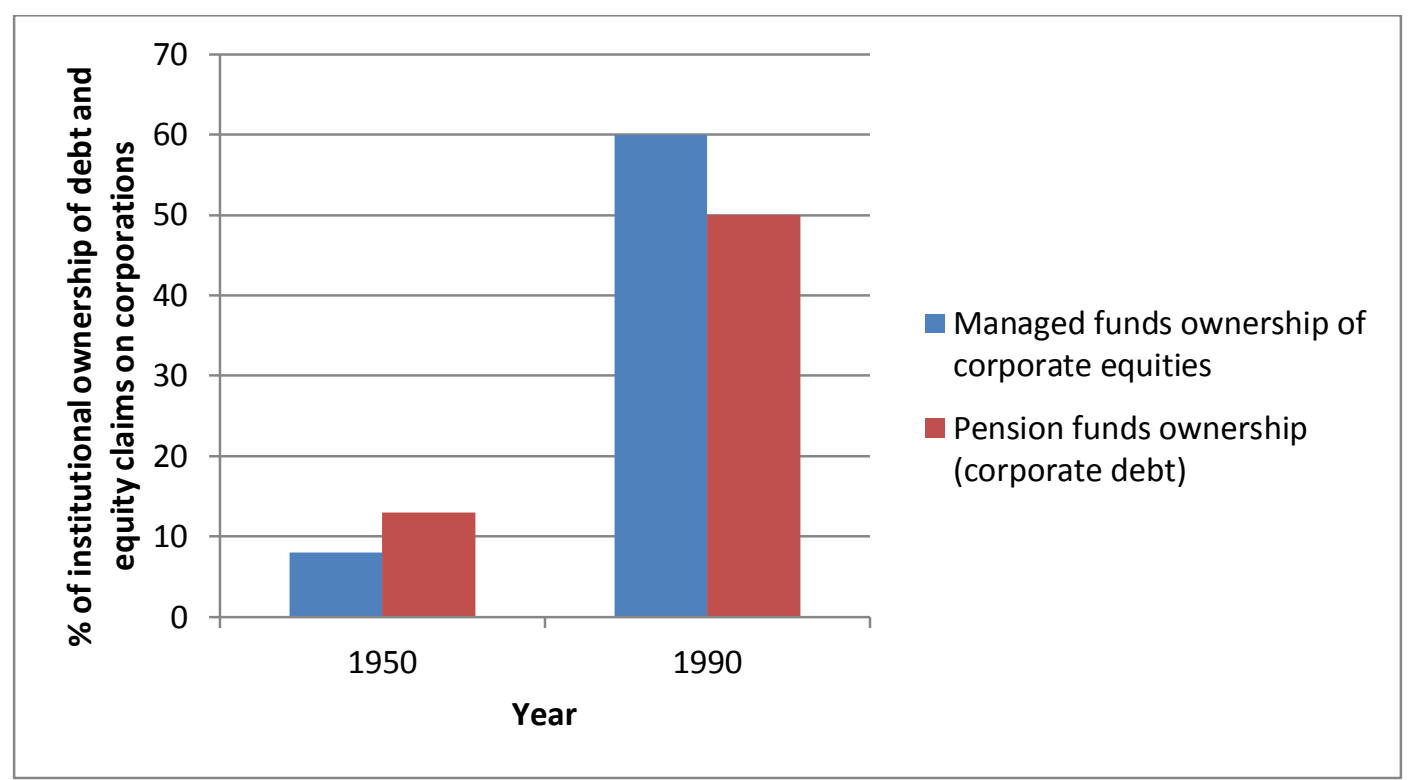

Source: Blankenbury and Palma (2009)

Perversely, securitization fundamentally altered banks' and credit-rating agencies' risk-assessment calculus due to the development of a secondary market which systematically reduced risk assessments by introducing tradability (Borio, et al, 2001). Borio, et al, (2001) identify banks' increasing focus on default risks under one year. Underlying this development was an assumption of the continuing liquidity of secondary debt markets. Borio, et al (2001) argued that risk-assessments subordinated actual risk to realized risk despite increasing actual risk. Securitization led to a decline in lending standards, allowing almost anyone to become a mortgage broker (Brunnermeier, 2008). Special Purpose Vehicles (SPVs) held the securitized mortgages which secured AAA ratings to economize on regulatory capital requirements (Gorton 2009). This condition was exacerbated by higher fees paid to rating agencies for structured products compared with corporate bonds' rating fees (Wray, 2007). Higher fees also applied to 'marginal' AAA ratings. Compounding this, many investors' risk models did not factor in broad-based real estate market declines. Many of these models were based on lower default rates found in previous markets when significantly tighter credit existed. Monoline insurers were sufficiently capitalised against individual defaults in a rising housing market, but with widespread defaults, the thin capitalisation of these companies confronted illiquid real estate markets. 
Prior to the sub-prime meltdown, the progressive innovation of the financial sector led to banks increasingly extending mortgages and credit to less creditworthy borrowers (Lansing, 2007; Shiller, 2008). The short term affordability of loans to borrowers was achieved by interest-only repayments or payments lower than the interest cost, no-equity loans and adjustable rate mortgages with "teaser" rates (Shiller, 2008). The prevalence of such financial innovations was positively associated with regions in which house prices rose faster than the market in general. These conditions were inherently unstable and, inevitably, destined to reverse as mortgages were reset higher to meet changing market interest rates. This defines the essence of a Minskian asset bubble; asset price-stability depending on continuing asset price rises, after a period of steep ascent.

Loan collateral requirements steadily declined over the GM, as did interest rate spreads (Dynan and Kohn, 2007). Until 2007, risk premia steadily contracted on rapidly expanding debt levels. In this environment banks were effectively forced to take de facto equity positions in the property market due to competitive pressures. Subprime mortgages, in effect, operated as 'long' positions taken by banks in property; securitization then shifted this 'property play' off balance sheet. As long as property prices continued to rise, banks had nothing to fear from individual loan nonperformance risk. Banks' exposure was limited due to the rising value of loan collateral.

The forces operating on liquidity conditions during the GM, if not new, were possibly unique in terms of mutual reinforcement. The failure of interest rates to rise during a dual investment and consumption boom, in Minskian terms, required functionally elastic credit creation to increase banks' incomes (Mullineux, 1990). This dictated substantial financial innovation by banks and other financial intermediaries, the free supply of reserves by the Central Bank or Treasury, or the combination of these factors. In the case of the US in the period of the GM, both of these forces operated to expand the supply of finance. This was due to financial industry deregulation, facilitating inter alia securitization, and the persistence of government deficits over a period of economic expansion, maintaining that supply of base money on which the multiplier could operate (Mullineux, 1990). 
The changes had a significant impact on the structure of the US financial system. Active secondary markets developed for home loans and, increasingly, for 'junk bonds'; student loan portfolios, and motor vehicle loans. This process of securitization notionally reduced risk through the pooling of loans, thereby reducing the consequences of individual loan defaults. These evolving features of the US economy were the result of progressive deregulation. Over this period household debt grew from 43\% of GDP in 1982 to 56\% in 1990 (Dynan, et al, 2005). The impact on aggregate demand was the relative stabilization of consumption compared to income. The key to the sustainability of this development is the smoothing of consumption in relation to income. As there was a steady increase in household debt this assumption relies on unsupported assumptions of abnormal (positive) future income growth.

Household debt levels rose in the US from 1984 in absolute terms and as a percentage of income (BIS Annual Report, 2001; Debelle, 2004; Tregenna, 2009). From 1984 to 2004 the household debt to income ratio rose from 0.6 times to 1.18 times, an historical high (Dynan and Kohn, 2007; Lansing, 2007). Household debt outstripped the increase in household wealth, rising from 4 times to 4.7 times income over the same period. The financial obligations ratio (FOR) to income also rose from $11 \%$ of income in 1980 to $18 \%$ in 2003 (Dynan, Johnson, and Pence, 2003). The FOR remained relatively stable in the period up to 2007 due to subdued interest rates (and, thus, lowered repayment obligations) but it remained near historical highs (Dynan and Kohn, 2007). Given historically low interest rates in the 2000s, debt sustainability issues were growing during this period.

The wealth effect of rising house prices, along with higher levels of mortgage debt assumed under mortgages due to rising house prices, was reflected in debt levels growing faster than house prices. Greenspan and Kennedy (2007) infer the high relative marginal propensity to consume housing wealth (0.6), relative to the financial asset wealth effect (0.2), from Federal Reserve Board data. They adjust their estimates for instalment debt due to the repayment of consumer bridging finance, suggesting a rise in consumption expenditure drawn from home equity. Arguably, the significance of these developments is related to the 'democratization of debt', directing the household wealth effect towards households with a higher marginal propensity to consume, especially in the context of reduced real wages for this group. 
A companion trend has been the decline in the personal savings rate since the 1980s (BIS Annual Report, 2001). The household savings rate, which averaged 9\% over the 1980s, fell to an average of 1.9\%, from 2000-2005 (Lansing, 2005). Lansing observes negative monthly savings from June through September of 2005. FaulknerMacDonagh and Muhleisen (2004) attribute the declining savings rate to the wealth effect. This trend further supports the inference to systemic instability when considering the increase in de facto debt due to the rise in vehicle leasing (in lieu of purchase) by households from $1992(2.5 \%)$ to $2001(5.75 \%)$.

Various arguments from market efficiency suggest that consumption smoothing and greater capital allocation efficiency stem from reduced constraints on domestic and international capital flows in the period of the GM (Bean, 2003; Bibow, 2008; Finfacts Team, 2006). On this view the significant deregulation of financial markets facilitated the flow of capital to its best and highest use (Bibow, 2008). The 'new classical consensus' framework implied in Summers' (2005) argument isolates monetary policy improvements as the key driver of the GM. This explanation tacitly discounts the Minskian view that stability creates instability. Summers' view along with that of Nakov and Pescatori (2007) implicitly rejects the growth in factors (outlined above) as threatening economic stability over the GM as this view isolates the central role of improved monetary policy technology. Prima facie the success of monetary policy during the GM is called into question by recent economic and financial market instability. This does not imply stability in a deregulated state but that inept regulation could provide an independent source of instability.

Stock and Watson (2003) admit difficulty in quantifying the impact of easier credit on consumption, although they infer its importance and that any change in, or threat to, the stability of consumption would logically entail an impact on aggregate demand. Further, reduced volatility in the housing construction sector arose due, at least in part, to adjustable interest rate mortgages, the 'democratization of debt', and progressive rises in the level of household debt (Fernandez, et al, 2008; Stock and Watson, 2003). Market-efficient views suggest that these factors point to the operation of consumption 'smoothing', facilitated by increased access to debt and, presumably, predicated on sustained, above-trend rises in future income (as financial obligations 
ratios have been steadily rising since the early 1980s). Clearly, the recent period of debt-deflation serves as a challenge to income 'smoothing' conceptions. Instead, the view of debt-engorgement is indicated, reflecting a widespread and sustained systematic mispricing of risk, domestically and internationally.

\subsubsection{Derivatization}

Derivatization is a further financial innovation that was instrumental in the heightened financial fragility realised from late 2007. Derivatization involves the creation of financial instruments that derive their value as a function of an underlying asset. These derivatives may be used as risk hedges or as speculative instruments. In both cases (though more particularly where the counter-party is using them as leveraged speculative tools) they entail considerable risk. Derivatives tend to concentrate in few hands as the leverage they involve promotes their use as speculative instruments by higher risk investors who often may have insufficient capital to meet claims that arise if adverse events occur. The fact of the insurance effect 'illusion' only gains general appreciation after a severe market breakdown when claimants are met by counter-party defaults.

Derivatization has historically been unregulated due to the efficient markets' view that complete markets for all future dates are necessary for comprehensive risk hedging (Kregel, 2007). Mainstream views held that the depth, breadth and completeness of financial markets allow the spread of contractual non-performance risk to those best able to bear it. In this sense total risk was limited to the cost of entering a new hedge contract (Hentschel and Smith, 1995; Kregel, 2007). The general consensus was that derivatization had reduced risks and aided capital formation (Culp and MacKay, 1994; Hentschel and Smith, 1995; Horowitz and MacKay, 1995; IDSA, 2007; Khalik, 1994; Kohn, 2007). Indeed, Hentschel and Smith (1995) argued that no new risks are introduced by derivatives. Credit risk is mitigated through diversification and, where derivatives are used principally as hedges, through 'netting' (IDSA, 2007). Trichet (2007) acknowledges the view that risk is transferred to investors with longer time horizons, thereby reducing total risk. However, he argues that risk reduction by this means presupposes sufficient heterogeneity of investor behaviours and risk appetites, the correct valuation of risk, and stable relations in these variables. At this 
point evidence for the existence of these necessary conditions does not exist (Trichet, 2007).

While on a Minskian view derivatization may have reduced certain instances of short term volatility it is less clear that it has entailed a systematic reduction of total risk. Buffett (Chairman's Report, 2002) stated:

"We view them as time bombs for both the parties that deal in them and the economic system...[I]n our view...derivatives are financial weapons of mass destruction, carrying dangers that, while now latent, are potentially lethal."

Buffett notes that risk had become concentrated in the hands of derivatives traders, a view that echoes concerns raised by the Government Accounting Office (GAO) (1994). Buffett (2002) argued that the financial strength of derivatives' counterparties poses a significant risk to the financial system. Where derivatives are concentrated in a few hands, and used as speculative tools, their potential risk-spreading function is obviated. Further, collateralization may not offset counter-party credit risks where counterparties hold large net positions in illiquid assets as was the case with the Long Term Capital Management (LTCM) crisis in 1998 (Greenspan, 2005). Shiller (2012) ascribes evolving risks in this area to errors in regulation but the causes of these errors (discussed in section 4.2) appear to be largely driven by endogenous forces.

In light of the GFC and ensuing recession, the case that derivatives dispersed risk is doubtful. Competitive pressures for returns led market participants during the 'euphoric phase' of the economic expansion to concentrate risk to increase returns in what was a low interest rate environment. The speculative use of derivatives facilitated leveraged exposure and, thereby, obviated the risk-spreading ability of the hedge-use of derivatives.

\subsubsection{Corporations and their growing reliance on debt financing over the Great Moderation}

The progress towards a lightly regulated financial sector is arguably the source of increasing cyclical volatility in corporate financing flows (as observed in figures 47 below). This thesis has identified a central link between equity price performance and 
corporate financing flows (except in 1979). Figures 4-7 depict net US corporate financing flows over each of four periods (approximately decades) from 1970 through to 2013. Until 1983 there is a broad balance in financing flows. Modest corporate debt inflows are generally matched by corporate equity inflows. Retained earnings and rising asset price equity readily explain the greater assumption of corporate debt relative to equity. A clear divergence in patterns of corporate financing flows emerges in 1984, approximate to the generally accepted beginning of the US Great Moderation. From this point corporate financing flows appear to be strongly negatively correlated. This general condition is subject to qualification by periods of consolidation in which the respective financing flows converge. In particular, the period 1991-1994 reflects corporate financial consolidation when, during the first (early 1990s) recession of the GM, US corporations reduced their reliance on debt inflows and consolidated their Balance Sheets with positive net corporate equity inflows and net corporate debt outflows (net debt retirement).

Figure 4: Patterns in corporate external financing composition from 1970-1980

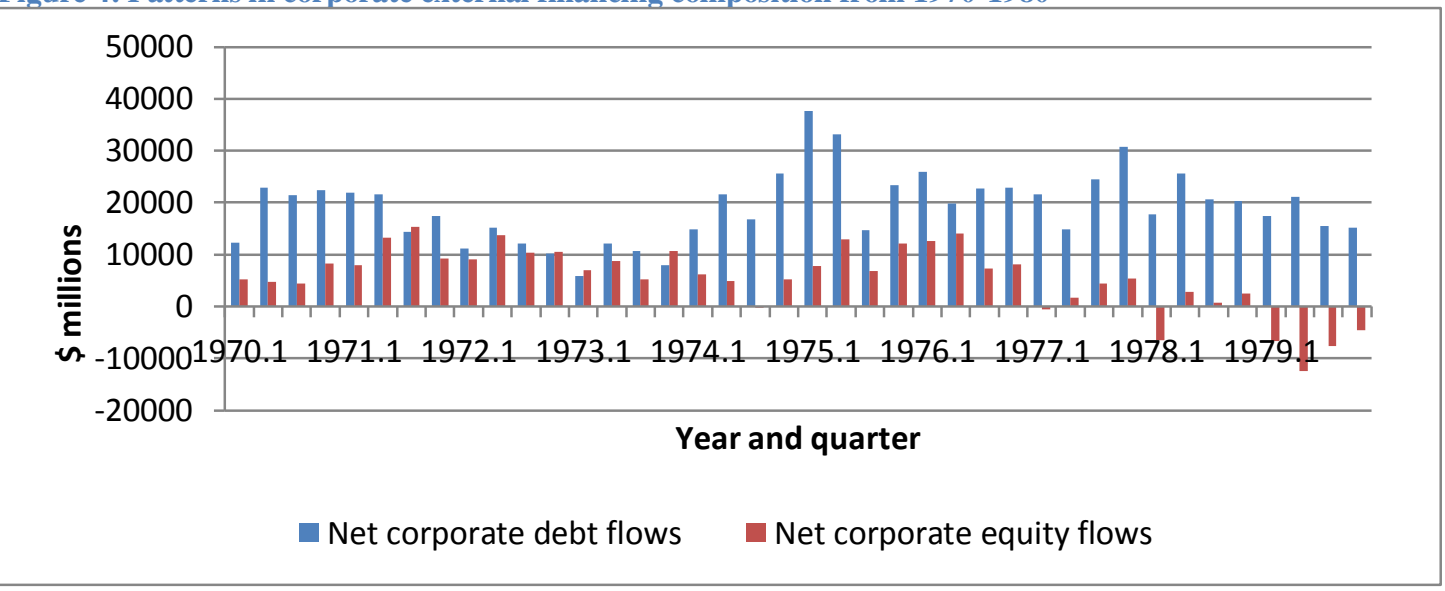

Note: Correlation between debt and equity flows over this period: 0.23 ; -0.64 (19801989); -0.4 (1990-1999; and -0.34 (2000-) 
Figure 5: Patterns in corporate external financing composition from 1980-1990

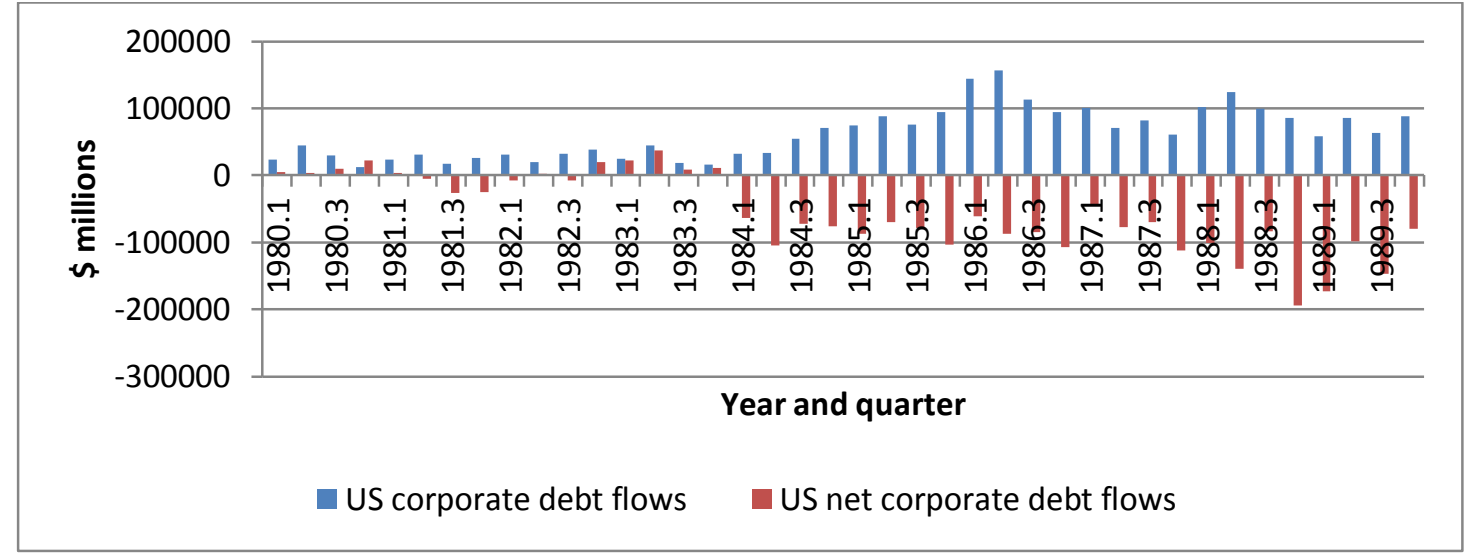

Figure 6: Patterns in corporate external financing composition from 1990-2000

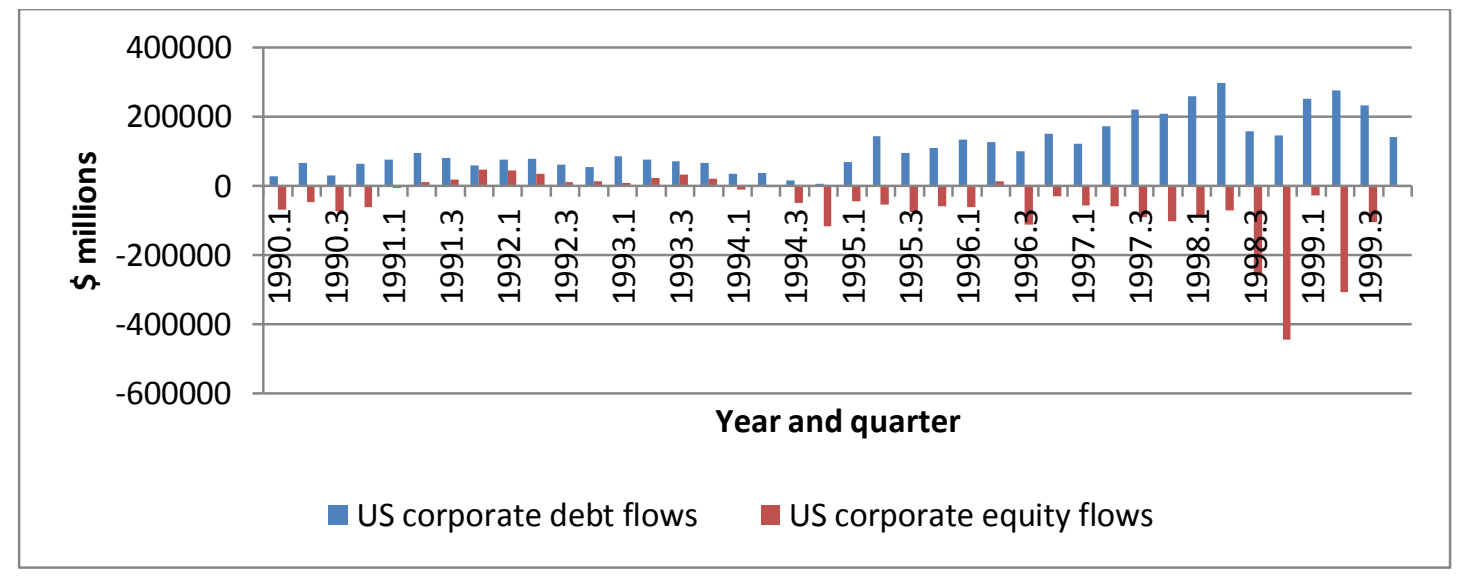

Figure 7: Patterns in corporate external financing composition since 2000

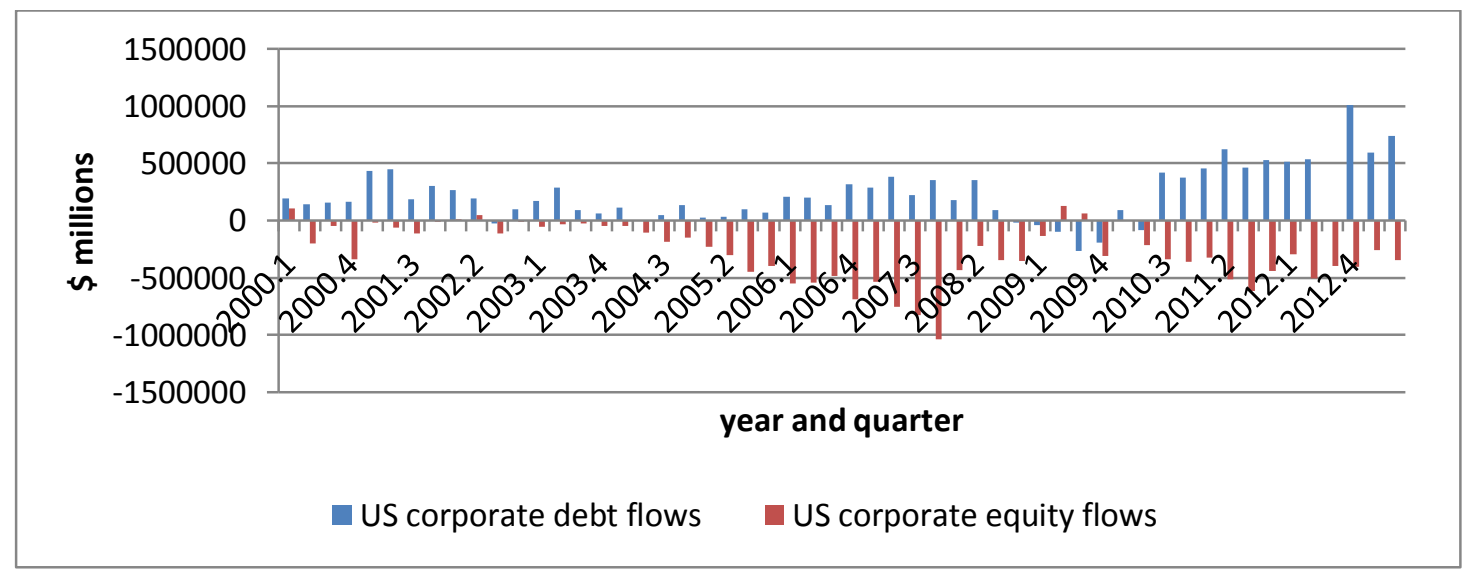

\subsubsection{Changes in financing of the wider US economy over the period 1970- 2011}

Broad changes in the flow of finance occurred over the period 1970 through to 2011. The US Federal budget was maintained broadly in balance until 1974 when net 
government debt to GDP reached a post-World War II low of 23.9\%. Subsequent to this period, recessions of the 1970s, in part caused by a succession of external shocks, resulted in a modest expansion of the Federal budget deficit. Despite this, with some growth in the real economy, total Federal Government debt stood at less than $2 \%$ higher relative to GDP at the end of the 1970s. The 1980s and 1990s see a period of elevated growth in the Federal budget deficit as a succession of peacetime (and frequently growth era) deficit spending occurs. This reached almost 50\% in 1993 in the aftermath of the first Gulf War and the recession of the early 1990s. It again reached these elevated levels in 2009, again with tandem influences from an economy in recession and war in Afghanistan and Iraq.

Figure 8: The relationship of US Federal government deficits to GDP in the period from 1974-2010

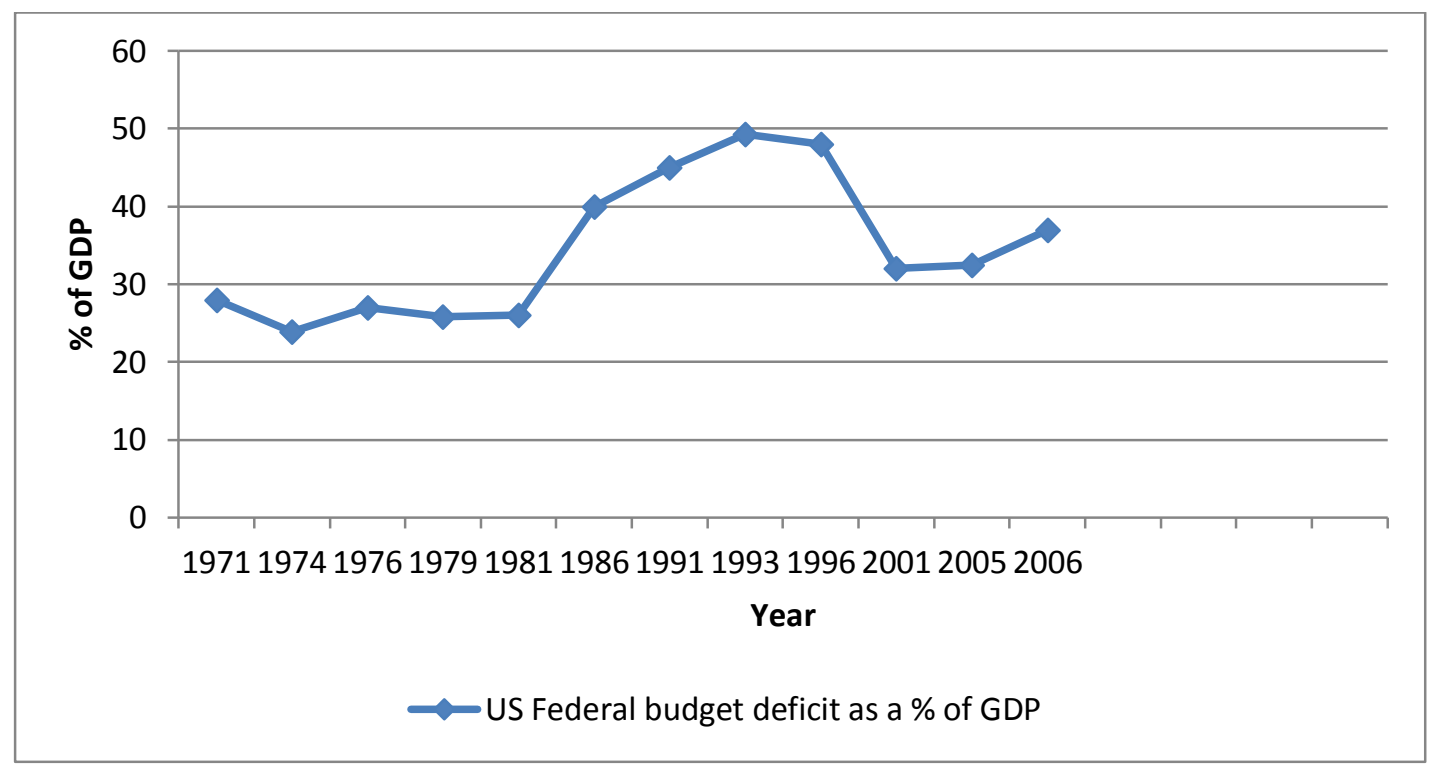

Source: Schwabish and Gri (2012).

Broad developments in US Federal budget deficits relative to GDP are depicted in figure 8 . The relevance of the trend towards greater governmental borrowing over the period is similar to that made in relation to cycles in corporate borrowing. A persistent and growing reliance on debt, whether at the micro- or macro-level, implies elevated financial fragility. Just as growing corporate debt financing composition comes to rely on persistent asset price rises as identified by Minsky, persistent Federal Government budget deficits increasingly rely on growth in the economy. Moreover, and more immediately relevant to this thesis, the persistence of government budget deficits provides an independent source of stimulus to the economy but it is not a stable 
growth catalyst. Further, heightened instability must logically be presaged by such deficits when, as in the US, they coincide with periods of strong growth and are used to support substantially unproductive investment.

Another economy-wide metric indicating economic instability or the growth in the potential for economic and market instability is the US current account. Notably, the US current account was essentially balanced over the 1970s. Although there was a series of modest deficits in this period they remained sufficiently small in the context of a growing economy that there was little change in the debt-to-GDP relationship compared with post-World War Two lows (see figure 8). This was to change in the 1980s and beyond as large peacetime deficits were incurred. This, in conjunction with the growth in US Federal Government budget deficits from the 1980s (see figure 8), created independent sources of reserve or high-powered money from which the financial sector is able to grow broader money supply and, in effect, produced inflationary growth in the economy. Further, the absence of these deficits in the 1970s is likely to have constrained economic growth in that period and disrupted the signalling potential of the micro-financial variables selected in this thesis. 


\section{Current Account Balance}

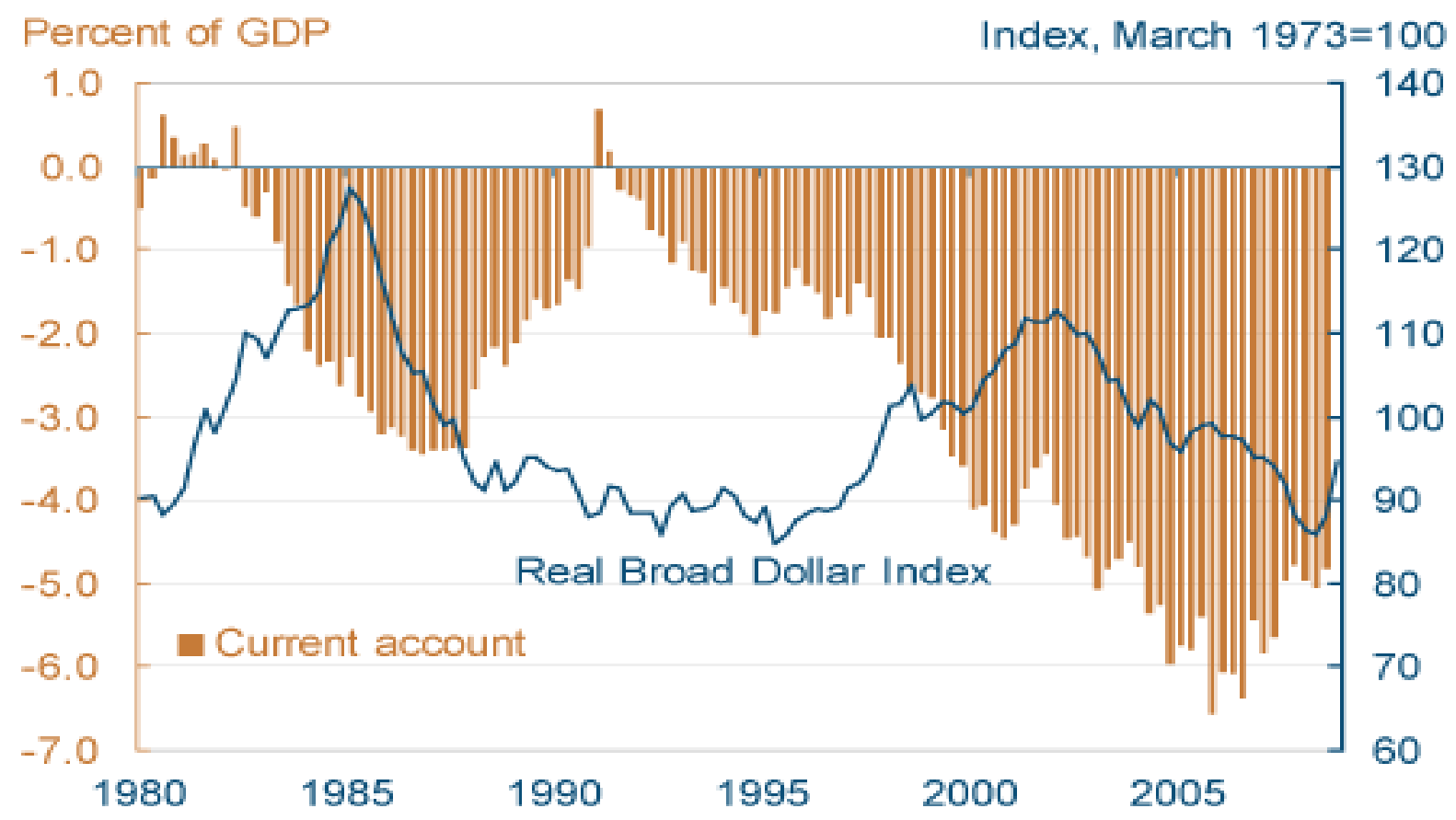

Sources: Bureau of Economic Analysis, Board of Govemors of the Federal Reserve System.

These factors support the inference that macro-financial signals of future market movements were suppressed in the 1970s. Moreover, it is reasonable to speculate that the external shocks of the period further frustrated the ability of the economy to grow through debt build-up.

\subsubsection{International financial liberalization as an endogenous cause of macro- financial stability, foreign investment flows, and the GM}

Securitization also increased the globalization of finance, freeing assets from national boundaries (Wray, 2009). This led to a number of global imbalances. These imbalances include sustained periods of current account deficit in which deficit countries sustained high and rising national currencies relative to net saver countries. This was true of the US as the issuer of the global medium of exchange (D'Arista, 2009). The US dollars' status as the world's primary reserve currency fostered ballooning deficits in the net borrower countries because they had been unable to trade their way out of deficit through expanding exports stimulated by lower exchange rates. The excess foreign-held US dollar reserves created by US current account deficits needed to be recycled into US financial instruments for investors to receive a return. 
This depressed US interest rates, encouraging (often) consumption borrowing and, thereby, aggravated the US current account deficit further (D’Arista, 2009).

Deficits have been persistent for the US since 1983 (as shown in figure 9) with the exception of a slight surplus related to the recession of the early 1990s (Bibow, 2008). The aggregate level of household and national debts has grown through a long period of economic expansion. Kindleberger (1989) identifies the Duesenberry effect, an asymmetric consumption response to changing income levels. This manifests as a lesser proportional decrease in consumption with declining income, relative to consumption increases on increasing income. Further, the Duesenburry effect confounds the assumption that liberalized capital flows would, when primarily directed by market forces, gravitate to their best and highest uses. The notion of flows going to the "best and highest use" would appear to entail capital gravitation towards less capital-sufficient countries.

Collectively, the risks described above were compounded by the Central Banks' commitments to low inflation. Short term interest rate responses to signs of elevated inflation helped ensure the containment of inflation and also reduce the risk of rising future interest rates. Previously, the case was made that changes in the labour market, and labour/capital power relations, aided the containment of inflation. This effect was reinforced by foreign investor perceptions of a credible US Central Bank commitment to low inflation. Low interest rates were reinforced by the acceptance of overseas investors who essentially used the US dollar as a hedge against the volatility demonstrated in their own (Asian and Russian, respectively) currencies in the 1997 Asian crisis and 1998 Russian crisis. In particular, Asian countries have historically used the US dollar peg to constrain inflation, essentially free-riding on US price stabilization monetary policy (McKinnon and Schnabl, 2004). Independent of their trade position vis a vis the US, inter-regional trade competitiveness concerns prevented individual currency appreciations against the US dollar. Beyond a relative decline in their trade position, significant losses would arise from large US dollar asset holdings (McKinnon and Schnabl, 2004).

Cabarello, Farhi, and Gourinchas (2006) argue that the imbalances in capital flows into the US are responsive to US markets' advantage in the creation of financial 
assets, and thus, do not imply imbalance, the US advantage is comparative and the comparator may be considered nascent as a result of the speed of development in a number of countries. Dooley, Folkerts-Landau, and Garber (2004a; 2004b), argue that a long period of US current account deficits is sustainable, without a significant decline in the dollar. Against this, Muusa $(2003 ; 2004)$ contends terminal limits to accumulated external liabilities must exist, probably at levels significantly lower than $100 \%$ of GDP. Cooper's (2008) position is that equity supply constraints result in an overdependence on price intermediation, while decreasing supply. Simply, on this view, rapid growth in emerging economies has led savings to outstrip financial market development in those economies. The result has manifested in the global asset boom of recent years, with pervasive low yields, including interest rates. This, in turn, has established sufficient conditions for a consumption-fuelled boom, led by the US. This provides a further reason for this thesis' focus on the US market and economy. A perverse feature of this environment is that rising equity prices actually contract equity supply, and the more strongly they rise, the stronger the supply contraction (Cooper, 2008). This is supported by a progressive increase in debt as prices rise, and the real economy grows. This lends support to Minskian analysis that preferences turn to debt over booms as lender and borrower margins contract.

The 'Twin Deficits' of the US, the government deficit and the current account deficit, have arisen over the GM as a significant threat to economic stability (Edwards, 2005). To this, the previously described rise in household debt can be added (Cynamon and Farazzi, 2008). Since the late 1990s in the US, the previous rapid increase in private investment of the early to late 1990s was substantially substituted by a rise in US government deficit spending and, subsequent to 2000, a debt-fuelled consumption boom (Edwards, 2005). Rising debt levels pose the risks described by Minsky (1986) to economic stability as growth in debt stocks requires unreliable assumptions of increased future income if they are to be stable. Progressively, over the GM, asset markets have risen to become highly vulnerable to any threat of endogenous price volatility, including shifts in sentiment. Interest rate resets to higher levels on subprime mortgages following initial teaser rates, resulting in increased loan defaults, may have been sufficient to destabilise asset markets (Cynamon and Farazzi, 2008). Asset markets' stability (housing and stock) became dependent on continuing asset price rises as is a characteristic of Minskian ponzi debt-financed projects (Minsky, 1986; 1992). 


\subsection{Errors in regulation}

Laissez faire proponents have raised the case that financing innovations which increased instability in the financial system were brought about largely by the Community Reinvestment Act (CRA) (1977) (Wallison, 2009). This argument is the 'inept government intervention' argument for financial market and economic dysfunction. This legislation required banks to 'democratise' debt, extending homeownership to disadvantaged minorities. This was initially vaguely specified but was reinforced by the 1990s affordable housing mission adopted by Congress. The difficulties and expense of enforcing loan contracts even where States allowed lenders to seek security of greater value than the mortgaged property, effectively allowed mortgagees to walk away from 'underwater' mortgages. Basel 1 further stimulated property overinvestment by defining adequate bank capitalisation as $8 \%$ of the riskadjusted loan. For AAA-rated mortgage-backed securities (MBS) the $8 \%$ reserve requirement related to $20 \%$ of the security's value, or just $1.6 \%$ of the total. Collectively, these factors form the basis for Wallison's (2009) view that government interference caused the sub-prime crisis. He tells us that favourable terms offered to CRA borrowers had to be extended to 'conforming' ${ }^{18}$ borrowers, heightening financial risk.

Against Wallison's position Stiglitz (2009) views banks as the primary 'villains'. This blame is qualified by the argument made earlier in this chapter (and also by Stiglitz), that a competitive financial sector compelled banks to leverage highly in search of returns in order to support their share prices. Stiglitz (2009) notes that a lower percentage of CRA mortgages were defaulted on compared with conforming loans. Fannie Mae and Freddie Mac were principally suppliers of conforming loans which were substantially responsible for the scale of losses at both companies. Moreover, if Wallison's priority was to isolate the causes of the sub-prime crisis, rather than pursuing an ideological aversion to regulation, it is unclear why he neglects to mention the Taxpayer Relief Act (TRA) (1999), which excluded houses under $\$ 500,000$ from capital gains tax (Gerstad and Smith, 2009) and the house price inflation this created. These factors were compounded by the ability of the financial sector to

\footnotetext{
18 'Conforming borrowers' describes those mortgagees who met existing acceptable levels of creditworthiness criteria.
} 
securitise (sell on) mortgages, increasing the moral hazard at the point of mortgage origination. ${ }^{19}$

Independent support is available for Stiglitz's (2009) position in Acharya and Richardson's (2009) identification of banks' actively 'gaming' financial market liberalization. The development of off-balance sheet entities in which to house guarantees to investors in mortgage backed securities (MBS) supports the view that banks' priorities were to defeat capital adequacy regulations. Banks described the guarantees they provided on the MBS they initiated as 'liquidity enhancements' which, under Basel 1, were required to be of less than one year in duration. Yet they continually renewed these guarantees for further periods of less than one year. Essentially risks became concentrated in banks, a position banks needed to continue to support to sustain the securitization (or 'initiate and distribute') market. Further, the mortgages were designed to reset after a period, leaving the bank 'long' property in the event the market failed to continue to rise. This scenario is archetypical of a Minskian ponzi debtdominated economy. In this light the sustenance of the economy depended on the continuing appreciation of the housing market (Acharya and Richardson, 2009). In Minskian terms sustained above historical trend growth requires the support of a progressive gravitation towards a ponzi debt-dominated economy.

Shiller (2012) in Finance and the Good Society argues that errors in regulation were the central cause of the sub-prime crisis and subsequent global recession. His case is based on the failure to license mortgage brokers before the GFC and a lack of regulatory restraint of mortgage providers promoting adjustable rate mortgages (ARMs). These factors inter alia incentivised mortgage providers and brokers to encourage borrowers into potentially unaffordable home loans. Despite regulatory changes such as the 2010 Dodd-Frank Act that addressed a number of problems that led to the crisis, Shiller (2012: 51) notes that, "There remains much in....issuing a mortgage that simply cannot be seen or policed by the government". A further point noted by Shiller (2012) is that regulators may have been captured by large companies

\footnotetext{
${ }^{19}$ Notably, because banks had to offer guarantees on lower rated tranches of securitizations and also because they had to continue to 'roll over' these guarantees to support the market, it is arguable moral hazard was less of a factor than may be implied from the ostensible removal of securitised mortgages from bank Balance Sheets.
} 
and that politics was important to policy maker failure to identify the coming crisis. $\mathrm{He}$ notes that few major policy making bodies around the world warned of the pending crisis although some did acknowledge that risk was 'to the downside'.

Despite Shiller's (2012) 'apologia capitalist financial infrastructure' he acknowledges a number of pervasive forces that seem to support the inevitability of a system break down. Policy makers besotted with the status or prestige of large and prominent companies, brokers and lenders incentivised to extend loans to borrowers representing poor credit risks, borrowers (presumably en masse) who were too witless to appreciate that interest rate resets following a 'teaser' period would render their mortgages unaffordable, and credit agencies undemanding ratings' criteria in euphoric markets seem to be systemic failures described by Minsky's (1986) euphoric phase. While no particular feature of the period can be described as inevitable it is more reasonable to infer that the general permissiveness of financial system regulation may have been so. To suggest that this confluence of factors was a consequence of isolated or idiosyncratic errors which, although unfortunate, are not endogenous is doubtful. We would need to enquire why such 'errors' were so heavily biased to the support of the economic expansion and why they systematically increased risk. Shiller seems to be, at least in part, motivated by a desire to re-dress the recriminatory tendency to throw the 'baby out with the bath water'. From this base he is arguably too liberal in discounting systematic errors. However, Shiller's (2012) argument that stronger regulation could serve to constrain cyclical excesses to an extent is fundamentally reasonable.

\subsection{Summary}

The discussion in this chapter is developed from Minsky's (1986) view that market-based economies and stock markets are endogenously unstable and that financial institutions, influenced by competitive market pressures, are central to this instability. The GM period is considered to identify the generally under-recognised role of financial sector deregulation as an important cause of the GM. Unlike more common explanations involving structural changes in the economy, the absence of large external shocks, and monetary policy effectiveness, the role of financial liberalisation lends itself more readily to the end of the GM and the subsequent dysfunction of markets. 
The period was further 'smoothed' by globalization and the flow of cheap money into the US. Seen as a safe haven, particularly in the aftermath of the 1997 Asian financial crisis, the US attracted substantial capital inflows of cheap debt capital. The 'hedge' value of the US dollar meant that foreign investors required modest returns only (Perelstein, 2009). This low-interest finance substituted for domestic savings which declined to historically low levels in the 2000s. Coupled with this the investment boom of the 1990s gave way to a consumption boom in the 2000s. The consumption boom was further supported by rapid house price inflation which created 'wealth effect' consumption spending as homeowners borrowed against the increasing equity of their houses to consume (Greenspan and Kennedy, 2007). The broad environment of low interest rates further fuelled these developments.

Evidence of the progressive deregulation of domestic and international financial markets is combined with evidence of growing credit (debt) levels to advance the case for a Minskian interpretation of business and market cycles. Further, inevitability is identified in developments in financial sector regulation and monetary policy over the period. This general proposition supports the relevance of debt as a variable that is central to the operation of modern business cycles and cycles in stock markets. Debt finance is a substitute for owners' equity so it follows that equity is also important. The potential relevance of corporate debt and equity flows, their relationship to each other and money prices (interest rates) are also indicated. Variables developed on this basis are employed as test variables for the development of market forecast models and are central to the extension of theory of corporate financial structures advanced in this thesis.

The evolution of the modern economy and its financial markets has undermined elements of Minsky's (1986) FIH. When combined with observation of modern-period corporate debt and equity flows and the relationships between these flows and the level of the US stock market a foundation is established for modifying Minsky's focus on elevated corporate leverage levels at point in the business cycle in favour of a focus on flows. The short term market forecast focus of this thesis further recommends the inclusion of technical variables in forecast models, including market price and trading volume histories. 
Chapter five relates the inefficiency of markets outlined in chapter two to the endogenous macro-financial volatility identified in this chapter with implications for corporate financial structures. This extension involves positing an explanation for observed stock market macro-financial flows that provides a more compelling fit with those observations over the period 1980-2011 than existing theories of corporate financial structure and preferences do. 


\section{Chapter five: locating this thesis in contemporary corporate financing literature}

\subsection{Introduction}

This chapter develops a theory about cycles in external corporate financing flows. This is both intrinsically important as an addition to existing theories of corporate financing and also as the basis for identifying systemic risks to aid market forecasting. These cycles in company financing flows correlate moderately with asset market cycles. Starting from a foundation of Modigliani and Miller's (1958) (hereafter MM) investor indifference to corporate financial structure, developments in corporate financing theory are surveyed. A macro-financial gap in theories of corporate financial structures is identified and an alternative explanation is developed. Beyond the contribution this makes to our understanding of corporate financing structures and preferences, this chapter continues to build the case for isolating corporate debt and equity flows as important indicators of future market movements. Corporate financing flows' variables contribute to model development in chapters six and seven.

The period from the early 1980s reflects a pro-(market)-cyclical preference for debt substitution of equity as the primary source of external corporate financing. This observation has not been explained by existing theories of corporate financing preferences and behaviours. Cooper (2008) observes that corporate debt and equity flows move counter to observed movements in goods markets and also counter to conventional theoretical expectations. Rising equity prices appear to correlate with corporations' increasing share repurchases, from a position of net equity issuance at points after more severe market breakdowns. Therefore, it is reasonable to infer that rising share prices are the catalyst for share repurchases. However, this initial causal relationship must logically create a feedback loop in which share repurchases fuel further share price rises as they create an independent source of demand. This may be expected to manifest in further share price rises and, thereby, alter the supply/demand equation systematically as those share price rises become progressively more substantial with the progression of market booms.

Conventional theories of corporate financial structure and corporate financing preferences find little support in the evidence presented in graphs 2.0 and 2.1. These 
graphs depict cycles in corporate debt and equity flows, with debt closely mapping market movements and equity flows moving counter to the market and debt flows. This is identified in greater detail in chapter two, section 2. 0 .

Trade off theory and pecking order theory do not provide compelling explanations for the empirical observations of pro-cyclical corporate debt substitution for equity. Likewise, MM are only able to explain contemporary corporate financing flows' observations by treating retained earnings and asset revaluations as identical to (external) equity finance. While the identity may be substantially true of retained earnings it is less clearly so of asset revaluations as a de facto substitution of these, for external equity increases the vulnerability of corporations to asset price declines. Moreover, as noted by Baker (2009), the sustainability of retained earnings is at least partially endogenous with rising markets and buoyant economies.

It is necessary to have a sound theoretical basis to our understanding of corporate financing structures if we are to understand the range of important factors determining those structures. Such a theory must provide a good fit with observations. In light of pro-market cyclical corporate external debt financing preferences (over equity) implications are that ensuing EPS dilution and the issue of current shareholder wealth maximisation are important considerations in corporate financing decisions. Further, the 'factual' basis for these priorities and the mechanism for achieving them are extrapolative expectations; the belief that recent historical share price trends will continue in the foreseeable future. This default assumption precludes future market collapses. The persistence of this failure to extrapolate from longer term historical performance, which supports the persistence of cycles in asset prices, sees corporations forced by market crashes and sustained lower average market prices to consolidate their balance sheets with the issue of expensive (in the period of substantial market declines) new equity. In simple terms, there is a strong market pressure to treat equity gains caused by rising markets as permanent up to points of market collapse. This process mimics Minsky's (1986) view that investment more generally gravitates towards elevated risk and that extended market rises become supported by continuing asset price rises only. Any theory of corporate finance must 'fit' these facts to either a very short term optimisation explanation of corporate finance or with systemic, aggregate corporate financing 'mistakes'. The mistake is plausibly more of a temporal mismatch 
in the relative contributions of corporate debt and equity financing caused by competitive pressures to perform and short term management incentives, against more persistent corporate finance structures.

The approach adopted here to testing these theories is based on deductive inferences drawn from empirical evidence. The case is argued that conventional corporate finance theories fail to adequately explain observations of macro-financial corporate external financing (debt and equity other than retained earnings or from the sale of fixed assets) in the period 1980-2011 and that these can be better explained within a Minskian extrapolative expectations framework. This thesis makes the case that conventional theories of corporate external financing flows are inconsistent with all but the most 'strained' interpretations of the observed flows. The hypotheses identifying this issue are:

HO: Existing theories of corporate financial structures fully explain corporate macro-financial flows in the US in the period 1980-2011.

H1: Existing theories of corporate financial structures offer incomplete or incorrect explanations of US corporate macro-financial flows in the period 1980-2011. That is, observed cycles in corporate debt and equity macrofinancial flows are inconsistent with existing theories.

Hla: Deductive inference supports an alternative Minskian interpretation of observed corporate macro-financial flows: that prior market price trend extrapolation supports corporate preferences for debt or equity at different points in market cycles.

Each of the key existing theories of corporate financial structure is now analysed in sections (5.1-5.2.6). Empirical evidence relating to the theories is identified in section 5.3 and the tension between existing theories and modern-period empirical evidence is presented in sections 5.3-5.4. An alternative theory is developed in section 5.5. 


\subsection{The Modigliani-Miller 'indifference' theorem as a starting point in corporate financing research}

Preceding Modigliani and Miller's (1958) publication of 'The cost of finance, corporation finance and the theory of investment', finance as a field of academic enquiry lacked a theoretical basis. This publication can, therefore, be viewed as the genesis of finance as a distinct academic discipline. Subsequent to the publication of their theory much of the research in this area has focused on the proof, disproof, or qualification of Modigliani and Miller's 'indifference' theorem. Similarly, much of more recent theoretical development in finance is rooted in their research and its conclusions, lending greater specification to the original theory.

Figure 10: The value of the firm in relation to corporate financing and risk and return under the Modigliani/Miller indifference theorem

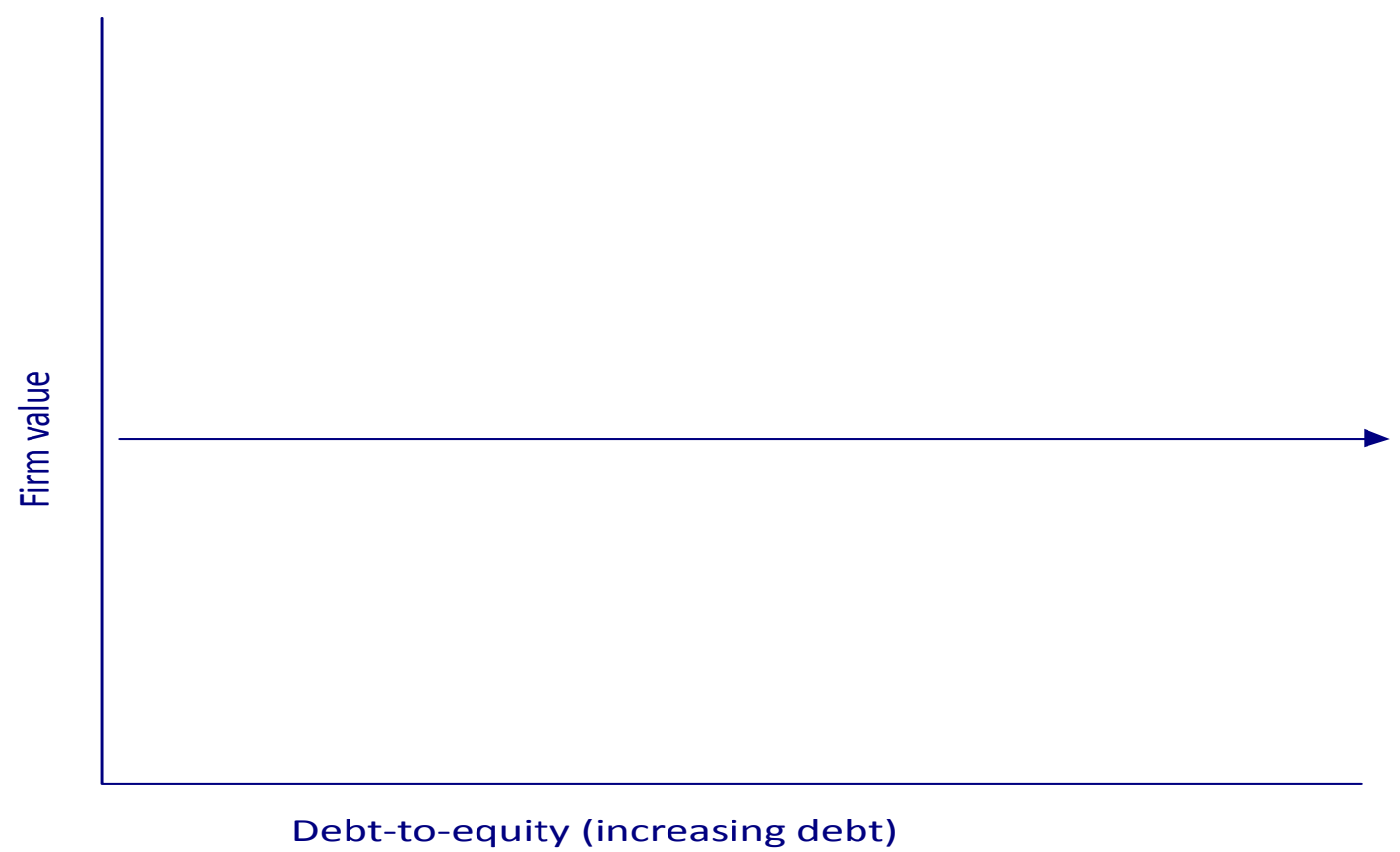

Figure 10 depicts the MM contention that corporate financing structures are a matter of indifference to investors in their valuation of firms. Risk and return offset each other so that the higher expected returns attributable to higher levels of corporate debt will not increase the value of the company due to the increased riskiness of the firm. The graph depicts a unitary relationship between risk and return and assumes debt levels are 
equivalent to total risk. Theoretically any of a spectrum of financing structures is, therefore, implied and a corporation's preference of debt or equity is simply one of where it wishes to position itself in terms of risk and reward.

MM states that investors are indifferent to a company's combination of debt and equity finance and they will value a company identically, regardless of its financial structure. In terms of two hypothetically identical firms, the addition of (comparatively) low-cost debt finance to existing equity finance for one of the firms should have no implications for the value of that firm. ${ }^{20}$ The expectation of higher returns from leverage is offset by investors' demands for higher returns as compensation for the elevated risk that arises due to the priority of debt claims. An implication of this is that an investor could achieve the same results by investing in the all-equity firm and individually borrowing against that holding as though they had invested in the debtequity firm (Weston, 1989; Modigliani and Miller, 1958).

MM, separately and together, developed their original theory to include related or derivative propositions that leverage has no affect on the weighted average cost of capital (WACC). A further proposition is that investors are indifferent to the dividend policy of a company (Miller and Modigliani, 1961). Together, these propositions constitute the elements of the MM theorem.

MM assumes that internal and external sources of finance are perfect substitutes with representative firms responding to prices in centralised securities' markets. Moreover, sources of finance are uniformly available at prices that reflect the fundamental value of future cash flows (Modigliani and Miller, 1958). This availability eliminates credit rationing and price (interest rate) variability. On this basis Minsky's (1986) notion of corporate (and wider economy) financing as an endogenous source of financial fragility and instability does not and cannot arise as systemic asset mispricing caused by credit availability or changes in the relation of debt-to-equity financing is assumed away. Thus, MM and Minsky's $(1986 ; 1992)$ FIH are mutually exclusive as

\footnotetext{
${ }^{20}$ The equity premium entails that debt is cheaper as long as there is an equity 'wedge' underlying corporate indebtedness. Notionally, debt would require the equity premium of a company that was $100 \%$ debt funded (assuming a homogenous priority of creditor claims on the company's assets). It is in the differential priority of debt holder and equity holder claims on a company that determines the relatively lower cost of debt.
} 
Minsky argues that cyclical changes in corporate financial structures are a key source of instability.

Further assumptions of MM include inter alia, that: no transaction costs exist, corporate limited liability has no impact on the optimisation of corporate financing structure (Durand, 1989; Weston, 1989), that markets are efficient and, thus, eliminate information asymmetries that might otherwise result in differential borrowing costs between the company and the individual, and that there are no taxes (Villamil, 2008). Qualifications to MM are typically structural in nature, entailing an upward (left to right) slope to the curve in graph 5.0. So, for example, assuming a tax advantage to debt financing a structural preference for debt is created, causing the curve to slope up.

Gordon (1989) describes the role of tax, corporate limited liability and institutional constraints on individual investors' borrowing for equity investment as constraints on the realism of MM. Tax impacts financing decisions of companies (due to its impact on investor preferences) to the extent of the differential between the (effective) personal tax rate and corporate tax rate due to corporate interest tax deductibility. Further, institutional constraints on individual borrowing for equity investment limit such borrowers to relatively high-cost margin loans, structurally favouring corporate leverage over 'homemade' leverage (where the investor assumes a proportion of debt for the purchase of all-equity companies).

Gordon (1989) considers the potential for signalling equity overvaluation as a consequence of issuing new equity. This argument underpins what became pecking order theory (further discussed in section 5.6). The signalling theory implications drawn by Gordon (1989) are based on the view that information asymmetry leads investors to interpret a new equity issue as evidence that insiders regard the company as overvalued. For this reason, as well as because of the increased supply of equity, rights issues (seasoned public offerings or SPOs) frequently depress stock prices. The market will re-adjust the share price and total equity value of the company down (before accounting for the value of the new equity raised) if a corporation seeks new equity. He argues that company leverage predates company taxation and that, therefore, the tax treatment of debt cannot provide a complete explanation for the use of leverage. 
The caveats or deviations from the assumptions of investor indifference to debt or equity financing of businesses are predictable of the stylized model (Miller, 1988). It is in the factors causing deviation, including: transaction costs, taxes, agency costs, sub-optimal managerial compensation contracts, information asymmetry and insufficiency (Stiglitz, 1988; Greenwald, Stiglitz, and Weiss, 1984), and taxation effects, that biases may structurally disrupt MM assumptions, changing the curve from flat to rising with increased debt. This qualifies investor indifference when one or more of MMs assumptions are violated. Research qualifying MM indicates that corporations may structurally prefer debt (or equity). However, notwithstanding the possibility of a change in structural factors that could lead to changes in optimal leverage levels, external financing cyclicality finds no reasonable explanation in structural qualifications to MM. As discussed in section 5.4, cycles in corporate external financing require an alternative explanation(s). That is $\mathrm{MM}$ must be qualified beyond the structural qualifications to account for cyclical changes in corporate financing sources as structural qualifications do not entail volatility in the MM curve, but that its accent changes.

\subsection{Theories relating to the role of company-specific factors in corporate financing}

A number of distinct theories have been developed since the beginning of the 1980s about company-specific factors determining corporate financing preferences. Within a broadly MM framework, greater specification has been given to factors influencing the risk and return profiles of companies other than the composition of a company's external financing or total financing. Factors such as company size, profitability, cash flows, and the stability of these and profits, were identified as important influences of corporate financing preferences (see: Titman and Wessels (1988) for an overview). These factors have been found to influence the debt to equity ratios of companies in successive research, supporting the view that the trade off between risk and reward is determined by a wider range of variables than is implied by MM. However, the MM implication still holds that two otherwise identical companies, distinguished by different financial structures only, would be valued the same by the market. MM indifference is to finance structure based on the equivalence of risk to return throughout the range of possible leverage levels of companies. 
Theories about factors driving corporate financing structures developed in the 1980s include the research of Bradley, Jurrell, and Kim (1984), Brealey and Myers (1984), Jensen and Meckling (1986), and Titman and Wessels (1988). Each of these theorists focuses on the dynamics determining company supply of corporate equity issues. Warner (1986) finds evidence that direct bankruptcy costs are higher for smaller companies. Bradley, et al, (1984) isolate the importance of earnings volatility on corporate debt and equity preferences and Titman (1984) finds that specialised assets reduce the propensity of corporations to incur debt. Each of these company-specific factors has found recurrent validation in empirical research, suggesting such results are largely uncontroversial. Evidence supporting the role of company size (amongst other factors) is identified in this section in the research of Frank and Goyal (2007).

Jensen (1986) argues that asymmetric information, agency risks, and incomplete contracts, entail that debt serves as a tool for disciplining management. This theoretical view is essentially an agency theory of corporate financing or, as Jensen (1986) refers to it, the free cash flow theory of corporate financing. Jensen's theory is based on the argument that free cash flow is a central driver of agency risks as management is able to 'empire build' and enrich themselves if free cash flows are high. Frequently management remuneration is tied to company metrics such as sales, incentivising management to retain earnings to build sales. In contrast, higher levels of debt (and dividends or share repurchases) discipline management by requiring them to undergo monitoring by the market at points of the alternative source of financing, new equity issues. In addition, Jensen's (1986) view indicates that share repurchases are value additive for agency reasons as well as for direct improvements they create in terms of enhanced earnings per share (EPS). In relation to dividends Easterbrook (1984) provides support for the free cash flow interpretation arguing that otherwise inexplicable dividend payments require companies to access capital markets for finance where monitoring costs are lower than would otherwise be the case. This is particularly true in the case of mature companies as it prevents investment in projects with low returns.

Jensen and Meckling (1976) suggest that firms with high debt and limited liability are incentivised to take on risky projects as they effectively transfer a quasiequity-level of risk to debt holders. Allowing this, and in terms of positioning free cash 
flow theory amongst other theories of corporate financing it implies a preference for debt. Although it may be viewed as a normative theory of corporate finance, with the addition of Jensen's (1986) implied assumption of market efficiency, it has become a quasi-descriptive theory of corporate finance. This is arguably a specific theory of mature company financing preferences and optimisation which cannot tell us of the constraints on optimisation, including Jensen's own preference for Employee Share Options (ESOs) as a control on agency costs (Roberts, 2001). Equally, the theory tells us nothing about transaction costs as a limiting factor in terms of growth companies. Further, as with other conventional theories of corporate finance, the free cash flow theory of corporate financing does not explain why euphoric market conditions require the greatest constraint of agency costs (indicated by increasing debt assumption and equity repurchases) yet those constraints dissipate upon market crashes. In contrast to MM, Jensen (1986) advances an implicitly normative theory of corporate financial structure with debt operating as a management disciplining mechanism. Minsky's (1986) FIH would view debt (or increasing debt) as evidence of moral hazard and growing risk to economic and market stability. So, in effect, Jensen argues that debt disciplines companies' management as management need to present their investment case to the market to raise new equity from investors. Conversely, Minsky (1986) views rising debt levels as a function of euphoria, the surfeit of new investment opportunities that arise in expanding economies, and the systematic mis-pricing of risk as reflected in rising asset prices and low interest rate risk premiums.

Minsky's (1986) FIH links cyclical debt increases to symptoms of moral hazard. As markets expand profitable opportunities increase but in the late stages of an expansion increasing risk must be accepted to continue to profit as the more opportunities become saturated with investment. These conditions foment further risktaking and errors in risk assessment based on extrapolation from past returns. By relating high levels of corporate debt to expansion-period validation of past debt contracts, through the performance by debtors of obligations under those contracts, it is reasonable to infer a Minskian notion that corporate over-indebtedness is a more general feature of 'euphoric' markets. By adding these features to the corporate rebalancing of its financing structure relative to market value (Roberts, 2001) a further basis to infer bubbles arises. 
A number of researchers (including: Friedman, 1985; Clark and Sunley, 1989; Mitchell, 1983; and Bodie, 1989) contend that corporate leverage has been steadily increasing. Mitchell's (1983) research observed increases in corporate debt and declining reliance on new equity between 1960 and 1980. Clark and Sunley (1989) observe a stable relationship between US corporate debt to GNP from 1969 to 1983 at $30 \%$ of GNP, followed by an increase to $37 \%$ of GNP in the five years to 1988 . These researchers do not infer market imbalance in these developments but, rather, that there has been a structural shift in preferences for the level of debt economy-wide. Clark and Sunley provide context by identifying a more general reliance on debt across the economy, with even greater increases in household and government debt relative to GNP when compared with increasing corporate reliance on debt finance. Mitchell (1983) notes that although corporate debt levels to book values have 'deteriorated' (that is, debt has increased relative to book values which are based on historical cost accounting) if market values are used as a comparison then the extent of the increase in corporate reliance on debt is appreciably less than it appears. Mitchell also notes the lower relative cost of debt when compared with equity over the period (1984-1989), inferring companies have made a rational response to prices. ${ }^{21}$ In addition, Bodie (1989) identifies the role of defined benefit pension funds' incentives to match their liabilities with long-dated debt instruments as a demand driver of increased corporate debt issuance. Corporations respond to new demand as that demand drives the cost of debt down.

Recent empirical research provides support for many of the theories of corporate financing structures developed in the 1980s. Warner's (1986) argument that direct bankruptcy costs are higher for smaller companies corresponds with Frank and Goyal's (2007) findings that company size is an important and positive correlate of debt financing. Similarly, Bradley, et al's (1984) position that earnings volatility is negatively related to corporate debt funding implies that industry membership, found to be the most important determinant of corporate financing structure by Frank and Goyal (2007), remains important. These factors are micro-structural qualifications to

\footnotetext{
${ }^{21}$ This assessment of the relative cost of debt and equity is made ex post and without an evaluation of bankruptcy costs (risk). Alternatively, the implication of Mitchell's observation is that the market was dysfunctional.
} 
MM that cause a change in the slope of the MM curves of individual companies, relative to each other. Again, they do not explain volatility in the curve.

\subsubsection{The broad theoretical frameworks of corporate financing structures}

Subsequent to Modigliani and Miller's (1958) seminal work in corporate finance, a range of corporate finance theories have been developed in a bid to better understand corporate financial structures, preferences, and motivations behind observed financing behaviours. Amongst these are trade-off theory, pecking order theory and market timing theory. Trade-off theory advances the case that corporations trade-off taxation advantages against deadweight bankruptcy costs in determining the optimal level of leverage to use in their financial structures (Kraus and Litzenberger, 1973). Pecking order theory advances the view that an adverse selection premium exists, with the greatest premium applying to equity as it has the greatest risk as a residual claimant. Debt involves the next greatest premium as it is buffered by the company's equity, and, finally, retained earnings have no premium. On this basis new investment will first be funded from retained earnings, then debt, and, lastly, equity (Myers and Majlauf, 1984). More recently, market-timing theory has been advanced as an important determinant of corporate financing decisions (Roberts, 1984; Hovakimian, Hovakimian, and Tehranian, 2004; Hovakimian, Opler, and Titman, 2001; Baker and Wurgler, 2001; and Welch, 2004). This theory argues that corporations time the market to exploit high stock prices by issuing new equity after run-ups in those companies' stock prices.

Each of these theories fails to fully explain empirical observations. The following sections outline the basic structure of the key theories of corporate financing. This forms the basis from which to identify a gap in existing theories (as depicted in figures 1 and 2). Trade off theory and pecking order theory have no explicit role for cycles in corporate financing structures, whereas market timing theory appears to misspecify the nature of the observed cycles in corporate financing preferences.

\subsubsection{Trade off theory}

Trade off theory states that companies trade off greater returns due to the tax advantages of debt interest deductibility against the greater costs of increased bankruptcy risk attached to the use of debt (Baxter, 1967). As a modification to MM it does not assume a constant relationship between debt-to-equity ratios and company 
value. The trade off is determined by idiosyncratic company-specific and industryspecific) features. However, trade off theory is a theory about corporate financing and, allowing that individual firms face particular tradeoffs and optimal debt levels, such optimal levels are (according to the theory) both identifiable and corporate financial structures converge on optimal debt-to-equity relationships (Kraus and Litzenberger, 1973).

Hackbarth, Hennessy, and Leland (2011) find evidence supporting trade off theory in corporate debt structures. Weak companies' debt financing is sourced wholly from banks whereas stronger companies use market debt and bank debt. This allows stronger companies to give seniority to bank debt and, thus, lower the interest cost of this source of debt. Further, in countries where the bankruptcy regime is 'soft', bank debt capacity is lower than in countries with robust regimes. However, it is notable that pecking order is also consistent with the evidence provided by Hackbarth, et al (2011).

Trade off theory may be 'fitted' to an explanation of cycles in corporate financing composition of debt relative to equity through the argument that successive debt contract performance, rising cash flows, profits and asset prices (and therefore collateral) all imply reduced bankruptcy risks. It argues that reduced bankruptcy risks balanced against increasing corporate tax liabilities on rising profits support a preference for debt during booms (Baxter, 1967; Kraus and Litzenberger, 1973). Booms fuel profit increases which also increase total tax liabilities that may be reduced by increasing borrowing. This provides tax deductible interest costs whereas dividends are not tax deductible (Shyam-Sunder and Myers, 1999). However, this argument is essentially circular as it implies a (non-existent) put option exists over past asset price rises. Further, it balances the benefits of price appreciation on company market values with fixed, typically long term debt liabilities. As the veracity of trade-off theory under such conditions hinges on extrapolation from past market movements to future movements, without an independent basis for that extrapolation, trade-off theory does not perform well at the point of market breakdown (See figure 14 and in the discussion in section 5.2.6). At or shortly after points of market collapse, if sustained for any length of time, heavily indebted companies must issue new equity at heavily discounted (compared with pre-crash equity) prices. Trade off theory cannot plausibly explain these developments without arguing against corporate finance optimisation. 
Furthermore, Miller (1977) argues that the trade-off implied in trade-off theory is between large and certain taxes and rare (and by his account) low deadweight costs of bankruptcies. At a theoretical level Miller implies the unbalanced nature of the tradeoff has little functional meaning, likening it to a horse and rabbit stew balanced with one horse and one rabbit.

Figure 11: Trade off theory and firm wealth maximisation.

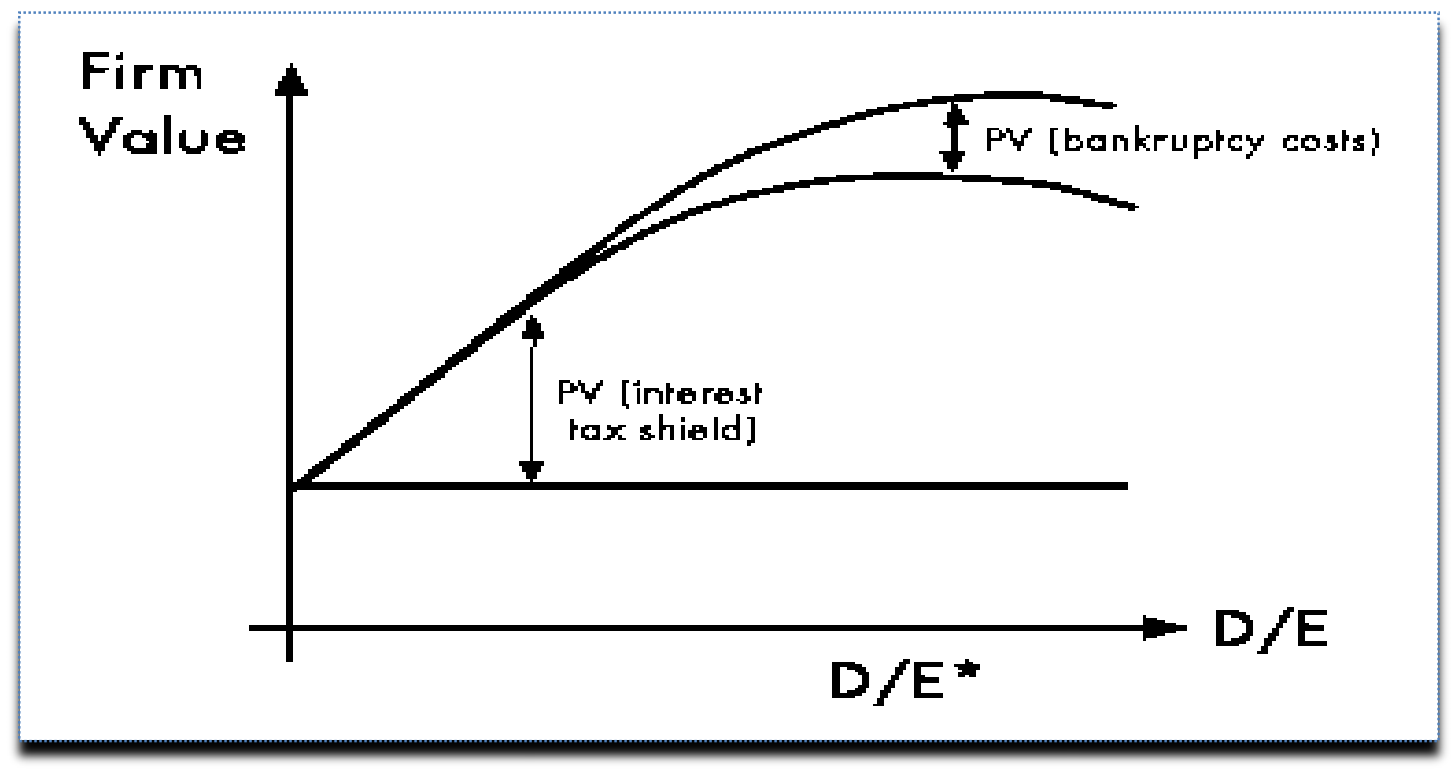

Source: Shyam-Sunder and Myers (1999). p. 220

Figure 11 shows a line parallel to the $\mathrm{x}$-axis which represents the trade off-theoretical view of the value of an all-equity company. The curve rising from the all-equity horizontal line shows that as debt increases relative to equity the trade off is altered between the tax shield provided by debt and (growing) bankruptcy risks (and costs). Initially, the introduction of debt increases the value of the company. Beyond the optimal debt level growing bankruptcy risks cause the increasing initial value due to debt to peak and then fall, as bankruptcy costs outgrow the tax benefits of debt. Debt and equity involve a trade off between risk and return with company value constant relative to different debt-to-equity ratios up to the point where bankruptcy risks (PV) exceed the returns' improvement attributable to the tax shield. ${ }^{22}$ This sees the

\footnotetext{
${ }^{22}$ The tax shield is created by the assumption of tax deductible debt. Tax deductions are allowed on interest payments whereas dividends are paid from after-tax profits. In essence, the tax shield effect, assuming efficient markets and an exhaustive tax 'net', equate to the differential between corporate and (investor) individual tax rates.
} 
divergence of the curves with PV of bankruptcy costs exceeding the tax shield. The optimum relationship between debt and equity maximises firm value is found at $\mathrm{D} / \mathrm{E}^{*}$, the point at which the present value of the tax shield effects and bankruptcy costs maximise firm value (or shareholder wealth in contemporary terms). Miller (1977) qualifies MM (1958) on the basis that the trade off is unequal. Relatively large and certain taxes are offset by small and rare deadweight bankruptcy risks, thus the tradeoff is one that broadly implies a preference for corporate debt financing. In terms of figure 11 Miller's (1984) view of the trade off would manifest in one or both of: the $\mathrm{DE}^{*}$ would be further to the right or a lesser fall in the curve after DE* would occur. It is also possible to infer that the decline in company value observed to the right of $\mathrm{DE}^{*}$ would meet the horizontal all-equity company valuation in a (hypothetical) all-debt firm.

\subsubsection{Dynamic trade off theory}

Dynamic trade off theory was developed in response to empirical challenges to trade off theory. The theory allows that companies may deviate from their target (optimal) capital structure but they will adjust towards the target. Evidence for this theory is found in relation to Malaysian companies by Abdeljawad, Nor, Ibrahim, and Rahim (2013). They find that companies further from their target financial structure (and particularly those more leveraged than is implied by the target) move towards their target faster than those which are closer to the target. Abdeljawad, et al (2013) note that this adjustment is slow and, so, does not preclude pecking order or market timing theories.

Danis, Rettl and Whited (2013) develop evidence for a dynamic trade off interpretation of corporate financing. The failure of traditional trade off theory to explain certain phenomena, including the frequently observed negative relationship between profitability and use of leverage, motivated the development of dynamic trade off interpretations and modelling. Danis, et al (2013) argue that evidence challenging trade off theory is substantially due to the failure of static models to account for rigidities in corporate financing dispositions. That is, corporate financing does not move with the speed or liquidity of inter alia asset price changes, so lags are expected. This conclusion finds support from Byoun (2008), Drobetz and Wanzenried (2006), and Elsas and Florysiak (2011). These traditional attempts to develop empirical 
evidence for a theory of corporate financing fail to account for debt issuance costs and the fact that lengthy periods of inaction in terms of corporate financing may be followed by large changes in leverage levels. Danis, et al (2013) find evidence that firms with higher profitability choose higher leverage levels and that there is a negative correlation between leverage and profitability when firms are not refinancing. After such periods of financing change inaction, more profitable companies also select greater leverage, further supporting the dynamic trade off approach. In essence dynamic trade off theory imputes lags into the trade off in corporate financing between bankruptcy risk and returns.

Danis, et al (2013) also note the correspondence of new corporate debt issuance with share repurchases, inducting this as evidence for the dynamic trade off model and periodic capital re-balancing. Against their interpretation, Cook and Tang (2010) find that there is asymmetry in the speed and extent of the rebalancing of corporate financing in poor macroeconomic conditions when compared with favourable macroeconomic conditions. Arguably then, the process of increasing debt and decreasing equity coincident with each other is better explained by extrapolative expectations. Further, as discussed later in this chapter, these expectations have a positive bias over long periods of expanding markets that involves costly adjustments in periods of subsequent market decline which challenges trade off theory's view of corporate finance converging on optimisation.

\subsubsection{Pecking order theory}

Pecking order theory holds that corporations avoid adverse selection premiums by first using retained earnings to fund new projects, followed by collateralised debt, then riskier debt, and finally equity (Myers and Majlauf, 1984; Myers, 2003). ${ }^{23}$ Companies' preference for internal financing is based on the role of information asymmetry and higher cost of external funds. The stickiness of dividends prevents dividend cuts as an alternative to increasing external financing in response to changes in cash flows. Companies' boards resist sudden changes in dividends due to signalling effects which, where dividend cuts are involved, may adversely impact investor

\footnotetext{
${ }^{23}$ Adverse selection premiums are risk-based premiums charged on equity as opposed to debt due to the greater risk of equity as a residual claim on a company. Risk remains for different strata of debt so there exists a lesser premium for debt, whereas retained earnings require no premium.
} 
expectations about future earnings and, thus, current stock prices. A further implication of pecking order theory is that an excess of external funds should result in the repayment of debt, rather than the repurchase of equity. Graham and Harvey (2002) identify corporate opportunism implicit in pecking order theory, noting that corporations will not issue under-priced equity but will issue equity when it is overpriced. Thus, equity issuance constitutes a signal that equity is overpriced.

Empirical research supporting pecking order theory includes the work of Shyam-Sunder and Myers (1999), who find that pecking order theory is more explanatory of empirical evidence than trade off theory. In particular, Shyam-Sunder and Myers find that pecking order theory has better power to explain corporate financing choices, including observed funding of anticipated and unanticipated capital needs with debt in preference to equity by companies. The strength of pecking order theory is not compromised by unanticipated (by the company) demand for debt funding, implying that corporations plan to externally fund with debt (Shyam-Sunder and Myers, 1999). Notably, Shyam-Sunder and Myers' sample is composed of mature companies with mean book-to-debt ratios of just $18 \%$ so preferences for debt over equity are readily explicable within a trade off theory framework as the sample companies would be expected, on average, to fall in the regions (on graph 5.1) of increasing company value from increased debt as they hold low levels of existing debt. Evidence for the pecking order and adverse selection may be found, also, in the positive relationship between company size and leverage levels (such as that found by Harvey and Goyal, 2007). It is predictable that larger companies with more diversified income streams have a lower adverse selection premium and, therefore, have higher levels of leverage. Conversely, this relationship supports the greater adverse selection risk in smaller companies, with lesser analyst coverage, and, therefore, greater information asymmetry. 


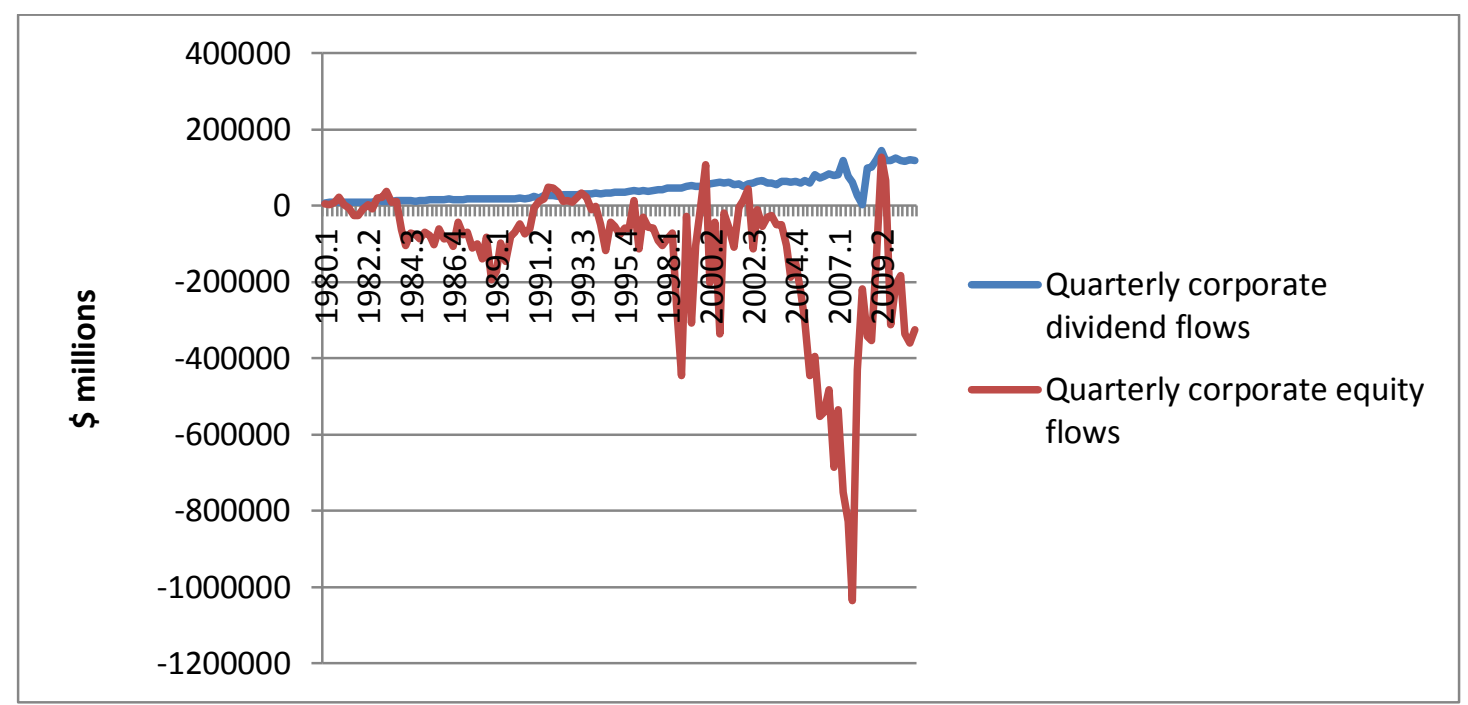

Source: Board of Governors of the Federal Reserve Bank, Z.1

Figure 12 indicates that US corporate dividend flows have increased in absolute terms over the period 1980-2011. There is a negative correlation between quarterly dividend and corporate equity flows, with a Pearson correlation value of -0.463 . This is significant at the 0.01 level (two-tailed). ${ }^{24}$ Also, much less volatility is observed in corporate dividend flows than in corporate equity flows and the respective volatilities are not systematically synchronous. In fact we only see substantial volatility in corporate dividend flows in the latter period, from 2005. (Dividend flow variance 1.014E9 against corporate equity flow variance of 3.633E10) No credible reason has been forthcoming for this heightened dividend volatility. Further, the relative size of the movements does not support inference to a substitution affect. An implication of this is that share repurchases are not substituted for dividends. That is, dividend yields may have declined for various reasons but they are unlikely, in the main, to have been replaced with 'quasi-dividend' share repurchases. The two phenomena do not appear to be strongly related. Furthermore, pecking order theory cannot cite an increase in retained earnings as a product of the 'pecking order' because that hierarchy of retained earnings, equity, and debt would be expected to be most subdued (or flatter) during periods of rising markets, yet declining dividends observe a secular trend. For these reasons it is implausible to argue that growing share repurchases are reliably,

${ }^{24} \mathrm{R}=0.463 ; \mathrm{R} 62=0.214 ;$ Adjusted $\mathrm{R}^{\wedge} 2=0.208$ 
systematically off-set by falling dividends. Therefore, the implication that cycles in corporate financing flows entail no cyclical increase in riskiness is unsound.

The decline in dividend yields appears to support a systematic shift towards financing determined according to pecking order theory. To the extent that greater retention of earnings supports new investment this outcome is consistent with the pecking order. However, pecking order theory cannot explain reversals of equity financing flows in periods of market decline. A key assumption of the theory is that adverse selection makes equity the most expensive form of finance and therefore the one least likely to be used. The theory does not offer a credible cause for the reacquisition of this expensive finance in periods of buoyant markets because the adverse selection hurdle has already been negotiated by the original issuance of that capital. It may explain why companies with distressed Balance Sheets need to issue new shares in periods of market decline and economic recession but, again; it is challenged in its assumption of cost-based company financial structure optimisation by observations of recurrent sub-optimal outcomes. These are reflected in large post-crash dilutions of existing equity stakes in the company and, frequently in such an environment, by company collapse.

Despite a long term increase in corporate financing reliance on internallygenerated funds, whether for stock repurchases or new investment, pecking order theory is a general theory of corporate financing rather than one that explains the changes in corporate financing since 1980. Any theory of corporate financing structural preferences must include a role for cyclical factors as an important consideration. Equally, this theory performs poorly if tasked to explain why long periods of broadly rising markets (and consequent high equity prices) result in accelerating share repurchases (as shown in figure 15). A basic assumption of pecking order theory must be that adverse selection premiums are approximately minimised at peak market prices for a company's (and the market's) stock (index level). In addition to these concerns Frank and Goyal (2003) find evidence that the deficit between internal funds and new investment in the US from 1971-1999 was tracked closely by equity issuance. This evidence raises doubts about a hierarchy of corporate financing preferences that favours debt over equity. Similarly, they find that pecking order does not apply to small companies, where information asymmetry is likely to be greatest and, therefore, 
theoretically most likely to reflect the identified pecking order. These considerations support the position that pecking order theory provides a poor fit with observed cycles in corporate debt and equity financing.

Certainly, in an era of declining dividend yields (which are now stable, but at historically modest levels of around 2\%) (Standard and Poors, 2013) retained earnings play an important role in corporate financing of new projects (See figure 13, below). Brav, Graham, Harvey and Michaely (1985) observe a trade-off or complementarity between share repurchases and dividend payments' value. An extensive body of research has focused on reasons for the decline in dividends and contemporaneous increase in share repurchases. A standard assumption is that there must be rational causes for these developments. Such research includes that of Fama and French (2001), who cite improved corporate governance, and reduced share transaction costs. Brav, et al (1985), writing near the beginning of this development, argue for the greater flexibility afforded corporations through share repurchases as they are able to tailor those repurchases to price by setting a limit on them rather than a targeted level of equity. Share repurchases also allow companies to time the market when re-acquiring stock. Other posited causes include a tax-induced substitution effect. There has been little compelling evidence presented for the tax effect, with Brav, et al (1985) citing only $21.1 \%$ of surveyed corporations identifying this as important in their decisions to prefer share repurchases. Further, the succession of Tax Reform Acts (TRAs) in the US since 1983 has, on balance, reduced the differential treatment of capital gains and dividends, reducing the tax disadvantage of dividends. 
Figure 13: The secular decline in modern era US corporate dividend yields and its relationship to market index changes.

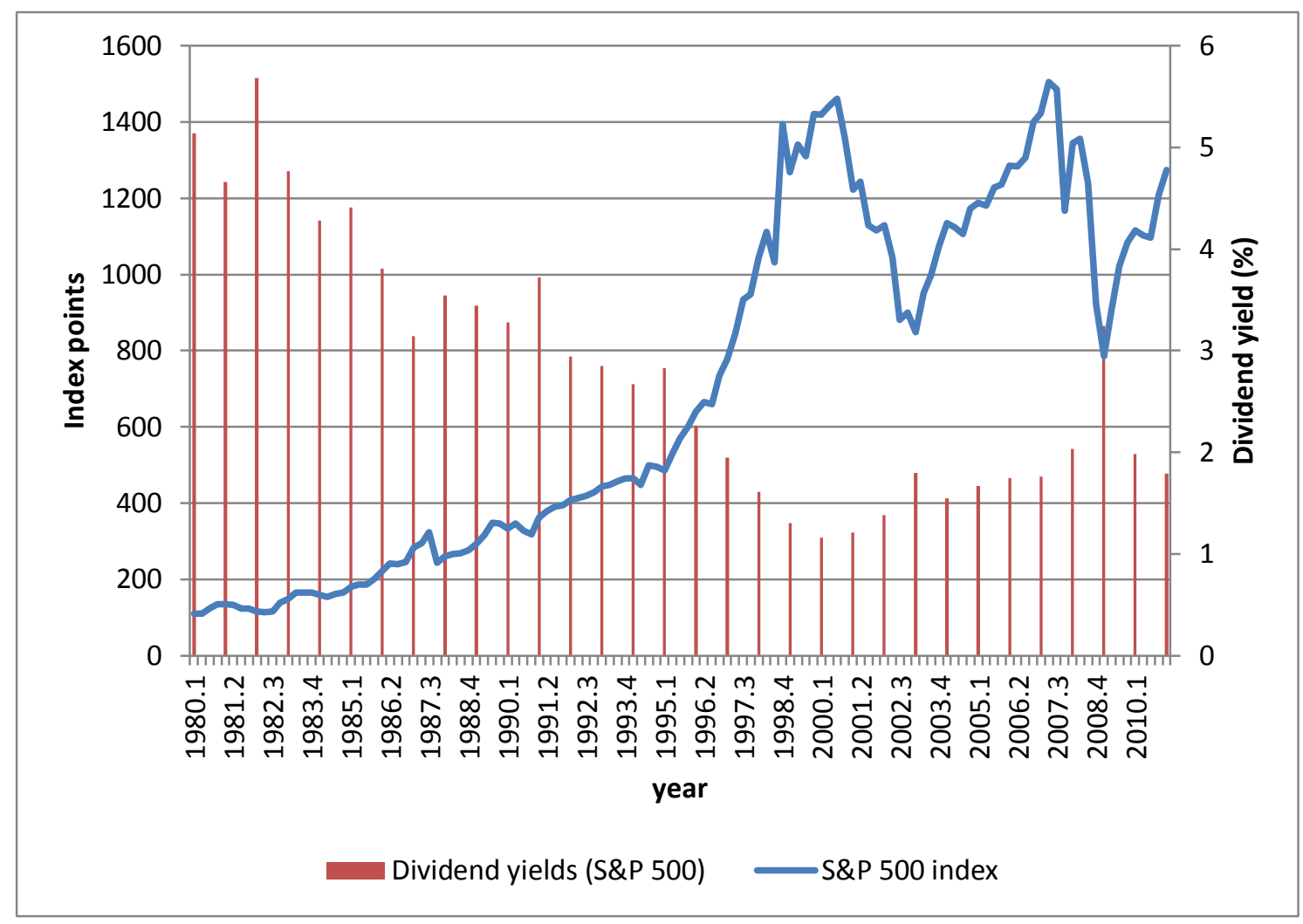

Source: Yahoo finance. http://nz.finance.yahoo.com/?p=finance.yahoo.com

Figure 13 provides grounds for the inference that dividend yield changes have been substantially affected by changes in market levels (in addition to the secular decline in those yields. Yields are found on the right hand axis and market index values on the left hand side of the graph. The vertical lines depict broadly declining dividend yields over the period, accompanied by sharp increases in the market index. It can be observed that dividend yields fall from over $5 \%$ at the start of the period, declining to $1.6 \%$ in the late $1990 \mathrm{~s}$. Yields have stabilised above $2 \%$ in the current period, with a notable increase to over $3 \%$ in 2008-2009 due primarily to the halving of the index level in that period. An implication of this is that the perception of a shift in company income distribution policies is overstated and is incidental to above trend growth in company capitalisations. That is, yield declines have been de facto replaced with capital gains, brought about by above historical trend rises in the S\&P 500 index over the 1980s and 1990s. When viewed in conjunction with figure 12, which shows a relatively stable growth in total dividend flows from corporations yield declines are more plausibly 
indicative of the abnormal gains in the market (in particular, through the 1990s) than of a tax-induced retreat from dividends as a form of income distribution.

Pecking order theory ostensibly fits declining dividend yields well as it prioritises internally-generated financing of corporations. However, this 'fit' implies that the pecking order did not hold prior to the decline in dividend yields. We observe a secular decline in dividends (see figures 12 and 13), against a cyclical movement in share repurchases, suggesting the substitution effect may be overstated. That is, share buybacks have not been substituted for dividends as a more tax efficient form of investor returns as they show a marked pro-cyclicality, against a long-term trend decline in dividend yields. Further, dividends are stickier than profits so, if substitution was occurring we would not expect to see share buybacks collapse with market crashes on the basis that they are substitutes for dividends. It is also notable that absolute dividend flows have increased almost continuously over the period 1980-2012, with a brief but notable and largely unexplained break in 2005 (see graph 12).

What becomes clear is that the most plausible reasons for declining dividend yields (and increased share repurchases) are: the rapid rise in equity markets over the 1980s and 1990s along with the more muted increase in total dividend flows over the same period, reduced transaction costs, increased confidence in Securities Markets regulation and corporate governance, and a shifting preference for the greater flexibility provided by share buy backs. With transaction costs declining individual investors could more readily relate their sale or acquisition of shares to their current/future consumption preferences.

Brav, et al (1983), identify the fact that share buy backs are more flexible than dividend payments. It is possible to time share repurchases to optimise the outcome of repurchase programs, buying at (relatively) low average prices, determined by recent market trends and/or averages, and by setting maximum prices paid. In essence, a corporate share repurchase program is able to exploit short term market volatility by 'mopping up' shares to a pre-determined maximum price. By this means a corporation may improve the outcome of such a program in terms of its affect on company fundamentals by buying sufficiently cheaply so that EPS and other fundamentals 
improve by more than the implied benefit of an equivalent dividend. This approach is able to exploit the flexibility of share repurchases over the period of each financial year.

\subsubsection{An alternative approach to traditional theories of corporate financing: the supply focus}

Conventional theories of corporate financing are focused on demand for corporate debt and equity (Baker, 2009). More precisely, conventional theories focus on treating demand for, and supply of, corporate debt and equity as equivalent (Baker, 2009). This demand focus relies on assumptions that the supply of corporate debt and equity is determined by an efficient market in which the price of the respective instruments settles at a fundamental equilibrium appropriately reflecting the value of future cash flows (Baker, 2009). A more recent body of research focuses on corporate finance supply dynamics formed by changing investor tastes, imperfect intermediation and corporate opportunism (Baker, 2009). ${ }^{25}$ These supply-side factors drive equity and debt prices away from fundamental value. Investor demand may be influenced by imperfections in finance intermediation, an issue compounded by the growing array of channels and investor types with increased heterogeneity of investment imperatives. ${ }^{26}$ These imperfections (when added to variations in investor tastes that may be influenced by behavioural considerations) allow opportunistic corporations to exploit information asymmetry. Baker (2009) isolates evidence of this corporate opportunism in incidences of seasoned equity issues increasing after market run-ups. ${ }^{27}$ That is, firms raise capital and invest when equity prices are high and interest rates are low. Conversely, the theory predicts companies will repurchase equity and debt will be retired when equity prices are low, and interest rates are high (Baker, 2009).

\subsubsection{Market timing theory}

Market timing theory indicates that new equity issuance will increase after runups in equity prices (Baker and Wurgler, 2002). Thus, the blue arrows (in figure 14) should, according to market timing theory, accompany rising net equity issuance, independent of the movement in net corporate debt flows. This is due to the greater

\footnotetext{
${ }^{25}$ Imperfect finance intermediation is a consequence of asymmetric information. Information asymmetry may be expected to alter investor demand for corporate equity and debt from what might be expected with a fully, homogenously informed market (Chinn and Kletzer, 2001).

${ }^{26}$ The heterogeneity of investor types includes: Hedge funds, Endowment funds, Mutual funds, Pension funds, private investors and corporate investors. The growth in heterogeneous imperatives relates importantly to the growth in various managed funds.

${ }^{27}$ Seasoned equity issues are any issues of shares occurring subsequent to initial public offerings (IPOs).
} 
value received (when compared with historical potential) with lesser (existing shareholder) dilutionary effects. On this basis we would expect to see equity issuance increasing with rising markets yet this is at odds with observed macro-financial flows as shown by the macro-financial outflow or decline in inflows of net equity financing of US corporations during rising markets in figure 15.

Figure 14: Changes in corporate financing preferences due to Market movements in equity prices.

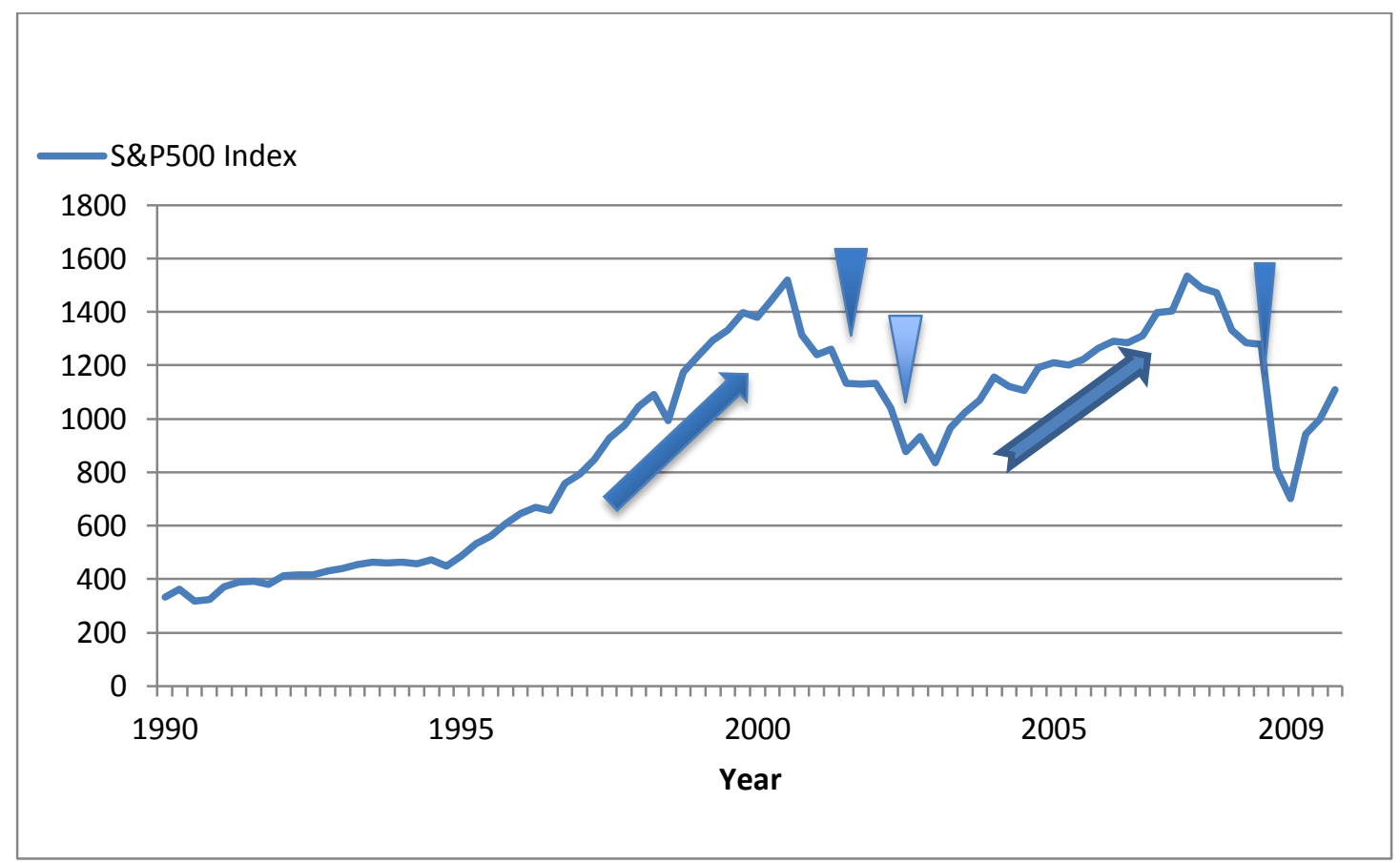

Source: Yahoo finance. http://nz.finance.yahoo.com/?p=finance.yahoo.com

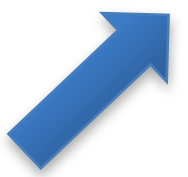

Periods in which market timing theory indicates elevated

share repurchases

Periods in which elevated share repurchases are observed

Market timing theory states that the opportunity to maximise the value of new equity issues motivates greater use of equity finance, implying a contrarian view that a run up in the stock price will be reversed by a mean-reverting stock price decline (Baker and Wurgler, 2002). This means that, with the caveat that markets observe a trend 
increase over the long run, any sustained run up is likely, at some point, to be reversed by a sizeable decline and period of consolidation. Walter and Milken (1973) provide early empirical evidence supporting market timing theory for the period 1966-1973. As identified in this chapter, the tendency of companies to exploit stock price run ups by issuing new equity has not held in more recent history. In fact, the evidence suggests a contrary interpretation whereby (again) extrapolative anticipation of future stock price movements results in accelerating share buy backs over periods of rising markets (See figure 15). Only during or shortly after periods of substantial market declines do we see corporations generally willing or compelled to issue new equity, often heavily discounted, to consolidate their Balance Sheets.

Balance Sheets become increasingly fragile over booms by the displacement of external equity by 'sticky' debt, retained earnings (typically re-cycled into new assets or share repurchases), and asset revaluations. This displacement makes companies vulnerable to any deterioration in market conditions (essentially describing a Minskian ponzi financing structure). Balance Sheet stability progressively becomes tied to rising asset prices and the maintenance of past asset price appreciation. Minsky's (1986) FIH framework provides a compelling fit with these modern developments in corporate financing flows. The FIH advances the case that corporate leverage grows over market expansions to exploit profitable new investment opportunities. This explanation fits with the progressive expansion-era substitution of debt for equity financing but relaxes the Minskian focus on rising leverage levels, which may be preserved if asset price rises occur very rapidly, even if debt also increases rapidly.

As noted Market timing theory suggests that companies exploit stock price run ups to issue new shares (represented by the rising arrows in figure 14). Yet observation broadly supports net declines or outflows of equity during these periods. Following Cooper's (2008) observations and evidence from macro-financial flows presented in figure 2, equity inflows increase at the points marked by the (downward facing) arrows (figure 14). It can be seen that between 2000 and 2004, and again from late 2007 through to the end of 2009, large inflows of corporate equity finance are depicted. This development coincides with declining or subdued equity prices. We see later, in figure 15 that market timing theory performs poorly empirically as an explanation of corporate financing preferences. Observed corporate financing flows (as per figure 16) support 
Minsky's (1986) view of increasing riskiness in corporate financing structures over booms.

\subsection{An empirical view of existing corporate financing theories}

Empirical research investigating each of the theories and evidence for and against is developed by Frank and Goyal (2007). They assessed the competing theories, finding that six key factors determine $72 \%$ of corporate preferences for debt or equity finance. These are, that:

1. Leverage is strongly positively related to industry type.

2. Market-to-book value is strongly negatively related to leverage.

3. The greater the level of tangible assets the higher the leverage.

4. Leverage is positively related to firm size.

5. Leverage is negatively related to profits.

6. High expected inflation results in higher leverage.

In terms of industry type it is plausible that this category subsumes (represents of proxies for) a variety of plausibly implicated company features related to industry, such as the in/stability of earnings or cash flows. Larger company size is expected to entail certain risk-reducing features, such as the diversification of earnings. The positive relationship between book values (and more particularly tangible assets) may support cheaper access to debt through collateralisation. The negative relationship between profits and leverage, as Frank and Goyal (2007) note, may be reasonably explained by the relative lumpiness of new investment. This is made more likely in the modern context in which dividend pay outs are low.

Frank and Goyal (2007) observe that market timing theory singularly fails to explain any of their key factor observations. Pecking order theory is able to plausibly explain why greater profits result in lower leverage but it is particularly ill-suited to explain the relationship between industry type and leverage levels, tangible assets and leverage, and firm size and leverage. They conclude that trade-off theory best accounts for their observations across the six factors, except for the negative relationship between profits and leverage. Frank and Goyal (2007) identify a plausible basis to accommodate the observed inverse relationship between corporate debt preferences and profitability, suggesting that building capacity is a 'lumpy' process that takes time. Given this, 
corporations may build retained earnings over time which could provide evidence of higher profits positively correlated with declining use of leverage.

Information asymmetry is centrally implicated in corporate financing choices and behaviours. It can arguably be inducted into each of the theoretical frameworks précised above. Chang, Dasgupta, and Hilary (1991) link information asymmetry to a corporate preference for debt over equity, stating that debt financing is negatively related to the level of analyst coverage. If this is true in the context of post-1983 observations (see figure 15) then information asymmetry must be counter-cyclical (to markets). There is no plausible way of advancing such a movement independently of extrapolative expectations. Moreover, the veracity of extrapolative expectations is objectively undermined by the persistence of economic and market cycles. That is, if asset price rises support debt substitution for equity, large asset price declines support equity substitution for debt. If corporations favour debt finance when the asymmetric information divide is large it follows that such corporations must maintain an equity 'wedge' or else pay onerous interest on debt finance. Under such conditions the corporation must presumably restore its leverage ratios to levels reducing adverse selection premiums, either with new equity or retained earnings. Because there is no plausible theoretical basis to connect recessions with reduced information asymmetry or economic expansions with an increase in this asymmetry this consideration is not likely to explain long term corporate financial structures.

Roberts (2001) argues that firms adjust their capital structures to re-balance changes in equity values, with a lag of between two and four years, owing to adjustment costs. Such a re-balancing implies corporations continually identifying and striving towards an optimal level of leverage. Roberts (2001) notes that traditionally researchers have assumed that long term average leverage ratios are optimal. Optimisation of corporate financial structures is also the conclusion of Opler, Sharon, and Titman (1997). They cite inter alia the case of American Home Products that, by their calculations, paid \$1.7 billion more in taxes (net of interest costs) from 1950 to 1989 than would have been necessary had the company maintained moderate levels of leverage (as opposed to none) over the period. Opler, et al (1997) finds support for the view that the historical trend towards an increased reliance on debt finance by corporations reflects a move towards optimisation. 


\subsection{Observations about modern developments in corporate financing flows}

Corporate asset values (market value) are determined in liquid markets yet corporate liability structures are more rigid, frequently involving long term debt commitments. Any sustained period of above average equity market rise will, on the re-balancing view, permanently (or at least with rigidities) alter the absolute level of debt finance used by corporations. Given the growing dependence on debt by companies it is plausible to doubt company and market resilience to declines in value as debt involves greater risk. Asset price rises are extrapolated from to support companies' decisions to repurchase their equity on the expectation of continuing price rises. As these developments proceed up to the point of market breakdown, the necessary Balance Sheet consolidation identified by Minsky (1986) is indicated by sharp reversals in corporate debt and equity flows during periods of acute and sustained market decline. Prevalent corporate finance theories assume rationality (and optimisation) in corporate financing decisions and structures on the basis of market price-trend extrapolation. However, this discounts the mismatch between liquid equity market prices and fixed corporate liabilities.

Corporate external financing has undergone substantial changes since the early 1980s. Over this period there has been a marked pro-cyclicality in corporate debt flows. Relative to market cycles corporate equity flows have moved almost as strongly counter-cyclically. Over the same period corporate dividends have declined in relation to market and company capitalizations. This raises questions about the modern corporate financing landscape and, in particular, the cyclicality of debt substitution for equity over rising markets and counter movements in declining markets. The discussion earlier in this chapter has referred to existing theories of finance against the evolving corporate environment. In many regards existing theories seem inadequate to explain cycles in contemporary corporate financing preferences. That is, expansion-period preferences for debt over equity, reversed in favour of equity after large market declines. In an important regard the limitations of these theories may reflect weaknesses in the assumptions underlying those theories.

Much of the theoretical development in corporate finance occurred in the shadow of market efficiency. This has motivated researchers to assume certain 'facts' 
that may not be reliable. Assumptions of corporate financing optimisation presuppose that corporate financing decisions are, at least on aggregate, rational and profit maximising. They do not allow space for variations in corporate control, misalignment of managerial incentives or investors who have, on balance, decreased the size of individual company holdings, diversified stock holdings, and economised on due diligence or activism ${ }^{28}$, instead relying on the greater liquidity and lower transaction costs to exit non-performing companies. These considerations have been compounded by portfolio theory as it supports diversification that reduces shareholders' stakeholdership in individual companies. Further reinforcement of this phenomenon of declining shareholder activism is a plausible result of modern Securities' Markets' regulation which imposes trading restrictions on larger shareholders. Each of these developments may disrupt key assumptions underlying important theories of corporate financing. Furthermore, as described above, none of the key theories identified above can plausibly, convincingly explain the cyclicality of shifts in corporate finance. To sharpen this point it seems reasonable to identify a systematic and general mistake made by corporations in determining the disposition of their financial structures.

The mistakes are most evident, and most evidently mistakes, in the case of successive and progressive debt substitution for equity in rising markets. This trend reverses sharply and coincidentally with large, sustained declines in markets (crashes or market breakdowns). The mistake lies in the costliness of (forced) Balance Sheet consolidation through new equity issuance when equity prices have fallen substantially. This trend has been repeating (see figure 15). Since the early-mid 1980s and successively larger cycles in corporate finance have corresponded with similar movements in markets. Because the cycles have recurred there is little reason to infer rationality or optimality as key determinants of corporate financing decisions. That is, if corporate financing choices aim to optimise the debt-to-equity relationship of a company (that is, if they are rational) they also recurrently fail to do so as, on aggregate, companies require expensive new equity issuance in depressed markets. Instead, Minsky offers a more plausible interpretation in which trend extrapolation and past debt contract validation support a steadily rising market. Over expansions obligations under

\footnotetext{
${ }^{28}$ Due diligence and stock holder activism operate together to provide monitoring of companies. This typically involves institutional stock holders with substantial stakes thoroughly investigating company fundamentals and taking an active role in management, frequently by occupying board positions.
} 
debt contracts are met by borrowers and where they are not, rising asset (collateral) prices minimise banks' losses. As this trend progresses it provides a cluster of data supporting the confidence of banks to lend greater amounts.

\subsubsection{Why do conventional theories of corporate financial structure fail to explain modern-period observed cycles in corporate macro-financial flows?}

Conventional theories of corporate financial structure are inconsistent with cycles in corporate debt and equity financing observed in the period 1980-2011. The relationship of external corporate financing flows to bubbles and market collapses does not provide a plausible fit with conventional theories. Each major conventional theory is founded on an assumption of market efficiency and corporate financing choices as solutions to the central imperative of optimising debt-to-equity in corporate financial structures. Cycles in corporate external financing most clearly contradict the foundations of conventional theories at or shortly after periods of substantial market decline. What seems to influence the substitution of debt for equity during market rises (up to the point of substantial decline) is disaster myopia and simple trend extrapolation. Disregard for the recurrence of the business (and market) cycles also appear to be features of corporate financing behaviour.

The described debt-to-equity disposition of companies at the macro-level does not fit existing corporate financing theories well, especially where there is little or no adverse news causing market falls. It is circular to say that a market collapse has increased the risk of corporate bankruptcy and, thus the risk associated with debt. This explanation requires that past market prices and price action are the basis for current market prices and a basis for inference to future prices. The assertion that market price action is an input into company valuation models is essentially an argument that the equity value of a company is determined by the market value of the company. This is both true and trivial. Equally, pecking order theory requires that risk is greatest in rising markets as equity issuance (the least lovely of all possible forms of corporate financing) increases at points after market rises end and, until that point, market rises are accompanied by progressively expanding debt financing. It is not clear that collapsing markets can be reasonably theoretically associated with reduced estimates of market risk. The least plausible of the main theories of corporate financial structure is market timing theory. This theory appears to directly contradict 1980-2011 observations by 
arguing that high equity prices result in increased equity issuance. This is clearly not true at market-wide levels. (See figures 15 and 16).

Figure 15: The relationship between S\&P 500 index movements and corporate debt and equity flows over the period 1983-2008

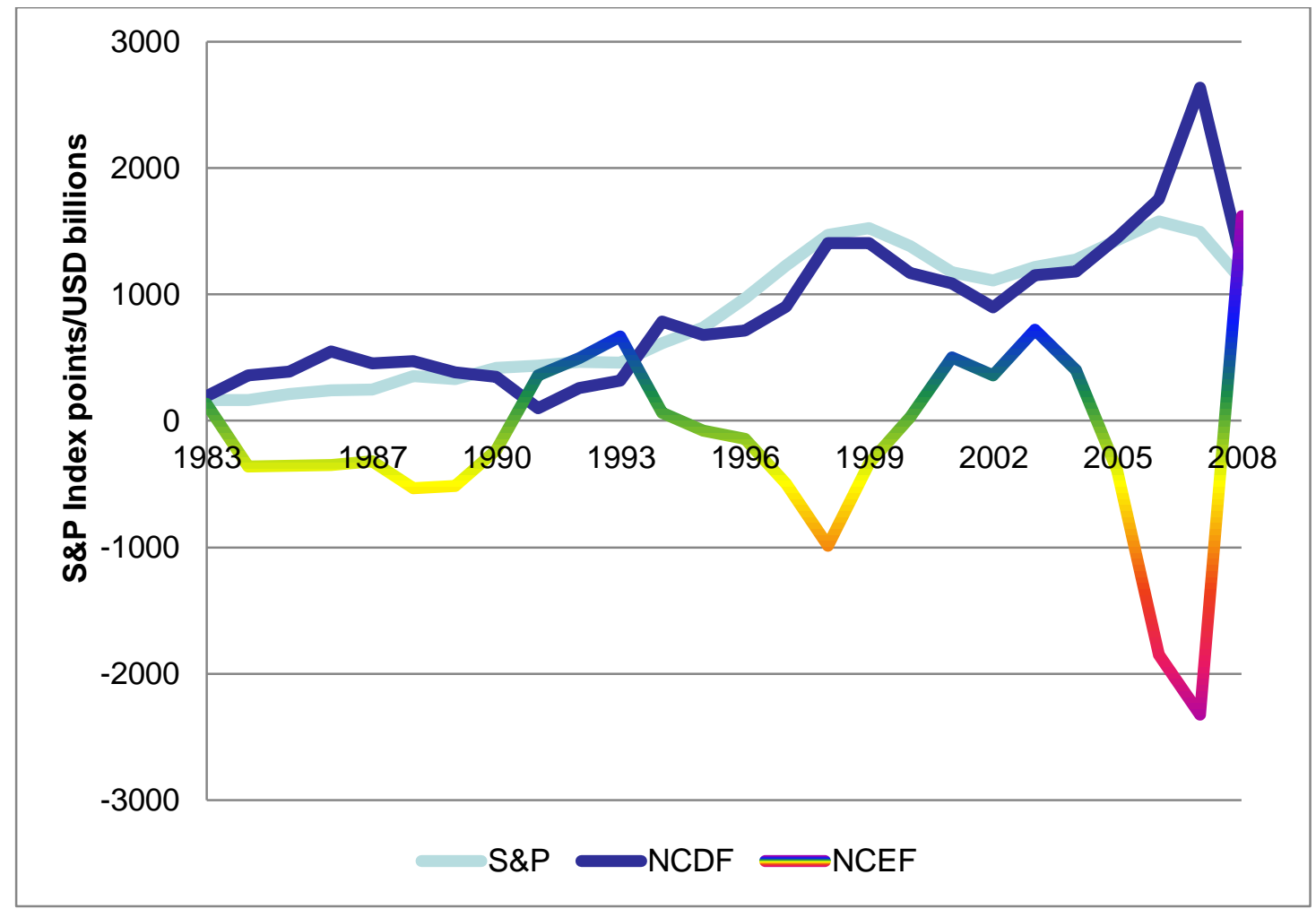

Source: Federal Reserve Board of Governors, series Z1

Notes: The pale blue line represents annualised data of the movements of the S\&P 500 index.

The solid dark blue line is net corporate debt flows (annualised).

The 'rainbow line (the net repurchase of equity) that lies largely below zero represents annualised net corporate equity flows over the period. Companies choose to issue equity or repurchase it. In general, the corporate equity line reflects an outflow. The changing hues aim to distinguish more extreme movements from lesser ones.

Figure 15 illustrates three clear cycles in external corporate financing (1983-1993; 1993-2003; 2003-2007). Arguably, convincing explanations for these cycles cannot be found in any of the key existing theories of corporate financial structures in light of the evidence presented above. The case may be made that an explanation is essential to understanding the determinants, nature, and stability of contemporary corporate financial structures. 


\subsubsection{Description of the relationships depicted in figure 15}

In the period from 1983-2012 broadly inverse movements in corporate debt and equity are observed in figure 15 . That is, corporate debt increased while equity decreased with share buy backs, rather than equity issues, despite the rising market of the 1980s 'bull run'. The early 1990s, a period of economic recession, sees a sharp reversal in flows of corporate debt and equity with a fall in net corporate debt issuance and a rise in corporate equity financing. These developments in external corporate financing coincide with a period of substantial and sustained market decline. Again, in 1993 the trend in external corporate financing is reversed with a sharp decline (and from 1994 a net outflow) in corporate equity financing and an inverse movement in corporate debt financing flows. Both of these movements continue until the late 1990s, paralleled by a strong, almost unabated, rise in the market over this period. The early 2000s see a reversal of these movements, accompanying the 'tech wreck', and later, the 'Twin Towers' terrorist attack (2001), with its coincident recession. From late 2003 these financing flows again reverse, accompanied by a strong rise in the market until late 2007. Both corporate debt and equity flows observe their most extreme movements in this period and provide support for the position that debt was substituted for equity. The relationship between observed financing flows and market cycles supports the view that MM investor indifference is implausible. Moving into 2008 these movements reverse sharply, approximate to the sub-prime crisis and Global Financial Crisis.

Damodaran (2007) suggests that the share buy backs that are endemic in the period studied may be fuelled by a deficit of new profitable investment opportunities rather than being swapped for debt finance. Corporate priorities depart from the traditional view of them to maximise the value of the company and target the maximisation of share holder wealth. To the extent that share buy backs reduce the dilution of earnings (Earnings per share or EPS) and other company fundamentals, share holder wealth maximisation is achieved through share buy backs. However, this process relies on extrapolation from past asset price performance (including the company's own shares) or the sustainability of past asset price rises, it has the potential to leave companies undercapitalized and vulnerable to a market downturn. This vulnerability is indicated by the process of reversing previous share repurchases with new equity issuance at a market-wide level. This is reflected in graph 5.5 in the rapid 
reversals of boom period corporate external financing flows at and during market crashes.

\subsection{Adding cyclical qualifications to existing structural qualifications to the Modigliani-Miller 'indifference' theorem}

Earlier in this chapter a number of structural qualifications to investor indifference to corporate financing structures were identified. This section draws from evidence of modern US corporate financing flows to support the position that a key qualification largely ignored to this point has been the cyclicality of external corporate financing (See figure 15). This appears to represent a paradox as it is contrary to the conditions in goods markets, which is a conventional basis for extrapolation to asset markets (Cooper, 2008). In goods markets, rising demand increases prices with a subsequent increase in supply. This increased supply will, ceteris paribus meet (and may even) exceed the former excess of demand, restoring price stability. Conversely, rising stock prices typically reduce the supply of equity. The most plausible basis for this phenomenon is that corporations rely on the extrapolation of past stock price performance to infer an implied cost of equity finance that exceeds that of debt finance (Cooper, 2008). Thus, over booms rational individual choices propagate and exacerbate conditions of financial fragility (Sawyer, 1989). These developments are consistent with Minsky's (1986) FIH as the successive performance of debt contracts over market expansions provide evidence that is extrapolated from, informing the general view that risk is low. These considerations support the progressive increase in credit availability as companies increase their levels of debt as it has a cheaper implied cost than equity. At this point rising debt levels significantly increase the probability of bankruptcy (Stiglitz, 1988). These developments are consistent with Minsky's (1986) FIH as the successive performance of debt contracts over market expansions provides evidence that investors extrapolate from, informing the general view that risk is low. These considerations support progressive increases in credit availability as companies increase their levels of debt.

These issues reflect a cyclical 'accelerator', driving the financing choice. Minsky (1986) identifies cyclical influences on credit costs. He describes the variability of lender and borrower margins over the business cycle. Debt is indicated where lender margins of safety (interest rate spreads, loan maturities, and collateral requirements) 
contract over expansive periods of the business cycle (Bracke and Fidora, 2008), coupled with interest rate tax deductibility as a constant structural feature. To the extent that the assumption of debt imposes a rigid, contractually determined impost on future cash flows (Mullineux, 1990), it entails greater risk to equity holders than additional equity funding. Unlike equity, which has no predetermined cost, the negative cash flows of borrowed funds under debt contracts do not adjust sympathetically to negative deviations in the borrowers own cash flows from those expected (Fisher, 1933; Minsky, 1986; Tobin, 1980). Veblen, 1904; Where the deviation is negative, it is rational to expect the lenders' margin to expand, aggravating adverse deviations in cash flows from expectations. Thus, debt inherently entails greater volatility than equity funding and can be expected to exacerbate market cycles. Further, debt flows, equity flows, and the relationship between these may provide important signals of future market movements.

Observations over the period 1980-2011 (depicted in figures 15 and 16) support the view that corporate financing structures influence and are influenced by cycles. Following Minsky (1986) this observation is driven by investor and corporate mood which, in turn, influences the demand for, and supply of, credit. Simply, risk and return estimates change with cycle phase, with risk assessed to be declining over periods of expansion and increasing in contractionary periods. Risk/return estimates then feed into the financial infrastructure which reacts to either ration or expand credit, respectively constraining the economy (and asset markets) or amplifying expansive phases (bubbles). Similarly, expected returns extrapolate from past returns and, thus, aggravate cycle phases (as shown in figure 16).

In contrast to existing theories of corporate financing choices the extrapolative expectations theory presented in this thesis specifically addresses cycles in corporate debt and equity external financing preferences. Over booms companies prefer debt as the explicit costs of debt are exceeded by the implicit costs of equity. In simple terms if market expectations are for the market to rise by $15 \%$ over the current year the issue of new equity dilutes current shareholder wealth maximisation by this amount. Conversely the explicit cost of debt is perhaps $5-7 \%$. The case made here is that an identification bias attaches greater weight to implied equity costs over the implicit costs of debt, discounting the implicit costs of risk associated with debt. This is consistent 
with Minsky's (1986) view that markets extrapolate from recent trends and, thus, systematically mis-price risk at different points in market cycles. A further contention advanced in this thesis is that we cannot speak of preferences at the point of substantial market declines. Instead companies are forced (rather than choose) to issue new equity as part of Minsky's (1986) balance sheet consolidation. These developments are depicted in figure 16.

Figure 16: Feedback between stock prices and corporate financing

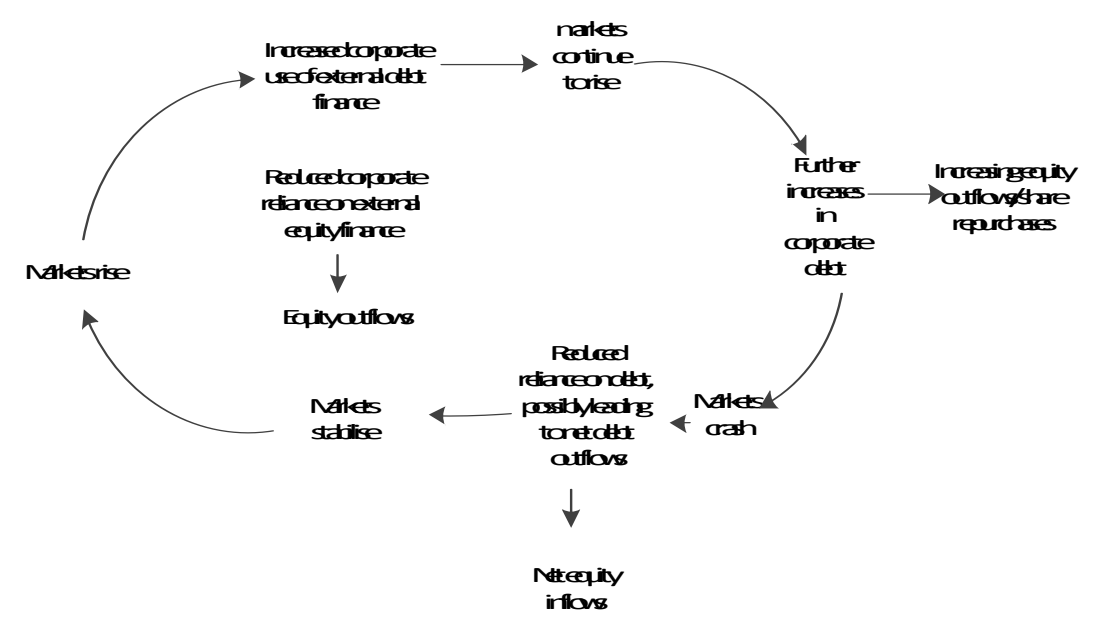

The implications of cyclicality in external corporate financing preferences on company financial structures refine the assumptions and depiction of trade off theory. In terms of figure 11 the risk assessments of economic agents and concomitant cycles in finance availability 'bubble' the curve reflecting the tax shield affect, sharpening the ascent of that curve above levels implied by the tax shield alone. At the point of the 'Minsky moment' the curve falls more sharply than the weight of bankruptcy costs implies in figure 11. In effect, cyclical corporate financing flows exacerbate market movements by implying a uniform and low bankruptcy risk that is independent of market cycle phase (or that is even counter-cyclical). This, then, approaches disaster myopia or the general under-assessment of risk followed by realisation of that risk and ensuing panic. 


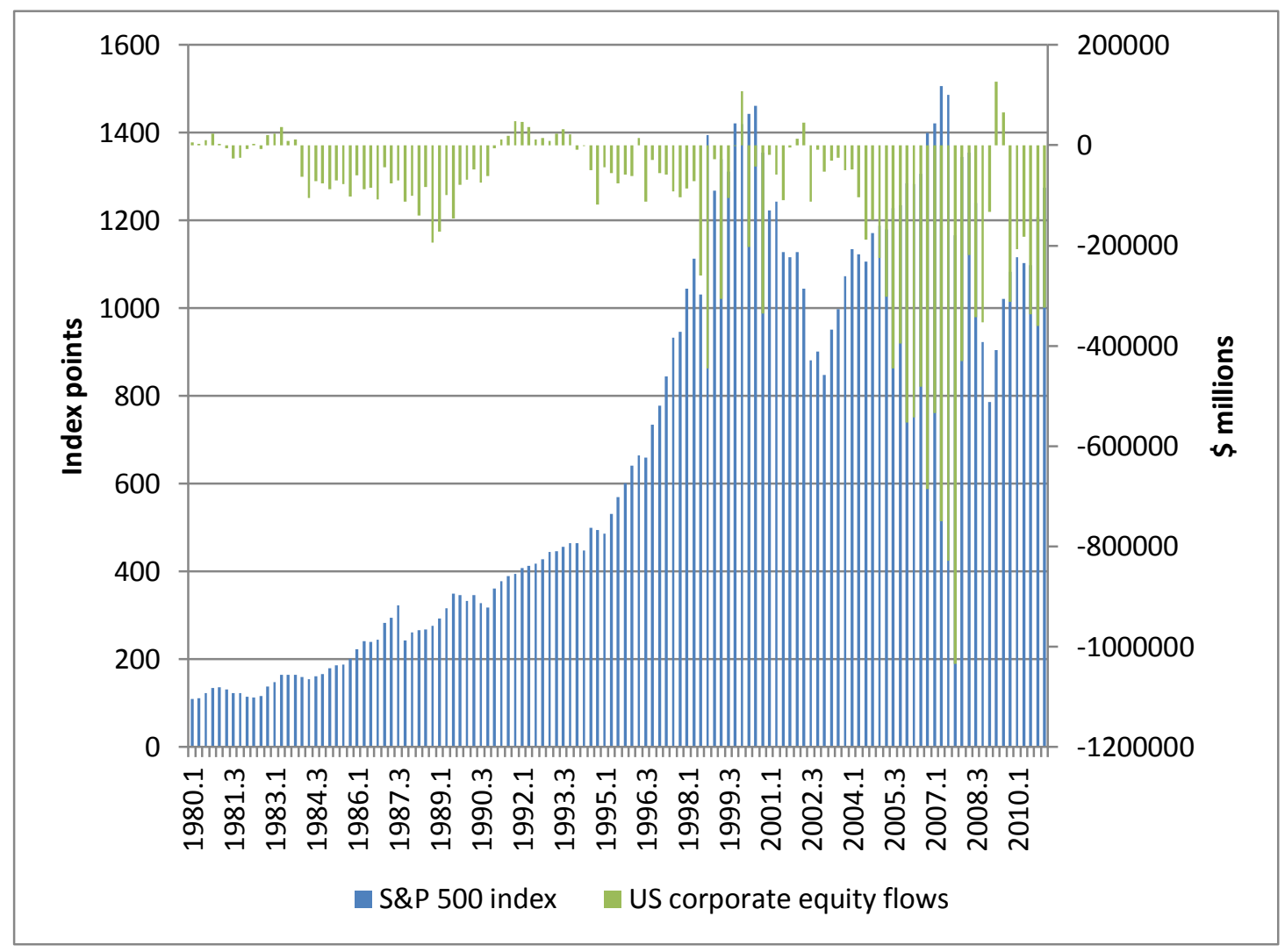

Figure 17 identifies the moderate negative relationship between the S\&P 500 index movements and those of non-financial corporate equity financing flows (Pearson correlation: -0.555). Notably, the bull market of the 1980s (from 1983), the 1990s (from 1993), and the 2000s (from 2003) are matched by progressively increasing equity outflows. Periods of recession and declining equity markets (the early 1990s, 22012002, and 2008-2009) reverse the direction of flows with declining equity outflows leading to modest equity inflows, typically for just two quarters at or approximate to the most extreme points of market dysfunction. These features support the potential of corporate equity flows as predictor (independent) variables of market movements.

Debt-burdened corporations are effectively able to transfer equity risk to debt holders due to the limited liability structure of companies. It is not necessary to invoke asymmetric information to explain the implied transfer of wealth from debt to equity holders. As per Minsky (1986) all that is required is the systematic mis-pricing of risk 
that accompanies the extrapolative expectations of market participants on aggregate during the 'euphoric' phase of the business cycle. In this sense the risk burden associated with the equity premium is borne by lenders in progressively greater proportion as firms adjust the composition of their financing over economic booms. A pro-cyclical preference for debt is observed to take place. Minsky describes the progressive validation of debt over booms as successive debt contracts are fulfilled. Rising asset markets supported by expanding economies compress lender margins. These margins (in Minsky's terms) comprise collateral requirements, loan maturities and level of interest rates required by lenders. History shows that boom-period contraction in lender margins, reflected in the narrowing of interest rate spreads and declining collateral requirements and exacerbated in the post-2001 period of the Great Moderation by historically low relative risk-free rates, acted to catalyse the bias towards corporate debt financing. This development was supported by contracting borrower margins (reflected in rising asset prices). This effect, in turn, supported the general perception that rising asset prices reduce lender risk as that risk is perceived as limited by the extent an outstanding debt is recoverable from collateral realisation. Similarly, the risk of default is deemed lower due to constraints on the recognition of moral hazard presented by the lenders' vested interest in retaining an appreciating asset.

Table 1 A comparison of existing theories of corporate finance and the hypothesis advanced in this research

\begin{tabular}{|c|c|c|c|}
\hline $\begin{array}{l}\text { Theory of } \\
\text { corporate } \\
\text { financing }\end{array}$ & Key points & Weaknesses & Solution \\
\hline $\begin{array}{l}\text { Modigliani- } \\
\text { Miller }\end{array}$ & $\begin{array}{l}\text { Investor indifference to } \\
\text { corporate financing } \\
\text { structure. Risk of debt } \\
\text { offsets higher returns due } \\
\text { to the debt 'tax shield'. } \\
\text { Corporate financial } \\
\text { structure has no impact on } \\
\text { company value }\end{array}$ & $\begin{array}{l}\text { Fails to account for } \\
\text { structural factors e.g. } \\
\text { taxes and limited } \\
\text { liability (Gordon, } \\
\text { 1986; Durand, 1989). } \\
\text { Fails to explain how } \\
\text { the market } \\
\text { periodically misprices } \\
\text { risk. }\end{array}$ & $\begin{array}{l}\text { Add a cyclical } \\
\text { component to } \\
\text { the explanation. }\end{array}$ \\
\hline 2. Trade off & $\begin{array}{l}\text { Companies balance the } \\
\text { risk of debt against } \\
\text { bankruptcy costs, } \\
\text { selecting the optimal trade } \\
\text { off between these. }\end{array}$ & $\begin{array}{l}\text { Fails to identify how } \\
\text { companies } \\
\text { periodically misprices } \\
\text { risk and are, thus, } \\
\text { forced into expensive } \\
\text { equity issues. }\end{array}$ & $\begin{array}{l}\text { Consider as a } \\
\text { theoretical } \\
\text { optimal state } \\
\text { and add cycle } \\
\text { component }\end{array}$ \\
\hline
\end{tabular}




\begin{tabular}{|c|c|c|c|}
\hline & & $\begin{array}{l}\text { The trade off is } \\
\text { between two unequal } \\
\text { forces. }\end{array}$ & \\
\hline $\begin{array}{l}\text { 3. Pecking } \\
\text { order }\end{array}$ & $\begin{array}{l}\text { Adverse selection } \\
\text { determines corporate } \\
\text { financing structure. } \\
\text { Internal funds have no } \\
\text { adverse selection premium } \\
\text { attached and so will be } \\
\text { used first, followed by } \\
\text { debt then equity. }\end{array}$ & $\begin{array}{l}\text { Fails to explain why } \\
\text { adverse selection is } \\
\text { increased by a } \\
\text { strongly rising market } \\
\text { or why that adverse } \\
\text { selection falls } \\
\text { substantially with a } \\
\text { market crash. }\end{array}$ & $\begin{array}{l}\text { Isolate adverse } \\
\text { selection premia } \\
\text { as a single } \\
\text { component in } \\
\text { corporate } \\
\text { financing } \\
\text { decisions and } \\
\text { add cyclical } \\
\text { variations in } \\
\text { market tastes }\end{array}$ \\
\hline $\begin{array}{l}\text { 4. Market } \\
\text { timing }\end{array}$ & $\begin{array}{l}\text { Corporations time the } \\
\text { market, exploiting run-ups } \\
\text { in share price to issue new } \\
\text { equity. Corporations buy } \\
\text { back equity when prices } \\
\text { are low. }\end{array}$ & $\begin{array}{l}\text { Fails to explain why } \\
\text { macro-financial data } \\
\text { indicate equity issues } \\
\text { only increase after a } \\
\text { fall in the market and } \\
\text { why high-priced } \\
\text { equity does not } \\
\text { appear to see greater } \\
\text { equity issues. }\end{array}$ & $\begin{array}{l}\text { Discount as an } \\
\text { essentially } \\
\text { subsidiary or } \\
\text { 'contrarian' } \\
\text { approach } \\
\text { without } \\
\text { implications for } \\
\text { the macro- } \\
\text { financial } \\
\text { picture. }\end{array}$ \\
\hline $\begin{array}{l}\text { 5. Sutton- } \\
\text { Minsky } \\
\text { The } \\
\text { extrapolative } \\
\text { expectations } \\
\text { theory of } \\
\text { corporate } \\
\text { financing } \\
\text { decisions }\end{array}$ & $\begin{array}{l}\text { Separate from a variety of } \\
\text { company-specific factors, } \\
\text { companies act on (price) } \\
\text { extrapolative expectations, } \\
\text { repurchasing equity as its } \\
\text { price rises and using more } \\
\text { external debt. They are } \\
\text { forced to consolidate } \\
\text { balance sheets during } \\
\text { substantial market } \\
\text { declines and reduce their } \\
\text { reliance on debt. }\end{array}$ & $\begin{array}{l}\text { Isolates a single factor } \\
\text { implicated in } \\
\text { corporate financing } \\
\text { and is otherwise silent } \\
\text { on factors such as } \\
\text { company size, cash } \\
\text { flow volatility, and } \\
\text { profitability. }\end{array}$ & $\begin{array}{l}\text { Add cyclical } \\
\text { influence to the } \\
\text { better evidenced } \\
\text { factors of } \\
\text { corporate } \\
\text { financing, such } \\
\text { as company } \\
\text { size, industry } \\
\text { type, tangibility } \\
\text { of assets, } \\
\text { stability of cash } \\
\text { flows, etc. }\end{array}$ \\
\hline
\end{tabular}

Table 1 identifies the key theories of corporate financial structure. Generic features of theories 1,2,3, and 4 assume corporate external financing choices are driven by rational imperatives of company (or shareholder) wealth maximisation. At their core these theories assume market efficiency. Theory 4 approximates existing shareholder wealth maximisation but also involves an implicitly contrarian strategy that presupposes some level of market inefficiency in its attempt to capitalise stock price 
run-ups, by 'taking some gains off the table'. That is, there is an implied assumption of market price mean reversion that sits outside of standard assumptions of market efficiency. Theory 5 prioritises macro-financial flows' cycles and is predicated on inefficiency greater than that assumed by theory 4 . Theory 5 argues that unfounded (recent) price trend extrapolation motivates companies to repurchase their stock altering comparatively (relative to equity market prices) sticky external financial structures based on an assumed permanence to, and continuation of, recent equity price increases. The key features of each theory are summarised, weaknesses are identified, and solutions advanced to address those short-comings in table 1.

\subsection{Can the proposed basis for active asset management overcome evidence that passive asset management systematically outperforms active management?}

The discussion in chapter two relating to the relative under-performance of active versus passive funds provides the context in which any proposal for active funds' management must exist. It is relevant to this thesis in that this research directly targets short term investment decisions and also in terms of the quasi-investment decision identified here as a financing decision (share repurchase). It is reasonable to assume that the corporation has made a financing decision (the decision to repurchase equity) on the basis that it perceives share repurchases as the best risk-adjusted use of funds available. This thesis aims to provide information to assist in the operationalization of that financing decision and, as such, is essentially an input into an active investment decision models.

The operational ability of the proposed models to improve returns over a default buy-and-hold strategy lies in evidence of improved implied returns' outcomes. Thus, continuous market exposure over the study period is a control against which to assess model outcomes. Given that this thesis advances two distinct models (discussed in chapter seven), one forecasting future quarters of market declines and the other market rises, and that in some quarters the models conflict, there are a range of reasonable outcomes. Later, in chapter eight, I outline the implied returns from a range of plausible applications of the models. 


\subsection{Summary.}

Existing theories of corporate financial structures fail to explain systematic mistakes made in corporate financing. Persons (1930) and Galbraith (1990) identify the general acceptance by market participants of the view that, 'this time it's different, we've moved beyond the business cycle'. This view gains adherents through Minsky's (1986) 'euphoric' phase of the business cycle Moreover, corporate financing behaviours at the macro-level effectively operationalise this view by progressively substituting debt for equity financing as markets rise. Because this strategy discounts the persistence of the business cycles, and because this persistence is a matter of empirical fact, those existing theories are necessarily incomplete. Instead, the market extrapolates from prevailing trends in company prices to infer ongoing pricing patterns consistent with the recent past. During euphoric phases this establishes the basis to infer that markets will continue to rise. Given this assumption companies repurchase their own equity as it is implicitly more expensive than debt finance, substituting debt. Yet, when the market enters a bear phase companies are forced to issue new equity at prices far below those of the bull market.

Chapter six outlines existing research relating to the valuation, modelling and prediction of market movements. Research in this field ranges from efficient market assumptions to assumptions of varying degrees of market inefficiency. The key research in this field is surveyed. Short term market prediction modelling and the theory underlying it are also considered. The aim of this process is to identify gaps in existing literature and research to determine viable independent variables for testing in market prediction modelling. This process is informed by the Minskian framework previously outlined and is also related to observations of regularities in the relative movements of markets, corporate debt flows, and corporate equity flows. The observed flows and market movements fit well within Minsky's FIH and it may even be said that they are predictable under the assumptions of the FIH. The gap identified lies between the short term predictions of essentially technical analysis and the very long term predictive success of Shiller's (2005) use of Price-to-earnings ratios. 


\section{Chapter six: The 'extrapolative expectations' theory of corporate financing and positioning it in relation to existing forecast models}

\subsection{Introduction}

Chapters two, three, and four identified the basis for this thesis view on the operation of markets. The aim of these chapters was to challenge the view that markets are reliably efficient and to suggest an alternative view, building the basis for independent variable selection for model building. In chapter two a qualified view of market efficiency was developed. Chapter three develops this qualified view of market efficiency in an absolute sense through a Keynesian-Minskian lens. The essentially endogenous nature of economic and market instability in market-based economies was linked to the financial sector in chapter four. This qualified view of market efficiency was applied to corporate financing and an alternative to existing explanations of corporate financial structure and preferences was presented in chapter five. Evidence for the positive statements made in these chapters was developed through a survey of recent US economic history in chapter five. These chapters built towards the current chapter and the development of a sound theoretical foundation for model building to predict future market movements by identifying the signalling potential of littleexplored variables. With this goal in mind existing models of risk-asset value, indices of financial fragility, and cycles are assessed, including evaluating the strengths and weaknesses of these indices. The assessment and customization of these indices forms the basis of this thesis' development of market-predictive models.

This chapter investigates existing attempts to identify fundamental value and market departures from fundamental value. These range from market efficient solutions, to minor qualifications to market efficiency, to the view that markets are never efficiently priced. I consider a selection of these approaches with a view to building a model of value specific to corporate equities. This process, in part, builds on elements of existing approaches but it is also undertaken to position and distinguish this thesis from related research. The purpose is to develop forecast models of short term equity market movements to add to investor decision models and to better inform share buyback strategies. It also involves positioning this thesis relative to existing research. 


\subsection{Determining fundamental value under assumptions of market efficiency: the capital asset pricing model (CAPM) and Arbitrage Pricing Model (APM)}

Models of fundamental value based on market efficiency include CAPM and APM (Arbitrage Pricing Model). In both cases fundamental values are identified by combining three inputs, although APM adds plausible macro-variable betas. These inputs are (1) the risk-free rate and (2) an appropriate risk premium. (3) In the case of CAPM, company stock price beta is the other input and it determines the risk premium. This measurement of risk and derivative valuation is based on market-wide risk. (3a) The APM extends CAPM to add betas for a company's sensitivity to identified macroeconomic risk factors. Issues arise in terms of determining a risk-free rate. Notionally, the intended holding period could determine the default risk-free referent, but this presupposes an asset is not held indefinitely, its holding is not subject to review, and the term of the investment is fixed. These assumptions are generally unreliable. In both CAPM and APM measures of historic asset price volatility (and in the case of APM, macroeconomic factor price volatility) determine fundamental value relative to the market. As part of the theoretical infrastructure of these models, the market itself is an invariably correct or fundamental value. Again, these models are essentially just particular specifications of market-efficient fundamental value derivations.

\subsubsection{CAPM}

CAPM was developed by Sharpe (1964) and Lintner (1965) as a model for the determination of the required rate of return on an asset necessary to justify its inclusion in a well-diversified portfolio, given the non-diversifiable risk of that asset. The theory's assumptions include that investors are: utility maximising, rational, price takers who are not subject to transaction costs or taxes, who can lend or borrow at the risk free rate of return, and who have all available information simultaneously (Paavola, 2006). These assumptions lead to a security market line (SML) which states that the expected return on a security equals the risk-free rate plus beta times the excess return on the market portfolio. Beta measures non-diversifiable risk and is the covariance of returns on the security and returns on the market divided by the variance of returns on the market.

The CAPM defines a fundamental value (relative to a market) for individual stocks based on an efficient market. Assumptions include that: returns' variance is an 
adequate measure of risk; investors have homogeneous expectations about the distribution of expected returns at a point in the future; and, that this agreement or expectation is a true reflection of the distribution of expected returns. Difficulties lie in the use of covariance as a proxy for risk. The Roll (1977) critique establishes that there is an, 'if, and only if' relationship between mean variance efficiency of the market portfolio and linearity between risk (as measured by beta) and expected return. Given that the market portfolio cannot be identified empirically there is no feasible test of CAPM. Standard proxies use a market index and, thereby, fail to capture a suitable risk reference which should include all investment alternatives, including all financial assets, real estate, consumer durables and human capital (Fama and French, 2004). The practical impossibility of developing such a market value means that typical applications restrict market risk identification to an observable input such as an existing index.

Valuation models based on market efficiency also include the Black-Scholes option-pricing model. This model does not determine the fundamental value of an option, except in relation to the price and price history of the underlying asset. So, again, it is a relative value model that does not necessarily provide an indication of fundamental value. The model explicitly uses the price and price volatility of the asset on which an option is based as the central determinant of the option's value. Apart from errors the model makes in suppressing evaluation of the risk of extreme events, it assumes fundamental value in a relative sense. In this regard it is distinguished from the aim of this thesis, to forecast market movements explicitly assuming inefficient markets at a broad level. Further, the Roll (1977) critique identifies the fact that fundamental value is an unobservable referent against which to establish an individual asset's idiosyncratic risk as this would require an assessment of risk across all possible investment alternatives. In essence only a questionable proxy for idiosyncratic risk is used and the systematic risk of the nominated market referent is suppressed. The key issue is that these models are relative value models and cannot identify the fundamental value of an asset. Thus, problems with CAPM reduce to its assumption of market efficiency and its use of unreliable referents.

The CAPM has been challenged by a number of studies, raising doubts about its practical application. This has resulted in augmentations or extensions to CAPM. 
Amongst these are the Inter-temporal Capital Asset Pricing model (or ICAPM) (Merton, 1973), and the Consumption Capital Asset Pricing Model (or CCAPM) (Breeden, 1979; Rubinstein, 1976). ICAPM adds new state variables to company Beta, such as company stock return covariance with labour income, consumption opportunities, and investment opportunities at future time $t$. The addition of betas for these variables to explain expected returns determines the optimal portfolios on the basis of multi-factor variance efficiency. ICAPM remains linear, but entails multiple factors.

The APT was widely seen as a positive development as it reduced the number of assumptions required by CAPM and has gained greater empirical support. Empirical findings support the view that company beta alone is not adequate as a measure of risk, reflected in the fact that high beta stock returns tend to be overstated (Paavola, 2006). Beyond improved empirical support, the APT makes fewer assumptions than CAPM. The residual assumptions of APT are frictionless markets, with unrestricted trading and individual borrowing or lending at the risk-free rate, a sufficient range of investments to diversify away idiosyncratic risk, and the risk-aversion and utility maximising nature of economic agents (Paavola, 2006).

\subsubsection{The APT}

APT was developed as an efficient markets' evolution of the CAPM by Ross (1977). It aimed to explain empirical challenges (deviations from market efficiency) that persisted under the CAPM specification of risk measurement by incorporating macroeconomic shocks into the model of risk for companies (Reilly and Brown, 2003). APT provided a new model of risk (to that of CAPM) by extending risk measurement to a number of macroeconomic variables (Reilly and Brown, 2003). This information was then incorporated into risk assessments for individual companies. APT and APM add the micro-efficiency of company stock price betas to the macro-efficiency of macro-economic variables, implying that micro-efficiency is sensitive to macroeconomic variables.

APT extended the model to include macroeconomic risk betas. Initially APT left the potential additional variables undefined and unlimited. This attracted criticisms that the APT lacked a theoretical basis for variable inclusion (Morel, 2001). Chen, Roll, 
and Ross (1986), identified potentially stock-price relevant macroeconomic variables (shocks). Historical security price performances/betas were regressed on the betas of these variables and the company stock price beta of CAPM. The factors were selected to identify unexpected movements in asset prices that were undiversifiable (Chen, et al, 1986). ${ }^{29}$ The information about the variable needed to be timely and the variables required a theoretical foundation. These conditions led Chen, et al (1986) to identify the following influences to incorporate in an extension to CAPM:

- Inflation shocks

- GDP shocks

- Investor expectations shocks due to changes in the risk premia of corporate bonds relative to five-year Treasury bonds

- Surprises (shocks) in the yield curve

- And, oil shocks

Of these variables, changes in industrial production, yield curve 'twists', and risk premia 'shocks' were found to have greatest significance as explanations of observed market pricing. Inflation 'shocks' were found to have limited significance, and oil shocks were not significant (Chen, et al, 1986). Notably, subsequent research has found more equivocal results. Shanken and Weinstein (2006) found that 'reasonable alternative procedures' deliver substantially different results. A full-period postranking return approach is used which provides an alternative measure of portfolio betas. Given these betas' divergence with those used by Chen, et al (1986) most of the macro-financial variables identified in the original research show no significance. Equally, Shanken and Weinstein (2006) note research supporting the view that empirical support for APT is sensitive to the selection of sub-periods when estimating betas. That is, different results arise in relation to different segments of full-period APM models. Of the original macroeconomic variables only industrial output remains significant in Shanken and Weinstein's (2006) research in terms of a model of market prices for companies.

\footnotetext{
${ }^{29}$ Unexpected as used here means any changes in share prices that stock-to-company stock price beta alone would not have predicted.
} 
The potential for macro-variables to offer insights into market movements arises in APT. However, APT has different objectives from the present research, developed from different assumptions. Despite this, APM and this research share certain common features. APM indicates some variables relevant to this thesis. Where APM aims to identify macroeconomic variables that are plausibly implicated in individual stock price movements, the current approach aims to further refine the suite of variables considered by identifying variables that are plausibly indicated in the financial acceleration of equity markets. Consistent with Chen, et al (1986) these variables include interest rates and spreads. The aim is not to explain the efficiency of current market prices but to use macro-financial variables to develop prediction models of market direction.

The efficient market solution (the APT) to the 'misspecification' of risk by CAPM is linked to this thesis in terms of the relationship it hypothesises between macro-financial variables and valuations. However, it is distinct in many important respects. APT aims to explain the correctness (efficiency) of markets through examination of macro-financial variables which are then identified as better risk estimators (than CAPM) based on subsequent market price movements. The theory behind this thesis explicitly rejects market efficiency and, therefore, validation of the market through its anticipation of subsequent market prices. Simply, the concern here is not to establish particular company price reaction functions to a specified set of macro-financial risks but to describe the nature of macro-financial risk to company values with a view to forecasting market movements. This goal is based on the assumption that the levels of such risks are identifiable prior to widespread financial disruption and they exist in measures of aggregates reflecting bubbles. Further, this research makes no demand on the objective nature of any given market level. The positive statement made here is cautious in this sense. Typically, growing macrofinancial risk to companies will parallel rising equity prices as the action of financial acceleration supports increasing equity markets (Pepper and Oliver, 2002). Thus, growing macro-financial risk is likely to be accompanied by rising equity markets to the extent that those rising markets reflect the role of financial acceleration, and that this is a manifestation of excessive exuberance identified in Minsky's (1986) FIH as the 'euphoric' phase of the business cycle. Equally, periods of below average risk may be identified. 


\subsubsection{Other models: Extending CAPM with Fundamental factors}

Fundamental factors were added to CAPM risk specification by inter alia Fama and French (1995) in research motivated by anomaly research (to the efficient market hypothesis). In particular, the inverse relationship between company size and subsequent returns on a company's equity and the positive relationship between high book value to stock price and subsequent stock price performance required either the abandonment of the assumption of market efficiency or a revised model of risk. Fama and French $(1992 ; 1993 ; 2004)$ empirically developed a three-factor model by adding betas for company size and company book value-to market value ratios. The threefactor model improved the model's correspondence with observations over those of CAPM. Notably, the extended model still failed to account for abnormal momentum returns identified by Debondt and Thaler (1985).

The three-factor model was developed to augment CAPM as the added variables were able to be plausibly theoretically isolated as risk factors. Anomalies not included (such as abnormal momentum returns) have no efficient markets' theoretical foundation. The size anomaly is plausibly explicable in terms of a number of characteristics of larger companies compared to smaller ones, such as the greater capacity to diversify finance streams and revenue streams. Such features can reduce risk. However, the increased riskiness of high book value to market value companies (which have been shown to out-perform growth companies over time) is less obviously a risk indicator. Fama and French (2004) argue that lower returns may be achieved on the assets of companies with high book values relative to their market prices, when compared with the return on assets achieved by high growth companies. This is clearly a heroic argument as it fails to account for the systematic out-performance of 'high book value' companies. For this reason the 'prospects' view is tenuous. Equally, Fama and French (2004) tacitly concede the lack of any plausible basis to implicate momentum anomalies in company riskiness as they do not attempt to incorporate the factor into their extended CAPM model.

In contrast to the efficient markets' apologia-predicated extensions of CAPM advanced by inter alia Fama and French $(1992 ; 1993 ; 2004)$ this thesis proceeds on the basis that extensions to CAPM are unsupported theoretically. Markets may not (or may not invariably) reflect an objective assessment of fundamentals (or the distribution of 
future cash flows of a company). In light of the case made in chapter two, that markets are not reliably efficient, the following sections identify and describe research predicated on the view that markets are frequently mis-priced, either undervaluing or overvaluing future cash flow distributions or, by miscalculating risk.

\subsection{Existing implicit and explicit models of market values under assumptions of market inefficiency}

An alternative body of views hold that markets are not reliably efficient in a number of important regards. These views generally assume that the market is mispriced or, at least, unlikely to be priced purely on fundamentals at any given point in time. Beyond this it is also assumed that there are identifiable ex ante signals of this mis-pricing that allow forecasts to be made. These forecasts are typically very general in nature.

Historically, business cycle identification has adopted a number of approaches. In the modern era this area has received the attention of prominent economists. Included amongst these are: Mitchell and Burns (1938); Moore (1974); Checcetti (2003); Borio (2003; 2006); Borio and Lowe (2002); and Shiller (2005). The respective authors apply varying approaches. Mitchell and Burns, and Moore adopt a substantially descriptive, approximately real-time approach, assessing leading, lagging, and coincident indicators to identify phases in the business cycle. Moore (1974) identifies the evolving nature of this approach; subject to changes in data sets, understandings of the relative importance of different variables, and the economy. Borio and Lowe (2002) assess the priority of changes in credit aggregates as a primary business cycle indicator. Conversely, Shiller examines a movement from a defined long-run equilibrium value. Following the intuition underlying Shiller's (2005) approach, this discussion aims to isolate signs of future market direction as a basis for prediction.

Research and literature that aims at building an index of signs or causes of market or economic deviations from fundamental value typically has positive bubbles in focus, with the aim of deriving appropriate monetary policy responses to these. Such research also invariably assumes substantial departures from market efficiency. The monetary policy focus requires high levels of variable specification if the research is to productively address bubbles and concomitant adverse economic consequences, and to 
do this without creating its own negative effects. This issue is identified in Trichet's (2005) discussion of risk and related concerns about the occurrence of 'false positives' that his tentative support for Borio and Lowe's (2002) index delivers. Again typically, the implications drawn from such research are that direct interventions in the economy and/or markets are necessary. It does not attach concern to 'negative bubbles'. Although recessions are an important concern for economists and policy makers this concern is for the mitigation or prevention of these rather than their identification once in recession. In these key regards what I target is a less direct response that reduces the risks attached to 'getting it wrong' (producing a type one error). Accordingly, negative bubbles will be considered as well as the more typically addressed positive bubbles. Secondly, the focus of this research is on equilibrium value. Arguably, standard policy prescriptions that form the typical motivation for this area of research are the result of the asymmetric nature of current monetary policy. This policy tends to react more periodically but also more vigorously to deflationary threats than to the risk of elevated inflation. This concern is not relevant in the context of this thesis. Thirdly, what I aim at is a more general description of the economy and markets and, thus, to provide short term market forecast models.

\subsubsection{Minor departures from market efficiency}

Long-Term Capital Management (LTCM) developed a model for arbitraging identified anomalies. This is one of the more modest (and localised) departures from market efficiency. Again, the strategy established assets' values relative to other assets. Examples include US Treasuries compared with US corporate debt or Russian treasuries compared with Russian rouble-based bank loans. LTCM identified past trends in these series' relative pricing. This implies fundamental value is the historical relative price trend. Departures from trend were then arbitraged. Assumptions underlying this approach were that the compared series would revert to historical trends and that values would converge on maturity.

A suite of factors undermined the LTCM model. These included its progressive use of leverage, and an increasing move into less liquid assets. Notably, the model was failing to produce abnormal (positive) returns prior to increased leverage and this was a key cause of the greater use of leverage in an attempt to satisfy investor returns expectations. Those issues are not relevant to the present thesis. What is relevant is the 
identification of the circumstances leading to the failure of the compared assets to revert to trend, such as debt default. Assumptions underpinning the expectation of trendreversion are that risk remains constant over time. This is not a sound base to rely on. More importantly, the LTCM arbitraging model is not a fundamental value model but one that identifies relative value, and then only in relation to a small set of 'companion' assets. The LTCM model determines its view of fundamental value from the market (similar to Black-Scholes) but it relaxes the assumption of market efficiency slightly to infer that historical relative-price trends equate to fundamental value and that departures from those historical trends constitute departures from fundamental value.

Other trading strategies have been developed by quantitatively-orientated funds that aim to exploit minor and localised deviations from a purely efficient market (described as 'anomalies' from an efficient market perspective). The Roll \& Ross Fund exploits research identifying price-to-book and price-to-earnings 'anomalies'. Yet again, these approaches identify trading opportunities from the base of assets that are undervalued relative to other assets. Unlike the present research they assume a broadly efficient market. In this view the market broadly reflects fundamental value. Minor exceptions to market efficiency create the basis for market-relative gains.

\subsubsection{Behavioralism}

Behavioural explanations of market movements range from the rational to the irrational. The view of market efficiency and of markets as reflections of fundamental value occupies the classical economic end of the spectrum. The view that markets are essentially irrational occupies the other end of the same spectrum. Between these views lies the behaviouralist view that markets may be influenced primarily by rationality but this does not entail that they reliably reflect fundamentals. As argued here, investor rationality does not require that market prices are accurate measures of fundamentals. Investors must frequently supplement objective assessments with speculative inputs. The plausibility of sentiment influencing such assessments appears strong. Equally, information cascades and herding appear to offer plausible explanations for market price behaviour as observed.

A body of research based on behavioralism explores reasons why markets might reflect pricing inefficiencies. Morck, Schleifer, and Vishny (1990) argue that markets 
are not driven solely by fundamentals but by investor sentiment. They employ the view that closed-end funds' discounts to the net asset value of their portfolios provide a measure of the influence of sentiment. Their view is that arbitraging is risky and that the activities of investors arbitraging mispriced value stocks may not, therefore, eliminate mispricing as those investors limit their positions. Other researchers observe trend extrapolation as a source of market movements (La Porta, Lakonishok, Schleifer, and Vishny, 1997). Cooper, Dimitrov and Rau (2001) found that companies adding 'dot.com' to their names during the late 1990s increased their share prices by $74 \%$ about the time of the change, without any change in their underlying businesses. Equally, those companies' values increased relative to the market in the wake of the 'tech wreck' by removing the 'dot.com' from their names. Pepper and Oliver (2002) identify a feedback loop through which excess investor liquidity drives share prices up generally. Any of these factors may result in information cascades in which private information is subordinated by investors to crowd behaviour (Bikchandani, Hirshleifer, and Welch, 2008). Social learning and risk-aversion may result in herding which treats the behaviour of others as an independent source of information (Hirshleifer, Hong and Hong, 2007).

Daniel, Hirschleifer, and Subrahmayan (2001) build their theory of asset pricing from the foundations of the risk-based pricing of efficient markets' models. They add to this base the role of the over-confidence of some investors in their ability to identify stock pricing signals. A mis-pricing equilibrium results as caution limits the actions of smart arbitrageurs to eliminate the pricing effect of over-confidence (elsewhere this tension has been described as between information traders and noise traders (Greenwald and Stiglitz, 1981).

\subsubsection{Money supply, credit, and liquidity as influences on asset prices}

Pepper and Oliver (2002) identify the role of liquidity in driving equities away from fundamental value. Liquidity trading is caused by market participants' need to raise cash or when they have surplus money to invest. In contrast to fundamentals trading, liquidity trading corrupts the efficiency of market prices established by information trading. However, price trading will cause liquidity trade movements from fundamentals to revert to an efficient level. From this, any factor that systematically 
and persistently, but unsustainably, alters liquidity creates a positive or negative bubble. This is compounded by extrapolative expectations which build on the trend.

The motivation behind the ideas of Pepper and Oliver are similar to those behind the approach adopted in this thesis. They credit Keynes as one of the key theorists of this line of thought. Liquidity, in the argument of Pepper and Oliver, is essentially determined endogenously. Bank lending stretches credit availability to accommodate demand. Whatever level of base money exists in an economy it is sufficient for bankcreated credit to multiply almost indefinitely. Demand for money is not reliably stable as it is determined by expectations that extrapolate from recent business and market trends. These expectations can cause money demand trends, building supply over economic expansions or collapsing it through recessions. From these factors Pepper and Oliver infer asset price bubbles caused by sustained growth in monetary and credit aggregates.

In a similar vein to the research of Pepper and Oliver (2002), Detkin and Smets (2004) found that broad money supply and credit developments are among the few early indicators of high-cost asset price booms. This argument is also advanced by Renshaw (1995), who makes the case that conditions of a money gap and a budget deficit of greater than $3.5 \%$ of GDP are highly correlated with rising stock prices and they are necessarily unsustainable in the long run. Western (2004) holds this view, although with the caveat that velocity volatility may confound meaningful inferences from the growth in money supply in terms of a) the causal relationship and b) monetary policy implications.

Borio and Lowe (2002) and Trichet (2005) make a case for the growth of the 'credit gap ${ }^{30}$, relative to historical average credit to GDP, as the best indicator of future economic and financial instability. They link credit 'overproduction' to rising as set prices. Acknowledging the difficulty posed in establishing a financial vulnerability index, the authors describe the views presented as a preliminary step towards such an objective. Their paper considers a large cross-section of countries (34) over the period

\footnotetext{
${ }^{30}$ The credit gap is defined as a deviation in credit-to-GDP, in relation to its trend. This is essentially an historical average, adjusted for any long term, systematic bias in credit aggregates and so is more muted (and concomitantly), less likely to produce false positive predictions, than credit-to-GDP simpliciter.
} 
1960-1999. They focus on cumulative process (the length multiplied by magnitude of the gaps above threshold) versus growth rates in credit, investment and asset price gaps. ${ }^{31}$ Their finding is that an asset price gap of $40 \%$, combined with a credit gap of $4 \%$, reduces false positives to below $5 \%$, but it is predictively successful in only $42 \%$ of cases. Conversely, a credit gap at the same threshold is predictively useful in $78 \%$ of cases, with $18 \%$ false positives. In simple terms the single-factor 'credit gap' model successfully predicts almost four fifths of observed events but it comes at the cost of falsely predicting events nearly one fifth of the time (as opposed to less than $5 \%$ of the time in the case of the dual factor model). Importantly, and in contrast to Borio and Lowe (2002), Adalid and Detkin (2007) find that monetary aggregates demonstrate stronger information regarding financial vulnerability than private credit does.

The present research is developed as a particular specification of this general body of research. It draws on insights provided by this focus but is not explicit in terms of the extent to which the identified variables are causal or symptomatic. That is, financing structures and institutions support financing flows and these are held as the transmission mechanism of financial instability. There is no separate requirement of them to be the cause of financial market instability. Arguably, such flows simply reflect competitive tendencies that are inherent to market-based economies. However, it is more plausible to assume endogeneity in financing flows through their interaction with market prices.

\subsubsection{Tobin's $Q$ and imputed returns}

Boldrin and Alva (2009) examine company fundamental value at a more basic, independent level. They employ Tobin's Q combined with a required rate of return to arrive at their conclusion that US stock markets were fundamentally undervalued from the mid-1970s through to the mid-1980s. This approach suffers from a number of limitations distinct from those affecting Shiller's measures (See: 6.3). Tobin's Q focuses on tangible assets and so suffers from the problems described in section 6.3 in relation to Price-to-earnings ratios. These problems relate to the 'conventional' basis to the calculation of PERs, including changing measurement bases and depreciation.

\footnotetext{
31 The asset price gap is determined by separate and aggregated price information on residential property, equities and commercial property. This is inflation adjusted. The $40 \%$ threshold is against long term averages. The authors make the case that each component only acquires meaning as a risk indicator in the presence of the other.
} 
Arguably, this could be resolved with a more inclusive measure of a company's value but the required rate of return is estimated and the actual rate of return is determined $e x$ post, being based on dividend flows and subsequent market movements as components of net cash flows.

If we were to consider any historical time series of a market then a period before a substantial and sustained rise or fall in that time series would (retrospectively) have been a good/bad time to buy, assuming such a rising trend is imputed as a return. All Boldrin and Alva appear to be telling us is that there are (positive/negative) abnormal returns to be had by investing at the start of a bull or bear market. Even without the serious limitations described, such a metric would have little value in the present case as fundamental value in this case, is something that is validated by future market movements rather than being identified ex ante.

\subsubsection{Cash flows and sales}

Morck, Schleifer, and Vishny (1990) employ cash flows and sales as their measures of fundamental value. This approach improves on Shiller's (2005) approach (see: 6.3) as it uses measures that are not influenced by accounting conventions to the same extent as earnings ${ }^{32}$. Certainly, sales and cash flows can be advanced or deferred to a degree but this should balance out over any reasonable number of periods. The concern is that these variables reflect the influence of liquidity and its impact on changing market levels as the basis for identifying fundamental value. Sales and cash flows may have rising asset prices as an independent driver which renders such signals self-justifying.

\subsubsection{Quantification of sentiment}

Sentiment quantification is the basis for an approach by Credit Suisse (CS) to identify trading strategies. This approach follows an essentially contrarian strategy. It builds from behaviouralist explanations of perception bias, disaster myopia, social contagion and herd behaviour. The model was developed in 1997 and it is the CS Global Risk Appetite Index (GRAI) (CS Global Investment returns Yearbook, 2012; CS Monthly Report, 2011). This index determines excesses of exuberance and pessimism on the basis of the relative performance of safe assets (government bonds) against risky

\footnotetext{
32 The limitations of accounting information relate primarily to changes in accounting conventions, including measurement bases. This is discussed extensively from section 6.3.
} 
assets (equities). The long term trend in the performance of these asset classes is inferred as a measure of fundamental value. The approach has yielded significant positive abnormal returns in the period 2009-2011 suggesting some substance to the approach (CS monthly report, 2011).

The CS GRAI approach has similarities to the approach adopted in this thesis. In both cases it is assumed that asset price movements deviate from fundamental value and that these deviations are identifiable. Further, trading rules may be developed to exploit these deviations and expected mean reversions. Equally, departures from trend are inferred as excesses of exuberance or pessimism in both instances. However, the CS GRAI is concerned with identifying favourable asset class mixes. This research focuses on equities and identifies fund flows' financing corporations as an important proximate signal of sentimental excess, rather than the relative performance of equities and bonds. The CS GRAI does not accommodate co-movements in bonds and equities and it provides an equity or bond-relative fundamental value. Rising bond prices may co-move with rising equity prices and maintain their historical relationship, supporting the strategy of market-weight positioning. Instead the model signals deviations from historical trend.

\subsection{Alternative measures of fundamental value: Shiller's index}

The 'inefficient market' approaches outlined so far do not explicitly identify a concept of fundamental equity market value, nor do they present a basis for inferring a notion of fundamental value. The most any of these approaches do is to implicitly and negatively define a (positive) movement from fundamental value. That is, when liquidity or credit is high/er than normal (historical trend) or, alternatively, when cash flows or sales deviate above past trends then a bubble exists. Shiller comes closer than this to an index of fundamental value by identifying ten year average price-to-earnings ratios (PER) above historical averages and house prices compared with historical trend. House prices are also related to incomes or household affordability.

Shiller's (2005) implicit index is composed of observations of long term relational values of housing stock and equity securities' prices. For the purposes of this thesis Shiller's measures of stock prices relative to earnings only are relevant. Shiller's implied index of deviations in asset prices from their long run equilibrium relates the 
S\&P Composite Stock Price Index (inflation adjusted) to earnings over the period 18702005. He makes the case that significant increases in stock prices relative to earnings implies overvaluation, potential 'bubbling', and a heightened risk of mean reversion. Shiller relates price-to-earnings ratios (PERs) to interest rates movements over the period 1881-2005. This connects with earnings as the absolute value of assets is determined by the relation of risk assets to risk-free proxies. With this in view, risk asset prices tend to move inversely to interest rates. This identification is provided empirical support by Shiller of what is an essentially Minskian contraction of lender margins and increasing borrower margins over periods of economic and market booms.

Shiller (2005) uses widely-employed conventional measures to determine fundamental value. ${ }^{33}$ Shiller's primary measure of equity market fundamental value is the PER. He relates PERs (after averaging them over ten years to control for recessioninduced rises in PERs) to long term averages. In essence Shiller's model treats the longterm average PER as a reflection of fundamental value. The process involves a form of de-trending. Shiller does not explicitly identify when a market is overvalued beyond the relationship between current and past PERs but argues that PERs far above historical average imply overvaluation. His focus is on overvaluation so he does not explicitly identify when markets are undervalued. However, it is reasonable to infer undervaluation of PERs when they are significantly below historical average.

Problems arise with the use of PERs and other accounting information-derived metrics, such as price-to-book value (net asset value). Apart from certain methodological concerns about Shiller's manipulation of his data, he relies on a metric that is subject to change. The growth of fair value accounting measurement and different components included in profit impacts earning and PER, without an underlying change in economic reality. Similarly, the reality that accounting information describes is subject to change, and systematic biases in accounting measurement bases aggravate a decline in comparability of 'fundamentals' over time. Specifically, the growth in research expenditure in the last decades of the twentieth century may have suppressed accounting earnings over the period, as research

\footnotetext{
${ }^{33}$ These are widely used in the sense of concurrent valuations of companies or industries, relative to each other, not in terms of total market fundamentals as Shiller uses them.
} 
expenditure is expensed as a matter of accounting requirements. Research also frequently produces intangible assets which are not recognised when they are developed internally. This is despite the fact that research is arguably long-term value accretive. These issues recommend caution in the inferences that can be drawn from PER levels and changes in levels, relative to historic levels.

A concern independent of the reliability and consistency of PERs is that Shiller implicitly argues for the objectivity of a 'correct' PER level. This position depends on an unstated auxiliary assumption that risk levels remain constant over the long term. Allowing that the basic view that investors require risk-adjusted returns is correct, any sustained variation in risk levels will flow through to PERs. ${ }^{34}$ PERs as measures of market mis-pricing, separate from an assessment of market risk, assumes a structural constancy in that risk over time. This point implies overdetermination in Shiller's assessment of market risk on the basis of PERs. Without an assumption of constant risk over the long term PER historical averages are not a reliable determinant of fundamental value.

Shiller (2005) developed a system of market risk assessment that achieves some success. However, his forecasts cover long periods and are very general. Much of the detail or richness of information that investors are interested in is not available using Shiller's approach. He describes the overvaluation in the market in 1996 and, in 1998, he speculates that the market will be little higher in real terms in a decade. Such observations are too broad, omitting too much detail, to usefully inform investment decisions. This is less of a criticism than a distinction between what Shiller aims to do (and what he achieves) and the shorter-term, more precise focus of the present research.

As with liquidity theories of market cycles and financial fragility, that examine various monetary and credit aggregates, the current research shares similarities with Shiller's research. His focus is on bubbles in housing and equity markets. The present research is concerned solely with equity markets and the forecast of short term market movements. A further distinction is that Shiller is able to make very general, long term

\footnotetext{
${ }^{34}$ Even without an efficient markets' presumption that this process is rapid, the influence of changing risk levels will flow through eventually.
} 
statements about his expectations for future market movements whereas the present undertaking aims to provide richer detail, with shorter term movements in markets as the focus.

\subsection{Short term market prediction modelling}

A variety of short term market prediction models exist. These are typically technical in nature; identifying patterns and trends in market trading volumes and prices. The genesis of modern technical prediction models is generally viewed as lying in the development of Dow Theory, although technical approaches preceded this. Other models include Elliot Wave theory which is based on mass psychology and infers identifiable regularities in the behaviour of markets; Candlesticks; the Butterfly Effect Theory which monitors the speed and acceleration of price movements to identify trends; frequent use of moving averages of varying lengths, and movements through these averages; and a number of relational predictive models such as the Long Term Capital Management model and Credit Suisse GRAI index. Despite the extent of trader reliance on these models academia in general maintains that markets (certainly in the short term) follow a random walk and are, therefore, unpredictable (Houthakker, 1961; Kendall, 1953; Malkiel, 2003a; Schwert 2003a; 2003b).

A general assumption of short term market prediction models is that the parsimony of the fewest possible predictive variables is to be preferred (Atsalakis and Valavanis, 2009). Inputs to short term modelling commonly include market opening and closing prices as well as daily highs and lows (See: Donaldson and Kamstra, 1999; Halliday, 2004; Thammana, 1999; and Tang, Xu, Wan, and Zhang, 2002). Transaction volumes are also commonly used (See: Doesken Abraham, Thomas, and Paprzycki, 2005; Ajith, Baikunth, and Mahanti, 2003; and Ayob, Nasrudin, Omar, and Surip, 2001). Previous day closing prices are also included in some methods (Atsalakis and Valavanis, 2006). Research in this field may also include various exchange rates (Huang, Nakamori, and Wang, 2005). Such modelling is frequently augmented by fundamental analysis (Atsakis and Valavanis, 2009).

Common features of short term market prediction modelling lie in their use of proximate (daily, prior day/s) inputs. These models typically aim to achieve forecast accuracy over succeeding day/s or weeks. As such they target the systemisation of 
trading rules. Adapting this very short term focus, and cognisant of generalities across the preferred indicator variables, this thesis adapts market volume and price (level) histories, including quarterly market movements. This development is consistent with Minskian analysis and its prediction of expansionary, euphoric, panic, and recovery phases of the business cycle, each phase variously driving market price (level) and trading activity levels (volume). The approach is also consistent with Dow Theory and its market cycle phases (Sabrapriya, 2012).

The genesis of modern short term asset market forecasting is generally viewed as lying in Charles Dow's development of the basic principles that were later to become known as Dow Theory (Subrapriya, 2012). As with standard short term forecast modelling it is a form of technical analysis. Dow Theory describes three observationbased market movements (Brown, Goetzmann, and Kumar, 1998). These include the main movement lasting from under one year to several years. A secondary consolidating movement retraces part of the primary or main movement and lasts between ten days and three months. Minor movements or short swings retrace some of the secondary movement and last from a few hours to several weeks. Major movements are divided into three basic phases. These include the accumulation phase in which knowledgeable investors acquire/dispose of stock (dependent on the anticipated direction of the trend). This leads to the public participation phase in which increasing numbers of investors mimic the activity of knowledgeable investors. Phase three is characterised by rampant speculation. In this phase knowledgeable investors begin to invest/divest their holdings (Sabrapriya, 2012). This is equivalent to Minsky's euphoric phase. Heightened volumes and price and volume volatility are expected at this time.

Dow Theory is characterised by a number of assumptions. These include that markets are reasonably efficient and that market averages reflect all knowledge about a stock (or the market); industrial and transport indices must both confirm a trend; the trend continues until there is a clear reversal; and, market volumes confirm a trend (Sabrapriya, 2012). These considerations support the inclusion of historical market price and volume data as test variables in the predictive models developed in this thesis.

Dow's theoretical base is broadly market-efficient. The theory requires trend confirmation by different major market indices. These include industrial and transport 
indices. Trend confirmation also requires supporting trading volumes. Low volume movements do not entail a change in the trend as they may be due to a variety of factors. This aspect of Dow Theory is based on the correctness of aggregate investor expectations. Further, definitive signals are required to signal the end of a trend (Sabrapriya, 2012). This adds to the confirmation outlined above a requirement for a distinct departure from the trend to ensure that what is observed is not merely a minor reversal.

Elliott Wave Theory is based on crowd psychology and assumes regularities in market movements. Developed by Ralph Elliot in the 1920s the theory assumes market reactions are followed by predictable reactions. The assumed pattern is a main trend of five waves with three corrective phases. After eight phases a market trend is complete, to be followed by a new five-three pattern. Different patterns may be assumed by Elliott Wave Theorists including Fibonacci patterns, identified as recurrent in nature, harmonic and fractal ratios are also used by some proponents. It is assumed that markets, as natural phenomena follow identifiable natural movements.

Candlesticks are used especially as very short term predictive tools. Originally developed by a Japanese rice trader, candlestick-type graph bars depict the opening and closing prices of a market, stock or commodity, and the high and low prices in a given period of trading. The original motivation for this approach was the rice trader's observation that natural markets in which supply and demand were unconstrained were predictable by this method. These candlestick formations have been developed to incorporate moving averages of various lengths to augment short term price trend prediction.

The Butterfly Effects Model monitors the speed and acceleration of price movements, arguing that a slight initial disturbance can have a big impact on future stock prices. Plausibly, large knowledgeable market participants are likely to be first movers based on greater access to information. Approximate to the accumulation phase of Dow Theory this trading by information traders is likely to drive prices up reflecting long term expectations for changes in value. Arguably, this strategy reflects a refinement and early reaction prospect but is essentially a derivative of Dow Theory (Stock Forecast, undated). 
A number of relative price-based prediction models have also been developed. Long Term Capital Management (LTCM) trading strategies were based on identifying historical trends between related assets and inferring this historical trend constituted an exploitable anomaly. This method was based on an assumption that any departure from past pricing relationships would revert to trend. In a similar fashion the Credit Suisse GRAI index identifies relative departures between a risky asset portfolio and one which is risk free to adopt what is an essentially contrarian strategy, operationalised by overweight positions in the 'under-valued' asset basket.

Despite general academic resistance to the concept of short term market predictability (see, for example: Houthakker, 1961; Malkiel, 2009; Schwert, 2003; 2003a) each of the identified approaches has attracted considerable support from market participants. For the purposes of this research, candlestick analysis is too short term in focus, relating more clearly to day-trading or periods of no more than a few weeks. Elliott Wave Theory, independent of its usefulness, is longer term in its forecasts and there is no analytically obvious way to adapt it to quarterly predictions. Moreover, it identifies causality and the aim in this thesis is to isolate proximate causes rather than to create a superstructure in which each causal connection is identified. Corporate financial flows' data may well have psychological and fundamental drivers, and may be an independent driver in their own right, but, for the present purposes, this is subordinate to their signalling effect. Thus, common features that emerge from Dow Theory and Butterfly Effect Theory, and which are consistent with Minskian analysis, indicate the inclusion of market price and volume histories as independent test variables.

Trend analysis, whether motivated by assumptions of (near) efficient markets or behavioralism, indicate the use of historical price and volume data. This addition to more explicitly Minskian-derived variables is consistent with Minsky's (1986) FIH as it is reasonable to expect price and trading volume signals to accompany the different phases of Minskian business cycles, such as elevated trading volumes and price volatility in the euphoric (disposal) phase of the cycle. These considerations indicate the testing of independent variables which include market level (price) history and trading volume history as signals of future market movements. 


\subsection{Summary and implications for the current research}

In line with the case made in chapter two and the different aims identified of models of fundamental value based on market efficiency this thesis develops the view that fundamental market value is unobservable but, also, that there are signs supporting inference to the direction of market deviation from fundamental value. This position assumes the market is inefficient in the short term. Consistent with the views of behavioural economics, this argument identifies the role of sentiment, of herding, and of outcomes that support fundamental value as just one of the inputs in to market prices. Another element to the approach indicated is that markets, over the long term, progressively improve in terms of their reflections of fundamental value. The use of a Minskian perspective advances the case for using signs of the transmission of varying degrees of economic instability through financial variables. The selected variables include corporate debt and equity flows.

Shiller's (2005) work is an important 'inefficient markets' attempt to predict market movements. Shiller (2005), unlike CAPM ${ }^{35}$ and APM, does not start from an assumption that the market (or a market) is a sufficient proxy for fundamental value. However, Shiller's index, although related to market forecasting, and operating from the same assumption of market inefficiency used in this thesis, provides only long term forecasts. Notwithstanding the success of Shiller's work, it leaves a gap in terms of short-term forecast models. Issues of the reliability and consistency of the information bases used by Shiller have also been identified in this chapter.

This chapter has identified existing research related to market forecasting and equity valuation modelling. A gap in existing research has been identified in terms of the dearth of short term market forecast modelling (other than that derived from essentially technical analysis). Further, the lack of research or modelling based on

\footnotetext{
${ }^{35}$ At a theoretical level CAPM assumes that all competing investments are the referent for fundamental value although its operationalisation has effectively reduced it to such the assumption that a single market (such as the S\&P 500) is a sufficient proxy for all investment alternatives.
} 
funding flows is an identifiable gap. I address these issues from an 'inefficient markets' perspective, incorporating funding flows into theory and market forecast modelling. The extrapolative expectations theory of corporate financing decisions is the basis for this development. Further, elements of current technical analysis which are consistent with Minsky's FIH are also employed to augment model development.

Chapter seven builds on the conclusions of this and preceding chapters to develop the methodology for modelling future market performance. The aim is to isolate predictive variables of short term market movements. The preceding chapters have provided indications of potential independent variables for use in regressions. These variables are selected on the basis that current levels of market efficiency may be improved through the use of variables indicated from an analysis of markets based on the insights of Minsky (1986). The broad regularity of corporate financing flows and their relationship to market movements supports the inclusion of these as test variables. These and other variables are discussed in the following chapter. 


\section{Chapter seven Methodology}

\subsection{Introduction}

This chapter describes the methodology used to econometrically test the central claim of this thesis; that macro-financial variable factors provide signals of subsequent market movements which may be isolated to produce market forecast models. The 'market' tested is the S\&P 500 index. Central to this undertaking is the previously identified and expounded theoretical case (chapters two, three, four and five) that markets cannot reliably reflect fundamental value. On this view, markets at a broad level do not reflect the aggregation of fully informed and rational assessments of the distribution of future cash flows, which are later validated by market prices. Instead of the notion of efficient markets, a number of factors operate to confound markets' reflection of fundamental value. Relevant factors include: momentum, market cycle phase, sentiment, the Keynesian 'beauty contest' or view that investors care less for company or market fundamentals than they care for their own (and heterogeneous) views of other investors' opinions on fundamental value, and liquidity. ${ }^{36}$ The view of market efficiency argued for previously supports each of these factors as inputs that augment investors' aggregate net cash flows' estimates in their calculations of equities' net present values or, more precisely, reflect aggregate investor expectations about the trajectory of short term equity price movements.

The key themes developed in this thesis to this point include: a general argument in favour of inefficient markets; Minsky's (1986) hypothesis of the endogenous instability of market-based economies and of asset markets; the primary role played by financing structures and channels in creating instability (Minsky, 1986); and, the importance of the financing channel in particular as both a transmission mechanism of instability and as an independent source of that instability and creation of asset price bubbles. Each of these elements and observations of repeating behaviours in corporate debt and equity flows particular to the market phase from 1980 to 2012 from the US equity markets, provide the basis for independent variable selection. These theoretically and observation-indicated macro-financial variables provide the test variables for

\footnotetext{
${ }^{36}$ Keynes' 'beauty contest' describes investors' focus not on stocks they feel will perform well (fundamentally and operationally) but those stocks they believe other investors believe will outperform in the future (Keynes, 1936).
} 
separate binomial logistic regressions on market rises and market falls, assessed on a quarterly basis.

From the basis of the theory outlined two primary 'Sutton' market forecast models are developed. These relate, respectively, to quarters of market increase and decline. The models have been developed from a suite of theoretically indicated variables. These variables include: corporate financing flows, historical market movements, interest rates, money supply aggregates, monetary policy proxies, and current account deficits. The aim with these variables is to identify liquidity conditions and their impact on future company valuations. This involves focusing on companyspecific indicators in the main and on flows data to improve the precision of forecast modelling over that achievable through the use of 'stocks' (debt and equity) variables.

\subsection{Hypotheses}

The hypotheses tested set the null (H2) as an essentially unpredictable market but it is one that rises over time. That is, there is no ability to forecast future market movements except that the market will rise over the long term. Conversely, the alternative hypothesis (H3) is that by using certain predictors it is possible to predict future market movements. The implied hypotheses are as follows:

H2: Future Equity market movement forecasts cannot be improved over those implied by a random walk.

H3: A number of macro-financial variables improve forecasts of market movements over those implied by a random walk.

Evidence for $\mathrm{H} 3$ relies on the ability of the models developed in this thesis to provide increased implied returns over those achievable by a buy-and-hold strategy (H2). The hypotheses are tested for the period 1980-2012. Because markets rise above risk-adjusted levels over the long term, a successful forecast model must be able to improve returns over those that assume the unpredictability of markets. To the extent that this is achieved (discussed in chapter eight 'Findings'), holding in mind that such models start from a default presumption of risk-asset exposure, any increase in implied returns is attributable to that model's signals to withdraw from (and return to) equity 
markets. Model dependent and independent variables are detailed in sections 7.3 and 7.4 .

\subsection{Binomial logistic regression}

The methodological approach adopted in this thesis involves the use of binomial logistic regressions to identify the optimal combination of theoretically indicated variables best able to improve forecasts of market movements. This method is used due to the need to divide the dependent variable (DV) into 'buy' and 'sell' classifications. In simple terms the same set of predictor variables cannot be expected to predict alternative outcomes from a single regression. The excessive demand that simple linear regressions would place on the independent variable (IV) predictors is identifiable from the regressions detailed in chapter eight. Notwithstanding, there are commonalities in the respective (buy/sell) model predictors and, although some encouragement may be taken from the reversal of signs on common or similar variables, relying on the same variables would be incomplete. The position adopted here is that it is not only the case that perfect symmetry is unlikely to define relevant predictor variables, respectively, in the buy and sell models, but that this asymmetry may be aggravated by factors outside those contemplated in the models. It would be heroic to assume the tested variables were exhaustive of causality on stock prices, even if we were to limit such an assumption to macro-financial variables. For this reason a dichotomous dependent variable makes less onerous demands on the predictors than would a linear approach, assuming a more 'approximate' ability to explain the dependent variable (Stone and Rasp, 1991).

It would be too ambitious to assume that the variables isolating opposing DVs would, themselves, be reliably and consistently opposite. For this reason a more practical approach is to divide market movements by sign (rise/fall) and separately test theoretically indicated variables against a categorical (dichotomous) DV. These factors indicate the use of a binomial logistic regression (Peng and So, 2002; Stone and Rasp, 1991).

Binomial logistic regression is appropriate for analysing dichotomous outcome variables (Peng and So, 2002). The use of binomial logistic regression is predicated on the assumption that the DV event is linked to a linear combination of IVs by a logit 
cumulative density function (See appendix 1.1). The probability of a DV event occurrence, based on regression co-efficients (IVs) included in the model, is determined by taking the (natural) logarithm of the odds (or log-odds) of an event occurrence (Wenxia and Whitmore, 2010). The predicted value of the logit is then converted into predicted odds (of a DV occurrence) using the inverse of the natural log (or exponential function) to produce an odds ratio. Individual co-efficients (IVs) odds ratios of less than 1 indicate that a unit increase in the IV reduces the probability of the DV event. The converse is true of IVs greater than 1 (Wenxia and Whitmore, 2010).

The statistical package used to analyse regression test variables in this research is SPSS. SPSS employs an iterative process which befits non-normally distributed residuals (as in the case of dichotomous DVs). A tentative solution is posited as the first iteration from which SPSS works through a series of iterations, successively adding predictor variables (IVs) and rejecting those that new variable inclusions have rendered outside the inclusion threshold (statistical significance). This process ends when changes in parameter estimates are negligible. This point is described as convergence. In situations where the iterative process fails to converge, a number of causes may be indicated. These include that: there are too many predictors; multi-collinearity between predictors may be indicated; there may be sparseness of DV events; or, there is complete separation (by which the two groups of dichotomous DVs are perfectly separated by the scores or odds ratios on one or more IVs).

It is generally accepted that logistic regression requires more (DV) events per parameter (co-efficient) than linear regression. Hosmer and Lemeshow (1980) suggest that there should be at least ten DVs for each IV, but there is no consensus about the number of DV events required per parameter (Stone and Rasp, 1991). Suggestions have been made that as many as one hundred per parameter may be necessary. Notwithstanding 'rules of thumb' concerning the required ratio of DVs to IVs, some confidence may be taken from modest standard errors (SEs) relative to co-efficient means. Where SEs are small relative to parameter means, these parameters may be said to be accurately estimated. Small SEs also imply that the increased risk of multicollinearity that attends greater numbers of IVs has not been realised and that, therefore, the model predictions produced are not simply (flawed) artefacts of statistical processes. 
Stone and Rasp (1991) argue that sample sizes or the ratio of DVs to IVs are not central concerns in the application of logit models to data regression analysis. Where model mis-calibration occurs it is typically a function of DV skewness rather than because of the sample or population size or chosen IVs. For this reason and because logistic regression generally leads to greater correct classification of binary outcome DVs, Stone and Rasp (1991) argue for its superiority over ordinary least squares (OLS) regression (linear models). This argument forms part of the basis for selecting the logit model. Logistic regression has been also been used in accounting and finance research by (amongst others) Shultz (1995) and Carcello and Nagy (2002). For a survey of the use of logistic regression analysis in these fields see Baniv and MacDonald (1999).

Model power is an important determinant of the success of a model. Power comprises two components. Power is determined by the probability that a model will reject the null hypothesis when a hypothesis is true, that is, the probability that the model does not produce a type-2 error (or false negative). This defines the model's sensitivity. The second element of power is the probability of a finding of difference from the null that does not exist (a false positive or type-1 error). The aim of a successful model is to minimise type- 1 and type- 2 errors. This involves a trade off from the default (constant-only) model starting point which is majority selects the majority of the dichotomous IV for all periods extent of the more common of the two outcome (DV) variables and, thus, produces no type- 2 errors but has 100\% type- 1 errors. An increase in one error-type is likely to be strongly related to a decrease in the other error-type. The most powerful model is the one that optimises the trade off, achieving the greatest overall model success. This aim forms an important determinant of the regression process conducted in this research.

For the reasons identified, the dependent variable has been drawn as a dichotomous variable representing market rises (1) or no rise (0). A separate model is developed using quarterly market declines in which a quarter of decline is denoted 1 and a quarter of no decline is 0 . A threshold is employed (of less than 1\%) on minor increases and decreases to ensure that the implied risk-free rate does not invalidate translation of the forecast or prediction model into a decision model. That is, it constrains identification of an event to those that are economically significant. 
The use of binomial logistic regressions in preference to a linear regression is also predicated on an assumed level of imprecision or incompleteness in the models developed. The theory developed in this thesis is predicated on the absolute endogeneity of financial market volatility. Such an approach discounts the role of external shocks and, so, is reductionist. This is done to isolate endogenous instability rather than to suggest external shocks have no impact on the economic system. Thus, it is incomplete but deliberately so.

An additional advantage is that by setting up two distinct (buy and sell) models it is possible to extend or diversify the potential applications of the models. This is due to the binomial logistic regressions' (and Hosmer-Lemeshow test) ability to determine odds ratios which, when different models offer competing signals, creates an ability to arbitrate that competition by reference to investor preferences and relative probabilities. That is, in circumstances when the 'buy' model predicts a buy and the 'sell' model also predicts a sell or quarter of market decline. Alternatively, the respective probabilities of each signal can form the selection criteria. The models look at each quarter and predict the probability of an event, thus probabilities will be equal to or greater than one and both models could predict an event but at different probabilities. The selected approach can be tailored to investor preferences in which a preference for the buy signal maintains risk asset exposure and it represents a higher risk strategy. Conversely, a sell signal preference will see the investor withdraw from risk asset holding more frequently than if they had a preference for risk asset exposure, representing a lower risk tolerance. This further adds to the decision-usefulness of the approach adopted here. As noted in chapter eight, as the sell models (S1 and S2) have a lower type-1 (relative to 'buy' model type-1 errors) error rate an optimising strategy favours the 'sell' model signal at points where the two models' conflict.

A binary logistic regression is employed to assess the incremental value added to the model of risk over the default (constant-only) or buy-and-hold-implied model by each of the explanatory variables. The default binary logistic regression position crystallizes an essentially neo-classical, market-efficient position on the unpredictability of future market movements when taken over an extended period. That is, in each period it is equally likely that a dependent variable event will occur, based 
on historical incidence and time. Further, there is little (no) likelihood of more than one event occurring in a single period and, thirdly, each event is independent of preceding events. These assumptions describe a default starting point from which significant coefficient values define an improvement in the basic assumptions of market efficiency. Such values are expected to aid the anticipation of subsequent market movements. In this manner they may improve on the basic assumption that markets correctly price all relevant information through the aggregate operation of knowledgeable, rational, riskaverse economic agents eliminating abnormal, risk-adjusted returns.

The form of the binomial logistic regression is:

1. $\ln \left(\frac{P i}{1-p i}\right)=\beta_{0+} \beta_{1} x_{1 i}, \beta_{2} x_{2 i}+\ldots \ldots . .+\beta_{k} x_{k i}$

Where $P i$ is that the market will rise (or, in the alternative model, that it will fall), in the subsequent quarter $(t+1)$ and $\beta_{j}$ is the regression co-efficient of the corresponding variable $X_{j}$. Hence the probability of a rise in the market (or fall in the alternative model) occurring in $t+1$ can be calculated from the regression form:

2. $P i=\frac{e^{\text {scorei }}}{1+e^{\text {scorei }}}$

Where "scorei" is the value of $\beta_{0+} \beta_{1} x_{1 i}, \beta_{2} x_{2 i}+\ldots \ldots . \beta_{k} x_{k i}$ for the market, and $e$ is the base of natural logarithms.

The notion of a random walk (the essential unpredictability of the market) indicates the use of the incidence of market rises (and falls) against total periods examined as the measure of the likelihood of an event (quarter ahead market rise or fall). The more frequent of the 'event' or 'non-event' represents the default position in binomial logistic regression. That is, without the addition of IV co-efficients to the intercept the model favours the more common of two dichotomous dependent variables for every quarter. So, where the market rises more than half of the time the interceptonly model binomial logistic regression identifies a market rise in all quarters, with a probability equal to the size of the majority of the two dichotomous variables. For example, if the 'event' occurs $60 \%$ of the time the intercept-only model predicts a $60 \%$ 
probability of that occurring in all quarters. By adding the empirically supported assumption of secular equity market rises we can approximate the probability of future market movements on the assumption of a random walk with a buy-and-hold strategy, or continuous market exposure. ${ }^{37}$

\subsection{The forward stepwise approach to regression, multi-collinearity, and 'cut points'}

Using the forward stepwise approach to binomial logistic regression provides some protection against multi-collinearity. Multi-collinearity is further guarded against by removing variables with large standard errors (SEs) relative to co-efficient means (which reflect a failure to accurately estimate the parameter). However, there is a risk that this approach may settle on final predictor variables that do not represent the best possible combination of predictor variables. This method begins with no variables in the equation and then it systematically enters variables with the lowest p-value. Variables already included are removed if the inclusion of an additional variable that meets the inclusion threshold causes an existing variable to fall below the inclusion threshold. This process continues through a series of iterations until no more variables are eligible for inclusion or exclusion (removal) from the model. That is, the process of entering new variables and removing 'disqualified' variables continues up to the point of the convergence of parameter estimates, whereby those estimates do not change or change negligibly.

After identifying large SEs as a basis for removing variables that may be included in a model showing an improved (albeit potentially spurious) superior fit with observations the remaining variables are then selected for significance. Initial testing was set at $70 \%$ confidence to avoid eliminating variables too readily that, in other combinations, may contribute to a predictive model. This is a response to the limitations of forward step-wise variable selection identified above. The conventional 'cut point' or point at which the models predict a $50 \%$ or greater likelihood of an event occurring was used. Some experimentation with lower probability event identification was conducted. This was found to produce only negligible improvements in model forecast ability, achieved at the cost of (an expected) steady increase in the occurrence of type-

\footnotetext{
${ }^{37}$ This does not imply that we can predict market movements on the basis of a random walk in stock or market prices but that, given the long term rise in asset markets, continuous exposure is a logical derivation.
} 
2 errors. Without a systematic improvement in overall model results (i.e. a systematic reduction in overall type- 1 and type- 2 errors) there was no plausible basis to pursue this approach further. Equally, there is no theoretical or practical foundation for deviating from the conventional 'cut point'.

\subsection{The dependent variable}

Figure 18 depicts the implied returns on S\&P 500 index movements over the period 1980 to 2012. From the description provided above, identification of the dependent variable is based on isolating periods in which returns are greater than $1 \%$. Although an approximation to risk-adjustment, the $1 \%$ rate is somewhat arbitrary but risk-adjustment offers a number of advantages. It serves to eliminate minor movements that offer limited potential for trading gains, it reduces the demand on the predictors for sensitivity to even small, economically marginal 'events', and it does so removing only $14 \%$ of all quarters under examination. There are 62 rises (above threshold) or 'buy' quarters and 48 'sell' quarters, or movements below the threshold (or 110 buy or sell quarters out of 128 quarters). Those movements below the threshold are coded for regression analysis as non-events. Notably, the general tendency in model performance with the excluded events coded according to their (minor) directional movement is a modest deterioration in model performance (increase in type1 and -2 errors). 
Figure 18: Quarterly changes in the S\&P 500 index after risk-adjustment

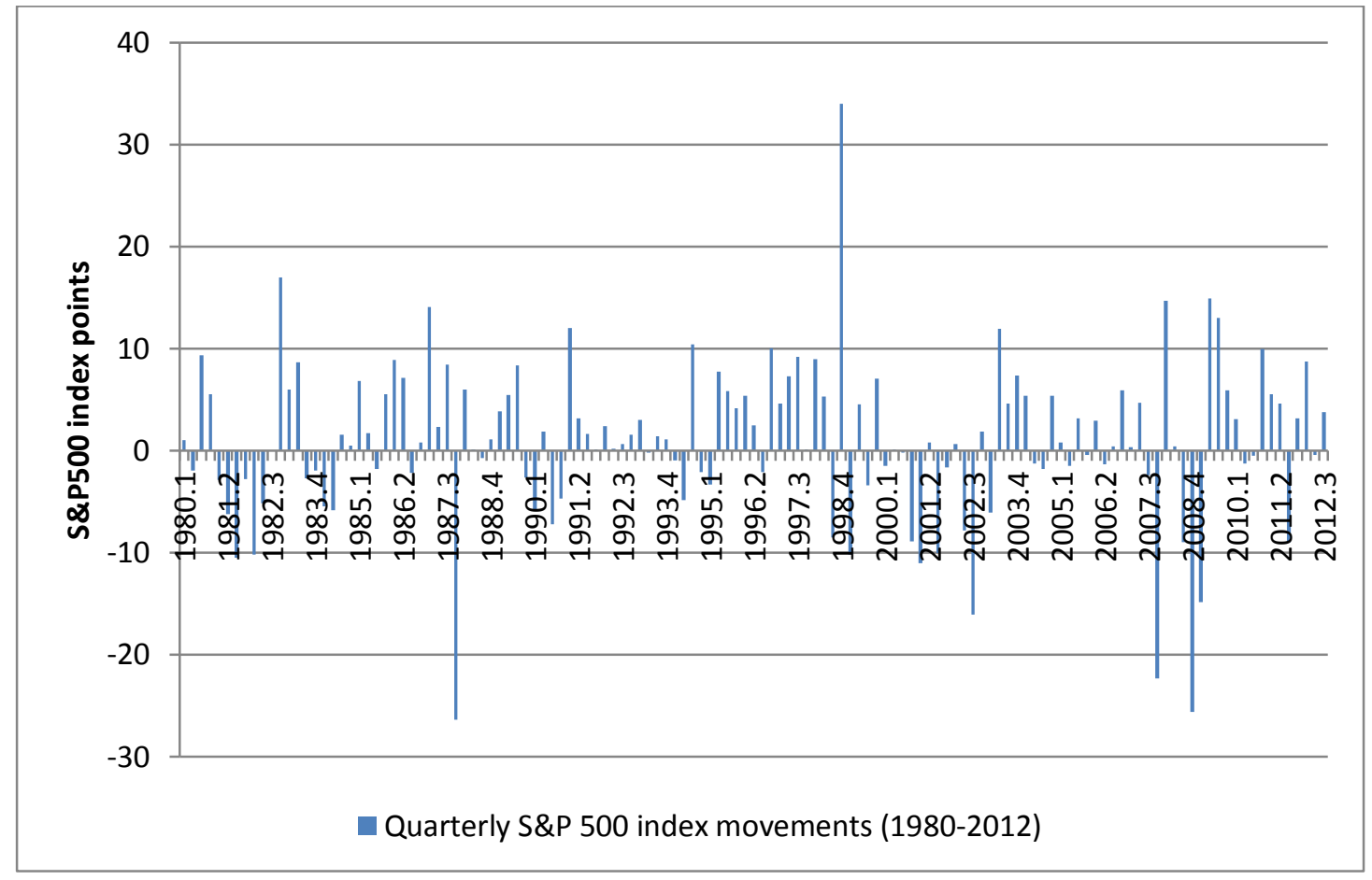

Source: Yahoo Finance

Transaction costs are solely relevant for the process of trading and have different implications for alternative plausible applications of the buy and sell models. Clearly, these costs impact asymmetrically on the buy-and-hold model and those developed in this thesis as they are functionally irrelevant to the buy-and-hold strategy. However, and progressively so, explicit transaction costs have diminished to less than $0.2 \%$ (one sided) and the models (Hasbrouck, 2009; Jones 2002) on any plausible application, do not imply high levels of 'churn'. On these bases it is reasonable to discount the impact of transaction costs although we might infer a minor downward adjustment of implied returns from the use of the models developed here if implied transaction costs were included.

7.5 Minsky, the FIH, qualifications to these and adaptation of the framework to tailor it to short term market forecasts

Following the FIH (Minsky, 1986), the hypotheses are advanced that:

- Extending booms and successive asset price rises cause risk premia assessments to contract.

- This is due to price trend extrapolation (Shiller, 2005) 
- Thus, rising asset prices are self-reinforcing and support greater borrowing

Independent variables (IV)s indicated on this basis include: historical market prices, corporate interest rates, and corporate financing flows.

Simply, there is no plausible reason to assert a utility optimizing reconfiguration of debt-to-equity that is observably pro-cyclical without a companion assumption that risk is systematically mispriced, reduced at certain points in the cycle, or that it is primarily a function of trend extrapolation. The key point here is that substantial trend reversal generally occurs near market peaks and this fact challenges the veracity of trend extrapolation. Independent of the efficiency with which information is priced into the market (or otherwise) market crashes, as a minimum, indicate that the market misprices stocks due to a paucity of information.

Minsky tells us that bankers suffer from asymmetric information and that subjectivity also enters bankers' decisions (Nasica, 2010). The lending process is inherently pro-cyclical, resulting in easy credit during booms (test variable: corporate debt flows) and credit rationing in periods of market dysfunction during a crash (test variable: corporate equity flows) and subsequent recession (Nasica, 2010). Minsky also raises doubts about equilibrium economics, suggesting general equilibrium theory is pre-institutional. Shubik (2010) argues that bankruptcy laws play an important role in creating perverse incentives that may disrupt general equilibrium economics' assumptions and that, even assuming agent rationality; a rational system does not follow logically or necessarily from that agent rationality. This is consistent with Minsky's views. These considerations may be expected to affect credit availability as well as demand for that debt. Independent of the supply or demand drivers (and the relative power of each) it is plausible to posit their reflection in corporate financing flows.

Minsky (1986) identifies bankers as entrepreneurs operating in a competitive industry to maximise profits. Tregenna (2009) has established the central operation of increased lending as the driver of profits with a negligible role for increased efficiency. Given these conditions each bank is compelled to increase business and this drives the economic system and markets to increasing levels of financial instability. As an expanding economy and rising asset markets create a history of debt contract 
performance, these events also support further lending. The individual bank or banker must continue to lend or forgo profitable opportunities. This entails that rationality supports ever more lending up to the point when historical evidence indicates a retreat from risk. This occurs with asset prices declines (market crashes) and with increasing debt non-performance. Central to the theory in this research is not that economic agents are irrational but that individual rationality does not reliably support macro-financial or economic stability. This is an important element of the FIH (Papdimitriou and Wray, 2010).

Given bankers' incentives and the (assumed) systematic mis-pricing of risk at different points in market cycles a range of variables is indicated. We might expect interest rate behaviour to influence future market movements. Equally, credit supply and demand (or more precisely, the equilibrium level of supply and demand) may be expected to presage market movements. Contractions in corporate credit may be expected to pre-empt market declines whereas, typically, rising corporate debt will align with rising markets. Further, equity contraction is an observable companion of rising markets, implying a debt/equity substitution effect. These considerations support the signalling potential of corporate financing flows and interest rates.

Papadimitriou and Wray (2010) identify the relevance of the FIH to the period 2004-2008. Against this view some flaws in the FIH have been identified (Bellofiore, Halevi, and Passarella, 2010). The following section outlines these issues and suggests that the FIH's deficiencies have been overstated. Necessary qualifications to the FIH are made and market forecast model variables inferred from Minsky's work are described. These qualifications take account of criticisms (or extensions) of the FIH but are largely made to re-configure Minskian-implied variable selection from a theory of business cycles to one applicable to market movements. The qualifications are also made to adapt the FIH to a shorter-term focus than the business cycles of Minsky's work.

It has been observed that in the period subsequent to 2000 economic expansions and accompanying market rises have not increased corporate leverage. Bellofiore, et al (2010) notes that leverage may actually fall as new investment is funded from retained earnings. This is clearly linked to the discussion in chapter two (and graph 2.0), relating 
to the decline in dividend yields in the period 1980-2012. With higher retained earnings in the modern era the ability to fund new capital investment internally increases. Bellofiore, et al (2010) makes the further observation that the post-2003 recovery saw almost flat demand for new capital from US corporations. These developments challenge a key element of the FIH that had, prior to 2000, found empirical support for its proposition that expansion periods result in increasing corporate leverage.

Another issue Bellofiore, et al (2010) suggest is that Minsky's FIH disregards the role of consumer credit and real estate booms as a source of economic instability. Writing in 1964 Minsky specifically identified a role for real estate debts in contributing to instability. Minsky also noted that the (then) recent instability was not caused by excessive corporate leverage, which was at moderate levels (Kregel, 2010). Although not contemplating a central role for household debt as a primary source of instability this criticism is, in some sense, anachronistic because the financial system and supply of debt to households had evolved considerably in the period after Minsky's death. In this light Minsky's FIH is not deficient in this regard and, so, there is no clear need to consider or accommodate this issue.

Dymski (2010) identifies the need to internationalise Minsky's essentially closed-economy model. The process of internationalisation involves the need to account for cross-border imbalances in factor flows. This argument does not imply a criticism of the FIH but it does acknowledge the evolution of global capital flows with much greater flows between countries in the modern period. These increasing global capital flows require, as a de minimus, that proxies for these flows and potential imbalances in these form part of a contemporary investigation of domestic (national) markets' operation.

Minsky's FIH also identifies an important role for governments and central banks in crisis response (Minsky, 1992). These governmental or quasi-governmental responses have become increasingly important in Minsky's view, in the era of financial institution concentration. Amongst reasons for the growing importance of the role of government and of regulators due to financial sector concentration are the risks of contagion and the greater distance created between the borrower and lender with the decline of relationship banking and the concomitant rise of securitisation. The role of 
government is important in Minskian terms, as adept government action can ameliorate the impact of economic and financial market collapses.

However, as an implication of Minsky's precept that stability creates instability, it follows that the amelioration of market or economic collapses, in extremis, entails a stability that trades-off relative near-term stability for increased moral hazard and greater subsequent risks of financial fragility. That is, monetary policy may stabilise markets in the short term creating a market confidence in inter alia the interventions of monetary authorities and, thereby, supporting progressively risky behaviour. Market participants become sanguine in the confidence that the government will insulate them from the consequences of market excesses. The so-called 'Greenspan put' has been implicated in creating moral hazard as it is seen as limiting risk or, arguably nationalising it (Spencer and Huston, 2006; Tvede, 1997). Further, its use means the necessary process of balance sheet consolidation that Minsky attributed to recessions or depressions is by-passed through a range of mechanisms, including negative real interest rates and emergency liquidity supply. These responses may forestall economic or financial market disruption or even allow the resumption of the boom but they also compound imbalances in the economy, preventing necessary consolidation. For the reasons outlined in the preceding paragraphs, variables tested include proxies for monetary policy (the FFR and discount rates).

\section{6 reconfiguring the FIH-implied proxy variables identifying stability to accommodate criticisms of the FIH}

As stated, Minsky (1986) identified rising corporate leverage over booms due to corporations borrowing to make new capital investment. If such growing corporate leverage reliably followed maturing economically-expansive phases then corporate debt stocks may be expected to provide signals of future market movements. However, recent evidence indicates that corporations do not consistently increase leverage (Bellofiore, et al, 2010). As has been previously identified, declining dividend yields (and concomitant increased retained earnings) are likely to have played a role in this situation. A further aspect, not previously addressed, is that rapid price rises such as occurred from 2004-2007 had the affect of moderating changes in leverage despite increasing debt financing (as per graph 2.1) by increasing equity values substantially. In light of these factors corporate leverage did not increase over the period. This limits 
the use of Minsky's leverage ratio as a determinant of financial fragility in the modern context. Events including the 2008 sub-prime crisis, global financial crisis and economic recession support the view that financial fragility existed (as do the large declines in equity markets parallel with these developments).

This theoretical base indicates the signalling potential of corporate financing flows but also suggests the potential weakness of these flows. The strong relationship between debt and market increases and the negative relationship between market levels and corporate equity flows may be driven by market levels. From a causal perspective this would allow us to better predict the changing composition of corporate financing from market levels rather than the other way around. Notwithstanding these concerns and cognisant of greater rigidities in corporate financing structures compared with market price movements, potential exists for the pre-emptory or signalling potential of corporate financing flows.

Dymski's (2010) concern that Minsky's FIH is essentially a closed-economy model is legitimate. The solution may be in extending the range of test variables to include proxies for imbalances in international capital flows. With this in mind, and given the coincidence of current account deficits in the US with the period of the Great Moderation (1984-2007), I have included US current account balances as a test variable.

The key elements of Minsky's FIH that are employed as the theoretical basis for this thesis and variable selection (for testing) are that:

1. Markets are inherently unstable structures that do not inexorably find new stable equilibria quickly after existing instability is disrupted (Minsky, 1986; Papadimitriou and Wray, 2010).

2. Economic and financial market stability builds the foundations for subsequent instability. It is in the expansive and euphoric phases of the cycle that risk is systematically mispriced.

3. Systematic features of a competitive banking system and broader financial sector undermine market discipline as a macroeconomic stabiliser. The micro-level rationality of the utility-maximising economic agent does not prevent perverse or destructive outcomes. 
4. "Big Bank" approaches to monetary policy and its management have, or may have, an important influence on the financial stability of an economy. As a concomitant of this, monetary policy mis-management may have a substantial and adverse impact on the economy. Thus, monetary policy variables (proxies) could improve a market-predictive model. As monetary policy affects credit availability (through open market operations) and price (Federal Funds Rate; Discount Rate) it has potentially important supply implications on liquidity conditions. It is likely that monetary policy variables have an impact on corporate financing flows as endogenous money supply growth and levels are, in part, a function of the monetary base they have to build from.

5. As noted previously, the key modification to the FIH is that debt levels are subordinated to flows as their usefulness as signals of financial fragility has weakened. The adaptations largely reflect a changed environment from that of the past. The focus on external financing flows is also indicated on the grounds that I aim to identify relatively short term movements and risks to future market levels, rather than to describe (in advance) the specifics of each business or market cycle. Flows do not tell us about leverage but may offer insights into aggregate market expectations. Rising markets are extrapolated to infer further rises. In an era of rapidly expanding credit availability this supports a preference for debt finance, reducing the forfeiture of implied future profits on existing shares through the influence of dilution. In periods in which risk perceptions are subdued and the preference for debt is high, individual companies substitute debt for equity finance. However, their balance sheets may be preserved through retained profits and asset price rises. To the extent that leverage ratios are sustained by asset price appreciation this is equivalent to borrowing progressively more against the rising value of real estate. This equates to Minsky's increasing speculative or ponzi units over the duration of an economic expansion. Individual corporations may or may not depend on continuing asset price rises but, at the minimum, their balance sheet positions are increasingly tied to elevated and rising market levels. These variables form part of the broader 'Sutton' model. 
Points 1-3 indicate that we may be able to identify signs of future market movements. If markets are endogenously unstable it follows that there are endogenous signs of that instability. It is reasonable to assume that market instability, if systemic, builds and that this process occurs cumulatively. However, by examining increments (by quarters) it may be possible to model future quarterly market movements, refining cumulative signs to those more proximate to the predicted quarter. This forms part of the process for modifying Minsky's (1986) FIH with the use of quarterly flows' data. Point 2 indicates market volumes and price history test variables, as well as corporate financing flows. Points 2 and 3 support the use of corporate interest rates and changing equilibria in the demand and supply of credit (or corporate debt flows' data) as test variables. Point 4 introduces the basis for considering monetary policy proxy variables and point 5 indicates substituting flows for leverage levels that Minsky (1986) favoured.

\subsection{Adaptation of the FIH-indicated variables to fit them to the focus of this research}

Minsky's FIH describes the role of corporate financial structures and financial institutions in the process of the business cycle. As such it describes developments over periods of several years, from recession, through to recovery, expansion, euphoria and crash, returning to recession. In contrast this research focuses on quarterly market movements. This determines a shift in focus from the economy as a whole to asset markets and, more particularly, equity markets. The research focus here is also much shorter term than Minsky's, with the aim of forecasting future market movements by each quarter.

The specifically asset market focus provides some indication of prospective test variables. The near-term focus further narrows prospective variables. I isolate as test variables:

- corporate debt flows

- corporate equity flows

- net debt flows less net corporate equity flows (separately)

- $\quad$ integrated with equity and debt (S\&P 500 index) movements

- net dividend flows

- Interest rates 
Financing flows link to the FIH as Minsky (1986) focused on inter alia banker incentives, banks as profit-driven entrepreneurs, and credit expansion as a driver of bank profits. The supply (and thus the price) of such flows may, therefore, be expected to be positively related to equity market prices. Equally, Minsky (1986) describes falling borrower margins as asset prices rise, reducing the need for reserves, driving equity outflows as well as increasing asset prices and demand for credit (debt).

The variable, net corporate debt flows minus net corporate equity flows, typically involves debt inflows and equity outflows. The aim of this variable is to capture the full effect of the changing disposition of external corporate financing. The rationale for this is that external finance is uncomplicated by the asset price feedback loop that sees corporate equity increased by rising markets and, so, in a sense justifies rising markets because they are rising. The two elements of this integrated variable capture the changing flow of total external corporate financing that does not rely on leverage ratios or total indebtedness. In this sense they depart from Minsky (1986) introducing an accommodation of observations in the 2000s by allowing that the absence of new investment opportunities could support rising markets where such asset price rises were catalysed wholly or almost wholly by the expansion of credit. This approach is adopted as a response to criticisms of the FIH's inability to satisfactorily explain the market boom from 2003, without a substantial increase in new investment or in levels of corporate leverage.

Corporate dividend flows are also used. These flows reflect an element of the net equity contribution to corporate financing and, so, the changes in the total equity contribution to corporate financing. Added to these variables, Minsky's view of effective transfers between entrepreneurs and savers at different points in the business cycle supports the inclusion of a 'price' variable, represented here by real and nominal interest rates. Following Minsky (1986) we might expect interest rates to move sympathetically (inversely to) with rising markets up to an advanced point in Minsky's 'euphoric' phase of business cycles. Further, driven by demand, it is reasonable to anticipate reduced interest rates in and after periods of market decline. This effect is likely to be compounded by accommodative Central Bank policy settings. The interest rates employed are the Standard and Poors Baa rate. Notably, this rate is the lowest investment grade rate but is highly correlated with Aaa rates. Following Dymski's 
(2010) concern for the need to extend Minskian analysis and the FIH to accommodate increasing global capital flows and imbalances in these, I test US current account balances in binomial logistic regressions.

The inherent instability of market-based economies arises in periodic crises. Preceding a crisis, during a sustained period of economic and market expansion, the economy enters a euphoric or frenzy phase. This phase is preceded and accompanied by declining regulation constraining instability (Papadimitriou and Wray, 2010). The entrepreneur must draw on already employed resources from the circular flow (credit). ${ }^{38}$ Rising leverage accompanies asset price rises as companies leverage to growth expectations, employing new capital. As booms develop they shift income to savers, increasing interest rates and risk premiums to a point where increasing numbers of new investments become high risk (Papadimitriou and Wray, 2010). Additional independent variables indicated, include:

- market trading volumes

- market movements

Rising volumes may also be expected to accompany Minsky's euphoric phase and, thus, lead to rapid price rises. The interaction of these two variables may also be plausibly related to market declines and panic selling. This establishes a plausible set of relations that justify inclusion within the FIH framework, without exclusive reliance on that framework.

The final variables included for testing are proxies for the operation of the US Federal Reserve System. Minsky identified the potential role of a "Big Bank" system, or system in which monetary authorities were mandated to support the stability of the economy. The potential significance of this observation may have increased as of Alan Greenspan's incumbency as Chairman of the US Federal Reserve Bank and Federal Open Market Committee, as the US Federal Reserve began to specifically weigh asset

\footnotetext{
${ }^{38}$ Credit creation is finite at any point in time by the ability of the financial system to 'flex' reserves. This entails that entrepreneurs must access credit from a stock that, although flexible, is not unlimited. A further implication is that the conditions that expand credit (and debt) in buoyant economic phases almost aggravate the constraint on credit as most of the money destroyed is high-powered or reserve money.
} 
market stability in determining their monetary policy. For this reason I include the Federal Funds Rate and the Discount Rate as test variables.

\subsection{The data: independent variables, their source, and construction}

The macro-financial independent variables employed for testing for market forecast efficacy are determined on the basis of the theory previously outlined. The following section lists and describes (in table 2) the test variables. Section 7.5 linked the selected variables to theory. The test variables include:

Table 2: The regression test variables, their equation codes, and source of data

\begin{tabular}{|l|l|l|l|}
\hline No. & Variable & Code & Source \\
\hline 1 & S\&P 500 index level & $S \& P$ & Yahoo Finance; S\&P \\
\hline 2 & Net corporate debt flows & $N D F$ & $\begin{array}{l}\text { Board of Governors, } \\
\text { Federal reserve Bank; Z1 }\end{array}$ \\
\hline 3 & Net corporate equity flows & $N E F$ & As at 2. \\
\hline 4 & Net financing flow changes & $N F F$ & Calculated from 2minus 3 \\
\hline 5 & $\begin{array}{l}\text { Total net corporate financing flows x } \\
\text { S\&P500 }\end{array}$ & $N F F S P$ & Variables 1 x 4 \\
\hline 6 & Corporate equity flows x SP500 & $C E * S P$ & Variables 3x 1 \\
\hline 7 & Nominal Dividend flows & $N D V$ & $\begin{array}{l}\text { FRB Board of } \\
\text { Governors }\end{array}$ \\
\hline 8 & Real dividend flows & $R D V$ & $\begin{array}{l}\text { FRB Board of } \\
\text { Governors }\end{array}$ \\
\hline 9 & Real interest rates & $R I R$ & FRB Governors \\
\hline 10 & Nominal interest rates & $N I R$ & As at 7 above, series H15 \\
\hline 11 & Federal Funds rate & $F F R$ & As at 8 above, series H15 \\
\hline 12 & The Discount rate & $D C R$ & As at 9 above, series H15 \\
\hline 13 & Inflation & $I N F$ & $\begin{array}{l}\text { Bureau of Labour } \\
\text { Statistics }\end{array}$ \\
\hline 14 & Money-zero-to-maturity & $M Z M$ & FRB \\
\hline 15 & US current account deficit & $C A D$ & FRB \\
\hline 16 & Market trading volume & $V O L$ & Yahoo finance; S\&P \\
\hline
\end{tabular}

These variables are assessed at up to ten lags (quarters) each to determine those most productive in terms of reliable occurrence precursory to substantial changes in market levels. The basis for selecting lags of ten periods (quarters) was that a number of signals (or prospective signals) could be reasonably expected to precede and cause subsequent signals. This reflects Fisher's (1933) view that the cause of an economic or market cycle could be as little as proximity to preceding cycles. 


\begin{tabular}{|c|c|}
\hline 1. $S \& P$ & $\begin{array}{l}\text { The Standard and Poors } 500 \text { index; widely regarded as highly representative of } \\
\text { US equity markets generally (US Securities Exchange Commission (n.d.); } \\
\text { Standard and Poors (2013) }\end{array}$ \\
\hline 2. $N D F$ & Net corporate debt inflows (external company financing flows. Non-farm, non- \\
\hline & $\begin{array}{l}\text { financial companies. An assumption is made that S\&P } 500 \text { financing flows are } \\
\text { analogous with broader market as S\&P } 500 \text { data only covers part of the period. }\end{array}$ \\
\hline 3. NCF & $\begin{array}{l}\text { As above at } 2 \text { but relating to net corporate equity flows. These flows are often } \\
\text { negative }\end{array}$ \\
\hline 4. NFF & $\begin{array}{l}\text { NDF-NCF (or } 2 \text { above minus } 3 \text { above). This variable aims to capture total changes } \\
\text { in the composition of corporate external financing. Frequently there appears to } \\
\text { Be substitution of debt for equity. }\end{array}$ \\
\hline 5.NFFSP & $\begin{array}{l}1 \text { above multiplied by } 4 \text { above. The aim with this variable is to capture the broad } \\
\text { Observation of interaction between corporation financing flows and market }\end{array}$ \\
\hline 6.CE*SP & $\begin{array}{l}\text { Interaction between corporate equity financing flows and the market } \\
\text { Movements. }\end{array}$ \\
\hline 7. $N D V$ & Nominal dividend flows: is in billions of dollars of dividend (out) flows. \\
\hline 8. $R D V$ & Real dividend flows: 6 above deflated for CPI-U inflation (Note 1) \\
\hline 9. $R I R$ & Real interest rates; 9 below deflated for CPI-U inflation. (Note 1) \\
\hline 10.NIR & $\begin{array}{l}\text { Nominal interest rate: is the nominal interest rate as represented by S\&P } \\
500 \text { Baa bonds. The Baa rating is the lowest investment grade company debt } \\
\text { But is highly correlated with the highest rated Aaa debt. }\end{array}$ \\
\hline 11. FFR & $\begin{array}{l}\text { The Federal funds Rate is the rate, typically overnight, at which US depository } \\
\text { Institutions trade balances held at the US Federal Reserve between each other. } \\
\text { The rate is set by the open market but a target range is provided by the Federal } \\
\text { Reserve Board (Note 2) }\end{array}$ \\
\hline 12. $D C R$ & $\begin{array}{l}\text { The discount rate. The discount rate is the interest rate charged to comer- } \\
\text { cial banks and other depository institutions on loans they receive from their } \\
\text { regional Federal Reserve Bank's lending facility--the discount window. }\end{array}$ \\
\hline 13. INF & $\begin{array}{l}\text { Inflation. This is as recorded by the US Bureau of Labor Statistics (BLS). The rate } \\
\text { Used is the series CPI-U or CPI-(All Urban Consumers). (Note 1) }\end{array}$ \\
\hline 14.MZM & $\begin{array}{l}\text { Money zero to maturity. is } \mathrm{M} 2 \text { minus time deposits and money market } \\
\text { Funds. M2 is M1 + most savings accounts, money market accounts, retail } \\
\text { money market mutual funds, and small denomination time deposits } \\
\text { (certificates of deposit of under } \$ 100,000 \text { ). (Note } 3 \text { ) }\end{array}$ \\
\hline 15.CAD & $\begin{array}{l}\text { US current account deficits. They are the gap between total US imports and } \\
\text { exports, reflecting the gap between domestic saving and investment. (Note } 4 \text { ) }\end{array}$ \\
\hline 16.VOL & Trading volume on the US S\&P 500 index. \\
\hline
\end{tabular}

Notes to table 3 to further explain certain variables

Note 1 (variables 8, 9, and 13): Shiller uses Bureau of Labour CPI calculations in the form of CPI-U (All urban consumers). Elsewhere references in the literature in this area (principally Borio and Lowe, 2002), where they make reference to it at all, 
simply describe adjustment for inflation. For my purposes, in relation to the US there is no clear reason to depart from Shiller's approach. Total dividend flows complete part of the outflow of corporate equity. Although they are indirect functions of corporate profitability they, as with share buy backs, are more rigid effects

The only explicit objection I have located is that there were substantial changes in the CPI-U calculation basis in the 1980s and 1990s and that Shiller's deflation adds no incremental value over the method preferred by the critic Turner (2010) who prefers the use of the cyclically-adjusted price earnings ratio (CAPE). Turner argues that CAPE shows a near identical pattern to PER over the period of Shiller's coverage and that, therefore, CPI deflation adds no value. This may be true but the similar performance of the CAPE and Shiller's use of CPI-U supports the view that one may be substituted for the other without compromising the data as CPI-U and CAPE produce similar results.

Note 2 (variable 10): The Federal Reserve Banks offer three discount window programs to depository institutions: primary credit, secondary credit, and seasonal credit, each with its own interest rate. The rate used in this research is the primary credit rate although all rates are highly correlated. Under the primary credit program, loans are extended for a very short term (usually overnight) to depository institutions in generally sound financial condition.

http://www.federalreserve.gov/monetarypolicy/discountrate.htm

Note 3 (variable 14): This measure of money is preferred because it is a strong positive correlate of M2 and, therefore, does not constitute a radical practical departure from seminal work employing M2, such as that of Friedman and Schwartz (1963). Further, it is the measure preferred by Pepper and Oliver (2002) in their innovative research into the liquidity theory of asset prices. It has also proven to the best indicator of future inflation.

Note 4 (variable 15): Current account deficits are matched by capital account surpluses of the same magnitude and, at a national level, offer a measure of how much a country spends, relative to its income. Current account deficits are not inherently problematic where the capital account surplus is committed to high-quality capital investment. 
However, low quality capital investment such as excessive investment in housing stock (at inflated prices) or capital account surpluses applied to consumption, as is prevalent in housing booms (Greenspan and Kennedy, 2007), do not reflect high quality use of debt on a national scale. Equally, the so-called capital flows paradox implies instability. Persistent capital inflows to developed countries, especially when flowing from lesser developed countries, appears to contradict the identity of economic development; that developed countries are those most capital sufficient and that they typically have capital surpluses to invest in lesser developed countries. This is predicated on the view that the marginal utility of an additional dollar of capital, when applied to a capital-insufficient country, will involve greater productivity gains and greater returns than that same dollar applied to a developed economy in which there is, as a matter of definition, no paucity of capital relative to other factorial inputs.

In terms of the central theoretical structure of this thesis an increase in current account deficits may support an increase in the economy and asset markets as borrowings support growth in the economy and profits. However, rising or persistent current account deficits may also indicate growing financial fragility where they are not off-set by growth in productivity, relative to other countries. Such systemic imbalances may imply the gravitation towards a broad macro-economic equivalence to the FIH 'euphoric'-phase gravitation to increasingly speculative debt structures. Equally, after frequently expanding rapidly during economic and market downturns we might expect to see a decline in CAs as recoveries unfold.

Note $5\left(C E^{*} S P ; \quad N F F^{*} S P\right)$ : Integrated variables (5 and 6): Providing greater specification to the broad observations made in chapter five, the integration of variables is created by the multiplication of market movements with corporate financing flows and shows strong correlations with theorised signs on variable movements. The correlations described above are reflected between equity outflows and market rises and strong debt inflows accompanying market rises. Likewise, net funding flows (corporate debt flows minus corporate equity flows) are as expected (theorised) in chapter five. As net debt inflows are a general condition and corporate equity outflows are too this variable captures the changing total relationship (and composition) of external corporate financing over different phases of the market cycle. The integrated 
variable relationships of variables included in the models (along with the incidence of signs on these variables) are detailed in table 4.

Table 4 identifies the incidence of signs (positive/negative) on the model components that are integrated variables. These broadly follow the general patterns observed in chapter five, with debt inflows accompanying market rises and equity inflows accompanying market declines. In the case of corporate equity flows they move as generally observed in relation to the movement of the market $80 \%$ of the time.

Table 4: The incidence of signs on integrated variables.

\begin{tabular}{|c|c|}
\hline Integrated variables & Incidence of signs \\
\hline $\begin{array}{l}C E^{*} S P 500 \text { index }(2 \\
\text { and } 7 \text { lags })\end{array}$ & $\begin{array}{l}\text { Negative sign lag } 2 \text { comprises predominantly ( } 89 \%) \\
\text { negative CE movements (outflows) with positive S\&P } 500 \\
\text { movements }(75 \%+)\end{array}$ \\
\hline $\begin{array}{l}\text { Corporate equity } x \\
S \& P 500 \text { index }(6,8,9, \\
\text { and } 10 \text { lags })\end{array}$ & $\begin{array}{l}\text { In the case of each variable the direction of equity flows is } \\
\text { approximately } 80 \% \text { negative and approx. } 75 \% \text { positive for } \\
\text { the movement in the S\&P 500 }\end{array}$ \\
\hline $\begin{array}{l}\text { Corporate equity } \\
\text { flows } x \text { S\&P } 500(1 \\
\text { and } 9 \text { lags })\end{array}$ & $\begin{array}{l}\text { Predominantly }(81 \%) \text { corporate equity outflows, combined } \\
\text { with an increase in the S\&P } 500 \text { index }\end{array}$ \\
\hline $\begin{array}{l}N F F^{*} S P 500(1,2, \text { and } \\
8 \text { lags, negative signs })\end{array}$ & $\begin{array}{l}\text { Positive net fund flows at all lags combined with } \\
\text { predominantly positive index movements ( } 1 \text { lag }=77.5 \% ; 2 \\
\text { and } 9 \text { lags }=82 \%)\end{array}$ \\
\hline
\end{tabular}

Table 5 below identifies a range of research related to the current research. Each approach isolates one or more variables that precede market and/or economic instability. Typically, existing approaches aim at broad forward-looking statements or at the broad economy. The current research aims at greater specification by targeting shorter time frames than is, for example, the case with Shiller's research. In terms of the research of Borio and Lowe (2002), the aim differs in terms of a more specific focus on corporations. Borio and Lowe and Detkin and Smets (2004) aim to identify precursors to high-cost economic recessions. The table identifies variables used in existing models, the findings of those models and, under 'Limitations and observations', the gap in existing models. 
Table 5: Various economic and market forecast models 


\begin{tabular}{|c|c|c|c|}
\hline Economist & Variables & Findings & Limitations/observations \\
\hline $\begin{array}{l}\text { 1. Mitchell and Burns } \\
\text { (1938); Moore (1974); } \\
\text { Gordon (1986) }\end{array}$ & $\begin{array}{l}\text { Various leading, coincident and lagging } \\
\text { business cycle indicators, including } \\
\text { inventory levels, level of unemployment, } \\
\text { business confidence, etc }\end{array}$ & $\begin{array}{l}\text { Although irregular, business cycles show recurrent } \\
\text { signs. These may change over time and they may be } \\
\text { improved. }\end{array}$ & $\begin{array}{l}\text { Short term view, identifying near 'real time' signs of phases in the } \\
\text { business cycle. Identifies signs of disequilibrium rather than typical } \\
\text { approaches which prioritise positive bubbles. }\end{array}$ \\
\hline $\begin{array}{l}\text { 2. Borio and Lowe } \\
\text { (2002); Borio (2003; } \\
\text { 2006); Friedman }(1981 ; \\
\text { 1983; 1996; 1982; } \\
\text { 1999): Pepper and } \\
\text { Oliver (2002) }\end{array}$ & $\begin{array}{l}\text { The credit 'gap' and asset price (rise) } \\
\text { 'gap', respectively of } 4 \% \text { and } 40 \% \text { above } \\
\text { trend. Uses BIS data for combined asset } \\
\text { index of private and commercial real } \\
\text { estate and equity markets. }\end{array}$ & $\begin{array}{l}\text { The parsimonious single factor credit model predicts } \\
\text { approx. } 80 \% \text { of economic reversals. The inference } \\
\text { drawn is that 'excessive' credit increases typically } \\
\text { precede economic and financial market downturns. }\end{array}$ & $\begin{array}{l}\text { Focus is purely on positive bubbles. Type } 2 \text { errors (false positives) } \\
\text { occur in } 18 \% \text { of cases. Aims at monetary policy formation only. }\end{array}$ \\
\hline 3. Shiller (2005) & $\begin{array}{l}\text { Share prices above historical PE's \& } \\
\text { lower than historical div. yields. Housing } \\
\text { above CPI-adjusted base year } 100(1890)\end{array}$ & $\begin{array}{l}\text { High PE equity markets \& housing above CPI- } \\
\text { adjusted } 1890 \text { levels indicate overvaluation \& } \\
\text { subsequent mean reversion }\end{array}$ & $\begin{array}{l}\text { An equilibrium model. Over-reliance on the constancy of accounting } \\
\text { numbers. No assessment of changes in the size, amenity or } \\
\text { concentration of housing. }\end{array}$ \\
\hline $\begin{array}{l}\text { 4. Detkin and Smets } \\
\text { (2004); Adalid and } \\
\text { Detkin (2007); }\end{array}$ & $\begin{array}{l}\text { Monetary policy \& aggregates and credit } \\
\text { aggregates greater increase relative to } \\
\text { trend (average of pre-boom, boom, \& } \\
\text { post-boom) and a gap of } 10 \% \text { above trend } \\
\text { for asset prices (as per Borio \& Lowe in } \\
\text { relation to the asset price gap). }\end{array}$ & $\begin{array}{l}\text { High-cost booms are characterised by loose } \\
\text { monetary policy (deviation from the Taylor Rule). } \\
\text { Greater (than low-cost booms) asset price rises and } \\
\text { larger credit and money gaps. }\end{array}$ & $\begin{array}{l}\text { Focus is on monetary policy prescription. Priority is given to real estate. } \\
\text { Identifies 'high-cost' booms and so captures a sense of deviation from } \\
\text { equilibrium. }\end{array}$ \\
\hline 5. Renshaw (1995) & $\begin{array}{l}\text { Combines the money gap with budget } \\
\text { deficit of }>3.5 \% \text { as an indication of } \\
\text { instability }\end{array}$ & $\begin{array}{l}\text { Where budget deficits are accompanied by above } \\
\text { trend growth in money aggregates a high correlation } \\
\text { with unsustainable stock rises occurs. }\end{array}$ & $\begin{array}{l}\text { The money gap presupposes something 'correct' about the base year } \\
\text { referent. Budget deficits often grow over recessions. Nothing inherent to } \\
\text { such deficits indicates unsustainability without information on the types } \\
\text { of spending causing the deficit \& whether government deficits are } \\
\text { accompanied by private sector surpluses. Focus is on positive bubbles. } \\
\text { Identifies a sense or proxy for disequilibrium conditions. }\end{array}$ \\
\hline Sutton (2013) & $\begin{array}{l}\text { Models incorporate equity flows, } \\
\text { corporate debt flows and levels. Real } \\
\text { interest rates and real dividend flows, } \\
\text { market price and trading volume history. }\end{array}$ & $\begin{array}{l}\text { Relationship to existing research } \\
\text { Combines an estimate of disequilibration identified } \\
\text { in } 1,3, \& 5 \text {. Customises features of } 2,3, \& 4 \text { as the } \\
\text { basis for fragility indexation. Extends these features } \\
\text { to surrogates exhibiting good prospects as leading } \\
\text { indicators. Aims at accounting disclosures. Thus, } \\
\text { less 'intrusive' than proposals for monetary policy } \\
\text { formation. }\end{array}$ & $\begin{array}{l}\text { Uses proxies/ surrogates for movement towards financial fragility. } \\
\text { Extends Minskian analysis of capitalism's periodic gravitation towards } \\
\text { financial fragility. Focused on equity markets. Aims to provide a model } \\
\text { or models for forecasting market movements } \\
\text { Use of surrogates (particularly net equity flows) poses risks of a } \\
\text { question-begging analysis by which no sensible causal nexus can be } \\
\text { drawn between the sign \& its inferred indication. }\end{array}$ \\
\hline
\end{tabular}




\subsection{Summary}

This chapter outlines the approach adopted to determine the usefulness of a range of theoretically indicated macro-financial variables in forecasting future market movements. Binomial logistic regression has been employed in separate models to determine those variables best able to contribute to (respectively) a model of future quarter $(t+1)$ market movements. This involves testing the variables described in regressions on market rises and falls. Binomial logistic regression is used in situations in which there is a categorical variable with dichotomous outcomes. Because there is no reason to assume a high level of symmetry between indicators of market rises and falls separate 'buy' and 'sell' models are developed based on regressions on a dichotomous dependent variable of market rises (1) or no rise (0) and Market falls (1) or no fall (0)., reflecting market rises/falls in the following quarter.

The IVs identified for testing have been developed on the basis of Minsky's FIH. Modifications have been made to certain implications of the FIH to tailor Minsky's key insights about business cycles to short term equity market movements. A further basis for IV test variable selection involves qualifications to the FIH based on recent observations, including the disjuncture in the 2000s between corporate leverage levels and rising markets. These adaptations and qualifications are augmented by variables able to be plausibly inferred from the FIH but more explicitly used in short term technical analysis and prediction of stock market movements. Consistency between technicist approaches and Minskian indications of future market movements is further predicated on the common behavioralist roots of (in particular) Dow Theory and the FIH, by which sentiment influences market trading price and volume histories. 


\section{Chapter eight: Findings}

\subsection{Introduction}

This chapter describes the predictive models developed and the stock market-prediction improvements achieved by these models over results obtained from a buy-and-hold approach. Two primary models have been developed on the basis of testing a number of theoretically determined variables in binary logistic regressions. One model is the 'buy' model (B1), or model predicting subsequent quarter $(t+1)$ rises in the market. The other model is the 'sell' model (S1), or model predicting subsequent quarter declines in the market. The success of these models is assessed by the implied returns that would be achieved through their use as compared to the constant-only model (that is, the default binomial logistic regression model without independent variables). In markets that exhibit long term rises there are more quarterly increases in market index levels than decreases. The binomial logistic regression constant-only model ( $\mathrm{C} 1$ for the buy models; $\mathrm{C} 2$ for the sell models) mimics a buy-and-hold strategy as it selects the greater of the two dichotomous outcome variables.

The primary models developed are employed to determine the implied returns from investment in the S\&P 500 index over the period 1980 to 2012. These results, along with those obtained in a constant-only model, both in nominal dollars and after inflation adjustment in appendix three, are compared to augment the prediction model success with a view of how such improved outcomes might function at a practical level.

Two auxiliary or alternative models are also developed. One of these models augments the 'buy' model with the addition of four predictors (B2). This process provides some prediction enhancement. The second alternative model is developed to better predict the 'sell' side sub-period from 1985-1998 as the full-period model performs poorly over this period (S2). The aim here is not to produce an ad hoc series of models that achieve predictive success only ex post but to seek to identify variables in the sub-period which may provide explanations for the weakness of the full-period model in this sub-period. It is not, therefore, intended to argue for a hindsight application of the sub-period models but that qualifications to the use of the full-period model may be better specified. This is undertaken with a view to improving market participants' applications of the models. The more parsimonious (seven variable-S2) model provides a strong fit between predicted and observed quarters of market decline over the period from 1985-1999. 
The two full-period models (B1 and S1) and the sub-period 'sell' model (S2) are tested on market performance from the 1970s to assess the generalisability of the models to different periods. The result of this process was that neither of the full-period models was able to enhance the prediction of subsequent period market movements over the predictions achieved by the constant-only model $(\mathrm{C} 1 / \mathrm{C} 2)$. Considering the assumptions underpinning the development of the models this was not a surprising outcome. Individual model components (separate from the testing of the Z-statistics ${ }^{39}$ of the full-period models) were then tested and in the case of the sub-period 'sell' model (S2) only were two of the variables found to materially improve overall predictive success (economic significance) and be statistically significant at the $5 \%$ level for the 1970s. Equally, these two variables only had a Hosmer-Lemshow statistic greater than the conventional threshold of $0.5 .^{40}$ The reasons for the general poor performance of the principal models are discussed in the following chapter, along with interpretations of the implications of this failure for the key period of enquiry.

The following sections identify the model regression components for B1, B2, S1, and S2. Regression equations are provided along with changes in model goodness of fit (relative to $\mathrm{C} 1$ for the buy models and $\mathrm{C} 2$ for the sell models). The respective models' sensitivity and specificity are also identified. IVs are identified, along with their statistical significance, standard errors and their effect size.

\subsection{The full-period 'buy' model (B1).}

This model covers the period 1980-2012 and seeks to identify quarters of rising markets in $t+1$. Such periods are subject to the chapter seven threshold description of the dependent variable. This model is as follows:

$$
\begin{aligned}
& (8.1) . \ln \left(\frac{P i}{1-p i}\right)=0.071+0.801 R D V 3+1.007 N F F 3+1.013 S P / 2+0.986 S P / 3+1.104 V O L 1 \\
& +1.038 V O L 2+1.041 V O L 7+0.986 C E * S P / 2+1.008 C E^{*} S P / 7+0.927 N F F^{*} S P / 1+0.953 N F F^{*} S P / 2 \\
& +0.968 N F F^{*} S P 8
\end{aligned}
$$

\footnotetext{
${ }^{39} \mathrm{Z}$-statistics are developed by creating a single independent variable from the model weighted components of the 12 and 7 variable models along with those models constants. ${ }^{40}$ A Hosmer-Lemeshow statistic of greater than 0.5 implies that we accept the null that the model reflects a good
fit between actual and observed events.
} 
Key: RDF: Real dividend flows; NFF: net external corporate financing flows SP: Standard and Poors 500 index; VOL: trading volume on the S\&P 500 index; CE*SP: the S\&P 500 index level multiplied by NCE; NFF*SP: Net external corporate financing flows multiplied by the $S \& P 500$ index.

Table 6: Full-period 'buy' model (B1) variables, exponents, size and significance

\begin{tabular}{|l|l|l|l|l|}
\hline Variable and lag & $\begin{array}{l}\text { Co-efficient } \\
\text { estimates }\end{array}$ & $\begin{array}{l}\text { Standard } \\
\text { Error } \\
(S E)\end{array}$ & $\begin{array}{l}\text { Size of } \\
\text { the effect } \\
E x p(B)^{41}\end{array}$ & \\
\hline \multicolumn{1}{|c|}{ Real dividend: 3 RDF } & -.222 & .093 & 0.801 & .017 \\
\hline Net fund flows: 3 NFF & .007 & .002 & 1.007 & .005 \\
\hline S\&P 500: 2 SP & .013 & .005 & 1.013 & .017 \\
\hline S\&P 500: 3 & -.014 & .005 & 0.986 & .008 \\
\hline Volume (trading): 1 VOL & .099 & .026 & 1.104 & .000 \\
\hline Volume:2 & .037 & .017 & 1.038 & .031 \\
\hline Volume 7 & .040 & .013 & 1.041 & .003 \\
\hline Corporate equity*S\&P 500: $\mathbf{2}$ & -.014 & .004 & 0.986 & .001 \\
\hline$C E * S P$ & & & & \\
\hline Corporate equity*S\&P 500: 7 & .008 & .004 & 1.008 & .052 \\
\hline $\begin{array}{l}\text { Net fund flows*S\&P 500: } \mathbf{1} \\
N F F * S P\end{array}$ & -.076 & .020 & 0.927 & .000 \\
\hline Net fund flows*S\&P 500: 2 & -.048 & .015 & 0.953 & .001 \\
\hline Net fund flows*S\&P 500: 8 & -.032 & .012 & 0.968 & .007 \\
\hline Constant & -2.652 & .726 & 0.071 & .000 \\
\hline
\end{tabular}

Notes: Column one identifies the independent variable (IV) (described in chapter seven) and its form as presented in equations. Column two is the estimated co-efficient value of each of the IVs included in the model. Column three identifies the standard errors associated with parameter estimates (column two). In column four an odds ratio (or exponent) is provided which is the parameter estimate converted into a size (of variable influence) ratio. As per Appendix 1(5), an exponent below 1 decreases the $\mathrm{P}(\mathrm{Y})$ as it increases and increases $\mathrm{P}(\mathrm{Y})$ as

${ }^{41}$ Also known as the odds ratio, is calculated as: ODDS Ratio $=\frac{\mathrm{P} 1 /(1-\mathrm{P} 1)}{\mathrm{P} 2 /(\mathrm{P} 2-1)}$, where $\mathrm{P} 1$ is the probability of an event occurring and P2 is the probability of an event not occurring (Grimes and Schulz, 2008). 
it decreases. Where $\operatorname{Exp}(B)$ is greater than 1 the affects are the inverse of those outlined above (see appendix 1.5). The greater the distance an individual variable exponent is from 1 the greater the contribution that variable makes to the model. Column five identifies the statistical significance of each variable. Note that CExSP500/7 falls just outside the 95\% confidence interval but the inclusion of this variable adds moderately to the predictive success of the model as a whole. The economic significance of the models may be assessed by considering improvements in 'Total model performance' (row number 2 in tables 6, 8, 10, and 12) by comparing the percentage correct in column two against column three. This may be further expanded upon by relating the described successful event identification to the effect of this improvement over the constant-only model on implied returns, as identified in appendix 3.

As noted in chapter seven, integrated variables include Net funds flows x the S\&P 500 index (Nff*S\&P500/lag marker) and corporate equity flows $\mathrm{x}$ the S\&P500 index (CE*SP500/lag marker). The expectation of each of these variables is that they may assist in capturing the relationship between corporate financing flows in combination with changing market levels. These variables are driven by the basic insight provided by Cooper (2008) and, consistent with Minsky (1986), and aim to reflect that rising markets are, in part, motivated or signalled by changing corporate reliance on debt as a substitute for equity. In terms of $C E^{*} S P 500 / \operatorname{lag} x$ a negative sign is typically comprised of predominantly negative corporate equity flows with predominantly $(75 \%)$ positive S\&P500 index movements. In terms of $n f f * S P 500$, a positive sign is typically the inverse of that of the previous variable, reflecting an increase in net fund flows (or the net shift to debt, with an increase in external debt financing and a decline in, or outflow of, corporate equity). These features reflect the general observation that rising markets are usually concomitants of increasing corporate reliance on debt and are accompanied by equity outflows.

Table 7: Model goodness of fit, specificity, and sensitivity

\begin{tabular}{|l|l|l|}
\hline Goodness of fit, sensitivity, specificity & $\begin{array}{l}\text { Constant-only model } \\
(\mathrm{C} 1)\end{array}$ & $\begin{array}{l}12 \text { variable buy model } \\
(\mathrm{B} 1)\end{array}$ \\
\hline $1 . \quad-2 \mathrm{Log}$ likelihood $^{42}$ & 177.321 & 122.518 \\
\hline
\end{tabular}

\footnotetext{
${ }^{42}$ See appendix 1.3.
} 


\begin{tabular}{|l|l|l|}
\hline 2. $\quad$ Total model performance & $51.6 \%$ & $79.7 \%$ \\
\hline 3. $\quad$ Type-1 errors & $100 \%$ & $19 \%$ \\
\hline 4. $\quad$ Correct predictions/population & $0 / 62$ & $50 / 62$ \\
\hline 5. $\quad$ Type-2 errors & $0 \%$ & $21 \%$ \\
\hline 6. Correct predictions/population & $128 / 66$ & $52 / 66$ \\
\hline 7. Cox Snell R square & .02 (first iteration) & .348 \\
\hline 8. Nagelkerke R square & & .465 \\
\hline 9. $\quad$ Hosmer Lemeshow statistic & .026 (first iteration) & .654 \\
\hline
\end{tabular}

Table 7 shows that over successive iterations the $-2 \log$ likelihood ratio decreases substantially, reflecting a progressive decrease in the variance left unexplained by the model. ${ }^{45}$ Overall model performance increases from $51.6 \%$ accuracy to $79.7 \%$ (at 2), with the reduction in type-1 errors greater than the trade off in terms of type-2 errors (seen at 3, 4, 5, and 6 in the table above). Equally the Cox Snell R-square increases materially from the first iteration to the final 12variable buy model (from 0.20 to 0.348 , as seen at 7 in the table) and the Nagelkerke pseudo$\mathrm{R}$ square statistic increases from 0.026 at the first iteration, allowing the inference that the final iteration reflects a progressive and substantial improvement over preceding iterations. The Hosmer-Lemeshow statistic (at 9) supports the null that the model is a good fit with observations or, more precisely, that the model-predicted events are not significantly different from those observed.

\subsection{The 'augmented' 'buy' model (B2)}

The augmented model is as follows:

(8.2). $\ln \left(\frac{P i}{1-p i}\right)=-0.895+1.433$ Zstat $-0.744 F F R 2+-0.430 F F R 4+0.227 F F R 8+1.183 D C R 2$

\footnotetext{
${ }^{43}$ See appendix two for more detail.

44 See appendix 1.4.

${ }^{45}$ SPSS makes a series of attempts to fit the best model to the DV from the available variables. This continues through a series of iterations until changes in parameter estimates are negligible.
} 
Key: FFR: Federal funds Rate; DCR: the Discount Rate; Z-stat (B1): A single statistic (regression co-efficient capturing the weights and influence of the full 12-varaible 'buy' model.

The 'augmented' 'buy' model (B2) was produced by creating a Z-statistic of the 12variable 'buy' model (B1) and then adding proxies for Central Bank (Federal Reserve) monetary policy. By representing the 12-variable model as a single compound statistic, degrees of freedom are reduced. The added variables effected substantial improvements in the standard measures of model goodness of fit, reducing the $-2 \log$ likelihood (a measure of how much the variance the model fails to explain, whereby a reduction in $-2 \log$ likelihood reflects an improved model fit). As reflected in table 8, for the full-period this statistic fell from 122.518 to 104.017 between the 12-and 16-variable models (or Z-statistic of B1 with four new variables added). Notably, the four added variables were not found to be significant when added to the twelve-variable model (as opposed to the Z-statistic derived from this model). The Nagelkerke pseudo-R square rose from 0.465 (B1) to 0.58 (B2), reflecting a substantial improvement in the relative strength of B2. The Hosmer-Lemeshow statistic declined negligibly, being the only principal measure of robustness to show any deterioration.

Table 8: "Augmented" buy model (B2) co-efficient, Standard errors, exponents, and statistical significance

\begin{tabular}{|l|r|r|r|r|}
\hline Variable and lag & \multicolumn{2}{l|}{$\begin{array}{l}\text { Co-efficient } \\
\text { estimates } \\
\beta\end{array}$} & $\begin{array}{l}\text { Standard } \\
\text { Error } \\
(S E)\end{array}$ & $\begin{array}{l}\text { Size of } \\
\text { the effect } \\
\operatorname{Exp}(B)\end{array}$ \\
\hline Federal funds Rate: FFR2 & 1.433 & .291 & 4.191 & .000 \\
\hline FFR4 & -.745 & .323 & .475 & .021 \\
\hline FFR8 & -.431 & .246 & .650 & .080 \\
\hline Discount rate: DCR2 & .227 & .113 & 1.255 & .044 \\
\hline Z-statistic: Zstat (B1) & 1.183 & .456 & 3.265 & .000 \\
\hline Constant & -.895 & .610 & .409 & .021 \\
\hline
\end{tabular}

In terms of predictive success the larger model (B2) improved (decreased) type-1 errors materially and produced a marginal improvement in type- 2 errors as can be seen in table 9 . The combined effect was to increase the overall model performance from $79.7 \%$ to $82.8 \%$ in terms of successful event/non-event identification/non-identification. Both models (B1 and B2) reflect a material advance over the constant-only model $(\mathrm{C} 1)$ success (selecting the more 
common of the binary outcomes in all periods) of $51.6 \%$. For this reason, and because of possible process 'contrivance' implicit in the improved predictive outcome, the augmented model was explored simply as an exploratory measure.

Table 9: "Augmented" model (B2) goodness of fit, specificity, and sensitivity

\begin{tabular}{|l|l|l|}
\hline Goodness of fit, sensitivity, specificity & $\begin{array}{l}12 \text { variable buy model } \\
(\mathrm{B} 1)\end{array}$ & $\begin{array}{l}\text { "Augmented" model } \\
(\mathrm{B} 2)\end{array}$ \\
\hline 1. -2Log likelihood & 122.518 & 104.017 \\
\hline 2. Total model performance & $79.7 \%$ & $82.8 \%$ \\
\hline 3. Type-1 errors & $19 \%$ & $14.5 \%$ \\
\hline 4. Correct predictions/population & $50 / 62$ & $53 / 62$ \\
\hline 5. Type-2 errors & $21 \%$ & $20 \%$ \\
\hline 6. Correct predictions/population & $52 / 66$ & $53 / 66$ \\
\hline 7. Cox Snell R square & .348 & 0.436 \\
\hline 8. Nagelkerke R square & .465 & 0.582 \\
\hline 9. Hosmer Lemeshow statistic & .654 & .653 \\
\hline
\end{tabular}

Notes: A substantial decrease in the unexplained (by the model-B2) variance is observed at 1 above. Overall model performance improves marginally (at 2), with a small reduction in type 1 and type 2 errors (as shown at 3, 4, 5, and 6). At 7 nd 8 the pseudo-R squareds improve materially. At 9 a negligible decrease in the Hosmer-Lemeshow statistic is observed. This is the only key statistic to deteriorate.

The sell models (S1 and S2) are now considered, with improvements over the constantonly (C2) model in terms of specifity, sensitivity and goodness of fit provided. Variable effect size and statistical significance are also provided. 


\subsection{The full-period 'sell' model (S1) equation}

The 'sell' model (S1):

(8.3) $\ln \left(\frac{P i}{1-p i}\right)=0.006+2.244 N I R 7+0.512 R D V 10+0.251 N D F 2+1.006 N E F 7+1.006 N F F 2+1.009$ $N F F 5+0.993 N C E * S P / 6+1.006 N C E * S \& P 8+0.996 N C E * S \& P 9+1.003 N C E * S \& P 10+0.527 F F$ $R 7+1.845 D C R 1$

Key: NDF: net dividend flows; NEF: net corporate Equity flows; NFF: net external corporate financing flows; NCE*SP: net corporate equity flows multiplied by the S\&P 500 index; FFR: Federal Funds Rate; DCR: the Discount Rate.

In the periods 1980-1984 and 1999-2011 the 12-variable model (S1) performs strongly, producing just six type-one and six type-two errors, over 67 quarters. In contrast, from 1984(Q3) to 1999(Q3), the model fails to predict all but 2 of 14 'sell' quarters and falsely predicts three sell quarters. In simple terms the model produces poorer predictive models and negligible difference in the implied returns than a constant-only model (C2) (as shown in table 11).

Table 10: Variables, exponents (odds ratios) size of effect, and statistical significance for the 12-variable 'sell' model (S1)

\begin{tabular}{|l|l|l|l|l|}
\hline Variable and lag & $\begin{array}{l}\text { Co-efficient } \\
\text { estimate } \\
\beta\end{array}$ & $\begin{array}{l}\text { Standard errors } \\
(\mathrm{SE})\end{array}$ & $\begin{array}{l}\text { Exp (B) or } \\
\text { odds ratio }\end{array}$ & $\begin{array}{l}\text { Signif- } \\
\text { icance }\end{array}$ \\
\hline Nominal interest: NIR7 & .808 & .225 & 2.244 & .000 \\
\hline Real dividend: $R D V 10$ & -.669 & .169 & 0.512 & .000 \\
\hline Nominal dividend: NDF2 & -1.381 & .484 & 0.251 & .004 \\
\hline Corporate equity flows: NCE7 & .006 & .004 & 1.006 & .093 \\
\hline Net fund flows: NFF2 & -.006 & .002 & 0.994 & .001 \\
\hline Net fund flows: 5 & .010 & .003 & 1.009 & .004 \\
\hline Corporate equity*S\&P 500 index: 6 & -.007 & .003 & 0.993 & .006 \\
\hline Corporate equity*S\&P 500 index: 8 & .006 & .003 & 1.006 & .048 \\
\hline Corporate equity *S\&P 500 index: 9 & .004 & .002 & 0.996 & .054 \\
\hline Corp equity*S\&P 500 index: 10 & .003 & .002 & 1.003 & .103 \\
\hline Federal funds Rate: 7 & -.641 & .193 & 0.527 & .001 \\
\hline Discount rate: 1 & .613 & .179 & 1.845 & .001 \\
\hline
\end{tabular}




\begin{tabular}{|l|l|l|l|l|}
\hline Constant & -5.050 & 1.577 & 0.006 & .001 \\
\hline
\end{tabular}

Note: Three of the model variables are not significant at the $95 \%$ level, with one (CEXSP500/10) marginal at the 90\% level. These extra variables add to the predicted outcome success sufficiently to justify their inclusion.

Table 11: Full-period sell model (S1) goodness of model fit, specificity, and sensitivity

\begin{tabular}{|l|l|l|}
\hline Goodness of fit, sensitivity, specificity & $\begin{array}{l}\text { Constant-only model } \\
\text { (CS1) }\end{array}$ & $\begin{array}{l}12 \text { variable sell model } \\
\text { (S1) }\end{array}$ \\
\hline 1. -2Log likelihood & 166.003 & 113.009 \\
\hline 2. Total model performance & $64.8 \%$ & $81.3 \%$ \\
\hline 10. Type-1 errors & $100 \%$ & $37.8 \%$ \\
\hline 11. Correct predictions/population & $0 / 45$ & $28 / 45$ \\
\hline 12. Type-2 errors & $0 \%$ & $8.4 \%$ \\
\hline 13. Correct predictions/population & $128 / 83$ & $76 / 83$ \\
\hline 14. Cox Snell R square & .070 (first iteration) & .339 \\
\hline 15. Nagelkerke R square & .096 (first iteration) & 0.46 \\
\hline 16. Hosmer Lemeshow statistic & .357 (first iteration) & 0.968 \\
\hline
\end{tabular}

Again, a substantial improvement in model goodness of fit can be observed in table 11 with a decline in the unexplained variance over successive iterations and an improvement in the key Nagelkerke statistic. The Hosmer-Lemeshow statistic supports the view that the model is a good fit with observed dependent variable events.

\subsection{The sub-period 'sell' model (S2) or seven-variable model}

$(8.4) \cdot \ln \left(\frac{P i}{1-p i}\right)=0.026+0.181 R D V 6+1.039 N C D 7+0.95 N C D 8+0.965 N F F 3+1.053 N F F 5$ $+0.954 N C E * S P 1+1.201 N C E^{*} S P 9$ 
Key: RDF: Real dividend flows; NCD: Net corporate debt flows; NFF: Net external corporate financing flows; NCE*SP: Net corporate equity flows multiplied by the Standard and Poors 500 index.

Table 812 provides co-efficient values, standard errors, the size of variable effects, and statistical significance of each of the model variables.

Table 12: Variables, direction of influence, size and significance for the 'short period' 7 variable 'sell' model (S2) (1985-1999)

\begin{tabular}{|l|l|l|l|l|}
\hline Variable and lag & $\begin{array}{l}\text { Co-efficient } \\
\beta\end{array}$ & $\begin{array}{l}\text { Standard } \\
\text { error }(S E)\end{array}$ & $\begin{array}{l}\text { Size of } \\
\text { effect } \\
\text { Exp(B) }\end{array}$ & $\begin{array}{l}\text { Statistical } \\
\text { Significance }\end{array}$ \\
\hline Real dividend: 6 & -1.707 & .598 & 0.181 & .004 \\
\hline Corporate debt flows: 7 & 0.38 & .021 & 1.039 & .072 \\
\hline Corporate debt flows: 8 & -.045 & .021 & 0.956 & .031 \\
\hline Net fund flows: 3 & -.036 & .013 & 0.965 & .007 \\
\hline Net fund flows: 5 & .052 & .017 & 1.053 & .002 \\
\hline Corp. equity x S\&P500: 1 & -.047 & .019 & 0.954 & .014 \\
\hline Corp. equity x S\&P500: 9 & .184 & .060 & 1.201 & .002 \\
\hline Constant & -3.658 & 1.621 & 0.0258 & .024 \\
\hline
\end{tabular}

Notes: an exponent value of less than one entails that an increase in that variable will reduce the likelihood of an event (or sell in this case). Conversely, where $\operatorname{Exp}(B)$ is greater than one an increase in $\operatorname{Exp}(B)$ (or odds ratio) will increase the probability of an event occurring. Real dividend flows are dividend flows adjusted for inflation. The greater the variable's distance from 1 the greater the relative impact of that variable. This is conditioned by the size of the variable upon which that exponent acts. This supports the view that the key explanatory variables are real dividend flows, corporate financing flows and prior market movements in the case of this model. All but one of the variables in this equation is statistically significant at the 95\% level, with just NCD7 falling outside this level (at 7.2\%). 
Table 13: Short-period "sell" model (S2) goodness of fit, specificity, and sensitivity

\begin{tabular}{|l|l|l|}
\hline $\begin{array}{l}\text { Goodness of fit, sensitivity, and } \\
\text { specificity }\end{array}$ & Constant-only model & 7-variable sell model \\
\hline 1. -2Log likelihood & 61.921 & 30.07 \\
\hline 2. Total model performance & 77.4 & 93.5 \\
\hline 17. Type-1 errors & $0 \%$ & $2.1 \%$ \\
\hline 18. Correct predictions/population & $62 / 48$ & $47 / 48$ \\
\hline 19. Type-2 errors & $100 \%$ & $21.4 \%$ \\
\hline 20. Correct predictions/population & $0 / 14$ & $11 / 14$ \\
\hline 21. Cox Snell R square & .067 (first iteration) & .442 \\
\hline 22. Nagelkerke R square & .102 (first iteration) & .673 \\
\hline 23. Hosmer Lemeshow statistic & .464 (first iteration) & 0.972 \\
\hline
\end{tabular}

The short period (1984-1999) model (S2) fit is possibly the most compelling of all the models with the unexplained variance declining by more than half over the successive iterations, a substantial improvement in the Nagelkerke measure of goodness of fit, and a high HosmerLemeshow statistic. A further appealing feature of this model is that of the $3 / 14$ events it fails to identify, have average declines of fewer than $2 \%$ in the type- 2 error quarters whereas the average decline in those 'event' quarters it correctly identifies are slightly greater than $6 \%$. In simple terms, the missed quarters involve smaller, less economically significant declines.

\subsection{Variables failing to significantly contribute significantly to model development}

Certain of the variables tested were found to play no important role (are not statistically significant) in the explanation or predictive modelling for market movements. These include:

1. MZM (money zero to maturity): Despite the success Pepper and Oliver (2002) found in the use of MZM as a market predictor (in combination with other variables) it played no role in the modelling developed in this research. Individual testing of this series of 10 lags found no statistical significance, nor did the addition of this variable to other reasonable combinations of variables. Equally, the progressive elimination of those lags 
of this variable for which parameter estimates were unobtainable (large standard errors) produced no statistical significance for any lag of this variable, even at the $90 \%$ level. For these reasons this variable was rejected for use in predictive models.

2. Inflation: As with MZM no variable, either individually, in combination with each other, or with other statistically significant variables, was found to improve model goodness of fit or model predictive success over the constant-only model. Evidence of multi-collinearity occurred with large standard errors when using this IV. This is a predictable outcome as inflation adjustment has been incorporated in certain other variables. Beyond this, and in a similar relation to MZM, inflation may be too general to provide reliable indications in terms of equity markets.

3. Current account deficits: This variable was also found to contribute no statistical significance to market-predictive modelling. Again, it may be that such a general macro-economic series is not directly related to market movements. Given sustained and growing deficits over the period, in contrast to recurrent market cycles, it is reasonable to question a plausible statistical or economic role for this variable. This, no less so, when divergent influences impact the markets and demands on government external financing needs. This does not entail that a secular growth in current account deficits is riskless. However, the process is a long term trend and not likely to be importantly related to short term market movements.

\subsection{Implied returns from defaults and different applications of the models developed in this research}

As presented in Appendix 3, the C1 (constant-only comparator of B1) model column 1 (shaded) (raw dollars) produces a return from continuous exposure over the period 1980-2011 on an original investment of $\$ 1000$ of $\$ 11,041$. The 'optimum' model application produces implied returns of $\$ 58,986$ over the same period (raw dollars) and is calculated by arbitrating conflict between the signals from the 'buy' (B1) and 'sell' (S1) models on the basis of greatest predicted probabilities of an event (as shown in table 14). In this case an assumption is made that the user selects between the greatest probabilities of B2 and also that they successfully determine the underlying conditions in which to apply S2 sell signals. The short 'sell' model (S2) is used where the predicted probabilities exceed those of a competing signal from the fullperiod 'buy' model (B1). This is arguably dependent on hindsight (as discussed in chapter nine 'Discussion and Analysis') and thus, is not argued for as a practical or necessarily plausible application. 
Table 14: Arbitrating between Buy and Sell models when signals conflict

\begin{tabular}{|l|l|l|l|l|}
\hline \multicolumn{2}{|l|}{ Predicted probability } & $\begin{array}{l}\text { Aggressive } \\
\text { investor }\end{array}$ & $\begin{array}{l}\text { Probability- } \\
\text { based } \\
\text { investor }\end{array}$ & $\begin{array}{l}\text { Conservative } \\
\text { investor }\end{array}$ \\
\hline Buy model & Sell model & & & \\
\hline$<0.5$ & $<0.5$ & MP $\quad 1$ & MP & MP \\
\hline$>0.5$ & $<0.5$ & BUY & BUY & BUY \\
\hline$>0.5$ & $>0.5$ & BUY & PHP $\quad$ & SELL \\
\hline $\begin{array}{l}>0.5 ;>\text { SELL } \\
\text { model probability }\end{array}$ & $>0.5$ & BUY & BUY & SELL \\
\hline$>0.5$ & $\begin{array}{l}>0.5 ;>\text { BUY } \\
\text { model probability }\end{array}$ & BUY & SELL & SELL \\
\hline$<0.5$ & $>0.5$ & SELL & SELL & SELL \\
\hline
\end{tabular}

Table 14 shows the decision rubric based on the investor's risk/return profile. MP ${ }^{1}$ represents 'maintain prior position'. I.e. take no action. PHP 2 represents 'prefer higher probability'; > is greater than the following probability value; < is less than the following probability. The table represents different applications of the models at points where there are conflicting signals, based on individual investor characteristics.

The aggressive raw dollar approach (column 3 Appendix 3) involves opting for continued market exposure ('buy' model predictions) where conflict arises in the signals provided by the 'buy' and 'sell' models. This action is done independent of the respective probabilities of an event occurring. This approach produces an implied return of $\$ 33,724$ over the research period. The conservative approach (column 4) favours opting for 'sell' model signals where there is conflict between the models and it produces an implied return of $\$ 45,172$. Columns 5 -9 (of Appendix 3) provide similar information in CPI-U adjusted terms.

The inflation adjusted default return is found in column nine of appendix three and it produces a return of $\$ 3,860$ (following a buy-and-hold strategy) on an original investment of $\$ 1,000$ over the period 1980-2011. Respectively, the 'optimal' approach produces a return of $\$ 20,624$, the aggressive approach produces returns of $\$ 11,791$, and the conservative approach provides returns of $\$ 15,794$. In both the case of raw and CPI-U deflated series returns implied by the series of plausible model applications tested increase returns over their respective defaults of between three and more than five times. 
The 'optimum' series (in column 5) is not clearly operationalisable and is included to complete a spectrum of possible scenarios only. Also, some counter-intuitive results can be seen in the lower implied returns to more risky investment strategies. This may indicate the general tendency of the 'buy' models to remain 'stuck on' a buy signal during periods of rapid market rises (see: appendix two 'buy model' and the incidence of type 1 errors during periods of strongly rising markets), discounting the sometimes large reversals and increasing volatility that has been observed during these periods. Also, the 'sell' model, although producing more type 2 errors, has a low incidence of type 1 errors (see: tables 10 and 11). Given these features, sensitivity to sell model signals reflected in the conservative approach produces little adverse affect but often places the hypothetical investor out of harm's way during periods of major reversal. This interpretation is supported by the large divergence in the aggressive and conservative approaches' results as observed in appendix three, columns four and five (and columns seven and eight) in late 1987 and late 2007. Notably, as recently as 2005 the two series values approach convergence with the aggressive and conservative approaches within 5\% of each other as opposed to a $34 \%$ difference at the end of the period, suggesting the greater volatility of greater risk that might be expected under conventional assumptions of investment risk-reward trade-offs and the standard equation of riskiness with volatility.

A further point of note is that dividend contributions to total returns have been expressly excluded from all models. This is for a combination of practical and logistical reasons. Principally, the default model would accrue all dividend payments made over the study period. The various model-based approaches avoid exposure periodically but typically maintain market exposure, consistent with the relative frequencies of buy and sell signals. This lessens the total impact of dividends which is further minimised by an assumption of the risk-free rate as a substitute for market exposure. Beyond these considerations, which are likely to make the difference in total returns negligible, logistically determining the incidence of dividend payments over the entire period by quarter and, therefore, the dividend 'cost' of withdrawal from the market, would be challenging if not impossible. For these reasons the function of dividends in total returns is discounted. However, it is acknowledged that this artificially 'improves' the implied differential in returns between the default and those produced by the model applications to a small degree. 
Figure 19: Implied returns from continuous exposure to the market and different applications of the models developed in this thesis.

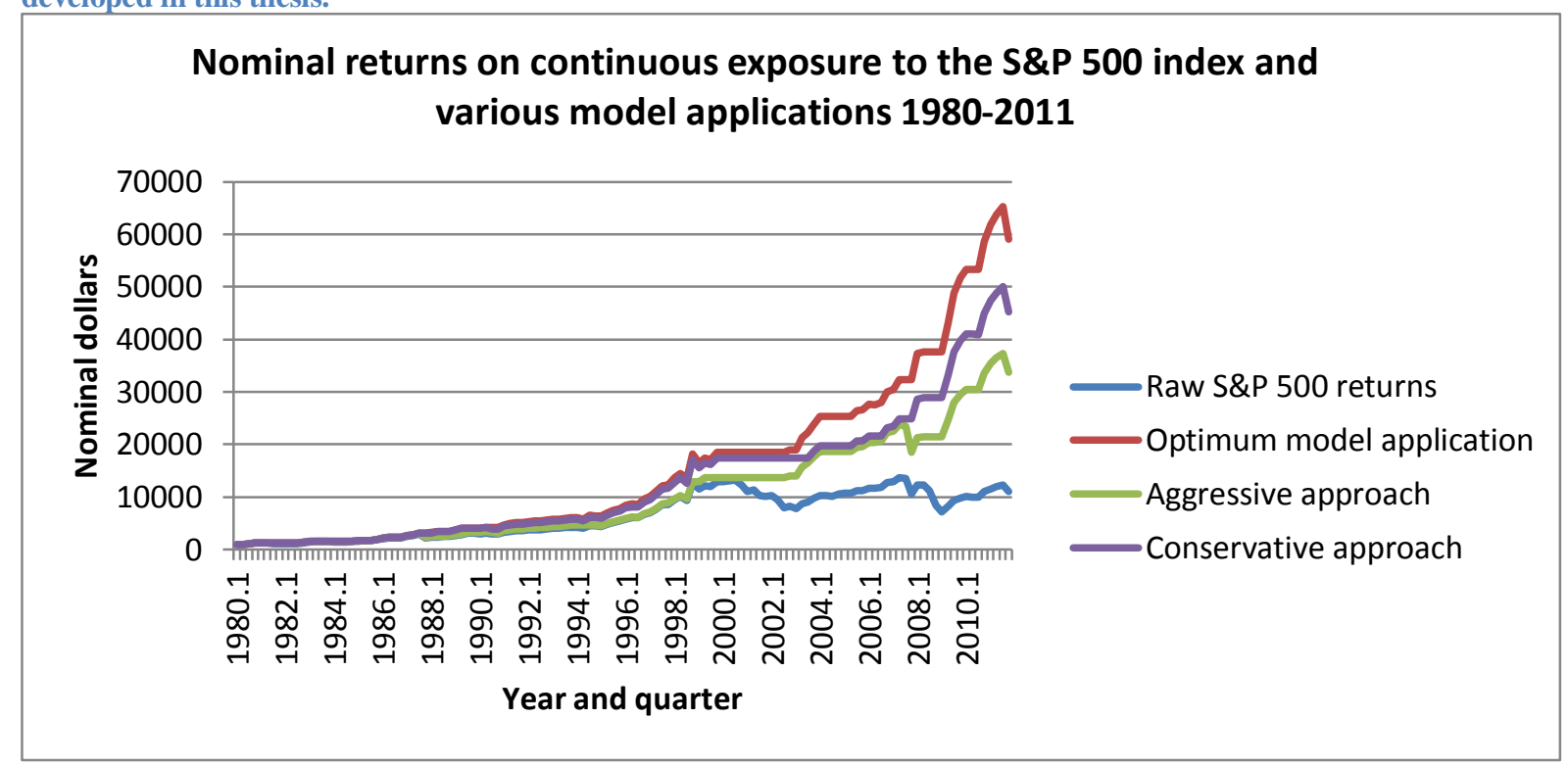

Figure 19 shows the implied returns from different applications of the models developed in this thesis along with those attributable to a buy-and-hold strategy (in raw S\&P 500 returns). Each of the more plausible applications (represented by the green line and purple line) represent a substantial increase over continuous exposure to the market over the period.

\subsection{The respective model performances when applied to the 1970 s $S \& P 500$ index}

Binomial logistic regressions run on quarterly movements in the S\&P 500 index (as the dependent variable) over the 1970s, and testing the models developed in this thesis, reveal no improvement in 'predictive' performance over the constant-only model. That is, the default position of 'buy and hold' starts by favouring the majority of a dichotomous dependent variable (21 out of 40 or $52.5 \%$ ). This result holds for the full-period models (B1 and s1) and the shortperiod sell model (S2) as represented by Z-statistics. ${ }^{46}$ Thus, the models are only better than a coin flip to the extent that one of the two possible outcomes is in the majority or, in effect, they add nothing. Running regressions on each model's components yields a modest improved predictive performance, as is identified in the following table. These results are examined in chapter nine.

\footnotetext{
${ }^{46} \mathrm{Z}$-statistics are developed by creating a single independent variable from the model weighted components of the 12 and 7 variable models along with those models constants.
} 
Table 15: Results of the study-period 12 variable B1 and S1) and 7 variable models (S2) and their components applied to the S\&P 500 index in the 1970s

\begin{tabular}{|c|c|c|}
\hline Buy model components & 12 variable model & 7 variable model \\
\hline Predicted: & Predicted: & Predicted: \\
\hline Default: $52.5 \%$ & Default: $52.5 \%$ & Default: $52.5 \%$ \\
\hline 2 variable model: $70 \%$ & 2 variable model: $75 \%$ & 2 variable model: $65 \%$ \\
\hline Type 1 errors: $36.8 \%$ & Type 1 errors: $19 \%$ & Type 1 errors: $33.3 \%$ \\
\hline Type 11 errors: $28.6 \%$ & Type 11 errors: $31.6 \%$ & Type 11 errors: $36.8 \%$ \\
\hline $\begin{array}{l}\text { Variables and significance: } \\
\text { S\&P500 (2 lags) .146 } \\
\text { CEXSP (7 lags) .097 }\end{array}$ & $\begin{array}{l}\text { Variables and significance: } \\
\text { CEXSP500 (8 lags) } 0.073 \\
\text { FFR (7 lags) } 0.152\end{array}$ & $\begin{array}{l}\text { Variables and significance: } \\
\text { Corp debt flows ( } 7 \text { lags) } \\
0.015 \\
\text { Corporate debt (8 lags) } 0.033\end{array}$ \\
\hline Hosmer-Lemeshow: 0.535 & Hosmer-Lemeshow: 0.332 & Hosmer-Lemeshow: 0.674 \\
\hline $\begin{array}{l}\text { Nagelkerke Pseudo R square: } \\
0.237\end{array}$ & $\begin{array}{l}\text { Nagelkerke pseudo R square: } \\
0.247\end{array}$ & $\begin{array}{l}\text { Nagelkerke pseudo R square: } \\
0.264\end{array}$ \\
\hline
\end{tabular}

Although components of each model improve prediction, the improvements are limited. In the cases of the buy model (B1) and the small sell model (S2) components HosmerLemeshow criteria are met for robustness, although both models have low pseudo-R squares. Only the variables in the small sell model (S2) are statistically significant at the $95 \%$ confidence level. Notably, this class of variables (corporate debt) was the only unique addition to that model over classes of components of the 12-variable sell model. For these reasons it is possible to conclude that none of the models developed in this research provide a compelling alternative to the default or constant-only model.

\subsection{Summary}

In general terms the findings support the value of the models in predicting market movements. The models appear to be robust on several different measures of goodness of fit and appreciably improve the ability to forecast market movements over those (implied) predictions provided by a buy-and-hold strategy, as is implied by a random walk about a secular rise in the market. The applications of the models to determine periods in which an investor might chose to withdraw from market exposure, produce substantially greater returns than the default. On this basis it is reasonable to advance the case that the models developed in this 
thesis have the potential to add value to investor decision models and that, in particular, they may be of value in the timing of corporate stock re-purchases. The failure of the models to improve market predictions over a default buy-and-hold strategy during the 1970s is discussed in chapter nine (Discussion and Analysis) and a case is made that this failure is not injurious to the application of the models, subject to the existence of certain generic features of the prevailing institutional environment.

Some caution needs to be adopted in the interpretation of the models' success. In all cases the models developed in this thesis exceed the guideline ratio of IVs to DVs. This issue was addressed in chapter seven and the case was made (as per Stone and Rasp, 1991) that the greater classification success of logistic regression on dichotomous DVs justified its use irrespective of concerns about the sparseness of DVs and that this would be expected, if it was a problem, to show in terms of large standard errors. 


\section{Chapter nine: Discussion and analysis}

\subsection{Introduction: the relationship of Minskian theory to market movements and market prediction model development in the post-1980 period in the US}

This chapter explains the binomial regression models' variables found to be statistically and economically significant in predicting (identifying) market movements over the period 1980-2012. The role of each model variable is considered in terms of its contribution to the separate prediction model. This discussion is drawn in the context of the relationship of the respective variables to Minskian theory. Amongst expected patterns in variables under the assumptions of Minsky's FIH are that growth in corporate debt, market trading volumes, and recent market price history will accompany future market increases. Qualifications to model performance are also made, identifying periods and conditions under which the models perform less convincingly. Key areas of concern are model performance-dependence on a specified (deregulated) institutional regulatory environment in which primary reliance is placed on market discipline, augmented by monetary policy. A further qualification is that model performance may be compromised by large or successive external shocks that prevent the systematic build-up of financial imbalances and that disrupt patterns in financing flows that, otherwise, would signal future market movements. In this chapter the variables which make no significant contribution to the prediction modelling are also identified. Plausible explanations for the inclusion or exclusion of variables are discussed.

Key external and economic events affecting the US economy are also identified and described. The implications of the specific or idiosyncratic events for the models developed in this thesis are considered in Appendix 4. These external and period-specific events are depicted by timelines which include quarterly market movements. This is augmented by an examination of the 1970s, major external shocks occurring in this period, and model applications to the market in the 1970s. Important differences in the institutional environment and the exposure to external shocks of the 1970s and the study period are identified and discussed.

\subsection{Key features of the period 1980-2012}

The monetary policy approach adopted in the US and across the developed world subsequent to the 1970s reflected lessons learned from the failure of the policies of the 1970s. Under the Chairmanship of Volcker, the US Federal Reserve Bank tightened monetary conditions from 1979, compounding a period of already high interest rates. This policy appears 
to have successfully subdued inflationary pressures of the 1970s early in the 1980s, with a concomitant decline in interest rates progressively over the 1980 s.

To the present and in the foreseeable future inflation control remains a central focus of monetary policy in developed economies. Under Alan Greenspan's Chairmanship of the US Federal Reserve Board in the second half of the 1980s asset market stability was added as a focus of monetary policy. Subdued inflation pressures since 2008, along with low growth, have driven monetary policy settings to persistently 'accommodative' levels with a near-zero Federal Funds Rate and successive injections of liquidity through quantitative easing. These factors support the view that, from 1979, there was a distinct break in monetary policy regimes.

Along with monetary policy shifts, regulation of domestic and international flows diminished. A succession of government legislative changes towards deregulation began through the 1970s and continued into the 1980s, 1990s and 2000s. It is over this period from the early 1980 s to 2012 that we observe increasingly strong pro-market cyclical flows of external corporate debt financing and strong counter-market cyclical flows of external corporate equity financing. As discussed in chapters four and five it is postulated that these financing flows play an important role in signalling and causing future market movements. As prudential regulation increasingly relied on market discipline the profit-motivated entrepreneurship of the banking sector described by Minsky (1986) asserted itself, progressively expanding bank-created credit. As noted by Tregenna (2009) most of the change in bank profits is positively tied to the size of bank debt asset portfolios as opposed to efficiency increases. This factor is likely to have created moral hazard for the US financial sector as a whole, inducing increasingly risky behaviour through increasing credit extension as the key driver of bank profits and bankers' remuneration (Stiglitz, 2009). The increasing reliance of prudential and monetary policies on market discipline to constrain risky behaviour disregarded the progressive systemic movement towards the financial fragility that was realised from late 2007. These conditions set the stage for increasing volatility in corporate (and household) external financing flows and allowed the build-up of financial fragility within and beyond the corporate sector, resulting in subsequent instability.

The case is made that 'shocks' may actively mitigate existing economic imbalances and vulnerabilities. It is both consistent with Minsky (1986) and reasonable to postulate that the relative dearth of external shocks in the post-1980 period created a stability that allowed the 
growth of systemic, endogenous, cumulative financial and economic fragility. Further, such conditions allowed the market to rise as persistently as it did over the 1980s and 1990s and, after a brief recession, in the 2000s, establishing the preconditions for the instability that ended the GM in 2007.

For the reasons identified above, and in light of arguments raised in chapter four (surveying the GM), sufficient conditions for the application of the full-period buy (B1) and sell models (S1) developed in this thesis occur when:

- Financial markets and institutions are only lightly regulated.

- Monetary policy is primarily focused on CPI (and inflation expectations') stability, whether with or without minor qualification by a separate consideration of asset market stability.

- External shocks are not sufficiently large (as in the 1970s) to create an independent constraint on the economy's gravitation towards instability as identified in Minsky's (1986) FIH.

As noted in chapter four, the US has sustained persistent current account deficits since 1984, with a single, minor exception in the recession of early 1990s, when the current and capital accounts were approximately balanced. This presents a post-1980 economy that emerged from recession in 1982 to grow strongly, supported by overseas savings. As discussed in chapter four where this occurs it is further aggravated when net overseas borrowing is applied to consumption expenditure and speculative bubbles such as the housing market to 2007. For the present purposes the US maintenance of large current account deficit positions (as continues today) is sufficient to support the comparability of the present with the balance of the post-1980 period. Moreover, it importantly distinguishes the pre- and post-1970s period as that earlier period did not feature large relative current account deficits or a systemic bias towards deficits (over surpluses). In simple terms current account deficits have been persistent and are likely to remain so in the foreseeable future. These deficits appear to reflect an additional international financial imbalance in the modern period and may be analogous to increasing corporate reliance on debt. 


\subsection{Major economic and external shocks and their influence on US markets}

The US economy experienced few major external shocks over the period 1980-2011 with just the Gulf War and three relatively minor foreign financial crises to 2000. Subsequent to 2000 only the 'Twin Towers' terrorist attack featured as an external shock in 2001, until the commodities price shocks of later that decade. Over the same period the US economy experienced the GM with strong rises in asset markets, interrupted briefly only in 1987, the early 1990s and 2000 (see Appendix 4). A sustained period of economic and asset price decline occurred from late 2007 and growth remains subdued in to 2013. Notwithstanding this asset markets have risen strongly from their trough in the first quarter of 2009 and remain at or near record levels in nominal terms today.

It is plausible that external shocks operate as automatic stabilisers of endogenous economic and financial market instability. Although undeniably speculative, this interpretation fits comfortably within the Minskian view that stability creates instability. Plausibly then, instability from beyond the economic system might be expected to regulate endogenous instability. No clear relationship between external shocks and proximate market movements is identifiable from a comparison between the graphs and the timelines (see Appendix 4). On this basis it is reasonable to infer that such shocks impact the economy but this impact is not systemic and this influence creates a level of instability that Minsky (1986) associated with systemic stability. Conversely, the stable 'fairweather' period of the GM allowed the build up of (endogenous) systemic excesses that resulted in the sustained period of instability since late 2007.

\subsection{Explanation: full-period buy model (B1)}

$$
\begin{aligned}
& \text { 8.1). } \ln \left(\frac{P i}{1-p i}\right)=0.071+0.801 R D V 3+1.007 N F F 3+1.013 S P / 2+0.986 S P / 3+1.104 V O L 1 \\
& +1.038 V O L 2+1.041 V O L 7+0.986 C E^{*} S P / 2+1.008 C E^{*} S P / 7+0.927 N F F^{*} S P / 1+0.953 N F F^{*} S P / 2 \\
& +0.968 N F F^{*} S P 8
\end{aligned}
$$

The buy model holds up well over the period 1980-2011, although it exhibits some tendency to identify declining quarters as 'buy' quarters in strong, almost persistently rising markets. (Note: size effects are identified in chapter eight, table 8.0).

\section{Explanation of B1 variables}


1. An increase in real dividend flows (RDV3) at 3 lags leads to a decrease in $\mathrm{p}(\mathrm{Y})$, where (Y) is a buy (or rising market) quarter by an economically significant amount. An increase in RDV3 may be due to an increase in nominal dividend flows or decreasing inflation. Dividends are typically more stable than inflation suggesting that this variable's significance is primarily due to a change in inflation. This is consistent with a more generally subdued economy at this point.

2. An increase in NFF3 leads to an increase in $\mathrm{p}(\mathrm{Y})$. This is likely to be the result of growing risk appetite and a rising market. This is the inverse of the effect identified at 1 above. This variable reflects that a succession of rising quarters may be generally expected (i.e. a broadly rising market).

3. An increase in the S\&P500 index at 2 lags (S\&P2) is consistent with the increase in NFF3 at 2 above. That is, it identifies a story of momentum as a basis for inferring subsequent positive market movements.

4. An increase in S\&P500 at 3 lags reverses the effect of NFF3 (see 2 above), with a decreased $\mathrm{p}(\mathrm{Y})$ accompanying an increase in this variable.

5. An increase in market trading volumes at 1,2 and 7 quarters each lagged increase the $\mathrm{p}(\mathrm{Y})$. In terms of VOL1 and VOL2 this is plausibly linked to Minsky's euphoric period in which the demand for shares surges, driving trading volumes higher. In terms of VOL7, this is more difficult to implicate in the $\mathrm{p}(\mathrm{Y})$ but it may reflect a turning point and the start of a period of expansion. Notably, the relative importance of VOL1 over VOL2 and VOL7 is reflected in greater distance of VOL1 and VOL2 from 1.

6. An increase in $\mathrm{CE}^{*} \mathrm{SP} 2$ reduces the $\mathrm{p}(\mathrm{Y})$. Typically, rising corporate equity flows (i.e. decreasing equity outflows or movement to positive flows) and a falling market reduce the $\mathrm{p}(\mathrm{Y})$ at 2 lags as the market sustains a 'bearish' phase, consolidating balance sheets, and retreating from the substitution of corporate debt for corporate equity finance that is favoured in 'bullish' markets.

7. An increase in $\mathrm{CE}^{*} \mathrm{SP} 7$ increases the $\mathrm{p}(\mathrm{Y})$. This is consistent with the timing of the variables at the increased market volumes (VOL1, VOL2) at 5 above. And indicates a consolidation phase which, in turn, supports a subsequent rise in the market in 7 quarters. The statistical strength of this variable may be overstated over the full period due to its strength in the early 1990s.

8. An increase in NFF1, 2, and 8 lead to a decreased $p(Y)$. Typically, an increase in NFF at any lag will involve the combined influence of increased corporate debt inflows and rising corporate equity outflows. So, where these variables increase, reducing the $\mathrm{p}(\mathrm{Y})$, 
the inference can be made that two quarters of prior financing flows that typically accompany a rising market, when following similar flows at 8 quarters, create an unstable market environment with growing risks of index falls.

An increase in NFF3, SP2, Vol 1 and 2 are all consistent with rising markets and Minsky's 'euphoric' phase. Increasing markets, volumes, and debt inflows support the market's momentum. An increase in $\mathrm{CE}^{*} \mathrm{SP} 2$ reduces the $\mathrm{p}(\mathrm{Y})$ as Balance Sheet consolidation pre-empts a fall in the market. The increase in $\mathrm{p}(\mathrm{Y})$ with a decrease in $\mathrm{NFF}^{*} \mathrm{SP} 1$ and 2 implies vulnerability. These variables appear to aggregate risk assessments of a market decline and imply Minsky's concept of stability begetting subsequent instability.

\subsection{Explanation for the augmented 'Buy' model (B2)}

(8.2). $\ln \left(\frac{P i}{1-p i}\right)=-0.895+1.433 Z$ stat $-0.744 F F R 2+-0.430 F F R 4+0.227 F F R 8+1.183 D C R 2$

The augmented Buy model B2 adds monetary policy variables to the Z-statistic of B1. Included as variables along with the individual variables of B1, these monetary policy variables do not improve the performance of the model. FFR2 has a large (exponent value 4.191) contribution to B2, increasing the prospect of a 'Buy' event with each unit of increase in FFR2 by over four times. FFR4 and FFR8 also have a large impact on B2, with both decreasing the chance of a 'Buy' event with each unit of increase in these variables (respectively by 0.475 and 0.650). The distance from 1 determines the size of the variable effect with an increasing influence with distance from 1. DCR2 increases the chance of a 'Buy' event (1.255) as it increases.

Rising FFR2 indicates that rising interest rates two quarters prior to the predicted (Buy) event $(t+1)$ support inference to a rising market. This may be plausibly linked to pressure on interest rates due to a buoyant economy, flowing through to future market rises. The same is true of DCR2. A decrease in FFR4 and FFR8 results in a $n$ increased $\mathrm{P}(\mathrm{Y})$ and may reflect periods of consolidation at these points from which market recovery can be expected.

Adding monetary policy variables captures operations that were only evolving in their present form at the time of Minsky's development of the FIH. The role of FFR2 and 4 and DCR 2 may be explained by the relation of changes in these variables as policy responses to 
future inflation expectations and the present state of asset markets. Where we have an increase in these variables we would expect interest rate increases to subdue the market but the opposite occurs. It is reasonable to infer that these variables' movement is not causative but symptomatic of a robust economy and asset markets, supporting inference to future rises.

\subsection{Explanation: full period sell model (S1)}

8.3). $\ln \left(\frac{P i}{1-p i}\right) \quad=0.006+2.244 N I R 7+0.512 R D V$
$10+0.251 N D F 2+1.006 N E F 7+1.006 N F F 2+1.009 N F F 5+0.993 N C E * S P / 6+1.006 N C E * S \& P 8+$
$0.996 N C E^{*} S \& P 9+1.003 N C E * S \& P 10+0.527 F F R 7+1.845 D C R 1$

In the case of the full-period sell model (S1) Nominal interest at 7 lags (NIR7) increases $\mathrm{p}(\mathrm{Y})$ as it increases. An increase in NIR7 is an increase in the interest rate as posted. Possible inflationary pressures may increase NIR, leading to an increase in $\mathrm{p}(\mathrm{Y})$ as economic and financial market expansion moves beyond a stable level.

An increase in real dividend flows at 10 lags (RDV10) decreases the $\mathrm{p}(\mathrm{Y})$. RDV10 may increase due to an increase in the nominal dividend, a fall in inflation, or a decline in the level of the market. As real dividends have broadly reflected a cyclically stable trend decline and inflation and market cycles are more cyclical (along with the fact that nominal dividends at 10 lags was not statistically implicated), support arises for the combination of market movements and inflation volatility for the role of this variable in the equation. Elevated inflation may coincide with a decline in the market. At 10 lags the implication arises that the operation of this variable is located around a cycle in economic and market expansion and contraction and that it represents a consolidation phase from which markets progressively recover before rising to unstable levels and the elevation of $\mathrm{p}(\mathrm{Y})$.

As nominal dividends increase at 2 lags (NDF2) the $\mathrm{p}(\mathrm{Y})$ decreases. An increase in NDF2 may be caused by a fall in the market or a rise in the nominal dividend. Typically, it is likely that the market has fallen and that two quarters subsequent to that fall it is in a recovery mode as the effects of balance sheet consolidation create a base for the market to rise from.

Increases in corporate equity at 7 lags (NEF7) increase the $\mathrm{p}(\mathrm{Y})$. Again, it is reasonable to infer that the market was in a consolidation phase at NEF7 and that this created the basis for 
subsequent growth and eventual instability as that growth translated into a bubble (or Minsky's euphoric phase), before a decline in the market (a Minsky moment). This period of heightened instability increase the $\mathrm{p}(\mathrm{Y})$.

Net financing flows: NFF2. As this variable increases the $p(Y)$ decreases. An increase in NFF2 is typically an increase in external debt financing and a rising outflow of corporate equity financing (typically as share buybacks). Such movements generally accompany a rising market as the market's appetite for risk grows. This equates to a Minskian period in which borrower margins contract as they are prepared to pay more for assets, propelling markets higher. Further, it identifies a period in which there is a reasonable expectation of market price trend extrapolation and successive rises in the market. In contrast, NFF5 has the opposite impact, with an increase in NFF5 leading to an increase in the $p(Y)$. This relationship may simply be the product of cycle phase and the possibility that an increase in this variable reflects growing market risk appetite, greater rewards (actual or perceived) to the re-purchase by companies of their own equity, and a deficit of new investment with expected returns sufficient to justify risk.

$\mathrm{CE}^{*} \mathrm{SP} 6$ increases reduce the $\mathrm{p}(\mathrm{Y})$; CE*SP8 increases increase the $\mathrm{p}(\mathrm{Y})$; CE*SP9 increases reduce the $\mathrm{p}(\mathrm{Y})$; CE*SP10 increases increase the $\mathrm{p}(\mathrm{Y})$ : Individually, these variables are difficult to theoretically implicate because movement in them can be due to different causes. We may suppose increases in these variables (with companion equity inflows) occur during market falls at ten and eight lags and quarters of market rises (with equity outflows) at six and nine lags. A further difficulty in theoretical justification is the distance of these variables from the DV. It is possible they are causally active or they may be symptomatic. Lying near the minimum time scale for a full business cycle they may reflect sub-cyclical flows and market movements and simply stand as after- effects or ripples upon ripples.

Typically (approximately $80 \%$ of the time), increases in these variables are the result of a decline in corporate equity financing outflows (possibly turning positive) and a falling market (approximately $75 \%$ of the time). Where there is a decrease in these variables it is typically the result of a rising market, accompanied by growing corporate equity outflows. That is, the market is likely to be falling or in a consolidation phase as risk aversion re-emerges following period of market-participant ebullience. There is no precise or certain explanation for the volatility in these variables at points so remote from the succeeding period of market 
decline. However, it is plausible that this volatility reflects a consolidation period or, more precisely, where the movement in these variables reflects a consolidation period with a decline in $\mathrm{CE}^{*} \mathrm{SP} 10$ and 8 , and a rise in $\mathrm{CE}^{*} \mathrm{SP} 9$ and 6 , the period intervening such movements and the $\mathrm{p}(\mathrm{Y})$ they respectively 'anticipate' is due to the affect of market expansion on market sentiment. Where this subsequently induces market euphoria it may propel the market to unstable levels, heightening the $\mathrm{p}(\mathrm{Y})$. Conversely, where the variable movements are reversed, with an increase in CE*SP8 and 10, and a decrease in CE*SP6 and 9, the syncopation of these variables' movements relative to the preceding scenario reflects the reduced likelihood of a (Y) event in the future.

An increase in the US Federal Funds Rate at 7 lags (FFR7) decreases the p(Y). An increase in FFR7 may be due to the Federal Reserve Board attempts to control inflation or, as was the case in the 1990s, to 'lean against the bubble'. It is difficult to assign a theoretically meaningful reason for the behaviour of FFR7 and it may simply describe the distance from a period of tighter monetary policy before systemic imbalance resurface, placing downward pressure of the market. Again this is consistent with Minsky's link from stability to instability. The second of these possibilities is a product of the augmented Taylor Rule. The process of 'augmentation' entailed using variously tight and easy monetary policy settings to control inflation and inflation expectations but also to support or subdue financial markets.

The Discount Rate (DCR) and the Federal Reserve Board influence on it had a similar purpose to that of the FFR. An increase in the discount rate at 1 lag increases the $p(Y)$. We may consider such a movement of this variable as a pre-emptory movement that subdues the market in the subsequent quarter.

\subsection{Explanation: short-period sell model (S2)}
(8.4). $\ln \left(\frac{P i}{1-p i}\right)=\quad 0.026+0.181 R D V 6+1.039 N C D 7+0.95 N C D 8+0.965 N F F 3+1.053 N F F 5$ $+0.954 N C E * S P 1+1.201 N C E * S P 9$

The short-period sell model (S2) includes an increase in real dividend flows at 6 lags decreases $\mathrm{p}(\mathrm{Y})$ (a declining market or 'sell' event) so, where RDV6 decreases there is an increased $\mathrm{p}(\mathrm{Y})$. An increase in RD6 reflects either: 
1. Declining inflation, or

2. A dividend increase

As nominal dividend flows are the most stable time series of the three (with a declining trend until stabilisation in the 2000s), a change in dividends is the least likely of the explanations. The $\mathrm{p}(\mathrm{Y})$ is a likely result primarily of declining inflation as dividends are more stable than inflation generally event. Plausibly, such an environment includes greater economic stability and subdued inflation and inflationary pressures. Conversely, the likelihood of a falling market is increased by a declining RDV6, most generally reflected in a rising market and increasing inflationary pressures. This fits within the FIH framework as rising inflationary pressures in a cyclical period of growth accentuate the risk of market instability. As reflected in the exponent on this variable (shown in table 8.6) its effect in the model is large. A unit increase in RDV6 reduces the probability of a Sell event more than five times.

Corporate debt flows at 7 lags (i.e. NCD7) increases the $\mathrm{p}(\mathrm{Y})$ as it increases and reduces the $\mathrm{p}(\mathrm{Y})$ as NCD7 reduces. The opposite influence on $\mathrm{Y}$ is observed with NDF8. This may reflect a period of consolidation in the market whereby a decreasing appetite for risk (reflected in declining NDF8) 8 quarters or 2 years prior is replaced by a re-emergence of risk appetite shortly thereafter (at 7 lags or $13 / 4$ years prior), suggesting the occurrence of short-cycle 'bubble' that results in a heightened risk of a subsequent decline in the market. Typically, the expectation would be for a series of rises in the market from the point of NDF7. Where the movements are reversed (i.e. NDF8 increases and NDF7 decreases) the reduced $p(Y)$ reflects a more nascent phase in the expansionary cycle, mitigating the risk of over-valuation and subsequent market decline.

Declining Net funding flows (or more precisely, the decline in a debt bias in external corporate financing) at 3 lags decrease the $\mathrm{p}(\mathrm{Y})$ whereas $\mathrm{p}(\mathrm{Y})$ increases with an increase in NFF at 5 lags. Increasing NFFs are typically comprised of corporate equity outflows and corporate debt inflows. This variable is determined by deducting corporate equity inflows from corporate debt inflows. As corporate equity flows are overwhelmingly negative over the period 1980-2011 it follows that the deduction of corporate equity financing flows from corporate debt inflows leads to a larger absolute number in most quarters. This variable aims to capture Minsky's view of a progressive rise in risk due to the structure of corporate financing over periods of economic expansion and rising markets. These considerations suggest that debt 
build-up (or the growing preference for debt-funded corporate external financing) precedes a break in this trend 3 quarters prior to the quarter of market decline. Where the NFF decreases at 5 lags a period of consolidation (often related to a period of market and economic decline) is indicated. Where NFF levels are decreasing at 3 lags the indication is one of declining risk appetite, expressed through a decline in the net preference for corporate debt financing. This also supports the view of NFF as an important early indicator of re-emerging risk aversion and a subsequent increase in $\mathrm{p}(\mathrm{Y})$.

When corporate equity financing flows multiplied by the S\&P500 index (CE*SP), at 1 lag increase, the $\mathrm{p}(\mathrm{Y})$ decreases. An increase in $\mathrm{CE} * \mathrm{SP} 1$ reflects a consolidation period. The typical direction of corporate equity flows is negative and, typically, these negative flows accompany a rising market. Thus, the increase in $\mathrm{CE}^{*} \mathrm{SP} 1$ indicates a decline in the market accompanied by reduced equity outflows. These movements reflect a general retreat from risk during periods about or during market decline. Where these events occur there is an increased likelihood of subsequent market recovery. Evidence for this recovery lies in the role of $\mathrm{CE}^{*} \mathrm{SP} 2$ in the buy model as an increase in that variable increases the probability of a market rise.

$\mathrm{CE}^{*} \mathrm{SP} 9$ has the inverse influence to that of $\mathrm{CE}^{*} \mathrm{SP} 1$. An increase in CE*SP9 increases the $\mathrm{p}(\mathrm{Y})$ (market decline). A rise in CE*SP9 is typically the result of declining corporate equity outflows and a falling market. At 9 lags this period of consolidation has sufficient time to create a basis for a subsequent rise, resulting in future market instability and the increased $p(Y)$ in 9 quarters.

\subsection{The period of financial market deregulation}

The period 1984-1999, in which the full-period sell model almost consistently fails to predict 'sell' quarters, is marked by a number of features. The period encompasses two periods of sustained abnormal index growth occurring over the bull runs of the 1980s and 1990s. In particular, the 1990s "Super bull run" is a departure from past market movements. Over this period the index rises rapidly and is typically interrupted by acute but relatively brief periods of market decline. This era of above historical index growth may have subsumed 'sell' signals relevant to the period 1980-2011 in a predominantly rising market. Anecdotal evidence for this arises in both 'buy' and 'sell' models as the buy model typically reports type 2 errors during sustained periods of market rise. Conversely the full-period 'sell' model typically produces type 1 errors during such periods. Notably, the entire period 1984 to 1999 , a period of sustained 
above historical average market growth is marked by, on average, very low predicted probabilities of market reversal. This fits with the general nature of market performance over the period.

In contrast, the seven variable model covering the period 1984-1999 is highly successful in isolating periods of market decline, and has just one type-two error over the period. The model better explaining this period of a predominantly rising market includes independent variables reflecting corporate debt and equity flows, and variables integrating corporate equity flows with market levels. This model shares two of these variables with the full period model. Although at different lags, the models also share other variables, including real dividend flows. However, the two models differ in a number of important regards. The smaller model employs real dividend flows at 6 lags, corporate debt at 7 and 8 lags, net fund flows at 3 and 5 lags, and corporate equity flows multiplied by the S\&P 500 index at 1 and 9 lags. This simpler sell model successfully predicts 11 of 14 events (or 3 type-one errors).

\subsection{Why is the seven variable model (S2) so successful?}

As has been noted in chapter four, the period from 1984 is described as GM. This is a period marked by abnormally low inflation and output volatility and above historical average economic growth. As a subsidiary feature some economists have noted an increased level of financial market volatility over the period (Wray, 2007). This feature is not universally accepted. A further feature of the period is the origin of Central Bank policy targeted at inflation control and, from 1987, at asset market stability. In light of the youth of such policies their effectiveness may have been greater in the early stages of their implementation. This period coincides with the period in which S1 fails almost completely.

The policy of the Central Bank in the period after Alan Greenspan's ascent to the Chairmanship of the US Federal Reserve Board and (in consequence), the Chairmanship of the Federal Open Market Committee (FOMC), was marked by the assessment of financial market stability as a separate consideration in the formation of monetary policy. In the early 1980s Central Bank policy involved the application of the Taylor Rule, if approximately, to focus purely on inflation targeting. Greenspan's incumbency saw the Taylor Rule extended, the socalled augmented Taylor Rule, to weigh the stability of asset markets against inflation priorities. In practical terms this involved the use of the Federal funds Rate and Discount Rate along with Central Bank liquidity supply to the economy based on balancing concerns about 
inflation with those about the stability of markets. This issue has been addressed in greater detail in chapter four.

Specifically, the Central Bank under Greenspan reacted to its concerns of an overheating market, independent of concerns about emerging inflation, by 'leaning against' the bubble. This was reflected in interest rate rises through periods of the 1990s when there was no underlying concern about rising inflation. Similarly, the Federal Reserve engaged in monetary policy easing in periods of rising inflation when asset markets were in need of support (Spencer and Huston, 2006). This was most clearly observable in the period from late 20012004. Fears of a debt deflation were prevalent at the start of this period leading the central bank to support markets with negative real interest rates.

Importantly, the period from 2001-2003 was the final time during the GM that the Central Bank attempted to support falling asset markets by easing monetary conditions. A number of prominent economists (including Taylor, 2008) causally relate this period of 'accommodative' monetary policy conditions to the subsequent GFC, noting that negative real interest rates were maintained over the period 2002-2004. For the purposes of the present thesis this is important as it marks a sustained departure from the Taylor Rule because concerns about rising inflationary pressures (noted by Taylor, 2008) were subsumed by those about the risks of debt deflation. Inference to the reduced ability of monetary policy to stabilise asset markets arises in the longevity and extent of the market decline through to early 2003, as well as the length and magnitude of the required monetary policy easing. These factors combine to suggest both monetary policy changes and the market reaction to these explain the abnormal period in terms of the predictive efficacy of the sell models. However, it is arguable that monetary policy operated by supporting a progressive, substantially uninterrupted rise in the market, beyond levels that were sustainable by underlying fundamentals. This interpretation is supported by the extent and length of the market decline over 2001-2003 and during the GFC, as a departure from market behaviour over the 1980s and 1990s. The inherent instability created by this Central Bank 'stabilising' influence, resulted in greater subsequent instability as an inherent feature of the market. 


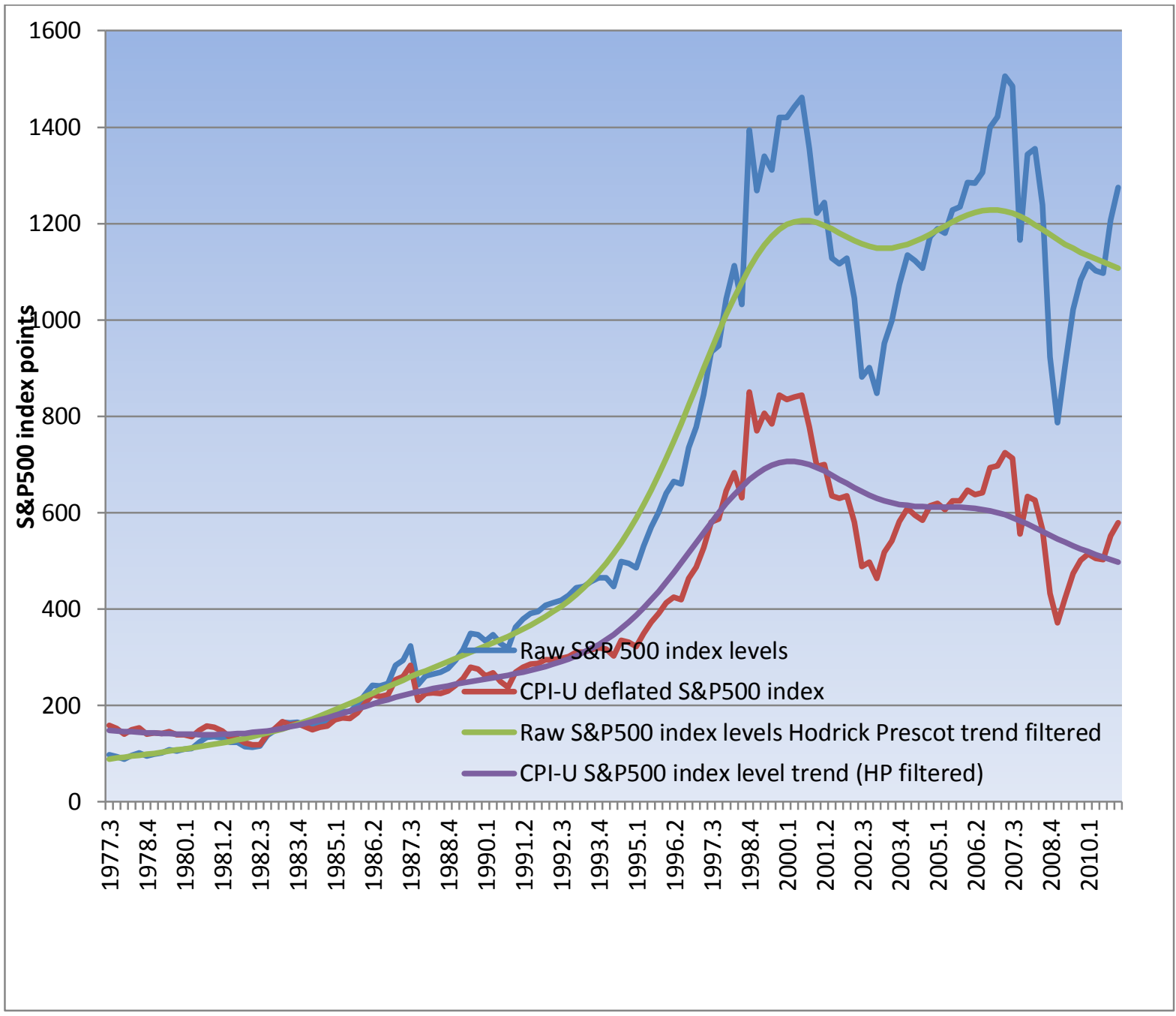

Figure 20 presents the S\&P 500 index over the period 1977 to 2011 in raw and CPI-U deflated terms. The associated smoothing or trend lines added to the two time series depictions highlight the rapid change in the accent of the trend in market levels over the period in which the full sell period model breaks down. Over this period there is a rapid acceleration, the period being marked by elevated growth in the market index. It is reasonable to assume that the increases of the 1990s reflected substantial bubbling. This view is supported by the failure of the market to reacquire levels seen in early 2000 until 2007 (nominal) and, in inflation-adjusted terms, the market has yet to re-acquire those levels in 2013. The trend lines indicate the speed of the market's recovery and acuteness of its falls in the 1990s and the bull run of the 1980s. In this period 'sell' signals appear to have been subsumed by the prevalence of 'buy' signals (the strength of the rising market. The trend lines also indicate a progressively rapid rate of increase in the market over the period 1984-1999. This above historical trend rise is interrupted by short-lived but sharp falls. It is plausible that the general characteristics (bullishness) 
'buried' the 'sell' signals in what was a market that ex post was clearly and overwhelmingly one which supported investor exposure.

\subsection{How do we know when to use S1 or S2?}

The two sell models ( $\mathrm{S} 1$ and $\mathrm{S} 2$ ) create the need to establish how or if it is possible to determine when a model is applicable and which model it is that is applicable. This concern is reinforced by the observed poor performance of both 'sell' models and the 'buy' model (B1) in relation to S\&P 500 predictions during the 1970s. In particular, the relative weakness of the models in predicting market movements in the 1970s gives rise to doubts about the generalisability of the models. These concerns may be addressed by linking the failure of the models to distinct institutional structures prevailing in the two periods.

Specifically, the period 1980-2011 (and subsequently) is identifiable as one in which financial markets and institutions are substantially deregulated. Market discipline is the central mechanism for regulating the financial system during this period. This system is supported by Central Bank policy that aims principally at the control of CPI inflation. Arguably this system may do little more than defer economic instability, substituting present stability for long term stability and increasing moral hazard as market participants become convinced that monetary policy is applied asymmetrically to support asset markets and avoid depressions. This inference is supported by Minskian analysis and by observation of the heightened and lengthy period of instability following the end of the GM. Since 1987 this focus has been added to by a Federal Reserve Board concern for financial and, more specifically, asset market stability. However, the operationalisation of the so-called augmented Taylor Rule has been systematically asymmetrical, with larger, more vigorous responses to deflationary concerns than with concerns for future inflation (Spencer and Huston, 2006). Further, Central Bank responses when tightening monetary policy settings have frequently occurred in the absence of inflationary pressures but when asset markets have been rising strongly and, thus, less likely to be affected by (in particular) rising interest rates.

The preceding considerations support the view that as long as economic and financial market regulation is essentially left to market discipline the underlying relevance of the models holds. In essence the models identify markets' endogenous propensity to instability. This entails that as markets become highly laissez faire the models perform well. This is qualified in relation to sustained periods of abnormal index rises, interrupted by only brief, acute periods 
of consolidation. This development is identified and discussed in the chapter eight development of model S2, due to the failure of S1 over the middle of the research period.

Notably, the poor performance of the full-period sell (S1) model is not sustained into the 2000s during periods of (broadly) sustained market decline or through the strong rise from the end of the first quarter of 2009. These features support the view that the full-period model should be abandoned in favour of the 7-variable model (S2) only after recurrent false predictions occurring in a period of sustained market rises. More specifically, in markets generally rising strongly, and in which the sensitivity of model S1 repeatedly compromises its successful event identification $\mathrm{S} 2$ is preferable.

Having said this, it is not clear that switching between models is plausible or practical. It is also arguable that hindsight would be essential to the application of the short sell model. For this reason the primary function of the development of the short sell model was to seek an explanation for the weakness of the full period sell model. Notwithstanding, given the novel features of this sub-period and its duration there is some basis to believe the sub-period model could have been applied some time after the start of the 'anomalous' period.

\subsection{General commentary}

There are theoretical grounds to the selection and testing of the variables identified as indicators of future market movements. We can observe that, across the three models (B1, S1, and S2), temporally nearer variables (lags 1, 2, and 3) account for fourteen of the thirty variables identified. This is inherently reasonable as the impact of these variables is more immediate (being more proximate) and less likely to be dissipated by economically endogenous or exogenous influences. Secondly, the buy model (B1) is dominated by such temporally proximate variables (75\%) and it performs, on the whole, better than the sell models (S1 and S2). The two sell models' variables are more evenly dispersed over the ten lags tested and tend, on average, to include variables in the more remote of the range. Notably, the full-period sell model (S1) breaks down in the period 1984-1999 and requires augmentation with a second model (S2) for that period but, there are no other comparable prediction models available.

Similarities exist between the models. Real dividends (at different lags) feature in each, as do net fund flows and corporate equity multiplied by the S\&P500 index. In each model different measures of external corporate financing flows play an important role in completing 
the models. Features unique to the buy model (B1) are the role played by coefficients for previous market rises and market volumes, which provide support for a simple technical view of markets' movements.

The two sell models (S1 and S2) are, in some sense, more closely aligned to each other than either is to the buy models (B1 and B2). Notably, the short period sell model reverses sign on the variable it shares with the buy model, NFF at 3 lags. The signs on NFF5 are the same, as they are, respectively, at 2 and 3 lags of NFF, on the large and small models. Further, the short sell model largely contains variables in the full sell model, except for corporate debt flows at 7 and 8 lags. Elsewhere, the variables are at different lags except in the case of CE*SP9, where the small sell model has a positive sign and the large model's sign is negative.

The improved performance of S2 (over S1) for that part of the study period is plausibly the result of a model that is more sensitive to corporate financing flows. In particular, corporate debt played an important role in this period and the introduction of two debt variables appears to be importantly implicated in the greater success of that model. Equally, the closer proximity of $\mathrm{CE}^{*} \mathrm{SP} 1$ to the predicted event may play a role in the model's greater success. An increase in $\mathrm{CE}^{*} \mathrm{SP} 1$ is generally the result of rising corporate inflows or declining corporate equity outflows) and that this movement is typically seen at or about the point of large market corrections. As market declines in the shorter period were generally acute and short-lived, the greater predictive success of CE*SP1 is readily explicable as markets rebounded after just a single quarter of decline in this period. Likewise, $\mathrm{p}(\mathrm{Y})$ increases in the period 1984-1999 as CE*SP9 increases. Potentially, the inclusion of this variable for this period is related to the longer periods of sustained growth experienced in the 1980s and 1990s. Thus, prior market consolidations (at 9 lags) may have broadly supported market increases over 9 quarters, extending the period of benefit to the market from balance sheet consolidation. This also serves to explain why the 1984-1999 period sell model does not perform well on the full period.

Financial de-regulation allows for market-driven financing flows and prices. For this reason signs of future market movements may be stronger through periods of light regulation of the financial sector. Markets and companies are more rapidly able to adjust capital structures, in particular, with the (volitional) assumption of debt and (often forced) issuance of equity at points of market or economic crisis. Equally, interest rates are able to move freely without 
regulatory constraint to reflect in market prices (index levels) and trading volumes. NIR and RIR may provide additional indications of future market movements.

\subsection{Summary}

The models developed can be employed in a number of realistic ways to improve investor returns over those obtainable from a buy-and-hold approach implied by a random walk with upward drift. The respective models employ a series of macro-financial variables, the effects of which can be plausibly implicated as signs or causes of subsequent market movements. The longer lags on certain variables included in the different models requires an additional assumption if signalling or causation are to be inferred, that those more (temporally) remote variables cause 'ripples' that influence the future. This is not too remarkable and is implied by Fisher's (1933) view that the cause of one (business) cycle need be no more than proximity from the preceding cycle. For this reason longer lags, sometimes with different signs on the same macro-financial variable to those more proximate lags of the same variable, create no substantial theoretical problems.

Certain features are worth noting. The failure of the models over the 1970s fits comfortably within a Minskian view that external shocks precluded the endogenous stability that creates the instability that Minsky (1986) describes. For this reason, coupled with the monetary policy of the 1970s that was less focused on inflation control than in the post-1980 period, it seems reasonable to conclude that the models are not specific to the study period but that they operate best within the context of a specific set of institutional features and that, only so long as those key institutional features remain approximately constant, then the models remain relevant.

The models developed in this thesis have application for investors in general but are particularly salient to the operations of corporate treasury functions. By isolating the importance of different lags of corporate external financing flows as important signals and causes of future market movements, along with other macro-financial variables it is possible for companies to improve the efficiency of stock repurchase programs by timing those buy backs. An important feature of stock repurchases is that they are tax-efficient forms of stockholder 'distribution' when compared with dividends. This advantage has grown as (stock) transaction costs have progressively declined over the study period. The typically large scale 
of stock repurchases further compounds the minimisation of transaction costs and, therefore, the relative efficiency of this form of return to shareholders over dividend distributions.

At an operational level the disposition of type one and type two errors suggests an optimal approach that shows sensitivity to the sell model. Equally, the relative out-performance of the 'conservative approach detailed in appendix three and discussed in chapter eight, recommends focusing on sell signals. The expectation is that stock repurchases can be executed more efficiently with the use of the models identified in this research. Future $(t+1)$ predictions of a quarterly decline recommend deferral of the execution of all or part of a re-purchase program. Conversely, an unqualified "buy" signal supports pre-empting the forecast rise in the market over the quarter by expediting stock repurchases. The objective of this process is to increase the efficiency gap between dividend payments and stock repurchases. 


\section{Chapter ten: conclusion}

\subsection{Introduction}

This thesis focuses on macro-financial flows to explore and extend theory relating to corporate finance and to develop prediction models of future market movements. This process is founded on theory drawn from Keynes and the financial Keynesian Hyman Minsky. Keynes (1936) and Minsky (1986) are developed and extended to account for an evolving corporate financial and economic environment. Key Minskian precepts are maintained, including: that markets and market-based economies are inherently unstable; external shocks are not a necessary catalyst for endogenous instability; stability creates instability; and, financial channels and institutions are both causative of financial fragility and the primary transmission mechanism of that fragility. Binomial logistic regression prediction models are developed and assessed for their statistical significance and contribution to improved investor outcomes. These models are found to substantially improve implied returns over those obtained from a default buy-and-hold approach in relation to the S\&P 500 index over the period 1980-2011. These results support the view that macro-financial flows' data can play an important role in corporate stock repurchase decisions as well as in investor decision models more generally.

\subsection{Theoretical underpinnings}

The theoretical structure adopted is developed from an important qualification to the efficient markets' hypothesis (discussed in chapter two). Keynes (1936) and Minsky (1986) provide the basic theoretical infrastructure to explore a view of markets that are importantly influenced by certain key forces that lead to systematic mis-pricing (inefficiency). Related to these inefficiencies is the central proposition advanced by Minsky that markets are inherently unstable. That is, markets recurrently gravitate towards financial fragility, preceding crisis. Minsky (1986) also maintains that stability creates instability. This theme is developed to advance the case that external shocks may actually mitigate endogenous, systemic instability. Following from this any market-based economy would be unstable even without external shocks and, as in the case of the GM and subsequent GFC, may become progressively less stable due to the length and intensity of preceding stability.

The second key Minskian precept employed in this thesis is that the financial system underlying capitalist economies is both the transmission mechanism and an independent source of market-based economies' instability. Minsky (1986) tells us that financial intermediaries are 
profit-maximising entrepreneurs who actively locate and exploit new opportunities to increase profits. They do this through progressively riskier lending and credit creation. This departs from more conventional perceptions of the financial sector as merely an intermediator of finance flows from lender to borrower. A financial sector so motivated exacerbates economic and financial market cycles as periods of expansion grow credit demand and the sector innovates to maximise its ability to leverage reserves, increasing the financial institutional ability to extend credit. Chapter four relates this theory to recent US history.

Chapter five develops existing theory of external corporate financing based on Minsky's (1986) insights. We learn from Minsky that there is a progressive gravitation towards increased risk over periods of economic expansion that, in post-crisis phases, will be reversed by balance sheet consolidation. This phenomenon appears to be closely reflected in corporate macro-financial flows in the post-1980 period. Notably, the focus on flows is an adaptation of Minsky as he focused on leverage (debt stocks relative to equity) as an indicator of financial fragility. This adaptation reflects a changed economic environment in the 2000s, in which a rising market was not accompanied by strong increases in new investment or increasing leverage. The use of flows' data also substantially addresses the problem of endogeneity between leverage levels and unrealised changes in asset price levels in periods in which asset prices increase strongly. The approach addresses the circular justification of market prices and leverage levels based on past (especially elevated) price increases. Flows' data also is likely to be of greater relevance to short term market movements which forms the focus of this research. The case is made that corporate financing flows are importantly influenced cyclically and that a key determinant of those cycles is the relative WACC of equity and debt finance.

\subsection{Related research}

Chapter six identifies existing research isolating indices of financial fragility and prediction models of market movements. A variety of models and research is considered including that based on assumptions of broadly efficient markets and that which assumes varying degrees of market inefficiency. This process was conducted with a view to positioning the current research. Equally, the aim is of this chapter is to inform the approach developed in this thesis. The nearest research located was that of Shiller (2005), who provides long term market forecasts on the basis of historical PERs. Borio and Lowe's (2002) research into the forecast of high-cost recessions also partly informs the research produced here. 


\subsection{Methodology, findings, analysis}

Chapter seven outlines the methodology employed. This chapter describes the use of binary logistic regressions to test macro-financial variables for inclusion in models against, respectively, market rises and falls. This procedure produces two primary models: one predicting 'buy' quarters in which the market rises in the quarter; the other predicting 'sell' quarters or those in which the market falls. Each of these models relates to the S\&P 500 index over the period 1980-2011. These models are compared with implied returns over the period 1980-2011 from a default buy-and-hold approach and are found to improve returns, on the basis of different reasonable applications of the model predictions, by between three and five times. The model variables and those variables theoretically indicated but found insignificant are discussed. The relationship between the model independent variables and Minskian theory is considered in chapter nine.

\subsection{Contribution}

This thesis provides a well-specified challenge to a central precept of prevailing theory in economics and finance, that markets are reliably efficient and, therefore, provide true reflections of fundamental value based on the aggregation of investor expectations of stocks' future cash flows. This contribution is explored through the application of insights provided by Minsky (1986) about market-based economies central tendency to instability and conditions of stability as a driver of that instability. Minsky (1975) tells us that external shocks are not required for instability to arise in market economies and that instability is an essential feature of systems in which money is a store of wealth. More specifically, instability is related in Minsky's FIH to fractional reserve banking, without requiring this as a necessary condition for market-based economies gravitation towards financial fragility. From this theoretical basis I develop the extrapolative expectations theory of cycles in corporate financing.

This thesis extends Minsky's (1986) position to make the case that external shocks, rather than being de-stabilising of market-based economies, actually regulate endogenous, systemic excesses and, therefore, stabilise market economies. External shocks prevent the stability that allows the progressive gravitation towards the unstable financing structures that Minsky (1986) describes. This issue is implicit in the chapter four description of the GM which includes the longest period of growth of developed economies and markets in history. Minskian theory supports the view that such a sustained period would build up systemic excesses that would necessarily require a lengthy period to unwind. Balance sheet 
consolidation from a period as long as the GM implies a painful and extended recovery in Minskian terms. This has been evident in the nature and length of the economic recovery since 2009.

A further contribution made by this thesis is an extension to our understanding of corporate financing structures and preferences. Existing theories fail to provide convincing explanations for observed macro-financial corporate financing flows as observed (See figures 1 and 2). Thus Ho is disproved; existing theories of corporate financing do not provide compelling explanations of observed corporate macro-financial flows. These theories explain such structures and choices on assumptions of market efficiency and agent rationality, resulting in shareholder wealth maximisation. Disaster myopia or discounting a small risk of an extreme, adverse event seems to offer a more persuasive explanation. Equally, market price trend extrapolation also appears to motivate corporate financial structure decisions.

Given the failure of existing theories of corporate finance to explain the identified observations, space is created to hypothesize an extension to existing theory of corporate financing structures and preferences. With the progressive issuance of debt over market expansions and the outflow of equity concurrent with this, it is reasonable to posit a Minskianderived theory of corporate financing. Following Minsky (1986) extrapolative expectations are built on the succession of previous asset price rises over an expansion. Corporations' expectations for future stock prices and price rises increase with successive and 'near' evidence of prior increases. Borrower and lender margins contract, with declining collateral requirements and smaller idiosyncratic risk adjustments which are met by declining borrower margins, reflected in steadily rising asset prices. The real trade off is to be drawn in terms of competing weighted average cost of capital (WACCs); those of corporate equity financing and those of corporate debt financing. Bankruptcy or liquidity (cash flow) risks are subsumed by lower interest rates for debt relative to the implied cost of equity dividends and the dilutional effects of an increase in equity. The implied cost of equity is those gains that would have been attributable to existing equity holders, based on stock price increases. This fits well with the decline in transaction costs for equities which now impose only minimal costs on investors who prefer current to future consumption.

A further contribution is the use of flows' data. This contrasts with prevalent approaches that focus on stocks or 'fundamentals'. Flows' data offers the prospect of 
'sharpening' the focus of 'predictive' modelling, aiming at more specific, short-term forecasts. Instead of focusing on cumulative effects it may be possible to enhance the immediacy of predictive modelling by avoiding the use of 'fundamentals' measures of financial market stability and by rejecting the use of stocks' measures. In both cases an additional (potential) advantage is that the feedback effects of market cycle phases may be reduced through flows' data. In particular, debt-to-equity, PERs, and cash flows' measures are all influenced by cycle phase. To an extent, asset mis-pricing is self-justifying as rising or falling prices feedback into stocks and fundamentals. This is less clearly a confounding issue with single period single period flows' data.

The final contribution arises in terms of the potential to forecast broad market movements. In light of the success of the models developed the potential exists to improve investor information sets and, thereby, improve their decision models. This finding confirms H3. In particular, the application of model predictions to corporate treasury functions, in the repurchase of stock, can enhance the relative efficiency of this quasi-stockholder return. Stock re-purchases are typically authorised at the end/beginning of a financial year and are conducted up to specified prices and volumes throughout the year/following year. A quarterly forecast of market direction has the potential to provide a 'buy' or 'delay' signal. Given the ability to improve corporate treasury functions the relative efficiency of such programs over dividend payments may be further enhanced.

\subsection{Limitations}

In recognition of the fact that the focus of this thesis is on endogenous economic causation of macro-economic and macro-financial instability in market-based economies arguments are developed in chapters three and four to justify the assumption that exogenous factors play only a minor role in that instability. Having stated this (and made the case for the stability of market economies in relation to external shocks), and without discounting the considerable support for this proposition amongst economists, the exclusive focus on endogenous causes of economic instability is a limitation. As there are no explicit variables representing external shocks in the models developed here (and no reasonable base from which to develop such variables) the models and their forecast capacity may be confounded by future shocks, especially where these are large or depart from historical shocks in some economically significant regard. 
A number of points arise in relation to the assumption of asset price bubbles. Important amongst these is the implication that exogenous shocks are a requisite catalyst for a boom, which (may) lead to a bubble (Filardo, 2004). If shocks are the foundation for imbalances in asset prices it is necessary to inquire whether these shocks are essential occurrences. Minsky (1986) follows Schumpeter in describing the role of a shock, but it is an unremarkable phenomenon. Fisher (1933) argues that the 'shock' may simply be the recovery from the preceding cycle and, thus, wholly endogenous. Stipulating that a political change, technological development, or some other development can be the 'shock' locus of a boom, which is then operated on by a financial accelerator, it is unnecessary to qualify Minsky's theory as historical descriptivism/particularism. The technology shock is a very ordinary and recurrent event. The theoretical dimension arises with the assertion of the inherence of capitalism's propensity to operate in a predictable manner on what are reliably recurrent phenomena.

A further point of note is that when we speak of bubbles certain difficulties are posed. Typically, on Minsky's analysis, bubbles will be preceded by fundamentals that justify rising asset prices, at least in the early stages (Bernanke, 2002; Bernanke and Blinder, 1992; Bernanke and Gertler, 2001; Cotis and Coppel, 2005; Detkin and Smets, 2004; Filardo, 2004). If a positive shock results in a boom, it is reasonable to assume that in the early stages of a boom, fundamentals will improve (Detkin and Smets, 2004). This is important in the limited sense that booms are notoriously difficult to diagnose as bubbles and are subject to differing definitions. Some economists identify bubbles solely as asset price appreciations unsupported by changing fundamentals while others argue that the mere concept is meaningless, and that there has never been a bubble (Rudenbusch, 2005; Garber, 2000). The lack of economic fundamentals necessary to support an asset price rise is itself an imprecise concept without an objective interpretation of fundamentals. Kindleberger's $(1988 ; 1991 ; 1996)$ definition of bubbles as precipitous price rises over short periods which prove unsustainable, resulting in a price collapse, has several difficulties. The definition entails that such phenomena are identifiable only in post-mortem. They are also vaguely defined and too eclectic, with 'precipitous' and 'short periods' open to interpretation (Aglietta, 1996). For the purposes of this discussion speculative bubbles are the focus here and these are described in chapter two.

A related issue of perhaps even more critical concern in relation to the operation of the models developed in this thesis is that they operate on a well-specified economic and financial institutional environment. This is the de-regulated domestic economies of developed countries 
and the freedom of global financial flows that have extended this economic liberalism around the developed world. Arguably, this forms an important element in model specification and it might be expected that the models would perform less well in a significantly altered environment. Given this, there would be a need to re-visit the models, perhaps with a view to modifying them, in the event that the era of light regulation of financial markets and economies was to change. Light regulation is also paralleled by a focus on monetary policy and the focus of that policy on inflation control, augmented by a separate concern for asset market stability. Despite signalling this issue it is one that has recurred in the field of economics and is no different to issues identified by Mitchell and Burns (1938) when they developed the NBER basis for leading, coincident and lagging business cycle indicators. Some measures will wane in importance, some will cease to be relevant, new variables will acquire relevance. This is more an issue of identifying the need to maintain the currency of such measures and models, rather than an inherent flaw.

Minsky's theoretical framework has been criticised inter alia for its silence on wealth distribution as a causal link to business cycles and, concomitantly, asset market cycles. Rasmus (2008), Dickens (1999), and Dymski (2002), have identified this as a deficiency in Financial Keynesianism. Arguably then, Minsky's 'financial' theory of business cycles identifies just one of the signs of financial fragility. This objection indicates that underlying business cycles are cyclically coincident with changing wealth and income distribution. By extending Minsky's analysis to the tension between labour and capital, a fuller understanding of business cycle causation may arise. However, this is of no consequence to this thesis. The FIH is able to provide proximate causation. For the purposes of developing forecast models for equity markets the FIH provides a sufficient theoretical basis.

Other criticisms of Minsky's (1986) framework for understanding business and market cycles include the fact that corporate leverage did not increase noticeably in the economic expansion of the period from 2003. This issue has been addressed in this research through a focus on flows' data. So, rather than Minsky's focus on debt stocks and the relationship of these to equity stocks, this research isolates debt and equity flows' data as signals or causes of market movements. On this basis the historically anomalous moderation of changing corporate leverage over economic expansions and the relative dearth of new investment in the post-2003 period are unproblematic for the approach and variables used in this research. 


\subsection{Summary}

This thesis has outlined a theoretical view of the operation of market-based economies and of equity markets as a basis for developing a fuller theory of the operation of those markets. Minsky (1986) forms the bedrock of this approach which has been adapted and customised, both in light of an evolving economic environment but also to tailor Minsky's key insights to the focus of this research. The result of this process is the development of models and model variables that allow us to better understand and predict market movements. A further result is the positing of a logical and plausible explanation for observed corporate financing flows in the US in the modern era. These results are (and should be) qualified by their relevance to a particular institutional environment. They can maintain currency or relevance only as long as that environment remains substantially constant with the environment of the research period (1980-2011). Nothing of this limitation invalidates the results located in this thesis and, as per Burns and Mitchell (1938), the need to adapt and modify the model is an assumed feature of it and is wholly consistent with a dynamic and evolving economic and market environment.

Having noted the qualifications or limitations to the research presented here it is important to note that it is contrary to prevailing economic theory. In light of the less than convincing explanations offered by the economics profession (and academy as a whole) it is not certain that this is such a bad thing. Perhaps more importantly it is reasonable to explore alternative explanations for phenomena that existing theory is unable to illuminate in any persuasive way. In this vein this thesis offers a fuller, I hope more persuasive, response to Queen Elizabeth II's question to the effect, 'why did no one see it coming', than that of Professor Luis Garicano, Director of Research at the London School of Economics' Management Department, that:

"At every stage, someone was relying on somebody else and everyone thought they were doing the right thing." 


\section{References}

Abdeljawad, I, Nor, FM, Ibrahim, I, and Rahim, RA. (2013). Dynamic capital structure tradeoff theory: Evidence from Malaysia. Proceedings of the $3^{\text {rd }}$ global accounting, finance, and economics conference, 5-7 May, Rydges, Melbourne, Australia.

Acemoglu, D. (2009). The crisis of 2008: Lessons for and from economics. Critical Review. 21(2): 185-194.

Acharya, W, and Richardson, M. (2009). Causes of the financial crisis. Critical Review. 21(2): 195-210.

Adalid, RA, and Detkin, C. (2007). Liquidity shocks and asset price boom/bust cycles. $E C B$ Working Paper No. 732. Accessed on 09-01-2010, at: http://ssrn.com/abstract_id=963147

Ajith, A, Baikunth, N, and Mahanti, PK. (2003). Hybrid intelligent systems for stock market analysis. In, Proceedings of International Conference on Computational Science.

Akerlof, GA. (2008). Comment on "household debt in the consumer age: source of growthrisk of collapse" (by BZ Cynamon and SM Farazzi). Capitalism and Society. 3(2): 1-3 (Article 4).

Akerlof, G, and Shiller, R. (2009). Animal Spirits-How human psychology drives the economy and why it matters for global capitalism, Princeton, NJ: Princeton University Press.

Allen, F. (2005) Modelling financial instability. National Institute. Economic Review. 192(1): 57-67.

Allen, F, and Gale, D. (2000). Bubbles and crises. The Economic Journal. 110(1): 236-255.

Allen, F, and Gale, D. (2006). Asset Price Bubbles and Monetary policy. Working Paper 0126. Pennsylvania: Financial Institutions Center of Wharton School. University of Pennsylvania. 
Altman, M. (1992). The Volatility of Business Cycles in Developed Market Economies, 18701986: Revisions and Conjectures. Eastern Economic Journal. 18(3): 259-275.

Arestis, P, and Sawyer, M. (2000). "New Consensus", New Keynesianism, and the Economics of the "Third Way". Working paper No. 364, Annandale-on-Hudson, NY: Jerome Levy economics Institute.

Ariel, RA. (1988). Evidence of intra-month seasonality in stock returns. In, Stock Market Anomalies. (Ed.) Dimson, E. Cambridge: Cambridge University Press.

Atsalakis, G, and Valakanis, K. (2009). Surveying stock market forecasting techniques- Part II: Soft computing methods. Expert Systems with Applications. 36(3-2): 5932-5941.

Avramov, D, and Werners, R. (2006). Investing in mutual funds when returns are predictable. Journal of Financial Economics. 81(2): 339-377.

Ayob, M, Nasrudin, MF, Omar, K, and Surip, M. (2001). The effects of returns function on individual stock price (KLSE) prediction model using neural networks. In, Proceedings of the International Conference on artificial intelligence, IC-AL 2001, pp. 409-415.

Azmat, G, Manning, A, and van Reenen, J. (2007). Privatization, Entry Regulation and the Decline of the Labour Share of GDP: A Cross-Country Analysis of Network Industries. Centre for Economic Performance, Discussion paper No. 86. London: London School of Economics.

Backus, DK, and Kehoe, PJ. (1992). International evidence of the historical properties of business cycles. American Economic Review. 82(4): 864-888.

Baker, D. (2007). Globalization: It doesn't just happen. Center for Economics and Policy research. Washington, DC: CEPR.

Baker, MP. (2009). Market-driven corporate finance, Available at SSRN: http://ssrn.com/abstract=1331567 or http://dx.doi.org/10.2139/ssrn. 1331567 
Baker, M, and Wurgler, J. (2002). Market timing and capital structure. The Journal of Finance. 57(1): 29-51.

Ball, R. (1978). Anomalies in relationships between securities' yields and yield-surrogates. Journal of Financial Economics. 6(2/3): 103-126.

Ball, R. (1989). What Do We Know About Stock Market Efficiency? In, A Reappraisal of the Efficiency of Markets. (Ed.) Guimaraes, RMC, Kingsman, BG, and Taylor, SJ. London: Plenum Publishing Corporation.

Banz, R. (1981). The relationship between return and market value of common stocks. Journal of Financial Economics. 9(1): 3-18.

Barberis, N. (2003). A survey of behavioural finance. In, Handbook of Economics and Finance, (Ed.) Costantidies, G, Harris, M, and Stulz, R. Elsevier Science; London.

Barnes, P. (2007). Minsky's financial instability hypothesis, information asymmetry and accounting information: the UK crises of 1866 and 1987, Accounting History, 12(1): 29-53.

Barnes, P. (2009). Minsky's financial instability hypothesis: Information asymmetry and accounting information. An addendum: the financial crisis of 2007-9 in the UK, available at: https://www.victoria.ac.nz/sacl/about/events/past-events2/pastconferences/6ahic/publications/6AHIC-30_FINAL_Paper.pdf

Barniv, R, and MacDonald, JB. (1999).Review of Categorical Models for Classification Issues in Accounting and Finance. Review of Quantitative Finance and Accounting. 13(1): 39-62

Basu, S. (1977). The investment performance of common stocks in relation to their price to earnings ratio: a test of the efficient markets' hypothesis. Journal of Finance. 32(3): 663-682.

Basu, S, and Taylor, AM. (1999). Business cycles in international perspective. Journal of Economic Perspectives. 13(2): 45-68. 
Baxter, ND. (1967). Leverage, risk of ruin and the cost of capital. Journal of Finance. 22(3): 395-403.

Bean, C. (2003). Asset prices, financial imbalances and monetary policy: are inflation targets enough? BIS Working Paper No. 140. Basel: Monetary and Economic Department: Bank for International Settlements.

Beaver, WH. (2002). Perspectives on recent capital market research. Accounting Review. 77(2): 453-474.

Becker, S. (2007). Global liquidity "glut" and asset price inflation. Fact or fiction? Current Issues. Deutsche Bank. Accessed on 20-05-2009, at: http://www.dbresearch.com/ResearchPROD/DRR_INTERNET_DEPROD0000000000210917.pdf

Bellofiore, R, Halevi, J and Passarella, M. (2010). Minsky in the 'new' capitalism: the new clothes of the financial instability hypothesis. In, The Elgar Companion to Hyman Minsky, pp. 100-116, (ED.) Papadimitriou, DB, and Wray, LR, Northampton: MA: Edward Elgar Publishing Ltd.

Bernanke, BS. (1983). Non-monetary effects of the financial crisis in the propagation of the Great Depression. Economic Review. 73(3): 257-276.

Bernanke, BS. (2002). Remarks by Governor BS Bernanke. Asset Price Bubbles and Monetary policy. Accessed on 12/02.2009, at:

http://www.federalreserve.gov/BoardDocs/Speeches/2002/20021015/default.htm

Bernanke, BS. (2004). The Great Moderation. Remarks by Governor Ben S. Bernanke. At the Meetings of the Eastern Economic Association, Feb. 20. Federal Reserve Board. Accessed on 21/12/2007, at: http://www.federalreserve.gov/boarddocs/Speeches?2004/20040220/default.htm 
Bernanke, B. (2005). The Global Saving Glut and the US Current Account Deficit. Remarks by Ben S. Bernanke at the Homer Jones Lecture (14 April). St. Louis: MO: Federal Reserve Bank.

Bernanke, BS, and Blinder, AS. (1988). Credit, money, and aggregate demand. American Economic Review. 78(2): 435-439.

Bernanke, B, and Gertler, M. (1999). Monetary policy and asset price volatility, Economic Review, 4th Quarter, pp. 17-51. Federal Reserve Bank of Kansas City.

Bernanke, BS, Gertler, M, and Gilchrist, S. (1999). "The financial accelerator in a quantitative business cycle framework," Handbook of Macroeconomics, in: J. B. Taylor \& M. Woodford (ed.), Handbook of Macroeconomics, edition 1, volume 1, chapter 21, pages 1341-1393 Elsevier.

Bhide, A. (2009). An accident waiting to happen. Critical Review, 21(2): 211-247.

Bibow, J. (2008). The International Monetary (Non-) Order and the "Global Capital Flows Paradox”. Working paper No. 531. Levy Institute of Bard college. Annadale-on-Hudson. New York.

Bikhchandani, S, Hirschleifer, D, and Welch, I. (2008). Information Cascasdes. In, The New Palgrave Dictionary of Economics, Second Edition, (Ed.) Durlauf, SN, and Blume, LE, http://www.dictionaryofeconomics.com/article?id=pde2008_I000103.

BIS Annual report (Bank for International Settlements). (2001). $71^{\text {st }}$ Annual report, 1 April 2000-31 March, 2001. Basel: Bank for International Settlements.

Black, F. (1986). Noise, Journal of Finance, 41(3): 529-543.

Black, L, and Hazelwood, L. (2012). The Effect of TARP on Bank Risk-Taking, Board of Governors of the Federal Reserve System International Finance Discussion IFDP 1043. Available at: http://www.federalreserve.gov/pubs/ifdp/2012/1043/ifdp1043.pdf 
Board of Governors of the Federal Reserve Bank (2013). Series Z1. www.federalreserve.gov/

Bodie, Z. (1989). The lender's view of debt and equity: the case of pension funds. Available at : http://www.bos.frb.org/economic/conf/conf33/conf33e.pdf

Boldrin, M, and A, Peralta- Alva (2009). What Happened to the US Stock Market? Accounting for the Last 50 Years, What Happened to the US Stock Market? Accounting for the Last 50 Years, FRB of St. Louis Working Paper No. 187.

Borio, C. (2003). Towards a macroprudential framework for financial supervision and regulation? Basel: Bank for International Settlements. Monetary and Economic Department.

Borio, C. (2006). Monetary and Prudential policies at a cross roads? New challenges in the new century. Basel: Bank for International Settlements, Monetary and Economic Department.

Borio, C, and Crockett, AD. (2000). In search of anchors for financial and monetary stability. Greek Economic Review. 20(2): 1-14.

Borio, C, Furfine, C, and Lowe, P. (2001). Procyclicality of the financial system and financial stability: issues and policy options. BIS Papers No. 1. Basel: Bank for International Settlements, Monetary and Economic Department.

Borio, C, and Lowe, P. (2002). Asset prices, financial and monetary stability: exploring the nexus. BIS Working papers No. 114. Basel: Bank for International Settlements. Monetary and Economic department.

Borio, C, and Zhu, H. (2007). Capital regulation, risk-taking and monetary policy: a missing link in the transmission mechanism? Keynote presentation at the ECB conference on the implications of changes in banking and financing on the the monetary policy transmission, Transmission, Frankfurt, 29-30 November, 2007. 
Bracke, T, and Fidora, M. (2008). Global liquidity glut or global savings glut? A structural VAR approach. ECB Working Paper No. 911. Frankfurt: European Central Bank.

Bradley, M, Jurrel, G, and Kim, EH. (1984). On the existence of optimal capital structure: theory and evidence. Journal of Finance. 39(3): 857-878.

Brav, A, Graham, JR, Harvey, CR, and Michaely, R. (2004) Payout policy in the Twenty first century. Journal of Financial Economics, 77(3): 483-527.

Brealey, RA. (1971). Security Prices in a Competitive Market. London: MIT Press.

Brealey, R, and Myers, S. (1984). Principles of corporate finance, New York: McGraw-Hill.

Breeden, DT.(1979).An Intertemporal Asset Pricing Model with Stochastic Consumption and Investment Opportunities. Journal of Financial Economics, 7: 265-96.

Broadway. (1998). Smith, Marx, Kondratieff and Keynes: Their intellectual life Spans, the Convergence of Their Theories based on Long Wave Hypothesis and the Internet. Accessed on 01-08-2009, at: http://www.southerndomains.com/SouthernBanks/p2.htm

Brousseau, V, and Detkin, C. (2001). Monetary Policy and Fears of Financial Instability. ECB Working Paper No. 89. European Central Bank. Accessed on 23/01/2008, at: http://www.ecb.eu/pub/pdf/scpwps/ecbwp089.pdf

Brown, C. (2004). Does income distribution matter for effective demand? Evidence from the United States. Review of Political Economy, 16(3): 291-307.

Brown, S, Goetzmann, WN, and Kumar, A. (1998). The Dow Theory reconsidered: William Peter Hamilton's track record reconsidered, Journal of Finance, 53(4): 1311-1333.

Brunnermeier, MK. (undated). Bubbles, http://www.princeton.edu/ markus/research/papers/bubbles_survey.pdf 
Brunnermeier, MK. (2008). Dechipering the liquidity and credit crunch 2007-2008. Working paper No. 14612. Cambridge. Massachusetts: MA: National Bureau of Economic Research.

Buffett, W. (2002). Chairman's Letter. Annual Report. Berkshire Hathaway. Omaha.

Bureau of Labor Statistics. 2013 U.S. Department of Labor Bureau of Labor Statistics, Washington, D.C ftp://ftp.bls.gov/pub/special.requests/cpi/cpiai.txt

Byuon, S. How and when do firms adjust their capital structures towards targets? The Journal of Finance. 63(6): 3069-3096.

Cabarello, RJ, Farhi, E, and Gourinchas, PO. (2006). An Equilibrium Model of "Global Imbalances" and Low Interest Rates. Research paper No. C06'149. Institute of Business and Economic Research, Center for International and Development Economics Research. Accessed on 04-05-2009, at: http://repositories.cdlib.org/iber/cider/C06-149

Cajueiro, DO, and Tabak, BM. (2006). Testing for rational bubbles in banking indicies. Physica A. 388(8): 1603-1609.

Campbell, J, Lo, A, and MacKinlay. (1997). The Econometrics of Financial Markets (1 $1^{\text {st }}$ Edition). Englewood: Prentice-Hall.

Carcello, JV, and Nagy, AL. (2002). Auditor industry specialisation and fraudulent financial reporting, Proceedings of the Deloitte \& Touche / University of Kansas Symposium on Auditing Problems: Fraud and the Audit Process: 94-118.

Cassidy, J. (2009). The Minsky Moment. The New Yorker (2 February). Accessed on 27/01/2009, at: http://www.newyorker.com/talk/comment/2008/02/04/080204taco_talk_Cassidy

Caverzasi, E. (2013). The missing macro link, Working Paper No. 753, Levy Institute of Bard College, available at: http://www.levyinstitute.org/pubs/wp_753.pdf 
Checcetti, SG. (2003). What the FOMC says and does when the stock market booms. RBA Annual Conference, 18-19 August, Asset prices and Monetary Policy.

Cecchetti, SG, Flores-Lagunes, A, and Krause, S. (2005). Assessing the sources of changes in the volatility of real growth. NBER Working paper No. 11946. Cambridge: MA: National Bureau of Economic Research, Inc.

Chang, X, Dasgupta, S, and Hilary, G. (1991). Analyst coverage and financing decisions, Working paper. http://www.bm.ust.hk/fina/staff/Dasgupta/Chang_Dasgupta_Hilary.pdf

Chen, N. (1991). Financial investment opportunities and the macroeconomy. Journal of Finance. 46: 529-554.

Chen, N, Roll, R, and Ross, SA. (1986). Economic forces and the stock market. Journal of Business. 56: 383-403.

Chinn, MD, and Kletzer, KM. (2001). International Capital lnflows, Domestic Financial Intermediation, and Financial Crises under Imperfect Information , In: Glick, R, Moreno, R, and Spiegel, MM (eds), Financial Crises in Emerging Markets (NY: Cambridge University Press for Federal Reserve Bank of San Francisco), pp. 196-237.

Choi, WG, and Oh, S. (2000). Endogenous Money Supply and Money Demand. IMF Working Paper/00/188: 1-35. Accessed on 2009-05-06, at http://ssrn.com/abstract/=880285

Clark, RA, and Sunley, EM. (1989). Corporate debt: what are the issues and what are the choices, National tax Journal. 42(3):273-282.

Commons, JR, McCracken, HL, and Zeuch, WE. (1922). Secular trends and business cycles. The Review of Economics and Statistics, 4(4):244-263.

Cook, DO, and Tang, T. (2010). Macroeconomic conditions and capital structure adjustment speed. Journal of Corporate Finance, 16(1): 73-87. 
Cooper, G. (2008). The Origin of Financial Crises. Central banks, credit bubbles and the efficient market fallacy. Petersfield: Harriman House Ltd.

Cooper, MJ, Dimitriov, O, and Rau, PR. (2001). A rose.com by any other name, The Journal of Finance. 61(6): 2371-2388.

Cotis, JP, and Coppel, J. (2005). Business cycle dynamics in OECD Countries: Evidence, causes and policy implications. Pp. 8-57 in, Kent, C, and Norman, D, Proceedings at a Conference, The Changing Nature of the Business cycle, Kirribilli.

Crockett, A. (2003). Central Banking under test? BIS Papers No. 18. Monetary stability, financial stability and the business cycle: five views, pp. 1-6. Basel: Bank for International Settlements, Monetary and Economic Department.

Cross, F. (1973). The behaviour of stock prices on Fridays and Mondays. Financial Analysts Journal. 29(6): 417-427.

Crotty, JR. (1990). Owner-manager conflict and financial theories of investment instability: a critical assessment of Keynes, Tobin and Minsky. Review of Radical Political Economics. 25(1): 1-26.

Crotty, J. (2008). Structural Causes of the Global Financial Crisis: A Critical Assessment of the 'New Financial Architecture'," Working Papers wp180, Political Economy Research Institute, University of Massachusetts at Amherst

CS first Boston Monthly Report (2011). https://www.credit-suisse.com/global/en/

$\begin{array}{lllll}\text { CS First } & \text { Boston } & \text { (2012). }\end{array}$ https://www.creditsuisse.com/investment.../cs_global_investment_return... 
Culp, CL, and MacKay, RJ. (1994). Regulating Derivatives: the Current system and Proposed changes. CATO Regulation. The Review of Business and Government. Accessed on 29/04/2009, at:

http://www.cato.org/pubs/regulation/reg17n4b.html

Cuthbertson, K, Nitzsche, D, and O'Sullivan, N. (2008). UK mutual fund performance: skill or luck? Journal of Empirical Finance. 15(4): 613-634.

Cynamon, BZ, and Farazzi, SM. (2008). Household debt in the consumer age: source of growth- risk of collapse. Capitalism and Society, 3(2): 1-27.

D'Arista, J. (2009). The evolving international monetary system. Cambridge Journal of Economics. 33(4): 633-652.

Daily Mail. (2008). Read more: http://www.dailymail.co.uk/news/article-1083290/Its-awful-Why-did-coming--The-Queen-gives-verdict-global-credit-crunch.html\#ixzz2cNR vdIdR Follow us: @MailOnline on Twitter|DailyMail on Facebook

Damodaran, A. (2007). Corporate finance, capital structure and financing decisions, Stern Business School. Available at: http://people.stern.nyu.edu/adamodar/pdfiles/country/Brcapstr.pdf

Daniel, KD, Hirschleifer, D, and Subrahmanyan. (2001). Overconfidence, arbitrage, and equilibrium pricing. Journal of Finance, 61(3): 921-965.

Daniels, B. (2008). Emerging Commons and Tragic Institutions, Environmental law, 39: 515571. Avaialable at:

http://papers.ssrn.com/sol3/papers.cfm?abstract_id=1227745

Danis, A, Rettl, DA, and Whited, TM. (2013). Testing dynamic trade off theory. http://www.danielrettl.com/DanisRettl_TradeoffTheory_2011.pdf 
Davidson, P. (2002). Keynes versus Kalecki: responses to Lopez and Kriesler. Journal of PostKeynesian Economics. 24(4): 631-641.

Debelle, G. (2004). Household debt and the macroeconomy. Basel: Bank for International Settlements. Monetary and Economic Department.

DeBondt, W, and Thaler, R. (1985). Does the stock market overreact? Journal of Finance. 40(3): 793-805.

DeLong, B. (1997). Assessing Globalization as a Cause of Blue-Collar Wage Declines. Accessed on 28/04/2009, at: http://econ161.berkeley.edu/Politics/Global_Wages.html

Detkin, C, and Smets, F. (2004). Asset Price Booms and Monetary policy. ECB Working paper No. 364. Frankfurt. European Central Bank.

De Vroey, M, and Pensieroso, L. (2005). Real Business cycle theory and the Great Depression: The Abandonment of the Absentionist Viewpoint: Discussion Paper no. 2005-54: de 1' Universite Catholique de Lo

Dhakal, D, Dharmendra, M, and Subhash, S. (1993). Causality between the money supply and share prices: A VAR investigation. Quarterly Journal of Business and Economics. Vol. 32(3): $52-74$.

Diba, BT. (1990). Bubbles and Stock Market Volatility. In, The Stock Market: Bubbles, Volatility and Chaos. (Ed.) Dwyer, GP, and Hafer, RW. Boston: Kluwer Academic Publishers.

Diba and Grossman. (1988). Explosive rational bubbles in stock prices? American Economic Review. 78(3): 520-530.

Dickens, E. (1999). A political-economic critique of Minsky's financial instability hypothesis; the case of the 1966 crisis. Review of Political Economy, 11(4); 379-398.

Dillard, D. (1988). Effective Demand and the Monetary Theory of Employment. In, Foundations of Keynesian Analysis. (Ed.) Barrere, A. New York: St. Martin's Press. 
Dimand, RW. (2004). Echoes' of Veblen's theory of business enterprise in the later development of macroeconomics: Fisher's debt-deflation theory of great depressions and the financial instability theories of Minsky and Tobin. International Review of Sociology. 14(3): 461-470.

Dimson, E, and Mussavian, M. (1998). A brief history of market efficiency. European Financial Management. 4(1): 91-193.

Doesken. B, Abraham, A, Thomas, J, and Paprzycki, M. (2005). Real stock trading using soft computing models. In, Proceedings of International Symposium on Information Technology: Coding and Computing ITCC, 2: 162-167.

Domhoff, GW. (2006). Power in America. Wealth, Income, Power. Accessed on 24/04/2009, at: http://www.sociology.ucsc.edu/whorulesamerica/power/wealth.html

Donaldson, RG, and Kamstra, M. (1999). Neural network forecastcombinig with interaction effects, Journal of the Franklin Institute. 336:227-236.

Dong, M, Hirshleifer, D, and Teoh, SH. (2007). Stock market misvaluation and corporate investment, MPRA Paper 3109, University Library of Munich, Germany, revised 05 May.

Dooley, M, Folkerts-Landau, D, and Garber, P.(2004a). The Revised Bretton-Woods System: The Effects of Periphery Intervention and Reserve Management on Interest Rates \& Exchange rates in Center Countries. NBER Working Paper No. 10332. Cambridge: MA: National Bureau of Economic Research, Inc.

(2004b). Direct investment, rising Real Wages and the Absorption of Excess Labour in the Periphery. NBER Working Paper No. 10626. Cambridge: MA: National Bureau of economic research, Inc.

Dow, S. (2008). Mainstream methodology, financial markets and global political economy. Contributions to Political Economy. 27(1): 13-29. 
Dreman, D. (1977).Psychology and the Stock Market, New York, NY: Amazon.

Drobetz, W, and Wanzenried, G. (2006). What determines the speed of adjustment to the target capital structure? Applied Financial Economics. 16(3): 77-99.

Durand, D. (1989). Reflections on the MM propositions: Thirty years later. Afterthoughts on a controversy with MM, plus new thoughts on growth and cost of capital. Financial Management, 18(2): 12-18.

Dyckman, TR, and Morse, D. (1975). Efficient Capital Markets and Accounting: A Critical Analysis (2nd Ed.). Englewood Cliffs: Prentice-Hall.

Dymski, GA. (2002). Post-hegemonic US economic hegemony: Minskian and Kaleckian dynamics in the neo-liberal era. Journal of the Japanese Society for Political Economy. 40(1): 247.

Dymski, G.A. (2010). Why the subprime crisis is different: a Minskyan approach, Cambridge Journal of Economics. 34(2):239-255.

Dymski, G, and Pollin, R. (1992). Hyman Minsky as Hedgehog: The Power of theWall Street Paradigm. In, Financial Conditions and Economic Performance. Essays in Honour of the Late Hyman P. Minsky. (Eds.) Farazzi, S and Papadimitriou, DB. London. Armonk: ME Sharpe Inc.

Dynan, KE, Elmendorf, DW, and Sichel, DE. (2005). Can financial innovation explain the reduced volatility of economic activity? Journal of Monetary Economics. 53(1): 123-150.

Dynan, K, Johnson, K, and Pence K. (2003). Recent changes to a measure of US household debt service. Federal Reserve Board's Division of Research and Statistics. Accessed on 10-122007, at: http://www.federalreserve.gov/pubs/bulletin/2003/1003lead.pdf

Dynan, KE, and Kohn, DL. (2007). The Rise in Household Indebtedness: Causes and Consequences. Finance and Economics Discussion Paper 2007-37. The Federal Reserve Board. Accessed on 12-01-2008, at: http://www.federalr4eserve.gov/pubs/feds/2007/200737/index.html 
ECB (European Central Bank). (2004). The Monetary policy of the ECB. Frankfurt: ECB. www.ecb.europa.eu/pub/pdf/other/monetarypolicy2004en.pdf

Edwards, S. (2005). Is the US Current Account Deficit Sustainable? And if not, how costly is Adjustment Likely to be? NBER Working Paper No. 11541. Cambridge: MA: National Bureau of Economic Research, Inc.

Elsas, R, and Florysiak, D. (2011). Heterogeneity in the speed of adjustment toward target leverage, International Review of Finance. 11(2): 181-211.

Entov, RM, and Poletaye, AV. (1991). Long Cycles: Preview and Current issues. In, Business Cycles: Theories, Evidence and Analysis. (Ed.) Thygesen, N, Velupillai, K, and Zambelli, S. Basingstoke: Macmillan.

Epstein, G. (1999). A comment on Edwin Dickens, Review of Political Economy. 11(4): 399405.

Erturk, KA. (2007). Advances in Monetary Policy and Macroeconomics. In, Advances in Monetary Policy and Macroeconomics. (Ed.) Arestis, P, and Zezza, G. Basinstoke: PalgraveMacmillan.

Evans, RW, and Makepeace, GH. (1979). Monetary Theory, Institutions and Practice. London: The Macmillan Press.

Fama, EF. (1970). Efficient capital markets: A review of the empirical work. Journal of Finance. 25(2): 383-417.

Fama, EH. (1990). Stock returns, expected returns, and real activity. Journal of Finance. 45: 1089-1108.

Fama, EF. (1998). Market efficiency, long-term returns, and behavioural finance. Journal of Financial Economics. 49(3): 283-306. 
Fama, E. F., and K. R. French. (1987). Forecasting returns to corporate bonds and common stock. Working Paper, University of Chicago (December).

Fama, E. F., and K. R. French. (1988). Permanent and temporary components of stock prices, Journal of Political Economy. 96(2): 248-273.

Fama, E. F., and K. R. French. (1988b). Dividend yields and expected stock returns. Journal of Financial Economics, Vol. 22(1): 3-25.

Fama, E, and French, K. (1992). The cross-section of expected stock returns. Journal of Finance. 47(2): 427-465.

Fama, EF, and French, KR. (1993). Common risk factors in returns of stocks and bonds, Journal of Finance. 47(2): 3-56.

Fama ,E, and French, K. (1995). Size and Book-to-market factors in earnings and returns. Journal of Finance. 50(1): 131-155.

Fama, EF, and French, KR. (2004). The capital asset pricing model: theory and evidence, Journal of economic Perspectives. 18(3): 25-46.

Fama, EF, and French, KR. (2010). Luck versus skill in the cross-section of mutual fund returns, Journal of Finance. 65(5): 1915-1947.

Farazzi, SM. (1992). Introduction: Conversations with Hyman P Minsky. In, Financial Conditions and Macroeconomic Performance. London: ME Sharpe, Inc.

Fazzari, SM. (1999). Minsky and the mainstream: Has recent research rediscovered financial Keynesianism? Working Paper no. 278. Ninth Annual Hyman P. Minsky Conference on Financial Structure, April 21-23, Jerome Levy Institute of Bard College: New York. 
Fender, J. (1981). Understanding Keynes. Brighton: Edward Elgar.

Fernandez, L, Kaboub, F, and Todorova, Z. (2008). On Democratizing Financial Turmoil: A Minskian Analysis of the Subprime Crisis. Working paper No. 548. New York: The Levy Institute of Bard College.

Ferri, P, and Minsky, HP. (1991). Market Processes and Thwarting Systems. Working Paper No. 64. Annandale-on-Hudson: NY: Jerome Levy Economics Institute of Bard College.

Filardo, A. (2004). Monetary policy and asset price bubbles: calibrating the monetary policy trade-offs. Basel. Bank for International Settlements: Monetary and Economic Department.

Findlay, MC. (1977). On market efficiency and financial accounting. Abacus. 13(2): 106-122.

Finfacts Team. (2006). Globalization: Corporate earnings soar as wage growth stalls in Developed World; Wages rising in China. Finfacts Business News Centre. Accessed on 26/04/2009, at:

http://www.finfacts.ie/irelandbusinessnews/publish/article_10005404.shtml

Fisher, I. (1933). The debt-deflation theory of the Great Depression. Econometrica. 1(4): 337357.

Flood, RP, and Garber, PM. (1994). Market Fundamentals versus Price-Level Bubbles: The First Tests.pp. 3-30.

Formaini, RL. (2004). Knut Wicksell: The Birth of Modern Monetary Policy. Economic Insights, 9(1): 1-7. Federal Reserve Bank of Dallas.

Frank, MZ, and Goyal, VK. (2003). Testing pecking order theory of capital structure, Journal of Financial Economics. 67(1): 217-248.

Frank, MZ, and Goyal, VK. (2007). Capital structure decisions: which factors are really important?, Working Available at: http://papers.ssrn.com/sol3/papers.cfm?abstract_id=670543 
KR French . (1988). Crash Testing the Efficient Market Hypothesis, in

NBER Macroeconomics Annual 1988, Volume 3, (Fischer, S ed). Pp.277-286. Chicago: MA:

MIT Press. Available at: http://www.nber.org/books/fisc88-1

Friedman, BM. (1981). The Roles of Money and Credit in Macroeconomic Analysis. NBER Working Paper No. 831. Cambridge: MA: National Bureau of Economic Research, Inc.

Friedman, BM. (1982). Time to re-examine the monetary targets framework. New England Economic Review. March/April: 15-23.

Friedman, BM. (1983). Money, credit and the Federal Reserve policy: Reply to Porter and Offenbacher. Economic Review. Nov/Dec: 30-34.

Friedman, BM. (1985). The substitutability of debt and equity securities. Pp. 197-238. NBER Corporate capital structures in the United States. University of Chicago Press. Chicago: IL.

Friedman, BM. (1986). Money, Credit, and Interest rates in the Business Cycle. In, The American Business Cycle- Continuity and Change. Pp. 395-458. (Ed.) Gordon, RJ. Chicago: IL: University of Chicago Press.

Friedman, BM. (1999). The Future of Monetary policy: the Central bank as an Army without a Signal Corps? National Bureau of Economic Research Working Paper No. 7420. Cambridge: MA.

Friedman, BM. (2006). The Greenspan Era: Discretion Rather Than Rules. AEA Meetings. January. Cambridge: MA.

Friedman, MF, and Schwartz, AJ. (1965). The Great Contraction: 1929-1933. Princeton University Press.

Fuhrer, JC, and Schuh, S. (1998). Beyond Shocks: What causes business cycles? An Overview. Conference series 42. Beyond Shocks: What causes business cycles. Federal Reserve Board of Boston: Boston: Illinois. 
Galbraith, JK. (1990). A Short history of Financial Euphoria. New York: NY: Penguin Books (USA) Inc.

Caginalp, G, Porter, D, and Smith, VL. (2000).Overreactions, Momentum, Liquidity, and Price Bubbles in Laboratory and Field Asset Markets, The Journal of Psychology and Financial Markets. 1( 1): 24-48.

Garber, PM. (1994). Tulipmania. Pp. 55-82. In, Market Fundamentals versus Price-level Bubbles: First Tests. (Ed.) Flood, RP, and Garber, PM. Cambridge: MA: MIT Press.

Garber, PM. (2000). Famous First Bubbles: The Fundamentals of Early Manias. Cambridge: MA: MIT Press.

Gatti, D, Gallegati, M, and Gallegati, M. (2005). On the nature and causes of business fluctuations in Italy 1861-2000. Explorations in Economic History. 42(1): 81-100.

Gerstad, S, and Smith, VL. (2009). Monetary policy, credit extension, and housing bubbles 2008 and 1929. Critical Review. 21(2): 269-300.

Gertler, M, and Lown, S. (1999). The information in high-yield bond spread for the business cycle: evidence and some implications. Oxford Review of Economic Policy. 15(3): 132-151.

Giese, J, and Tuxen, CK. (2008). Has excess global liquidity fuelled asset prices? Evidence from I(1) and I(2) cointegrated VAR models.

Goldstein, M, and Wang, F. (2005). The Next Emerging Market Financial crisis: What Might it Look Like? In, Financial Crises Lessons from the Past, Preparation for the Future. Washington: DC: Brookings Institution Press.

Goodhart, C, and Hofman, B. (2008). House prices, money, credit, and the macroeconomy. Oxford Review of Economic Policy. 24(1): 180-205. 
Gordon, MJ. (1989). Corporate finance under MM theorems. Financial Management. 18(2): $19-28$.

Gordon, RJ. (1986). Introduction. The American Business Cycle- Continuity and Change. (Ed.) Gordon, RJ. Chicago: IL: University of Chicago press.

Gorton, G. (1988). Banking panics and business cycles. Oxford Economic papers.40(4): 751781.

Gorton, GB. (2009). The Sub-prime Panic. European Financial Management.15(1): 10-46.

Gottschalk, P, and Smeeding, TM. (2000). Empirical evidence of income inequality in industrialised countries. In, Atkinson, $\mathrm{AB}$, and Bourguignon, $\mathrm{F}$ (Ed.). Handbook of Income Distribution. New York: Elsevier.

Government Accounting Office. (1994). Report on derivatives. GAO/GDD-94-133

Graham, J, and Harvey, C. (2002). How do CFOs make capital budgeting and capital structure decisions? Journal of Applied Corporate Finance. 15(1): 8-23.

Greenspan, A. (2002). Economic Volatility. Speech at a symposium sponsored by the Federal Reserve Bank of Kansas City. Jackson Hole: WY: Federal reserve Bank of Kansas city.

Greenspan, A. (2005). Risk Transfer and Financial Stability. Remarks by Chairman Alan Greenspan. Federal Reserve Board. Accessed on 12/11/2007, at: http://www.federalreserve.gov/Boarddocs/Speeches/2005/20050505/default.htm

Greenspan, A, and Kennedy, J. (2007). Sources and Uses of Equity Extracted from Homes. Discussion paper No. 2007-20. Washington: DC: Federal reserve Board Division of Research and Statistics and Monetary Affairs. Accessed on 02/01/2008, at: http://www.federalreserve.gov/pubs/feds/2007/200720/200720.pap.pdf

Greenwald, B, and Stiglitz, J. (1987). Keynesianism, New Keynesianism, and New Classical Economics. Oxford Economic Papers. 39: 119-133. 
Greenwald, B, Stiglitz, JE, and Weiss, A. (1984). Informational imperfections in the capital market and macroeconomic fluctuations. American Economic Review. 74(2): 194-199.

Grimes, DA, and Schulz, KF. (2008). Making sense of odds and odds ratios, Obstetrics and Gynecology. 111(2): 423-426.

Grinblatt, M, and Titman, S. (1989). Mutual fund performance: An analysis of quarterly holdings, Journal of Business. 62(3): 393-416.

Groenewold, N, and Fraser, P. (1997). Share Prices and Macroeconomic Factors, Journal of Business Finance and Accounting. 24(9-10): 1367-1383.

Grossman, SJ, and Stiglitz, JE. (1980). On the Impossibility of Informationally efficient markets. The American Economic Review. 70(3): 393-408.

Gruber, M, and Warner, J. (1977). Bankruptcy costs: some evidence. Journal of Finance. 32(2): 337-347.

Gruen, D. (2005). Discussion-Declining output Volatility: What role for structural change? (Kent, C, Smith, K, and Holloway, J). In, Proceedings at a Conference, The Changing Nature of the Business Cycle. (Eds.) Kent, C, and Norman, D. Kirribilli: Economic Group: Reserve Bank of Australia.

Hackbarth, D, Hennessy, CA, and Leland, HE. (2007). Can trade-off theory explain debt, The Review of Financial Studies. 20(5):1389-1428.

Hafer, RW, and Hein, SE. (2006). The Stock Market. Westport: CT: Greenwood Press.

Hamilton, JD, and Lin, G. (1996). Stock market volatility and the business cycle. Journal of Applied Econometrics. 11(5): 573-593.

Hall, RE. (1986). The Role of Consumption in Economic Fluctuations. In, The American Business Cycle- Continuity and Change. 237-266. Chicago: IL: University of Chicago Press. 
Halliday, R. (2004). Equity trend prediction with neural networks. Research Letters in the Informational and Mathematical Sciences, 6:15-29. Available at:

http://iims.massey.ac.nz/research/letters/

Harris, M, and Raviv, A. (1991). The theory of capital structure, Journal of Finance, 46(1):297356.The American Economic Review. 76(2): 323-329.

Hartwig, J. (2004). Explaining the aggregate price level with Keynes's principle of effective demand. Working paper No. 95. Swiss Institute for Business Cycle Research.

Hasbrouck, J. (2009). Trading Costs and Returns for U.S. Equities: Estimating Effective Costs from Daily Data, The Journal of Finance.Vol. IXLV, No. 3

Hein, E, and van Treeck, T. (2007). 'Financialization' in Kaleckian/Post-Kaleckian Models of Distribution and Growth. Working paper No. 07/2007. Macroeconomic Policy Institute.

Hentschel, L, and Smith, CW. (1995). Risks in Derivatives Markets. Working paper No. 9624. Pennsylvania. Wharton Financial Institutions Center. University of Pennsylvania.

Herring, R. (1999). Credit risk and financial instability. Oxford Review of Economic Policy. 15(3): 63-79.

Hilferding, R. Finance Capital: A Study of the Latest Phase of Capitalist development. London: Routledge \& Keegan Paul.

Horowitz, DL, and MacKay, RJ. (1995). Derivatives: The State of the Debate. Chicago Mercantile Exchange.

Hosmer D.W. and Lemeshow S. (1980) A goodness-of-fit test for the multiple logistic regression model. Communications in Statistics. A10:1043-1069.

Hasbrouck, J. (2009). Trading Costs and Returns for U.S. Equities: Estimating Effective Costs from Daily Data, The Journal of Finance.64(3): 1445-1477. 
Houthakker, (1961). Systematic and random elements in short term price movements, The American Economic Review. 51(2): 164-172.

Hovakimian, A, Hovakimian, G, and Tehranian, H. (2004). Determinants of target capital structure: the case of combined debt and equity financing. Journal of Financial Economics. 71(3): 517-540.

Hovakimian, A, T. Opler, and S. Titman. (2002). The capital structure choice: New evidence for a dynamic tradeoff model, Journal of Applied Corporate Finance ,15(1): 24-30.

Hovakimian, A, T. Opler, and S. Titman. (2001). Journal of Financial and Quantitative Analysis, 36(1):1-24.

Huang, W, Nakamori, Y, and Wang, S. (2005). Forecasting stock market movement direction with support vector machine, Computer and Operations Research, 32: 2513-2522.

IDSA (International Securities and Derivatives Association, Inc.) (2007). New York: IDSA Press Office.

Ikenberry, D and Lokinshok, J. (1989). Seasonal anomalies in financial markets. In, A Reappraisal of the Efficiency of Financial Markets. (Ed.) Guimaraes, RMC, Kingsman, BG, and Taylor, SJ. London: Plenum Publishing Corporation.

Jegadeesh, N, and Titman, S. (1993). Returns to buying winners and losers: implications for stock market efficiency. Journal of Finance. 48(1): 65-91.

Jensen, MC. (1978). Some anomalous evidence regarding market efficiency. Journal of Finance and Economics. 6(2/3): 95-101.

Jensen, MC. (1986). Agency costs of free cash flow, corporate finance Jensen, MC. (1986). Agency costs of free cash flow, corporate finance, and takeovers, American Economic Review.76(2): 323-329. 
Jensen, GR, and Johnson, RR. (1993). An examination of stock price reactions to discount rate changes under alternative monetary policy regimes. Quarterly Journal of Business and Economics. 38(2):26-51.

Jensen M, and Meckling, W. (1976). Theory of the firm: management behaviour, agency cost and ownership structure. Journal of Financial Economics. 3(4): 305-360.

CM Jones. (2002). Transaction costs.

http://www4.gsb.columbia.edu/cbs-directory/detail/494838/Jones

Kalecki, M. (1932) [1990]. Wage reduction during a crisis (41-44). In, Collected Works of Michal Kalecki, Volume 1. Capitalism, Business Cycles and full Employment. (Ed.) Osiatynski, J. Oxford: Clarendon Press.

Kalecki, M. (1968) [1991]. Trend and the Business cycle. In, Collected Works of Michal Kalecki, Volume 2, Capitalism: Economic Dynamics. (Ed.) Oziatynski, J. Oxford: Clarendon Press.

Kamarck, AM. (1983). Economics \& the Real World. Oxford: Basil Blackwell.

Kaminsky, GL, and Reinhart, CM. (1999). The twin crises: the causes of banking and balance of payment problems. American Economic Review.89(3): 473-500.

Karuse, K. (2004). Rate of interest in a growth theory with endogenous money. Cambridge Journal of Economics. 28(6): 889-901.

Kaufmann, S, and Valderama, MT. (2007). The role of credit aggregates and asset prices in the transmission mechanism-a comparison between the Euro area and the US. Frankfurt: Germany. Accessed on 04-05-2009, at: http://www.ecb.int

Keane, SM. (1983). Stock Market Efficiency Theory. Evidence and Implications. Oxford: Phillip Allen Publishers Ltd. 
Keister, LA. , and Moller, S. (2000). Wealth inequality in the United States. Annual Review of sociology. 26(1): 63-81.

Kendall, M. and Bradford Hill, A. (1953) The Analysis of Economic Time Series - Part 1:

Prices, Journal of the Royal Statistical Society. 116(1):11-34.

Kent, C, and D'Arcy, P. (2001). Cyclical Prudence- Credit Cycles in Australia. BIS papers No.

1. Accessed on 03-04-2009, at: http://www.bis.org/publ/bppdf/bispap01b.pdf

Keynes, JM. (1936) [1973]. The Collected Writings of John Maynard Keynes Vol. VII. The

General theory of Employment Interest and Money. Cambridge: Macmillan/Cambridge University Press.

Khalik, RA. (1994). Financial Economists Roundtable- Statement on derivatives Markets and Financial risk. (September, 26). Accessed on 05/04/2009, at:

http://www.stanford.edu/ wfsharpe/art/fer/fer94.html

Kindleberger, CP. (1989). Manias, Panics and Crashes. A History of Financial Crises. New York: Basic Books, Inc.

Kindleberger, C. (2000). Manias, Panics and Crashes. Fourth Edition. New York: NY: John Wiley \& Sons.

King, JE. (1994). Aggregate supply and demand analysis since Keynes: a partial history. Journal of Post-Keynesian Economics. 17(1): 3-31.

Kiyotaki, N, and Moore, J. (1997). Credit Cycles. Journal of Political Economy. 105(2): 211248.

Klein, PA. (1976). Business Cycles in the Post-war world. Some Reflections on Recent Research. American Enterprise Institute for Public Policy Research. Washington: D.C. 
Klein, PA. (2001). Assessing Business cycle Indicators: An End of the Century Perspective. In, Business cycle Indicators Handbook. The Conference Board. Accessed on 18-05-2009, at: http://www.conference-board.org/economics/bci/

Kleinknecht, A. (1981). Innovation, accumulation and crises: waves in economic development? Review. IV(4): 683-711.

Kleinknucket, A. (1987). Innovation Patterns in Crisis and Prosperity: Schumpeter's Long Cycle Reconsidered: London: Macmillan.

Kohn, D. (2007). Fed's Kohn- Credit derivatives may reuce risk. Federal Reserve Bank. Accessed on 04-02-2008, at: http://www.reuters.com/articla/bondsNews/idUSWA0000083200700322

Kose, MA, Otrok, C, and Prasad, ES. (2008). Global Business Cycles: Convergence or Decoupling. NBER Working Paper No. 14292. Cambridge: MA: National Bureau of Economic Research, Inc.

Kothari, SP. (2001). Capital markets research in accounting. Journal of Accounting and Economics. 31(1): 105-231.

Kothari, SP, Shanken, J, and Sloan, R. (1995). Another Look at the cross-section of expected returns. Journal of Finance. 50(1): 185-224.

Kraus, A, and Litzenberger, RH. (1973). A state-preference model of optimal financial leverage, Journal of Finance. 911-922.

Kregel, J. (2007). The Natural Instability of Financial Markets. Working Paper No. 523. Missouri: MO: Levy Institute of Bard College.

Kregel, J. (2010). What would Minsky have thought of the mortgage crisis? In, The Elgar Companion to hyman Minsky, (ed. Papadimitriou, DM and Wray, LR), Northampton, MA; Edwars Elgar Publishing limited. 
Kregel, J. (2009). Why don't the bailouts work? Design of a new financial system versus a return to normalcy. Cambridge Journal of Economics. 33(4): 653-663.

Krugman, PR. (2000). Technology, trade and factor prices. Journal of International Economics. 50(1): 51-71.

Krugman, P. (2006). The Great Wealth transfer. (Nov 30). Accessed on 13-05-2009, at: http://www.rollingstone.com/politics/story/12699486/paul_krugman_on_the_great_wealth_tr ansfer

Kydland, FE, and Prescott, EC. (1991). Hours and employment variation in business cycle theory. Economic Theory.1(1): 63-81.

Laffer, A. (2004). The Laffer curve: past, present, and future. Backgrounder No. 1765 Taxes, http://www.heritage.org/research/reports/2004/06/the-laffer-curve-past-present-and-future

Lansing, KJ. (2007). FRBSF Economic Letter, 2007-32, October. Federal Reserve Bank of San Francisco: CA.

La Porta, R, Lakinshok, J, Schleifer, A, and Vishny, R. (1997). Good news for value stocks: Further evidence on market efficiency. Journal of Finance. 52 (2): 859-874.

Larsen, SR. (2002). Uncertainty and consumption in Keynes's theory of effective demand. Review of Political Economy. 14(2): 241-258.

Lavoie, M. (2003). Effective demand and Sraffian normal prices. Review of Political Economy.15(1): 53-74.

Lavoie, M (2006). Post-Keynesian amendment to the New Consensus on monetary policy, Metroeconomica 57(2): 165-192. 
Lavoie, M, and Seccareccia, M. (2001). Minsky's financial Fragility Hypothesis: A Missing Macroeconomic Link? In P. Ferri and R. Bellofiore (Eds.), Financial Fragility and Investment in the Capitalist Economy: The Economic Legacy of Hyman Minsky, volume II. Cheltenham: Edward Elgar.

Lavoie, M, and Stockhammer, E. (2012). Wage growth: concept, theories and policies. In, Conditions of work and employment series no. 41, ILO. Geneva.

Lee, CMC. (2001). Market efficiency and accounting research: a discussion of capital market research in accounting by SP Kothari. Journal of Accounting and Economics. 31(1-3), 233 253.

Leijonhufvud, A. (2009). Out of the corridor: Keynes and the crisis. Cambridge Journal of Economics. 33(4): 741-757.

LeRoy, S, and Porter, R. (1981). The present value relation: tests based on implied variance bounds. Econometrica.49 (3): 555-574.

Lewis, MK. (1993). International financial deregulation, trade, and exchange rates. Cato Journal. 13(2): 243-272.

Lintner, J. (1965). The valuation of risk assets and the selection of risky investments in stock portfolios and capital budgets, Review of Economics and Statistics. 47(1):13-37.

Lo, AW, Mamaysky, H, and Wang J. (2000). Foundations of Technical Analysis: Computational Algorithms, Statistical Inference, and Empirical Implementation, NBER Working Paper No. 7613. www.nber.org/papers/w7613

Lo, AW, and MacKinlay, AC. (1990). Data-snooping biases in tests of financial asset pricing models. Review of Financial Studies. 3(2): 431-467.

Minsky, HP, and Whalen, CJ. (1996-1997). Economic insecurity and the institutional prerequisites for successful capitalism. Journal of Post-Keynesian Economics. 19(2): 155-170. 
Mishkin, FS. (2008). How Should We Respond To Asset Price Bubbles? Speech. Board of Governors of the Federal Reserve System. Accessed on 14/02/2009, at: http://www.federalreserve.gov/newsevents/speech/mishkin20080515a.htm

Mitchell, K. (1983). Trends in Corporation Finance, Economic Review (March). Federal Lo, AW., and MacKinlay, AC. (1999). A Non-Random Walk Down Wall Street, Princeton: Princeton University Press.

Lucas, RE. (1980). Methods and Problems in Business Theory. In, Lucas, RE, Studies in Business Cycle Theory, Cambridge: MA: MIT Press.

Luskin, DL. (2001). The Greatest Threat Facing the US Economy: Deflation. CapitalismMagazine.com. (19, November).

Lydall, H. (1998). A Critique of Orthodox Economics- An Alternative Model. London: Macmillan Press Ltd.

Maffeo, V. (2001). Effective demand versus wage flexibility: some notes on the causes of growth of employment in the USA in the nineties. Contributions to Political Economy. 20(1): $1-15$

Malkiel, BG. (2003a). A random walk down Wall Street: the time-tested strategy for successful investing. New York: NY: WW Norton.

Malkiel, BG. (2003b). The Efficient Market hypothesis and its Critics. CEPS Working Paper No. 91. Accessed on 10/03/2009, at:

http://www.princeton.edu/ ceps/workingpapers/91malkiel.pdf

Mankiw, GN, and Swagel, P. (2006). The politics of offshore outsourcing. Journal of Monetary Economics. 53(5): 1027-1056.

Martino, A. (1982). A monetary constitution for ex-communist countries, Cato Journal. 12(3): 533-555. 
Mauboussin, M. (2002). Revisiting market efficiency: The stock market as a complex adaptive system. Journal of Applied Corporate Finance. 14(4): 47-55.

McHugh, R. (1986). New view of the business cycle: Has the past emphasis on money been displaced? Economic Letter, Jan-Feb. Federal Reserve Board of Philedelphia; Pennsylvania.

McKinnon, R, and Schnabl, G. (2004). Current account surpluses and conflicted virtue in East Asia: China and Japan under the dollar standard. International Finance, 7(2): 169-201.

Merton, RC. (1973). An Intertemporal Capital Asset Pricing Model, Econometrica. Vol. 41(5): 867-887.

Miller, MH. (1977). Debt and taxes. Journal of Finance. 32(2): 262-275.

Miller, M H. (1988). Explaining the Events of October 1987. In After the Crash: Linkages between Stocks and Futures. AEI Studies, (Mackay, RJ, ed). American Enterprise Institute for Public Policy Research, University Press of America.

Miller, MH. (1988). The Modigliani-Miller propositions after thirty years. Journal of Economic Perspectives. 2(4): 99-120.

Miller, MH. (1990). The Crash of 1987: Bubble or Fundamental? In, Pacific Basin Capital Market Research. (Ed.) Rhee, SG, and Chang, RP. New York. New Holland Press.

Minsky, HP. (1975). John Maynard Keynes. New York: Columbia University Press

Minsky, HP. (1986). Stabilizing an Unstable economy. New Haven: CT: Yale University Press.

Minsky, HP. (1991). Financial Crises: Systematic or Idiosyncratic. Working Paper No. 51. Annandale-on-Hudson: NY: Jerome Levy Institute of Bard College.

Minsky, HP. (1992). The Financial Instability Hypothesis. Working paper No. 74. Missouri: MO: Jerome Levy Economics Institute. 
Minsky, HP. (1993). Finance and Stability: The Limits of capitalism. Working Paper No. 93. Annandale-on-Hudson: NY: Jerome Levy Economics Institute of Bard College.

Reserve Bank of Kansas City Economic Review. Available at: http://www.kc.frb.org/PUBLICAT/ECONREV/econrevarchive/1983/2q83mitc.pdf

Mitchell, ML, and Netter, JM. (1989). Triggering the 1987 stock market crash: Antitakeover provisions in the proposed house ways and means tax bill?Journal of Financial Economics, 24(1): 37-68.

Mitchell, WC, and Burns, AF. (1938). Statistical Indications of Cyclical revivals. In, Business Cycle Indicators. (Ed.) Moore, GH. Pp. 162-183. Princeton: Princeton University Press.

Modigliani, F, and Miller, MH. (1958). The cost of capital, corporation finance and the theory of investment. The American Economic Review. 48(3): 263-297.

Moore, GH. (1974). Economic Indicator Analysis During 1969-1972. In, Nations and Households in Economic Growth. Essays in Honor of Moses Abramowitz. Pp. 333-360. (Ed.) David, PA, and Reder, MW . New York: NY: Academic Press.

Morck, R, Schleifer, A, and Vishny, R. (1990). Do managerial objectives drive bad acquisitions, Journal of Finance. 45(1): 31-48.

Morel, C. (2001). "Stock selection using a multifactor model - empirical evidence from the French stock market, The European Journal of Finance. Vol. 7(4): 312-320.

Morgan, J. (2009). The limits of central bank policy: economic crisis and the challenge of effective solutions. Cambridge Journal of Economics. 33(4): 581-608.

Mott, T. (1988). The Real wage and the Marginal Product of Labour. Working Paper No. 12. Annandale-on-Hudson: NY: Jerome Levy Economics Institute of Bard College.

Mullineux, AW. (1990). Business Cycles \& Financial Crises. Ann Arbor: University of Michigan. 
Murphy, K, and Welch, F. (1991). The Role of International trade in wage Differentials. In, Workers and Their Wages. Changing patterns in the United States. (Ed.) Kostes, M. Washington: DC: American Enterprise Institute.

Muusa, M. (2003). Remarks on achieving monetary and financial stability. BIS Papers No. 18. Monetary stability, financial stability and the business cycle: five views, 24-27. Basel: Bank for International Settlements. Monetary and Economic Research Department.

Muusa, M. (2004). Exchange Rate Adjustments Needed to reduce Global payments Imbalance. In, Dollar Adjustment: How Far? Against What? (Ed.) Bergsten, CF, and Williamson, J. Washington, D.C: Institute for International Economics.

Myers, SC. (1977). Determinants of capital borrowing. Journal of Financial Economics. 5(1): 147-175.

Myers, SC. (1984) The capital structure puzzle. Journal of Finance. 39(3): 575-592.

Myers, SC. (2003). Financing of corporations. In, G. Constantinides, M. Harris, and R. Stulz (Eds), Handbook of Economics and Finance, Amsterdam, North Holland: Elsevier, pp. 215253.

Myers, SC, and Majlauf, NS. (1984). Corporate financing decisions when firms have information that investors do not have. Journal of Financial economics. 13(2): 187-211.

Nakov, A, and Pescatori, A. (2007). Oil and the Great Moderation. Research paper No. WP0735. Madrid: Banco de Espana.

Nasica, E. (2010). Banking in Minsky's theory. In, The Elgar Companion to Hyman Minsky, pp. 100-116, (ED.) Papadimitriou, DB, and Wray, LR, Northampton: MA: Edward Elgar Publishing Ltd.

North, DC, and Thomas, RP. (1970). An economic theory of the growth of the Western World. Economic History Review. 23(1): 1-17 
Ocampo, JA. Spiegel, S. and Stiglitz, JE. (2008). Capital Market Liberalization and Development. In, Capital Market Liberalization and Development. (Ed.) Ocampo, JA. And Stiglitz, JE. Oxford University Press. Oxford.

Opler, TC, Sharon, M, and Titman, S. (1997). Designing capital structure to create shareholder value. Journal of Applied Finance. 10(1): 21-32.

Paavola, M. (2006). Test of Arbitrage Pricing Theory Using Macroeconomic Variables in The Russian Equity Market. Bachelor's Thesis. Available at: http://www.doria.fi/bitstream/handle/10024/30869/TMP.objres.246.pdf

Palley, T. (2008). Endogenous Money: Implications for the Money Supply Process, Interest Rates and Macroeconomics. Working Paper No. 178. Political Economy Research Institute: University of Massachusetts-Amherst.

Papadimitriou, DB, and Wray, LR. (1999). Minsky's Analysis of Financial Capitalism. Working Paper No. 275. Annandale-on-Hudson: NY: Jerome Levy Economics Institute.

Papadimitriou, D, and Wray, LR. (2001). Are We All Keynesians (Again)? Policy Note 2001/10. Missouri: MO: The Levy Institute of Bard College.

Papadimitriou, D, and Wray, LR. (2010). Introduction: Minsky on money, banking and finance. In, The Elgar Companion to Hyman Minsky, pp. 100-116, (ED.) Papadimitriou, DB, and Wray, LR, Northampton: MA: Edward Elgar Publishing Ltd.

Pastor, L, and Veronesi, P. (2006). Was there a Nasdaq bubble in the late 1990s? Journal of Financial Economics. 81(1): 61-100.

Peng, CJ, and So, TH. (2002). Logistic regression analysis and reporting: A primer, Understanding Statistics. 1(1): 31-70. 
Pensieroso, L. (2005). Real Business cycle Models of the Great Depression: A Critical survey. Discussion Paper n. 2005-05: de l'Universit Catholique de Louvain: Dept. de Sciences Economiques.

Pepper, G, and Oliver, MJ. (2002). The liquidity theory of asset prices, Chichester: John Wiley \& Sons Ltd.

Perelstein, JS. (2009). Macroeconomic imbalances in the US and their impact on the international financial system. Working Paper No. 554. Missouri: MO; Levy Institute of Bard College.

Persons, CE. (1930). Credit expansion, 1920-1929, and its lessons. Quarterly Journal of Economics. 45(1): 94-130.

Pollin, R. (1997). The Relevance of Hyman Minsky. Working paper No. 183. Political Economy Research Institute. University of Massachusetts-Amherst.

Porter, D, and Smith, VL. (200?). Overreactions, momentum, liquidity, and price bubbles in laboratory and field asset markets. The Journal of Psychology and Financial Markets. 1(1): 24-48.

Porter, D, and Smith, VL. (2003). Stock market bubbles in the laboratory. Journal of Behavioral Finance. 4(1): 7-20.

Posner, R. (2007). Economic Analysis of Law $7^{\text {th }}$ ed (2007). Aspen Publishers, New York .

Prosner, RA. (2009). A failure of capitalism, Cambridge, MA: Harvard University Press,

Prasad, E. Rogoff, K. Wei, S. and Kose, MA. (2003). Effects of Financial Globalization on Developing Countries: Some Empirical Evidence. IMF Occassional Paper No. 220. Washington: DC: International Monetary Fund.

Pratten, C. (1993). The Stock Market. Cambridge: Cambridge University Press. 
Prychitko, DL. (2009). Competing explanations of the Minsky Moment: The financial instability hypothesis in light of Austrian theory. Review of Austrian Economics. Accessed on 08-04-2010, at: http://www.springerlink.com/content/g131473281177713/

Rajan, RJ. (1994). Why bank credit policies fluctuate; a theory and some evidence. Quarterly Journal of Economics. 109(2): 399-411.

Rajan, R. (2005). Global Current Account Imbalances: Hard landing or Soft landing. Accessed on 24-04-2009, at: http://www.imf.org/external/np/speeches/2005/031505.htm

Rasmus, J. (2008). The deepening global financial crisis: from Minsky to Marx and beyond. Crtique. 36(1): 5-29.

Reinhart, CM, and Rogoff, KS (2008). Is the 2007 US sub-prime crisis so different? An international historical comparison. Working paper No. 13761. Cambridge. Massechusetts: MA: National Bureau of Economic Research, Inc.

Ritter, J. (1991). The long-run performance of initial public offerings. Journal of finance. 46(1): 3-27.

Roberts, MR. (2001). The dynamics of capital structure: some evidence from international data. Journal of Finance. 50(4): 1421-1460.

Robinson, J. (1938). Introduction to the Theory of Employment. London: Macmillan and Co. Ltd.

Roll, R. (1977). A critique of the asset pricing theory's test: part 1: On past and potential testibility of the theory. Journal of Financial Economics. 4: 129-176.

Roll, R. (1988). The international crash of October 1987. Financial Analysts Journal. 44(5): $20-25$. 
Roll, R, and Shiller, RJ. (1992). Comments: Symposium on volatility in US and Japanese stock markets, Journal of Applied Corporate Finance, 5(1): 25-29.

Romer, CD. (1993). The nation in depression. Journal of Economic Perspectives. 7(2): 19-39.

Ross, SA. (1976). The arbitrage pricing theory of capital asset pricing. Journal of Economic Theory. 13(1): 341-360.

Rothbard, MN. (2003). The Kondratieff cycle: Real or Fabricated? Ludwig von Mises Institute. Accessed on 01-08-2009, at: http://www.lewrockwell.com/rothbard/rothbard44.html

Rousseas, S. (1992). Post-Keynesianism Monetary Economics (Second edition). Armonk: NY: ME Sharpe, Inc.

Rowbotham, M. (1998). The Grip of Death- A study of modern money, debt slavery and destructive economics. Charlbury: Jon Carpenter Publishing.

Rubinstein, M. (1976). The Valuation of Uncertain Income Streams and the Pricing of Options. Bell Journal of Economics. 7(2): 407-25.

Rudenbusch, GD. (2005). Monetary policy and Asset Bubbles. No. 2005-18. Federal Reserve Board of San Francisco. Economic Letter.

Russell, E, and Dufour, M. (2007). Rising Profit Shares, Falling Wage shares. Canadian Centre for Policy Alternatives. Toronto.

Sarbapriya, R. (2012). Revisiting the strength of Dow Theory in assessing stock market movement. Advances in Applied Economics and Finance. 3(3): 591-598.

Samuelson, R. (2005). The Mystery of Low Interest Rates. The Washington Post. (02/05/2009).

Santoni, GJ. (1987). The Great Bull Markets 1924-29 and 1982-87: Speculative Bubbles or Economic Fundamentals. Federal Reserve Bank of St. Louis Review. 69(9): 16-29. 
Sardoni, C. (1992). Market forms and effective demand: Keynesian results with perfect competition. Review of Political Economy. 4(4): 377-395.

Sardoni, C, and Wray, LR. (2005). Monetary Policy Strategies of the European Central Bank and the Federal Reserve Bank of the US. Working paper 431. Kansas City: Missouri: MO. Levy Economics Institute of Bard College.

Sargent, TJ. (1987). Macroeconomic Theory (Second Edition). San Diego: CA: Academic Press, Inc.

Sawyer, JA. (1989). Macroeconomic Theory. Keynesianism and Neo-Walrasian Models. Hemel Hampstead: Harvester Wheatsheaf.

Scharfstein, D, and Stein, J. (1990) Herd Behavior and Investment. American Economic Review. 80(3): 465-479.

Schmookler, J. (1966). Invention and Economic Growth. Cambridge: MA: Harvard University Press.

Schultz, SM. (1995). Audit reports for litigation loss contingencies. Journal of Applied Business Research. 9(1): 69-76.

Schumpeter, J. (1939). Business Cycles: A Theoretical, Historical, and Statistical Analysis of the Capitalist Process. New York: NY: McGraw-Hill.

Schumpeter, J. (1954) [2006]. History of economic analysis, Taylor \& Francis e-Library. http://digamo.free.fr/schumphea.pdf.

Schwartz, AJ. (2008). Anna Schwartz blames the Fed for sub-prime crisis. Telegraph (19/January). Accessed on 30/04/2008, at:

http://www.telegraph.co.uk/money/main.jhtml=/money/2008/01/13/ccschwartz113.xml 
Schwert, GW. (1990). Stock returns and real activity: a century of evidence. Journal of Finance, 45(4): 1237-1257.

Schwert, GW. (2003). Anomalies and Market efficiency. In, Handbook of the economics of Finance. (Ed.) Constantinides, GM, Harris, M, and Stulz, R. London: Elsevier-North Holland.

Schumpeter, J. (1954). The Analysis of Economic Change. In, Readings in Business Cycle theory. (Ed.) Ellis, HS. London: George Allen \& Unwin Ltd.

Shankin, JA, and Weinstein, M. (2006). Economic Forces and the Stock Market Revisited. Journal of Empirical Finance. 13(2):129-144.

Sharpe, WF. (1964). Capital asset prices: A theory of market equilibrium under risk. Journal of Finance. 19(3): 425-442.

Shiller, RJ. (1981). The use of volatility measures in assessing market efficiency. Journal of Finance. 36(2): 291-304.

Shiller, Robert J. (1987). "Investor Behavior in the October 1987 Stock Market Crash: Survey Evidence.” NBER Working Paper 2446.

Shiller, R. (1989). Investor Behavior in the October 1987 Stock Market Crash: Survey Evidence, in Market Volatility (1990), Shiller, RJ ed., Boston: MA: MIT Press.

Shiller, RJ. (2000). Irrational Exuberance, Princeton: Princeton University Press.

Shiller, RJ. (2003). From efficient markets theory to behavioural finance. Journal of Economic Perspectives. 17(1): 83-104.

Shiller, RJ. (2005). Irrational Exuberance. Second Edition. Princeton; NJ: Princeton University Press. 
Shiller, RJ. (2008). The Subprime Solution. How today's Financial Crisis Happened and What to Do about it. Princeton: NJ: Princeton University Press.

Shiller, RJ. (2012). Finance and the Good Society. Princeton University Press. Princeton: New Jersey.

(Short, 2013). Available at: http://www.advisorperspectives.com/dshort/updates/PE-Ratiosand-Market-Valuation.php

Short, D, and Turner, C. (2010). Removing the Cape from Robert Shiller's CAPE. Available at: http://www.advisorperspectives.com/commentaries/dshort_062910.php

Shyam-Sunder, and Myers, SC. (1999). Testing trade off against pecking order models of capital structure. Journal of Financial Economics. 51(2): 219-244.

Silica, B, and Cruikshank, J. (2000). The Greenspan Effect. New York: NY: McGraw-Hill Publishing.

Sims, CA. (1998). The role of interest rate policy in the generation and propagation of business cycles: What has changed since the 1930s? Conference Series 42.Beyond Shocks: What causes the business cycle. Federal Reserve Bank of Boston. Boston: Illinois.

Slaughter, MJ, and Swagel, P. (1997). Deindustrialization: Causes and Implications. IMF Working paper No. WP 97/42. International Monetary fund staff studies for the World Economic Outlook.

Smeeding, P, and Grodner, A. (2000). Changing Income Inequality in OECD Countries: Updated Results from the Luxemburg Income Study. In, Hauser, R, and Becker, I (Ed.) The Personal Distribution of Income in International Perspective. Berlin: Springer-Verlag.

Smith, A. (1776) [1952]. An Inquiry into the Nature and Causes of the Wealth of Nations. London: Encyclopaedia Britannica, Inc. 
Smith, VL, Suchanek, GL, and Williams, W. (1988). Bubbles, Crashes, and Endogenous Expectations in Experimental Spot Asset Markets. Econometrica. 56(5):1119-1151.

Solow, RM. (1970). Growth Theory. New York: NY: Oxford University Press.

Spencer, RW, and Huston, JH. (2006). The Federal Reserve and the Bull Markets. From Benjamin Strong to Alan Greenspan. Leviston: The Edward Mellen Press.

Standard $\quad$ (2013). Poors. Available at: http://fc.standardandpoors.com/sites/client/generic/axa/axa4/Article.vm?topic=5991\&siteCon tent $=8116$

Stiglitz, JE. (1988). Why financial structure matters. The Journal of Economic Perspectives. 2(4): 121-126.

Stiglitz, JE. (2004). Capital-market liberalization, globalization and the IMF. Oxford Review of Economic Policy. 20(1): 57-71.

Stiglitz, JE. (2008). Capital Market Liberalization, Globalization, and the IMF. In, Capital Market Liberalization and Development. (Ed.) Ocampo, JA. And Stiglitz, JE. (2008). Oxford: Oxford University Press.

Stiglitz, J. (2009). The anatomy of a murder: Who killed the American economy? Critical Review. 21(2): 329-339.

Stiglitz, JE, and Uzawa, H. (1969). Introduction. Cambridge Growth and Distribution Theory. In, Readings in the Modern Theory of Economic Growth. (Ed.) Stiglitz, JE, and Mirralees, JA. London: MIT Press.

Stiglitz, J, and Weiss, A. (1981). Credit rationing in markets with imperfect information. American Economic Review. 71(3): 393-410. 
Stiroh, KJ, and Strahan, PE. (2003). Competitive dynamics of deregulation: evidence from the US banking industry. Journal of Money, Credit, and Banking. 35(5): 801-828.

Stock, JH, and Watson, MW. (2003). Has the Business Cycle Changed? Evidence and Explanations. Prepared for the Federal Reserve Bank of Kansas City Symposium, "Monetary Policy and Uncertainty”. Jackson Hole: WO, August 28-30.

Stock Forecast Methods. (undated). http://stockforecast.wordpress.com/

Stone, M, and Rasp, J. (1991). Tradeoffs in the choice between logit and OLS for accounting choice studies. Accounting Review. 66(1): 170-187.

Strahan, PE. (2003). Real Effects of US Banking Deregulation. St. Louis. IL: Federal Reserve Bank of St. Louis. (July/August).

Summers, KH. (1986). Does the stock market reflect fundamental values? Journal of Finance. XLI (3): 591-601.

Summers, PM. (2005). What Caused the Great Moderation? Some Cross-Country Evidence. Accessed on 02-02-2008, at: http://www.kansascityfed.org/Publicat/PDF/3q05summ.pdf

Schwabish, J, and GRI, C. (2012).The US Federal budget. Congressional Budget Office. http://www.cbo.gov/sites/default/files/cbofiles/attachments/budgetinfographic.pdf

Sylla, R. (1991). Financial Disturbances and Depressions: The View from Economic History. Working Paper No. 47. Annandale-on-Hudson: NY: Jerome Levy Economics Institute of Bard College.

Tang, Y, Xu, F, Wan, X, and Zhang, Y. (2002). Web-based fuzzy neural networks for stock prediction. In, Proceedings of Second International Workshop on Intelligent Systems Design and Application. Pp. 169-174.

Taylor, JB. (2000). Remarks for the Panel Discussion on "Recent Changes in Trend and Cycle". Conference 'Structural Change and Monetary Policy', sponsored by the Federal 
Reserve Bank of San Francisco and Stanford Institute for Economic Policy Research, March 3-4.

Taylor, JB. (2008). The Financial Crisis and the Policy Responses: an empirical analysis of what went wrong. NBER Working paper No. 14631. Cambridge: MA: National Bureau of Economic Research, Inc. Accessed on 2009-05-06, at:

http://www.nber.org/papers/w14631

Temin, P. (2008). Real Business Cycle Views of the Great Depression and Recent Events: A Review of Timothy J. Kehoe and Edward C. Prescott's Great Depressions of the Twentieth Century. Journal of Economic Literature. 46(3): 669-684.

Thammano, A. (1999). Neuro-fuzzy model for stock market prediction. In, Proceedings of the ANN in Engineering Conference, ANNIE 99: 587-591

Thoma, M. (2009). Greenspan: The Fed didn't do it. Accessed on 02/05/2009, at: http://economistsview.typepad.com/economistsview/2009/03/greenspan-the-fed-didnt-do-it

Titman, S. (1984). The effects of capital structure on a firm's liquidation decision. Journal of Financial Economics. 13(1): 137-151.

Titman, S, and Wessels, R. (1988). The determinants of capital structure. The Journal of Finance. 43(1): 1-19.

Tobin, J. (1980). Asset Accumulation and Economic Activity. Chicago; IL; University of Chicago Press.

Toporowski, J. (1993). The Economics of Financial Markets and the 1987 Crash. Aldershot: Edward Elgar publishing Ltd.

Toporowski, J. (1999). Kalecki and the declining rate of profit. Journal of Political Economy. 11(3): 355-371. 
Toporowski, J. (1999a). Monetary Policy in an Era of Capital Market Inflation. Working Paper No. 279. Annandale-on-Hudson: NY: Jerome Levy Economics Institute of Bard College.

Treeck, T, and Sturm, S. (2012). Debates on inequality as the cause of the current economic crisis. Paper written for the project "New Perspectives on wages and growth: the potentials of wage-led growth.

Tregenna, F. (2009). The fat years: the structure and profitability of the US banking sector in the pre-crisis period. Cambridge Journal of Economics. 33(4): 609-632.

Trichet, JC. (2005). Asset price Bubbles and Monetary Policy. Speech. MAS Lecture..

Trichet, JC. (2007). Some Reflections on the Development of Credit derivatives. Accessed on 11/02/2008, at: http://www.ecb.int/press/key/date/2007/html/sp070418.en.html

Tvede, L. (1997). Business Cycles from John Law to the Internet Crash. (2 ${ }^{\text {nd }}$ edition). London: Routledge.

Tyson, LD. (2004). How Bush Widened The Wealth Gap. Not since the 1920s has income inequality been so great. Business Week (November 1). Accessed on 13-05-2009, at: http://www.businessweek.com/magazine/content/04_44/b3906038_mz007.htm

US Department of Treasury, Press room. (2008). HP-1207. Issued 24-October-2008. Available at:

http://web.archive.org/web/20081014212357/http://www.treas.gov/press/releases/hp1207.ht $\mathrm{m}$

University of Texas. (n.d.). Logistic Regression-Basic relationships www.utexas.edu/courses/.../LogisticRegression_BasicRelationships.ppt

US Securities and Exchange Commission (n.d.)

http://www.sec.gov/answers/indices.htm

Valdarrama, D. (2004). FRBSF Economic Letter No. 2004-38. The Federal Reserve Bank of San Francisco. Accessed on 14-05-2009, at: 
http://www.frbsf.org/publications/economics/letter/2004/e/2004-38.html

Veblen, T. (1904). The Theory of Business Enterprise. New York: NY: Charles Scribner's Sons.

Vicarelli, F. (1984). Keynes: The Instability of Capitalism. Philadelphia: University of Philadelphia Press.

Villamil, A. (2008). The Modigliani-Miller Theorem, New Palgrave dictionary of economics, available at: http://www.dictionaryofeconomics.com/article?id=pde2008_M000187

Wade, R. (2009). From global imbalances to global reorganisation. Cambridge Journal of Economics. 33(4): 563-580.

Wallison, PJ. (2009). Cause and Effect: Government policies and the financial crisis. Critical Review. 21(2): 365-376.

Walter, JE, and Milken, MR. (1973). Managing the Corporate Financial Structure,Working Paper No. 26-73, Rodney L White Center for Financial Research. The Wharton School, University of Pennsylvania.

Warner, J. (2008). Greenspan admits to 'flaw' in his free-market thinking. Accessed on 02/05/2009, at: http://www.independent.co.uk/news/business/comment/jeremy_warner

Wenxia, GE, and Whitmore, GA. (2010). Binary response and logistic regression in recent accounting research publications: a methodological note. Review of Quantitative Finance and Accounting. 34(2): 81-93.

Western, DL. (2004). Booms, Bubbles and Busts in US Stock Markets. New York: NY: Routledge Taylor \& Francis Group.

Weston, JF. (1989). What have MM wrought? Financial Management. 18(2): 29-38. 
Whalen, CJ. (1999). Hyman Minsky's Theory of capitalist development. Working Paper No. 277. Annandale-on-Hudson: NY: Jerome Levy Economics Institute of Bard College.

Whittington, G. (1985). Financial accounting theory: an overview. British Accounting Review. 85. (2): 4-41.

Willis, (2003). Implications of Structural changes in the US Economy for Pricing Behavior and Inflation Dynamics. Economic Review, First Quarter. 5-27. Federal Reserve Bank of Kansas City.

Wolff, EN, and Zacharias, A. (2007). The distributional consequences of government spending and taxation in the US, 1989 and 2000. Review of Income and Wealth. 53(4): 692-715.

Wolfson (1994). Financial Crises: understanding the postwar US experiemce, (Second edition. Armonk: ME Sharpe.

Wolfson, M.H. (1999). Financial instability and the credit crunch of 1966. Review of Political Economy. 11(4): 407-414.

Wood, G. (1999). Great crashes in history: have they lessons for today? Oxford Review of Economic Policy. 13(3): 98-109.

Wray, LR. (2007a). Endogenous Money: Structuralist and Horizontalist. Working paper 512. New York: Levy Institute of Bard College.

Wray, LR. (2007b). Lessons from the Subprime Meltdown. Working Paper No. 522. New York: Levy Institute of Bard College.

Wray, LR. (2008). Financial Markets Meltdown. What can we learn from Minsky. Working paper No. 94. Missouri: MO: Levy Institute of Bard College.

Wray, LR. (2009). The rise and fall of money manager capitalism: a Minskian approach. Cambridge Journal of Economics. 33(4): 807-828. 
Wray, LR, and Tymoigne, E. (2008). Macroeconomics Meets Hyman P. Minsky: The Financial theory of Investment. Working paper No. 543. Kansas City. Missouri: MO: Levy Institute of Bard College.

Yahoo Finance. (2013). http://au.finance.yahoo.com/?p=finance.yahoo.com

Zarnowitz, V. (1992). Business Cycles. Theory, History, Indicators and forecasting. Chicago: IL: National bureau of Economic Research/The University of Chicago Press.

Zarnowitz, V. (1998). Has the Business Cycle been Abolished? NBER Working paper No. 6367. Cambridge: MA: National Bureau of Economic Research.

Zarnowitz, V. (1999). Theory and history behind business cycles: are the 1990s the onset of a golden Age? Journal of Economic Perspectives. 31(2): 69-90. 


\section{Appendix 1:}

Key terms and measures of model goodness of fit

\section{Logistic regression}

Logistic regression is generally used in situations where the outcome variable is categorical and where there are one or more categorical or continuous predictor variables. Where we have a categorical outcome variable the assumption of linearity of normal regression is violated, indicating the use of logistic regression. The assumptions of logistic regression include that:

- The predictor (independent variables are linear)

- The errors are independent

- And, there is non-multi-collinearity between independent variables

Initially the model will always select the option with the highest frequency. In the case of the buy model it selects 'non-event' or non-buy periods as these constitute $51.6 \%$ of the total quarters considered. That is, the intercept-(constant) only model reports a 'percentage correct' at some level greater than $50 \%$ (in the case of binary logistic regression) by biasing towards the more frequently occurring of the dichotomous outcomes.

Logistic regressions make few assumptions about the distribution of the independent variables. That is, this method does not assume that the independent variables are distributed as a multivariate normal distribution with an equal covariance matrix. However, logistic regression does assume that there is a relationship between the logit (log to the base e) of the outcome variable and the predictors.

\section{Hosmer-Lemeshow test}

The Hosmer-Lemeshow test equation is constructed as follows:

$$
H=\sum_{g=1}^{n} \frac{\left(O_{g}-E_{g}\right)^{2}}{N_{g} \pi_{g}\left(1-\pi_{g}\right)} .
$$

$O_{g}$ denotes observed events

$E_{g}$ denotes expected events

$N_{g}$ denotes observations 
$\pi_{g}$ denotes the predicted risk for the $g^{\text {th }}$ risk decile group,

and $n$ is the number of groups.

The H-L statistic is an alternative to the model chi-square and it involves dividing subjects into ten ordered groups, comparing observed and predicted membership of each group. Groups are estimated on the basis of probability. A p-value is computed from the chi-square of the distribution with degrees of freedom given by the number of predictors used. A 0.5 threshhold is conventional (as is the case here) for determining whether or not to accept the null that there is no difference between the observed and predicted values. That is, well-fitted models show non-significance on the Hosmer-Lemeshow goodness of fit criteria.

\section{Log likelihood}

Large values for -2 Log Likelihood (-2 LL) indicate a poor fitting model. The -2 LL will get smaller as the fit improves.

- The overall fit of the final model is shown by the -2 log-likelihood statistic.

- If the significance of the chi-square statistic is less than .05 , then the model is a significant fit of the data.

- The log-likelihood ratio is a measure of how much unexplained variability there is in the data. Reductions in the log-likelihood statistic over that of the default model provide indications about the nature and level of compared models' explanatory power. A baseline (or default) model contains an identified level of unexplained variability. To the extent that a new model reduces this, it reflects an improvement on that baseline model. It should also be noted that added variables should appreciably (ill-defined) reduce the log likelihood if this measure of their additive value is to be satisfied.

\section{Pseudo-R squares: Nagelkerke}

Logistic regression does not have an equivalent statistic to the $\mathrm{R}^{\wedge} 2$ in OLS regressions as a measure of the goodness of fit. The model estimates from logistic regression are maximum likelihood estimates. They are not calculated to minimise variance. For this reason several pseudo- $\mathrm{R}^{\wedge} 2 \mathrm{~s}$ have been developed and these have the same scale as $\mathrm{R}^{\wedge} 2 \mathrm{~s}$ of linear regression, ranging from $0-1$. Pseudo- $\mathrm{R}^{\wedge} 2 \mathrm{~s}$ cannot be interpreted in the same way as $\mathrm{R}^{\wedge} 2 \mathrm{~s}$ as low Psuedo$\mathrm{R}^{\wedge} 2$ values are typical of logistic regression. Caution is necessary in their use and they are best used to evaluate multiple models predicting the same outcome from the same dataset. When 
used in this manner the higher the pseudo- $\mathrm{R}^{\wedge} 2$ the better the model fit to the data. In this sense the pseudo $\mathrm{R}^{\wedge} 2$ provides us with a good indication of the best model amongst competing models, rather than an absolute measure of the usefulness of a particular model.

Most pseudo R-squareds do not range from 0 to 1 although the Nagelkerke pseudo Rsquared does range from 0-1, but only superficially to more closely match the scale of the OLS R-squared. Two models with identical predictive success can have different pseudo $\mathrm{R}^{\wedge} 2 \mathrm{~s}$. While OLS minimizes the squared differences between the predictions and the actual values of the predicted variable this is not true for logistic regression. The way in which R-squared is calculated in OLS regression captures how well the model fits the data and this is not the case in an absolute sense of pseudo-R squareds.

\section{Use the odds ratio (OR), Exp(B), for interpretation.}

a. $\mathrm{OR}>1$, then as the predictor increases, the odds of the outcome occurring increase.

b. OR $<1$, then as the predictor increases, the odds of the outcome occurring decrease.

c. The confidence interval of the OR should not cross 1 .

In simple terms, where an exponent value is greater than one an increase in that exponent indicates an increased likelihood of an event and, conversely, a decrease reduces the likelihood of that event. Where the exponent is below one its increase will decrease the prospect of event occurrence and its increase will decrease the prospect of event occurrence. 


\section{Appendix 2:}

Market movements and model performance

1. Year and quarter

2. Changes in market levels from the prior quarter value of one. Where the value in a quarter exceeds 1 the market has risen since the previous quarter. Where the value in a given quarter is below one the market has fallen.

3. Predicted probabilities from B1. That is, for example, in $1980.1 \mathrm{~B} 1$ predicts a $58 \%$ chance of a market rise. B1 is the 12-variable buy model

4. B2: is the augmented Buy model with factors added as proxies for central bank policy

5. S1: Is the full-period, 12-variable sell model

6. S2: Is the 7-variable or short sell model covering the period from 1985-1999, in which the 12-variable model performs poorly.

Event identified The identified model has accurately predicted the market's direction Type 2

Type 1 error Type-2 error (a model predicts an event but there is no actual event) Type-1 error ( model fails to predict an event)

Table 16: Changes from a base of 1 in each quarter and the forecast accuracy of different model applications

1.

2.

3.

4.

5.

6.

\begin{tabular}{|r|r|r|r|r|l|}
\hline 1980.1 & 1.010592 & 0.58326 & 0.53368 & 0.14963 & \\
\hline 1980.2 & 0.980513 & 0.35003 & 0.13508 & 0.53034 & \\
\hline 1980.3 & 1.093646 & 0.63829 & 0.63249 & 0.46846 & \\
\hline 1980.4 & 1.055442 & 0.57642 & 0.51682 & 0.18616 & \\
\hline 1981.1 & 0.97172 & 0.28439 & 0.04422 & 0.4394 & \\
\hline 1981.2 & 0.937788 & 0.38407 & 0.01215 & 0.65748 & \\
\hline 1981.3 & 0.894961 & 0.28245 & 0.01511 & 0.92665 & \\
\hline 1981.4 & 0.972375 & 0.31624 & 0.00335 & 0.93832 & \\
\hline 1982.1 & 0.897957 & 0.46683 & 0.008 & 0.95918 & \\
\hline 1982.2 & 0.948461 & 0.20254 & 0.04958 & 0.98652 & \\
\hline 1982.3 & 0.999601 & 0.10808 & 0.0152 & 0.34423 & \\
\hline 1982.4 & 1.169417 & 0.2002 & 0.8128 & 0.00417 & \\
\hline 1983.1 & 1.059967 & 0.24228 & 0.90665 & 0.01944 & \\
\hline 1983.2 & 1.086564 & 0.10298 & 0.45725 & 0.11688 & \\
\hline 1983.3 & 0.972873 & 0.05254 & 0.48019 & 0.96019 & \\
\hline 1984.1 & 0.945363 & 0.20619 & 0.43445 & 0.75749 & \\
\hline 1984.2 & 0.941454 & 0.18989 & 0.27432 & 0.55544 & \\
\hline
\end{tabular}




\begin{tabular}{|c|c|c|c|c|c|}
\hline 1984.3 & 1.015576 & 0.20107 & 0.19798 & 0.56295 & 0.10943 \\
\hline 1984.4 & 1.005046 & 0.48192 & 0.3149 & 0.47998 & 0.00008 \\
\hline 1985.1 & 1.068477 & 0.55131 & 0.58306 & 0.00286 & 0.00003 \\
\hline 1985.2 & 1.017237 & 0.33698 & 0.51246 & 0.00603 & 0.00544 \\
\hline 1985.3 & 0.982345 & 0.47056 & 0.52985 & 0.33176 & 0.18575 \\
\hline 1985.4 & 1.055633 & 0.63079 & 0.842 & 0.19975 & 0.43951 \\
\hline 1986.1 & 1.088827 & 0.5362 & 0.75157 & 0.11669 & 0.30071 \\
\hline 1986.2 & 1.071236 & 0.64657 & 0.89677 & 0.39428 & 0.05078 \\
\hline 1986.3 & 0.978442 & 0.61788 & 0.81857 & 0.32101 & 0.08323 \\
\hline 1986.4 & 1.007906 & 0.51847 & 0.49577 & 0.11355 & 0.00206 \\
\hline 1987.1 & 1.14069 & 0.87593 & 0.91125 & 0.23228 & 0.01642 \\
\hline 1987.2 & 1.023589 & 0.76724 & 0.8362 & 0.08466 & 0.0001 \\
\hline 1987.3 & 1.083933 & 0.89026 & 0.96279 & 0.69346 & 0.00903 \\
\hline 1 & 2.Market & 3.B1 & 4.B2 & 5.S1 & 6.S2 \\
\hline 1987.4 & 0.736341 & 0.79507 & 0.86351 & 0.32909 & 0.96288 \\
\hline 1988.1 & 1.06012 & 0.8535 & 0.88729 & 0.28941 & 0.17197 \\
\hline 1988.2 & 1.00085 & 0.43292 & 0.39255 & 0.01751 & 0.01095 \\
\hline 1988.3 & 0.992507 & 0.73854 & 0.55983 & 0.00462 & 0.19182 \\
\hline 1988.4 & 1.011229 & 0.83024 & 0.78203 & 0.06325 & 0.01452 \\
\hline 1989.1 & 1.038817 & 0.90662 & 0.85712 & 0.05312 & 0.00013 \\
\hline 1989.2 & 1.054213 & 0.81051 & 0.57404 & 0.23107 & 0.49837 \\
\hline 1989.3 & 1.083538 & 0.93918 & 0.83355 & 0.85642 & 0.17658 \\
\hline 1989.4 & 0.973984 & 0.84467 & 0.67813 & 0.54052 & 0.90617 \\
\hline 1990.1 & 0.942328 & 0.65666 & 0.37817 & 0.50769 & 0.98972 \\
\hline 1990.2 & 1.019051 & 0.67483 & 0.50865 & 0.25458 & 0.01451 \\
\hline 1990.3 & 0.927539 & 0.57947 & 0.52211 & 0.13571 & 0.54703 \\
\hline 1990.4 & 0.953208 & 0.37135 & 0.39062 & 0.17914 & 0.82972 \\
\hline 1991.1 & 1.119987 & 0.63815 & 0.7404 & 0.08808 & 0.0034 \\
\hline 1991.2 & 1.031983 & 0.54636 & 0.61747 & 0.00719 & 0.00139 \\
\hline 1991.3 & 1.016722 & 0.46233 & 0.61635 & 0.15295 & 0.00206 \\
\hline 1991.4 & 1.000007 & 0.24787 & 0.26957 & 0.02826 & 0.00002 \\
\hline 1992.1 & 1.024108 & 0.42276 & 0.46173 & 0.08218 & 0.54788 \\
\hline 1992.2 & 1.001569 & 0.27038 & 0.38503 & 0.21326 & 0.00003 \\
\hline 1992.3 & 1.006173 & 0.21305 & 0.11733 & 0.1011 & 0.04271 \\
\hline 1992.4 & 1.015787 & 0.32248 & 0.26467 & 0.47515 & 0.00055 \\
\hline 1993.1 & 1.029844 & 0.48545 & 0.35947 & 0.23873 & 0.00007 \\
\hline 1993.2 & 0.997725 & 0.5241 & 0.47529 & 0.04958 & 0.00046 \\
\hline 1993.3 & 1.014474 & 0.55489 & 0.59207 & 0.06893 & 0.00409 \\
\hline 1993.4 & 1.01075 & 0.54235 & 0.59207 & 0.13453 & 0.01942 \\
\hline 1994.1 & 0.990583 & 0.44492 & 0.41084 & 0.15693 & 0.15995 \\
\hline 1994.2 & 0.951866 & 0.48269 & 0.41977 & 0.17863 & 0.87616 \\
\hline
\end{tabular}




\begin{tabular}{|c|c|c|c|c|c|}
\hline 1994.3 & 1.103838 & 0.56008 & 0.38575 & 0.23295 & 0.41595 \\
\hline 1994.4 & 0.978951 & 0.44778 & 0.17116 & 0.23936 & 0.15631 \\
\hline 1995.1 & 0.967172 & 0.80099 & 0.78938 & 0.20669 & 0.55315 \\
\hline 1995.2 & 1.077666 & 0.76434 & 0.71659 & 0.2391 & 0.02311 \\
\hline 1995.3 & 1.058687 & 0.76919 & 0.75867 & 0.17098 & 0.01871 \\
\hline 1995.4 & 1.04174 & 0.79223 & 0.81231 & 0.0528 & 0.53083 \\
\hline 1996.1 & 1.053423 & 0.92131 & 0.90946 & 0.11116 & 0.06279 \\
\hline 1996.2 & 1.025085 & 0.79289 & 0.78732 & 0.26981 & 0.03455 \\
\hline 1996.3 & 0.979087 & 0.8051 & 0.83641 & 0.22228 & 0.79174 \\
\hline 1996.4 & 1.100215 & 0.78091 & 0.83359 & 0.40665 & 0.1911 \\
\hline 1997.1 & 1.046504 & 0.7443 & 0.85056 & 0.09907 & 0.00004 \\
\hline 1997.2 & 1.07296 & 0.91122 & 0.93323 & 0.1925 & 0.00797 \\
\hline 1997.3 & 1.092144 & 0.75243 & 0.84518 & 0.16395 & 0.01235 \\
\hline 1 & 2.Market & 3.B1 & 4.B2 & 5.S1 & 1 \\
\hline 1997.4 & 1.000987 & 0.68043 & 0.65507 & 0.08686 & 0.01955 \\
\hline 1998.1 & 1.089442 & 0.87981 & 0.89447 & 0.14121 & 0.00136 \\
\hline 1998.2 & 1.052699 & 0.64599 & 0.51151 & 0.35357 & 0.00007 \\
\hline 1998.3 & 0.915234 & 0.8354 & 0.83471 & 0.45248 & 0.98483 \\
\hline 1998.4 & 1.340162 & 0.68509 & 0.62686 & 0.48036 & 0.00587 \\
\hline 1999.1 & 0.898479 & 0.44016 & 0.28648 & 0.4175 & 1 \\
\hline 1999.2 & 1.045153 & 0.99998 & 1 & 0.18294 & 0.00009 \\
\hline 1999.3 & 0.966426 & 0.00556 & 0.00109 & 0.40195 & 0.9984 \\
\hline 1999.4 & 1.070425 & 0.59393 & 0.89741 & 0.15581 & 0.01612 \\
\hline 2000.1 & 0.985378 & 0.11724 & 0.01755 & 0.95815 & \\
\hline 2000.2 & 1.001277 & 0.00014 & 0.00002 & 0.94738 & \\
\hline 2000.3 & 0.997761 & 0 & 0 & 0.7544 & \\
\hline 2000.4 & 0.911448 & 0.00509 & 0.00075 & 0.74999 & \\
\hline 2001.1 & 0.889625 & 0.00009 & 0 & 0.70943 & \\
\hline 2001.2 & 1.007923 & 0.03844 & 0.01644 & 0.00073 & \\
\hline 2001.3 & 0.899688 & 0.0146 & 0.00167 & 0.63751 & \\
\hline 2001.4 & 0.983853 & 0.13552 & 0.09893 & 0.35064 & \\
\hline 2002.1 & 1.006605 & 0.00782 & 0.00031 & 0.46463 & \\
\hline 2002.2 & 0.921633 & 0.00754 & 0.00083 & 0.72138 & \\
\hline 2002.3 & 0.839168 & 0.00046 & 0.00002 & 0.74085 & \\
\hline 2002.4 & 1.018901 & 0.1043 & 0.05381 & 0.0468 & \\
\hline 2003.1 & 0.938999 & 0.18431 & 0.07972 & 0.88622 & \\
\hline 2003.2 & 1.119153 & 0.71161 & 0.52607 & 0.33464 & \\
\hline 2003.3 & 1.046413 & 0.64668 & 0.89624 & 0.57324 & \\
\hline 2003.4 & 1.07332 & 0.82811 & 0.9333 & 0.07918 & \\
\hline 2004.1 & 1.054008 & 0.44226 & 0.3982 & 0.18381 & \\
\hline 2004.2 & 0.987427 & 0.13138 & 0.05372 & 0.52423 & \\
\hline
\end{tabular}




\begin{tabular}{|r|r|r|r|r|}
\hline 2004.3 & 0.981888 & 0.28869 & 0.10104 & 0.94414 \\
\hline 2004.4 & 1.053743 & 0.50959 & 0.21134 & 0.60535 \\
\hline 2005.1 & 1.007629 & 0.21873 & 0.03465 & 0.13799 \\
\hline 2005.2 & 0.985447 & 0.27112 & 0.05909 & 0.66583 \\
\hline 2005.3 & 1.031971 & 0.85071 & 0.79003 & 0.17048 \\
\hline 2005.4 & 0.996081 & 0.69266 & 0.49768 & 0.36036 \\
\hline 2006.1 & 1.029448 & 0.78788 & 0.69037 & 0.12931 \\
\hline 2006.2 & 0.986712 & 0.06624 & 0.01414 & 0.35768 \\
\hline 2006.3 & 1.004408 & 0.54377 & 0.7646 & 0.61606 \\
\hline 2006.4 & 1.059064 & 0.56781 & 0.75628 & 0.34832 \\
\hline 2007.1 & 1.003635 & 0.11539 & 0.23583 & 0.42739 \\
\hline 2007.2 & 1.046546 & 0.39205 & 0.73568 & 0.27461 \\
\hline 2007.3 & 0.975584 & 0.00847 & 0.00482 & 0.94426 \\
\hline $\mathbf{1}$ & $\mathbf{2 . M a r k e t}$ & $\mathbf{3 . B 1}$ & $\mathbf{4 . B 2}$ & 5.51 \\
\hline 2007.4 & 0.776517 & 0.00006 & 0.00002 & 0.41573 \\
\hline 2008.1 & 1.147113 & 0.83657 & 0.93255 & 0.16591 \\
\hline 2008.2 & 1.004319 & 0.12926 & 0.14056 & 0.1677 \\
\hline 2008.3 & 0.910265 & 0.00018 & 0.00002 & 0.96209 \\
\hline 2008.4 & 0.744078 & & 0.655 \\
\hline 2009.1 & 0.851573 & 0.30953 & 0.60682 & 0.86127 \\
\hline 2009.2 & 1.148979 & 0.90617 & 0.97756 & 0.00841 \\
\hline 2009.3 & 1.130141 & 0.9813 & 0.99787 & 0.0006 \\
\hline 2009.4 & 1.05915 & 0.81388 & 0.94801 & 0.00011 \\
\hline 2010.1 & 1.030797 & 0.80201 & 0.93477 & 0.43745 \\
\hline 2010.2 & 0.987392 & 0.43911 & 0.39849 & 0.5088 \\
\hline 2010.3 & 0.995163 & 0.22202 & 0.08278 & 0.38264 \\
\hline 2010.4 & 1.099698 & 0.9957 & 0.99975 & 0.10948 \\
\hline 2011.1 & 1.055459 & 0.99632 & 0.99959 & 0.00008 \\
\hline 2011.2 & 1.046341 & 0.94732 & 0.97107 & 0.27983 \\
\hline 2011.3 & 0.910341 & 0.02511 & 0.00776 & 0.10978 \\
\hline 2011.4 & 1.031617 & 0.80819 & 0.83571 & 0.0369 \\
\hline & 1.087306 & & & \\
\hline & 0.995826 & & & \\
\hline & 1.038111 & & & \\
\hline & & & & \\
\hline & & & & \\
\hline 20.6545 & \\
\hline
\end{tabular}




\section{Appendix three: implied returns from default variants and plausible model applications}

The green columns $(2,9)$ respectively identify nominal dollar and CPI_U deflated returns from continuous exposure (the default). Columns 3 and 6 identify returns from choosing the highest probability drawn from the most accurate of the competing buy and sell models (including S2) where it outperforms S1. The aggressive application (columns 4 and 7) favour buy model signals greater than $50 \%$, regardless of the strength of sell model signals. This approximates investors with a preference for risk (and return) exposure. Columns 5 and 8 reverse the preference for market exposure of columns 3 and 6 , favouring any sell signal greater than $50 \%$ independent of the strength of the buy signal. Contrary to conventional expectations the conservative approach delivers greater returns than the more risky aggressive strategy. This reflects the greater specificity but lower sensitivity (relative to the buy models) of S1.

\section{Column details}

1. Year and quarter

2. Value of $\$ 1000$ invested over the entire research period in raw dollars based on market movements (continuous exposure).

3. The optimum combination of buy and sell decisions based on greatest probability, using the short-period model where it applies (raw dollars). Aggressive approach, favouring risk asset exposure whenever the full-period buy and sell models conflict (raw dollars). In simple terms any conflict between B1 or B2 and S1 or S2 is decided in favour of B1 or B2, independent of the relative models' predicted probabilities.

4. Conservative approach, favouring sale whenever there are conflicting signals between the buy and sell models (raw dollars). This is the converse of the aggressive approach with conflict between B1 or B2 and S1 or S2 decided in favour of S1 or S2.

5. Optimum as per 3 above (CPI-U deflated dollars)

6. As per 4 above, CPI-U deflated dollars

7. As per 5 above (CPI-U deflated dollars)

8. Continuous exposure as in column 1 with adjustment for inflation.

9. CPI-U deflated continuous exposure. 
Table 17: Raw and CPI-U deflated returns from continuous market exposure and different reasonable model applications

$\begin{array}{llllllllll}1 & 2 & 3 & 4 & 5 & 6 & 7 & 8 & 9\end{array}$

\begin{tabular}{|c|c|c|c|c|c|c|c|c|}
\hline & Raw & optimum & Aggro & Conserv. & Optimum & Aggro & Conservative & CPI-U \\
\hline 1980.1 & 1000 & 1000 & 1000 & 1000 & 1000 & 1000 & 1000 & 1000 \\
\hline 1980.2 & 1005.638 & 1000 & 1000 & 1000 & 964.5607 & 964.5607 & 964.5607 & 969.9988 \\
\hline 1980.3 & 1123.034 & 1116.737 & 1116.737 & 1116.737 & 1057.771 & 1057.771 & 1057.771 & 1063.735 \\
\hline 1980.4 & 1223.788 & 1216.927 & 1216.927 & 1216.927 & 1123.416 & 1123.416 & 1123.416 & 1129.75 \\
\hline 1981.1 & 1233.154 & 1226.241 & 1226.241 & 1226.241 & 1102.36 & 1102.36 & 1102.36 & 1108.575 \\
\hline 1981.2 & 1202.146 & 1226.241 & 1226.241 & 1226.241 & 1077.809 & 1077.809 & 1077.809 & 1056.63 \\
\hline 1981.3 & 1121.215 & 1226.241 & 1226.241 & 1226.241 & 1047.821 & 1047.821 & 1047.821 & 958.0761 \\
\hline 1981.4 & 1123.943 & 1226.241 & 1226.241 & 1226.241 & 1032.948 & 1032.948 & 1032.948 & 946.7749 \\
\hline 1982.1 & 1047.195 & 1226.241 & 1226.241 & 1226.241 & 1024.529 & 1024.529 & 1024.529 & 874.9347 \\
\hline 1982.2 & 1027.371 & 1226.241 & 1226.241 & 1226.241 & 1009.251 & 1009.251 & 1009.251 & 845.5725 \\
\hline 1982.3 & 1051.832 & 1226.241 & 1226.241 & 1226.241 & 990.6572 & 990.6572 & 990.6572 & 849.7556 \\
\hline 1982.4 & 1251.523 & 1459.043 & 1459.043 & 1459.043 & 1176.686 & 1176.686 & 1176.686 & 1009.326 \\
\hline 1983.1 & 1352.823 & 1577.141 & 1577.141 & 1577.141 & 1271.929 & 1271.929 & 1271.929 & 1091.022 \\
\hline 1983.2 & 1499.409 & 1577.141 & 1577.141 & 1577.141 & 1256.143 & 1256.143 & 1256.143 & 1194.232 \\
\hline 1983.3 & 1494.408 & 1577.141 & 1577.141 & 1577.141 & 1216.018 & 1216.018 & 1216.018 & 1152.228 \\
\hline 1983.4 & 1500.045 & 1577.141 & 1577.141 & 1577.141 & 1230.441 & 1230.441 & 1230.441 & 1170.293 \\
\hline 1984.1 & 1453.851 & 1577.141 & 1577.141 & 1577.141 & 1216.85 & 1216.85 & 1216.85 & 1121.725 \\
\hline 1984.2 & 1405.747 & 1577.141 & 1577.141 & 1577.141 & 1203.905 & 1203.905 & 1203.905 & 1073.072 \\
\hline 1984.3 & 1465.4 & 1577.141 & 1577.141 & 1577.141 & 1190.89 & 1190.89 & 1190.89 & 1106.515 \\
\hline 1984.4 & 1506.229 & 1577.141 & 1577.141 & 1577.141 & 1182.182 & 1182.182 & 1182.182 & 1129.028 \\
\hline 1985.1 & 1641.266 & 1718.535 & 1718.535 & 1718.535 & 1280.506 & 1280.506 & 1280.506 & 1222.931 \\
\hline 1985.2 & 1701.191 & 1781.282 & 1781.282 & 1781.282 & 1310.679 & 1310.679 & 1310.679 & 1251.748 \\
\hline 1985.3 & 1702.373 & 1782.52 & 782.52 & 1782.52 & 1298.756 & 1298.756 & 1298.756 & 1240.361 \\
\hline 1985.4 & 1828.59 & 1914.678 & 1914.678 & 1914.678 & 1386.473 & 1386.473 & 1386.473 & 1324.134 \\
\hline 1986.1 & 2023.552 & 2118.819 & 2118.819 & 2118.819 & 1531.066 & 1531.066 & 1531.066 & 1462.226 \\
\hline 1986.2 & 2199.691 & 2303.25 & 2303.25 & 2303.25 & 1667.849 & 1667.849 & 1667.849 & 1592.859 \\
\hline 1986.3 & 2183.505 & 2286.302 & 2286.302 & 2286.302 & 1643.514 & 1643.514 & 1643.514 & 1569.618 \\
\hline 1986.4 & 2230.79 & 2335.814 & 2335.814 & 2335.814 & 1669.98 & 1669.98 & 1669.98 & 1594.894 \\
\hline 1987.1 & 2576.43 & 2697.726 & 2697.726 & 2697.726 & 1907.476 & 1907.476 & 1907.476 & 1821.711 \\
\hline 1987.2 & 2674.82 & 2800.749 & 2800.749 & 2800.749 & 1954.581 & 1954.581 & 1954.581 & 1866.698 \\
\hline 1987.3 & 2941.075 & 3079.538 & 3079.538 & 3079.538 & 2124.72 & 2124.72 & 2124.72 & 2029.187 \\
\hline 1987.4 & 2210.239 & 3079.538 & 2314.295 & 3079.538 & 2106.856 & 1583.317 & 2106.856 & 1512.128 \\
\hline 1988.1 & 2375.739 & 3310.13 & 2487.587 & 3079.538 & 2249.019 & 1690.154 & 2092.347 & 1614.161 \\
\hline 1988.2 & 2415.75 & 3365.877 & 2529.481 & 3365.877 & 2260.433 & 1698.732 & 2260.433 & 1622.353 \\
\hline 1988.3 & 2441.393 & 3401.606 & 2556.332 & 3401.606 & 2254.314 & 1694.133 & 2254.314 & 1617.961 \\
\hline 1988.4 & 2517.596 & 3507.78 & 2636.122 & 3507.78 & 2300.915 & 1729.154 & 2300.915 & 1651.407 \\
\hline 1989.1 & 2671.001 & 3721.52 & 2796.75 & 3721.52 & 2414.232 & 1814.313 & 2414.232 & 1732.737 \\
\hline 1989.2 & 2873.966 & 4004.312 & 3009.27 & 4004.312 & 2556.502 & 1921.23 & 2556.502 & 1834.847 \\
\hline
\end{tabular}




\begin{tabular}{|c|c|c|c|c|c|c|c|c|}
\hline 1989.3 & 3172.32 & 4004.312 & 3321.67 & 4004.312 & 2535.176 & 2102.987 & 2535.176 & 2008.432 \\
\hline 1989.4 & 3152.496 & 4004.312 & 3300.913 & 3979.289 & 2510.408 & 2069.429 & 2494.72 & 1976.382 \\
\hline 1990.1 & 3033.918 & 4004.312 & 3300.913 & 3979.289 & 2468.643 & 2035 & 2453.216 & 1870.399 \\
\hline 1990.2 & 3152.496 & 4160.817 & 3429.926 & 4134.816 & 2538.558 & 2092.634 & 2522.695 & 1923.371 \\
\hline 1990.3 & 2984.905 & 4160.817 & 3247.586 & 3915.003 & 2496.87 & 1948.848 & 2349.359 & 1791.215 \\
\hline 1990.4 & 2899.063 & 4160.817 & 3154.19 & 3915.003 & 2456.344 & 1862.081 & 2311.228 & 1711.467 \\
\hline 1991.1 & 3291.898 & 4724.624 & 3581.596 & 4445.502 & 2766.428 & 2097.146 & 2602.993 & 1927.518 \\
\hline 1991.2 & 3444.394 & 4943.49 & 3747.512 & 4651.438 & 2877.505 & 2181.35 & 2707.507 & 2004.912 \\
\hline 1991.3 & 3549.695 & 5094.622 & 3862.08 & 4793.641 & 2942.259 & 2230.438 & 2768.436 & 2050.029 \\
\hline 1991.4 & 3591.161 & 5154.135 & 3907.195 & 4849.638 & 2954.364 & 2239.614 & 2779.825 & 2058.463 \\
\hline 1992.1 & 3713.649 & 5329.933 & 4040.462 & 5015.05 & 3033.761 & 2299.803 & 2854.532 & 2113.783 \\
\hline 1992.2 & 3754.478 & 5388.532 & 4084.885 & 5070.188 & 3042.324 & 2306.294 & 2862.589 & 2119.75 \\
\hline 1992.3 & 3807.22 & 5464.229 & 4142.268 & 5141.412 & 3060.976 & 2320.434 & 2880.14 & 2132.746 \\
\hline 1992.4 & 3897.245 & 5593.434 & 4240.215 & 5262.985 & 3111.274 & 2358.564 & 2927.466 & 2167.791 \\
\hline 1993.1 & 4043.012 & 5802.643 & 4398.81 & 5459.834 & 3200.577 & 2426.262 & 3011.493 & 2230.013 \\
\hline 1993.2 & 4064.472 & 5833.444 & 4422.159 & 5488.815 & 3193.022 & 2420.534 & 3004.384 & 2224.749 \\
\hline 1993.3 & 4154.497 & 5962.65 & 4520.106 & 5610.387 & 3250.894 & 2464.405 & 3058.837 & 2265.072 \\
\hline 1993.4 & 4231.7 & 6073.453 & 4604.103 & 5714.645 & 3288.589 & 2492.981 & 3094.306 & 2291.336 \\
\hline 1994.1 & 4226.971 & 6066.667 & 4598.958 & 5708.259 & 3264.09 & 2474.409 & 3071.254 & 2274.266 \\
\hline 1994.2 & 4066.836 & 837 & 4598.958 & 5492.008 & 3120.65 & 2458.821 & .288 & 2174.324 \\
\hline 1994.3 & 4535.964 & 6510.143 & 4598.958 & 6125.535 & 3450.249 & 2437.358 & 3246.415 & 2403.973 \\
\hline 1994.4 & 4502.137 & 6461.593 & 4598.958 & 6079.854 & 3408.498 & 2425.956 & 3207.13 & 2374.883 \\
\hline 1995.1 & 4420.933 & 6345.046 & 4516.008 & 5970.193 & 3320.391 & 2363.247 & 3124.228 & 2313.494 \\
\hline 1995.2 & 4828.135 & 6929.474 & 4931.967 & 6520.094 & 3593.583 & 2557.688 & 3381.281 & 2503.842 \\
\hline 1995.3 & 5178.23 & 7431.941 & 5289.592 & 6992.876 & 3837.268 & 2731.128 & 3610.569 & 2673.629 \\
\hline 1995.4 & 5464.49 & 7842.789 & 5582.008 & 7379.452 & 4030.152 & 2868.411 & 3792.058 & 2808.022 \\
\hline 1996.1 & 5825.68 & 8361.178 & 5950.965 & 7867.215 & 4257.728 & 3030.385 & 4006.189 & 2966.586 \\
\hline 1996.2 & 6046.922 & 8678.711 & 6176.965 & 8165.989 & 4376.226 & 3114.725 & 4117.687 & 3049.151 \\
\hline 1996.3 & 5999.727 & 8610.976 & 6128.755 & 8102.255 & 4318.894 & 3073.919 & 4063.742 & 3009.204 \\
\hline 1996.4 & 6677.639 & 9583.934 & 6821.246 & 9017.733 & 4772.618 & 3396.852 & 4490.66 & 3325.338 \\
\hline 1997.1 & 7074.93 & 10154.14 & 7227.08 & 9554.249 & 5022.661 & 3574.816 & 4725.931 & 3499.556 \\
\hline 1997.2 & 7682.914 & 11026.73 & 7848.139 & 10375.29 & 5432.834 & 3866.752 & 5111.872 & 3785.346 \\
\hline 1997.3 & 8490.406 & 12185.67 & 8672.998 & 11465.76 & 5980.32 & 4256.418 & 5627.013 & 4166.808 \\
\hline 1997.4 & 8609.803 & 12357.03 & 8794.962 & 11627 & 6040.381 & 4299.166 & 5683.526 & 4208.656 \\
\hline 1998.1 & 9491.589 & 13622.59 & 9695.711 & 12817.8 & 6641.33 & 4726.884 & 6248.972 & 4627.369 \\
\hline 1998.2 & 10113.12 & 14514.63 & 10330.61 & 13657.14 & 7038.398 & 5009.493 & 6622.583 & 4904.028 \\
\hline 1998.3 & 9381.195 & 13464.15 & 9582.943 & 12668.72 & 6503.828 & 4629.019 & 6119.594 & 4531.565 \\
\hline 1998.4 & 12674.73 & 18191.13 & 12947.31 & 17116.43 & 8756.635 & 6232.427 & 8239.31 & 6101.216 \\
\hline 1999.1 & 11531.42 & 16550.21 & 12947.31 & 15572.46 & 7936.259 & 6208.572 & 7467.4 & 5529.616 \\
\hline 1999.2 & 12184.32 & 17487.28 & 13680.38 & 16454.16 & 8304.88 & 6496.946 & 7814.243 & 5786.454 \\
\hline 1999.3 & 11921.25 & 17109.71 & 13680.38 & 16098.9 & 8075.522 & 6456.93 & 7598.435 & 5626.648 \\
\hline 1999.4 & 12915.89 & 18537.24 & 13680.38 & 17442.09 & 8695.218 & 6417.023 & 8181.521 & 6058.423 \\
\hline 2000.1 & 12910.98 & 18537.24 & 13680.38 & 17442.09 & 8608.251 & 6352.841 & 8099.691 & 5995.548 \\
\hline 2000.2 & 13117.58 & 18537.24 & 13680.38 & 17442.09 & 8520.028 & 6287.733 & 8016.68 & 6029.06 \\
\hline
\end{tabular}




\begin{tabular}{|c|c|c|c|c|c|c|c|c|}
\hline 2000.3 & 13291.53 & 18537.24 & 13680.38 & 17442.09 & 8452.596 & 6237.969 & 7953.232 & 6060.663 \\
\hline 2000.4 & 12320.45 & 18537.24 & 13680.38 & 17442.09 & 8394.403 & 6195.022 & 7898.477 & 5579.192 \\
\hline 2001.1 & 11112.94 & 18537.24 & 13680.38 & 17442.09 & 8327.515 & 6145.66 & 7835.541 & 4992.284 \\
\hline 2001.2 & 11305.08 & 18537.24 & 13680.38 & 17442.09 & 8243.067 & 6083.338 & 7756.082 & 5027.1 \\
\hline 2001.3 & 10262.62 & 18537.24 & 13680.38 & 17442.09 & 8237.034 & 6078.885 & 7750.405 & 4560.2 \\
\hline 2001.4 & 10146.77 & 18537.24 & 13680.38 & 17442.09 & 8253.762 & 6091.23 & 7766.145 & 4517.879 \\
\hline 2002.1 & 10258.34 & 18537.24 & 13680.38 & 17442.09 & 8233.789 & 6076.491 & 7747.352 & 4556.506 \\
\hline 2002.2 & 9499.227 & 18537.24 & 13680.38 & 17442.09 & 8136.264 & 6004.518 & 7655.589 & 4169.349 \\
\hline 2002.3 & 8011.185 & 18537.24 & 13680.38 & 17442.09 & 8100.229 & 5977.924 & 7621.683 & 3500.652 \\
\hline 2002.4 & 8189.779 & 18950.49 & 13985.36 & 17442.09 & 8256.126 & 6092.975 & 7598.965 & 3568.026 \\
\hline 2003.1 & 7714.286 & 18950.49 & 13985.36 & 17442.09 & 8173.565 & 6032.046 & 7522.975 & 3327.26 \\
\hline 2003.2 & 8653.906 & 21258.71 & 15688.81 & 17442.09 & 9144.142 & 6748.326 & 7502.477 & 3722.358 \\
\hline 2003.3 & 9076.112 & 22295.88 & 16454.24 & 17442.09 & 9536.735 & 7038.058 & 7460.6 & 3882.174 \\
\hline 2003.4 & 9762.753 & 23982.65 & 17699.06 & 18761.65 & 10254.34 & 7567.642 & 8021.979 & 4174.291 \\
\hline 2004.1 & 10312.72 & 25333.67 & 18696.11 & 19818.56 & 10734.88 & 7922.283 & 8397.911 & 4369.91 \\
\hline 2004.2 & 10211.33 & 25333.67 & 18696.11 & 19818.56 & 10583.74 & 7810.743 & 8279.675 & 4266.026 \\
\hline 2004.3 & 10065.02 & 25333.67 & 18696.11 & 19818.56 & 10546.34 & 7783.142 & 8250.416 & 4190.041 \\
\hline 2004.4 & 10657.27 & 25333.67 & 18696.11 & 19818.56 & 10483.86 & 7737.03 & 8201.536 & 4410.31 \\
\hline 2005.1 & 10807.4 & 25333.67 & 18696.11 & 19818.56 & 10418.31 & 7688.656 & 8150.258 & 4444.476 \\
\hline 2005.2 & 10729.2 & 25333.67 & 18696.11 & 19818.56 & 10280.65 & 7587.063 & 8042.565 & 4354.014 \\
\hline 2005.3 & 11164.32 & 26361.07 & 19454.32 & 20622.29 & 10583.31 & 7810.425 & 8279.337 & 4482.195 \\
\hline 2005.4 & 11229.7 & 26515.44 & 19568.25 & 20743.06 & 10576.96 & 7805.741 & 8274.373 & 4479.507 \\
\hline 2006.1 & 11686.82 & 27594.8 & 20364.81 & 21587.45 & 10948.86 & 8080.201 & 8565.311 & 4637.013 \\
\hline 2006.2 & 11672.55 & 27561.09 & 20339.93 & 21561.08 & 10806.74 & 7975.315 & 8454.127 & 4576.821 \\
\hline 2006.3 & 11870.87 & 28029.38 & 5.53 & 21561.08 & 10876.89 & 8027.082 & 842 & 4606.529 \\
\hline 2006.4 & 12721.29 & 30037.37 & 22167.41 & 23105.68 & 11754.33 & 8674.634 & 9041.803 & 4978.142 \\
\hline 2007.1 & 12930.25 & 30530.78 & 22531.54 & 23485.23 & 11826.63 & 8727.987 & 9097.414 & 5008.76 \\
\hline 2007.2 & 13689.64 & 32323.84 & 23854.81 & 24864.51 & 12286.05 & 9067.034 & 9450.812 & 5203.33 \\
\hline 2007.3 & 13506.77 & 32323.84 & 23536.16 & 24864.51 & 12251.83 & 8920.999 & 9424.489 & 5119.524 \\
\hline 2007.4 & 10605.53 & 32323.84 & 18480.61 & 24864.51 & 12165.37 & 6955.341 & 9357.98 & 3991.486 \\
\hline 2008.1 & 12221.15 & 37247.98 & 21295.9 & 28652.31 & 13861.31 & 7924.966 & 10662.55 & 4547.928 \\
\hline 2008.2 & 12324.45 & 37562.82 & 21475.91 & 28894.5 & 13677.95 & 7820.139 & 10521.51 & 4487.77 \\
\hline 2008.3 & 11265.35 & 37562.82 & 21475.91 & 28894.5 & 13521.38 & 7730.621 & 10401.07 & 4055.154 \\
\hline 2008.4 & 8390.834 & 37562.82 & 21475.91 & 28894.5 & 13914.18 & 7955.197 & 10703.22 & 3108.168 \\
\hline 2009.1 & 7149.95 & 37562.82 & 21475.91 & 28894.5 & 13983.74 & 7994.969 & 10756.73 & 2661.756 \\
\hline 2009.2 & 8218.241 & 43175.17 & 24684.67 & 33211.69 & 15905.05 & 9093.444 & 12234.66 & 3027.47 \\
\hline 2009.3 & 9290.988 & 48810.93 & 27906.82 & 37546.9 & 17859.48 & 10210.85 & 13738.07 & 3399.489 \\
\hline 2009.4 & 9841.866 & 51705.01 & 29561.46 & 39773.11 & 18880.76 & 10794.76 & 14523.67 & 3593.886 \\
\hline 2010.1 & 10147.59 & 53311.13 & 30479.74 & 41008.59 & 19389.22 & 11085.46 & 14914.79 & 3690.669 \\
\hline 2010.2 & 10023.37 & 53311.13 & 30479.74 & 41008.59 & 19297.63 & 11033.09 & 14844.34 & 3628.271 \\
\hline 2010.3 & 9978.812 & 53311.13 & 30479.74 & 40826.3 & 19279.94 & 11022.98 & 14764.81 & 3608.832 \\
\hline 2010.4 & 10977.08 & 58644.34 & 33528.91 & 44910.52 & 21146.68 & 12090.26 & 16194.38 & 3958.25 \\
\hline 2011.1 & 11589.34 & 61915.28 & 35399.01 & 47415.45 & 22191.32 & 12687.51 & 16994.38 & 4153.786 \\
\hline 2011.2 & 11940.17 & 63789.53 & 36470.58 & 48850.78 & 22699.9 & 12978.28 & 17383.85 & 4248.982 \\
\hline
\end{tabular}




\begin{tabular}{|c|c|c|c|c|c|c|c|c|}
\hline 2011.3 & 12213.79 & 65251.33 & 37306.34 & 49970.24 & 22983.01 & 13140.14 & 17600.66 & 4301.974 \\
\hline 2011.4 & 11041.19 & 58986.83 & 33724.72 & 45172.81 & 20624.67 & 11791.81 & 15794.62 & 3860.539 \\
\hline
\end{tabular}




\section{Appendix four: Timelines detailing major idiosyncratic events over the period 1970 to 2013}

The incidence of economic features particular to each decade in the post-1980 period

Figure 21: The 1980s and major idiosyncratic events influencing the US economy

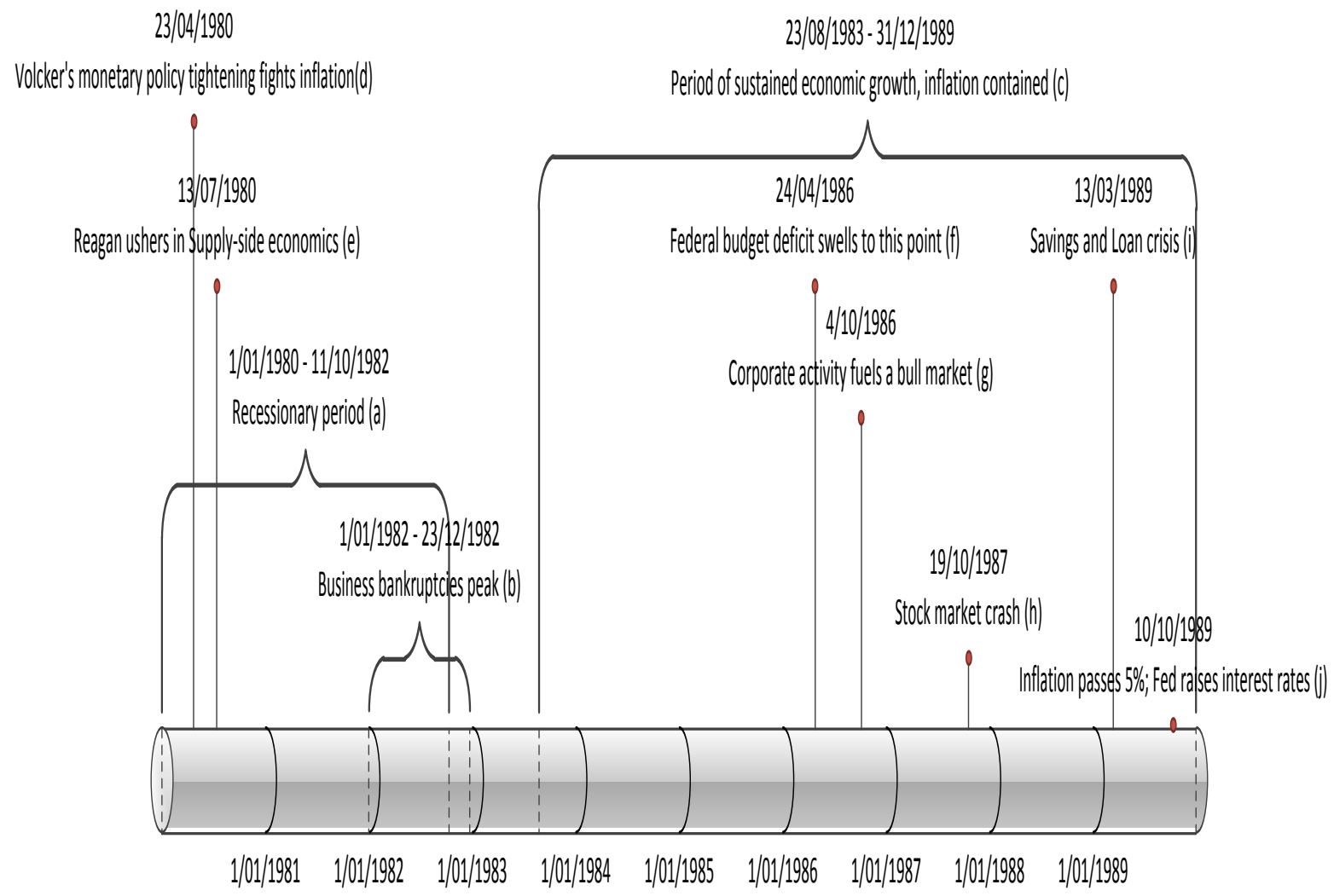

$1 / 01 / 1980$

$31 / 12 / 1989$

\section{Explanation of figure 21}

Market movements indicated below the timeline demonstrate no systematic relationship to identifiable 'shocks'. The 1980s began with a concerted monetary policy tightening, entailing elevated interest rates in response to the high inflation of the 1970s and early 1980s. Progressively, after two recessions from 1980 to 1982 as depicted at (a), (b), and (d) above, interest rates and inflation declined. Economic growth emerged out of this period, in part supported by expanding Federal Government budget deficits (c) and (e). Welfare cuts were insufficient to offset increased military spending and a decrease in tax rates which fuelled 
growing US Government budget deficits. These deficits swelled from $\$ 74$ billion in 1980 to $\$ 221$ billion in 1986 . These conditions and the merger and acquisition activity of the mid-1980s fuelled the Bull market of the period which, in turn, was interrupted by the 1987 stock market crash (g) and (h). The latter half of the 1980s was further marked by the Savings and loan crisis. Again, the impact of the Savings and Loan (S\&L) crisis appears to have been fleeting and minor as the market rapidly resumed its rise despite the crisis (i). The S\&L crisis, which occurred over the latter half of the 1980s, coincides with rising inflation (and the Federal Reserve Bank's interest rate tightening in response to growing inflation pressures) to create the conditions pushing the US economy into recession in the early 1990s, (i) and (j).

Figure 22: The 1990s and major economic events influencing the US Economy

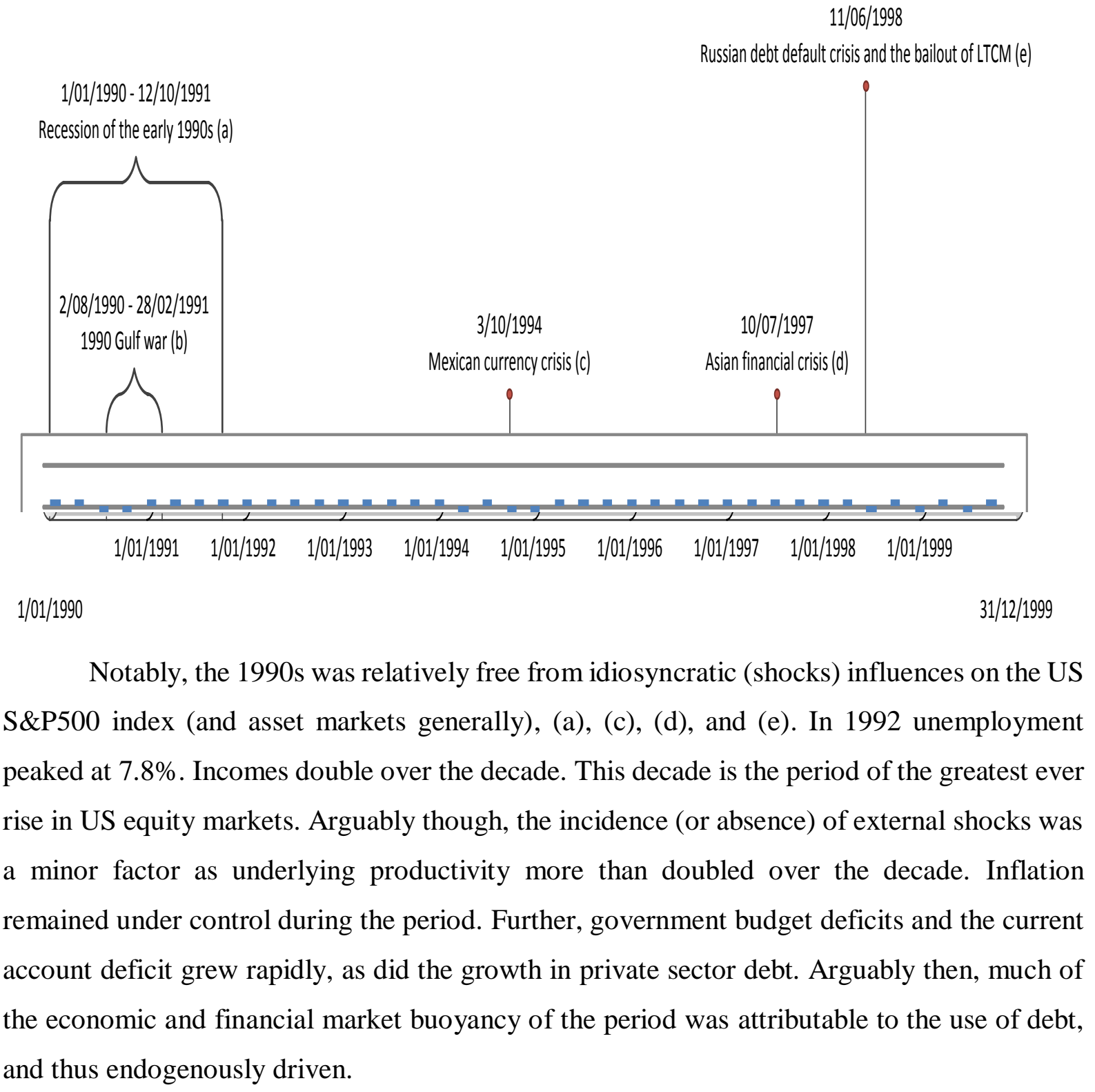


The case for the substantially endogenous drivers of economic growth in the US in the 1990s and concomitant growth in the S\&P 500 index may also be inferred from the market crashes of the early 2000s. In nominal terms US equity markets only regained their 2000 peaks in 2007, before crashing again during the sub-prime crisis. In real terms US equity markets have yet to reacquire levels reached in 2000. This suggests that markets became overvalued during the 1990s and that this development was in large part supported by growth in debt. This growth in debt is also clearly linked to the sub-prime crisis and ensuing GFC. Conversely, the only clearly exogenous shock, the 9/11 terrorist attack, may have aggravated an existing recession but this event is not clearly implicated in more than a minor and temporary impact on the S\&P 500 index.

Figure 23: The 2000s and major events affecting the US Economy

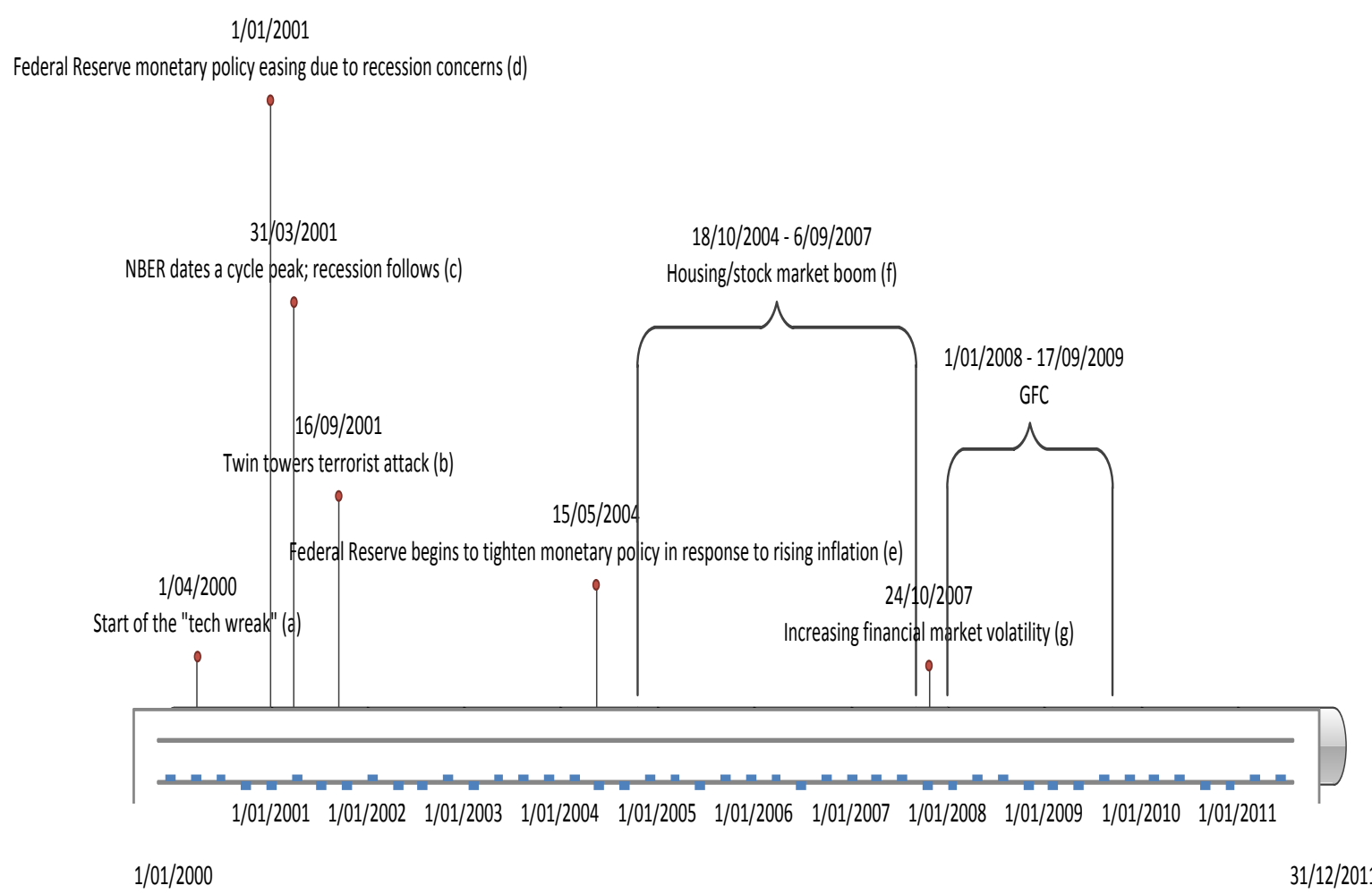

Early in April 2000 the 'Tech wreck' occurred. This involved the crash of the technology stockladen NASDAQ. The late 1990s had seen a surge in technology stocks and in the year preceding the crash the NASDAQ more than doubled in value. From early 2001 the US Federal Reserve Bank began loosening monetary conditions. The economic outlook appeared subdued and this was later confirmed by NBER business cycle dating to identify a peak in March of that year, (a), (c), and (d). In September of 2001 the 'Twin Towers' terrorist attack occurred, 
aggravating the economic slowdown since March. Despite widespread concerns and a vigorous monetary policy (easing) response, the US economy only declined modestly and for two quarters. This monetary policy 'laxness' has been attributed blame for the subsequent housing boom as inflation was allowed to exceed 3\%, albeit by a negligible amount, (b). Inflation peaks just above 3\% causing the US Federal Reserve to tighten their monetary policy, increasing interest rates, (e). (f), A housing market boom occurs over the period 2004-2007. A variety of views exist for the cause of this occurrence. (g), Increased volatility is observed in the later part of 2007. This becomes compounded by the emergence of the sub-prime crisis. 2008 is marked by a commodity boom and the progressive decline in equity markets until these markets reach a nadir in March of 2009. Although the US economy remains fragile subsequent to this the S\&P 500 (and other US markets) rise strongly from their March trough. With some volatility this trend continues into 2013. From 2008 a continual monetary policy easing has been in evident with a succession of Quantitative Easings (or QEs as they have become known) and sustained low FFR (held at little above 0\%). Inflationary pressures have not re-emerged in this period although these policies have, in part, supported a recovery in the housing market and strong rises in financial asset markets. These 'accomodative' monetary policies continue into 2013 to support the weak recovery in the broader economy.

\section{The US economic environment in the 1970s: applying the models to this period}

If the buy and sell models developed in this thesis are to be applied it is important to determine the conditions under which they are applicable and, in the case of the competing sell models, when each is applicable. It is necessary to identify features of the 1970s that compromise the application of the models so that these models may be qualified in the presence of such features. The 1970s was distinct from the period 1980-2012 in important ways.

The 1970s were marked by high inflation, a central bank that entertained the view that it could exploit a permanent trade-off between (higher) inflation and reduced unemployment, and it was period in which the economy was affected by a number of large external shocks. These are shown in chart A4.3. Furthermore, the financial sector of the US was still substantially regulated, as the 'New Deal' era process of economic and financial sector regulation was only slowly, although progressively dismantled through the 1970s and into the 1980s and 1990s. President Johnson's 'Great Society' extended the welfare state in the 1960s and this was further extended in the 1970s under the Nixon Administration. Increasing social 
welfare expenditure, in tandem with the Vietnam War, rapidly expanded government borrowing through a succession of Federal budget deficits. In the same period price controls were removed which further fuelled inflation.

The end of the so-named 'Golden age of capitalism' is dated to 1973. From this point inflation grew rapidly. Major external shocks came in the form of poor harvests in the USSR, driving global food prices higher, and, in 1973, the Yom Kippur war between several Arab states and Israel led OPEC to impose an embargo on its oil exports. US inflation rose rapidly, at least in part due to these forces, from 1973 and peaked in 1980 at almost 14\%. This period of elevated inflation was marked by high unemployment (reaching 8.8\%) and recession. In 1979 the Iranian revolution caused a second major spike in oil prices. It is generally viewed that these inflationary pressures exacerbated the period of stagflation (stagnant growth and high inflation) through 'easy' monetary policies that sought to support employment through tolerance of inflation. This policy was a demonstrable failure as low or stagnant economic growth accompanied high inflation and rising unemployment. Importantly, productivity gains were well below historical trend over the period.

In contrast the recent demand-driven oil shocks the 2000s, the shocks of the 1970s were greater in magnitude and supply-driven. Another feature of the 1970s was that the Federal Reserve Board in the 1970s believed that they could make a permanent trade-off between inflation and unemployment, allowing inflation to rise to support full employment. The success of this policy was partial in that only inflation rose, without achieving full employment. A third important difference between the 1970s and the period post-1984 is that the process of financial market liberalization had only just begun in the 1970s and many of the changes in financial market de-regulation were unfolding progressively over the 1970s and 1980s.

A potential difficulty arises in the failure of the models in the context of 'large' external shocks. A large body of evidence challenges the importance of external shocks in terms of their impact on the performance of economies (including: Balke, Brown, and Yucel, 2009; 2010; Kilian, 2008a; Kilian, 2008b; Kilian, 2008c; Nakov and Pescatori, 2005; Wong, 2012). Reason to doubt the importance of oil shocks as an important factor in economic performance is an observed 'asymmetry' in responses to the direction of oil shocks. As Jones (1996) observes, positive oil shocks (involving price drops) in 1960 and again in 1986 did not result in economic booms. This provides some support for the view that economies are able to adjust reasonably 
efficiently in response to such shocks and that instead, we should look to identify fundamental macro-financial factors as the cause for the economic instability of the 1970s. Equally, such macroeconomic fundamentals offer improved prospects for identifying the lack of model success identified.

Figure 24: Major idiosyncratic events affecting the US economy over the 1970s

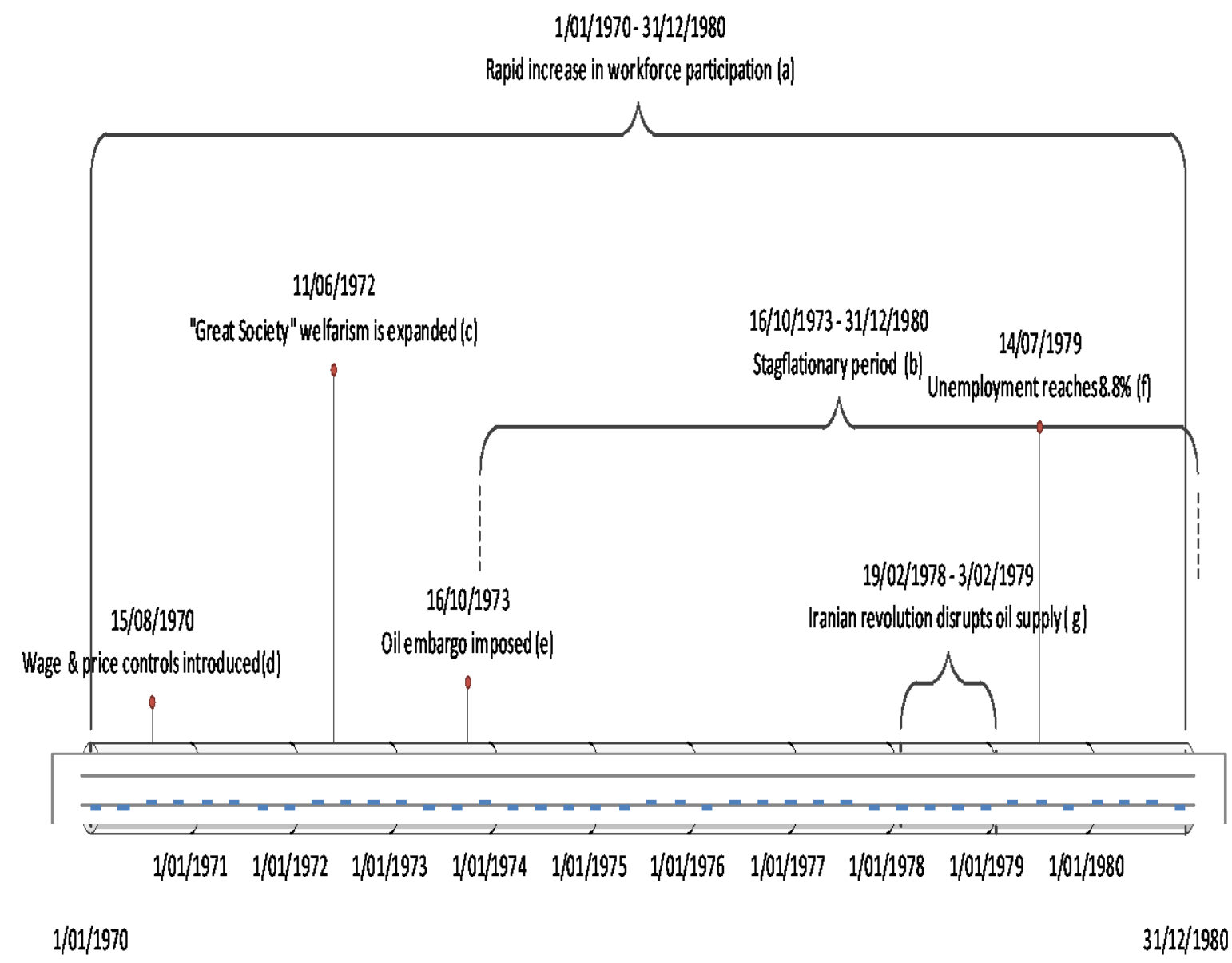

\section{Explanation of figure 24}

The period was marked by high inflation and a stagnant economy, (b), (e), and (g). Arguments have also been made that a belief guiding monetary policy authorities that they could permanently trade off higher inflation for employment growth was also responsible for the economic challenges of the period. Certain important structural changes also affected the US. The "Great Society" vision of President Johnson and the expansion of State welfarism that it entailed were further increased under Nixon who, in 1972, further extended governmental welfare programs in order to secure re-election (c). This policy greatly increased government budget deficits. Nixon's wage and price freeze was introduced in 1970 and, when it was removed it arguably increased price pressures within the economy (d). The 1970s are a period 
in which two major oil shocks impacted the US, from 1973 (e) and (g). A rapid increase in workforce participation occurred, with the end of the Vietnam War and increasing participation by women (a). These factors, when combined with external shocks appear to have led to the volatility of the period. They also appear to have adversely impacted the performance of US equity markets (compared to the post-1983 period). Importantly, the Federal Government maintained relatively subdued deficit spending until the 1980s. Further the US current account deficit turned persistently negative only in the mid-1980s. The combination of low growth, adverse external shocks, and rising inflation contributed to rising unemployment in 1979 (eventually exceeding $10 \%$ in the early 1980s as Federal Reserve Board Chairman Paul Volcker tried to rein in the inflation of the 1970 s by means of monetary policy tightening). In 1979 unemployment hit 8.8\%, up from 3.3\% at the start of the decade. With these facts in mind it is possible to see the absence of debt generally as an important reason for the subdued performance of the US economy over the 1970s.

\section{Major implications of the evidence from the 1970s}

It is necessary to qualify the models developed in this research as particular to a certain institutional environment. The key assumptions are that the institutional environment is lightly regulated and that market discipline is the primary instrument of that regulation. The institutional environment includes that the key monetary policy focus is on inflation control and the assumption that, given inflation control, economic and asset market stability is effectively assured. National and international capital flows freely and only minimal constraints are imposed on credit generation by monetary and prudential regulators.

It is reasonable to infer that economic stability establishes the preconditions for subsequent instability. Following Minsky's view that stability creates instability, the absence of stability, with economies buffeted by a series of external shocks over the 1970s, may have disrupted the sustained, systemic gravitation towards financial fragility. This is similar in key respects to the argument made in chapter five that agrarian societies observe subdued business cycles as imbalances are regulated by weather and perishability. Equally, subsistence removes endogenous business cycles from prospect as aggregate demand is always sufficient to meet aggregate supply. For these reasons it is necessary to qualify model applications to periods in which large and recurrent external shocks are not important regulators of economies' endogenous gravitation towards systemic imbalance. 
